\title{
complexity in land use change; the case of the Dutch dairy sector
}

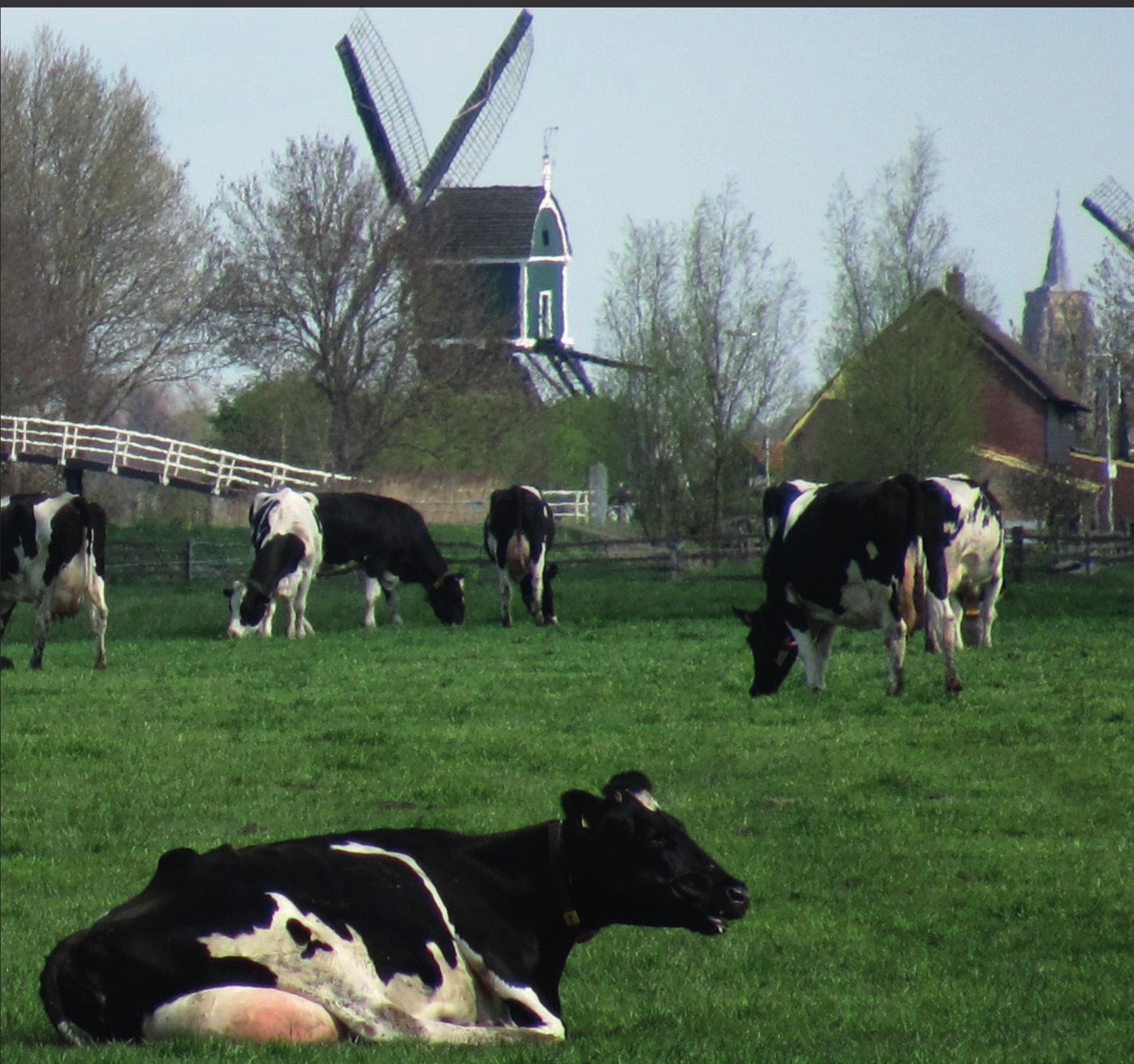

Anouschka Groeneveld 



\section{Complexity in land use change; the case of the Dutch dairy sector}




\section{Thesis committee}

\section{Promotor}

Prof. Dr W.J.M. Heijman

Special Professor Regional Economics

Wageningen University \& Research

\section{Co-promotors}

Dr J.H.M. Peerlings

Associate professor, Agricultural Economics and Rural Policy Group

Wageningen University \& Research

Dr M.M. Bakker

Associate professor, Land Use Planning Group

Wageningen University \& Research

\section{Other members}

Prof. Dr R. Finger, ETH Zurich, Switzerland

Prof. Dr A. Wossink, The University of Manchester, United Kingdom

Prof. Dr A.K. Bregt, Wageningen University \& Research

Prof. Dr E.S. van Leeuwen, Wageningen University \& Research

This research was conducted under the auspices of Wageningen School of Social Science (WASS) 


\title{
Complexity in land use change; the case of the Dutch dairy sector
}

\author{
Anouschka Groeneveld
}

\section{Thesis}

submitted in fulfilment of the requirements for the degree of doctor at Wageningen University

by the authority of the Rector Magnificus,

Prof. Dr A.P.J. Mol, in the presence of the

Thesis Committee appointed by the Academic Board to be defended in public

on Wednesday 20 June 2018

at 11 a.m. in the Aula. 
Anouschka Groeneveld

Complexity in land use change; the case of the Dutch dairy sector, 207 pages.

PhD thesis, Wageningen University, Wageningen, the Netherlands (2018)

With references, with summary in English

ISBN 978-94-6343-764-6

DOI https://doi.org/10.18174/443361 


\section{Table of Contents}

$\begin{array}{lll}\text { Chapter } 1 \text { Introduction } & 7\end{array}$

Mechanisms of land use change in the Dutch dairy sector 12

Objective and research questions $\quad 15$

Data and models 16

Chapter 2 The effect of milk quota abolishment on farm intensity: 19 shifts and stability

Abstract 20

2.1. Introduction 21

2.2. Background 23

2.3. Method 24

2.4. Results 32

2.5. Sensitivity Analysis 38

2.6. Discussion 38

2.7. Conclusions 41

Appendix 2A. Model description

Appendix 2B. Data used $\quad 50$

Appendix 2C. Additional model results $\quad 51$

Appendix 2D. Sensitivity Analysis $\quad 54$

Chapter 3 Complex dynamics in the uptake of new farming practices: 57 a case study for organic waste application

Abstract 58

3.1. Introduction 59

3.2. Methods 61

3.3. Results 75

3.4. Discussion 80

3.5. Conclusions 83

Appendix 3A. Farm model 84

Appendix 3B. Exogenous values for determining utility functions 89

Appendix 3C. Sensitivity analysis 91

Appendix 3D. Weights for profit, sustainability and labour 92

Chapter 4 Effects on participation and biodiversity of reforming 95 the implementation of agri-environmental schemes in the Netherlands

Abstract 
4.1. Introduction 97

4.2. Methods 99

4.3. Data 106

4.4. Experimental design 109

4.5. Results 110

4.6. Conclusions and Discussion 114

Appendix 4A. GAMS model 117

Appendix 4B. Sensitivity analysis 124

Chapter 5 Effects of changing social influence on participation and 131

biodiversity in agri-environmental schemes in the Netherlands

Abstract

5.1. Introduction 133

5.2. Modelling framework 135

5.3. Study area 135

5.4. Method and Data 136

5.5. Model 142

5.6. Scenarios 144

5.7. Results 145

5.8. Conclusions and Discussion 151

Appendix 5A. Determining the weights of the farmer 153

Appendix 5B. Indicator species and biodiversity scores 154

Appendix 5C. Mathematical programming models 155

Appendix 5D. Variation in model runs 162

Appendix 5E. Initial weights 165

$\begin{array}{lll}\text { Chapter } 6 & \text { Conclusions and Discussion } & 167\end{array}$

References $\quad 177$

Summary 195

Acknowledgements 201 


\section{Chapter 1}

Introduction 

Land use systems determine our well-being to a considerable extent, which is why so many policies have been formulated to regulate them. When land use systems are not fully understood, due to all kinds of nonlinearities and consequent complex behaviour, such policies may fail. An improved understanding of the behaviour of land use systems can help to predict how they will react to policies, thereby offering insights to improve policy design. Especially, policy makers and other stakeholders would like to avoid unexpected behaviour in land use systems. Therefore, the aim of this thesis is to improve our understanding of unexpected behaviour in land use systems. One specific type of unexpected behaviour, related to complex systems, is the regime shift, which will be the topic of this thesis.

\section{Regime shifts}

Regime shifts are a well-known concept within the study of ecological systems. In ecology, amongst other disciplines, the term regime shift is used to describe a sudden, rapid transition of a system from one stable state to another once a certain tipping-point is passed (Rietkerk et al., 2004; Scheffer et al., 2001). When studying unexpected behaviour in land use systems, this concept can be elucidating as well. It may be able to explain why sometimes small changes in circumstances lead to abrupt responses, or, contrarily, why sometimes a change in circumstances evokes no response from the land use system at all. The concept of resilience is related to regime shifts. Resilience indicates the maximum disturbance that can be applied to the system without causing a regime shift (Scheffer, 2009). This implies that shocks can be absorbed until a critical point is reached where a small change in a driving factor would be enough to set a regime shift in motion.

What exactly creates a disposition for regime shifts is subject to scientific debate. They are associated with a range of system properties, such as the presence of feedbacks, interactions between building blocks, excess of buffer capacity, etc. (Strunz, 2014; Brandt et al., 2013; Renaud et al., 2010; Foley et al., 2003). In this thesis I propose three mechanisms to be responsible for regime shifts in land use systems, being the existence of thresholds, cumulative effects, and feedbacks and interactions. Of course, other mechanisms may also evoke regime shifts, but this thesis focuses on these three mechanisms, which will be further explained hereafter.

In a system susceptible to regime shifts (at least) two alternative stable states exists (Scheffer \& Carpenter, 2003), a phenomenon referred to as bi-stability (or multi-stability). The states are relatively stable in the sense that a small change in the driver will - most of the times - not lead to a clear change in the system property. However, a gradual process might take place which decreases the attraction of the current state relative to the attraction of the other state, without any 
apparent changes occurring. In this case the driver gradually reduces the buffer capacity of the system until a certain threshold is reached and the system moves to the new state, i.e. the tipping point has been passed. This is nicely illustrated by the case described in Bakker et al. (2005), in which a sudden shift from agriculture to land abandonment took place, due to a gradual process of soil depth reduction. At first these reductions had no visible effect on the agricultural system, until the crop roots did not have enough space anymore, and there was a sudden drop in crop yields. As a consequence, the land was abandoned (Bakker et al., 2005). If a policymaker would be unaware of the decreasing buffer capacity of the system, which is moving towards a threshold, (s)he might incorrectly assume the policy has no effect at all. The policy might then be terminated just before reaching the threshold while it would have taken only a little bit longer to achieve the desired effect.

A transition of the system from one stable state to another does not necessarily result from a single driver, but can also result from the cumulative effects of several drivers. In this case several drivers work together to set off a shift within the system. Each of the drivers separately might not be strong enough to lead to a change, but a specific combination of these drivers might push the system past a tipping point. In this case, each driver gradually diminishes the strength of the prevailing processes, and once a threshold is passed another set of processes can prevail and the system restructures towards a new regime (Biggs, Schluter, and Schoon 2015; Peerlings, Polman \& Dries 2014). A policymaker might experience a much larger response to a policy measure than expected, if the small effect of the policy measure combined with the effects of the already existing drivers is just enough to reach a tipping point.

Interactions and feedbacks can also provide an explanation for abrupt responses within the system. Interactions between agents are the starting point for a number of self-reinforcing processes (Mercure et al., 2016). Agent interaction can take place when agents communicate, but can also take place when they observe each other. Social norms, networks and informal rules are a product of such agentinteraction, as are learning and social influence (Bell \& Hernandez, 2017; Cialdini \& Goldstein, 2004; Maru, McAllister \& Smith, 2007). Feedbacks as considered in this thesis are directed from the micro level to the macro level and vice versa. They play an important role in the understanding of land use systems. Feedbacks can also take place between different components on the same scale level, but these are less relevant for explaining the sudden transitions in land use systems that are described in this thesis. Furthermore, a distinction can be made into positive feedbacks and negative feedbacks. A positive feedback is self-reinforcing, and can lead to a point-of no return, after which the system changes (Manson, 2001). 
A negative feedback reinforces the current state of the system, leading to a more stable system (Keane, 2016). A policy maker not thinking of feedbacks might be puzzled as to why his policy has no effect (in the case of a negative feedback) or a much larger effect than expected (in the case of a positive feedback).

\section{Complex Adaptive Systems}

Within complexity theory, systems are considered not to be deterministic but to be process-dependent. Feedbacks between different scale levels allow the systems to self-organize (Folke, 2006) and interactions between its agents may underlie the emerging properties of the system (Levin et al., 2013). In a complex adaptive system (CAS), information, both from inside and outside the system, can be produced and processed (Mitchell, 2009). In this way the system is able to adapt to changing circumstances. Complex adaptive systems often exhibit strong autonomous and internal dynamics (Grimm et al., 2005): gradual changes in circumstances can result in non-linear responses. As a result, sometimes small changes lead to abrupt responses, while at other times the system may not respond to a change at all. The combination of small changes inducing large responses and large changes inducing small or no responses evokes an association with the phenomena of tipping points and regime shifts.

\section{Land use systems}

Land use systems can be perceived as an example of a complex adaptive system. They often result from human efforts to make a living on the biophysical environment (Bakker et al., 2012; Foley et al., 2005; Kalnay \& Cai, 2003; Matson et al., 1997; Tilman et al., 2001). These attempts to make a living include cultivating land for food production, creating buildings and infrastructure, and distributing and consuming goods and services. This has spatial and ecological consequences, such as nutrient displacement, changes in hydrological systems and greenhouse gas emissions (Bakker et al., 2012). We define land use systems in terms of the agents and their context. Agents are land users, i.e. the individuals who determine how the land is used. Often these are natural persons who own or lease the land (e.g. farmers or estate owners), but they can also be organizations or institutions (e.g. nature conservation organizations or water boards). Although these agents may interact with other actors (e.g. plants, animals, factories, policymakers), we do not consider these other actors as agents. The context is formed by the biophysical and socioeconomic environment which both facilitate and constrain the community of land users. The biophysical environment concerns the available natural resources (soil, water, nutrients) while the socioeconomic environment concerns the infrastructure, markets, and governance. Within the land use system 
a specific spatial land cover emerges as a result of the production choices made by land users.

To better understand unexpected system behaviour in land use systems, we take the Dutch dairy sector as an example of a land use system.

\section{The Dutch dairy sector}

An example of a complex land use system can be found in the Dutch dairy sector. The agricultural sector is the biggest land user in the Netherlands, taking up 54\% of the total Dutch surface area in 2012 (CBS, 2016e). Within Dutch agriculture the dairy sector is an important player; about 31\% of the farms in the Netherlands in 2016 were dairy farms (CBS, 2017a). In 2016 the dairy sector contained about 17000 farms, which together kept 1.8 million cows that produced about 14 billion $\mathrm{kg}$ milk. The number of dairy farms has diminished over time, while the average number of cows per farm has increased over time (LEI Wageningen UR, 2016). The dairy sector faces continuous change, both in the policy and technological domain. These changes are partly driven by concerns about the negative effects of intensive agricultural practices. Policies can be aimed at the individual farm, but the focus can also be on farm groups. The response of the farms to these changes is influenced by thresholds, cumulative effects, feedbacks and interactions.

\section{MECHANISMS OF LAND USE CHANGE IN THE DUTCH DAIRY SECTOR}

\section{Effects of thresholds, illustrated by production limitations}

Production limitations create thresholds after which a farm is no longer allowed to produce or producing becomes more costly. As long as the farm is far from the threshold, his decisions will not be constrained by the limitations and his decisions with and without the production limitations do not differ. If the farm produces at a level above the threshold, his decisions will differ between the situation with and without limitations. So, introducing or removing production limitations could result in a change in the land use system. Next, we describe the most important production limitations that form thresholds in the Dutch dairy sector.

In 1968 the EU introduced market-related price and income support for dairy farms. To prevent overproduction due to the price support the EU introduced supply quotas for milk in 1984 (Keane \& O'Connor, 2011). Because of the distortion to global trade, price and income support for milk received a lot of criticism and the EU took steps to gradually liberalise its dairy policy (Binfield et al., 2004; European Commission, 2017). Over time, support prices decreased and supply 
quotas increased (Keane \& O'Connor, 2011). Therefore, the difference between EU prices and world market prices became much smaller, and the EU decided to completely abolish the supply quotas for milk in 2015 (European Commission, 2015).

An increase in the amounts of nitrogen and phosphate produced in the dairy sector was expected as a consequence of the milk quota abolishment. The resulting environmental concerns led to an additional law, the "Wet verantwoorde groei melkveehouderij" or "Dairy law", which was introduced in January 2015 (Rijksoverheid, 2015b). Increasing the amount of phosphate produced on the farm has become more expensive in the new policy situation. Since the Dutch government also deemed it undesirable for dairy farms to become very intensive, an "Order of Council" that ensures land based-growth was introduced in September 2015. For intensive farms this new restriction means that additional farmland needs to be purchased when increasing the dairy herd.

The EU allows the Dutch farms to apply more nitrogen per hectare than other European farmers (known as derogation), in exchange for which the Dutch government agreed to a phosphate ceiling that limits the total amounts of phosphate that can be produced by the Dutch livestock industry (Tweede Kamer der Staten Generaal, 2015). Since the milk quota abolishment resulted in an increase in the phosphate production, there is a danger of losing the derogation. Therefore, additional legislation that introduces phosphate rights for dairy farms was introduced that limit phosphate production of the dairy sector. The phosphate rights are implemented from January 2018 onwards (RVO, 2018).

Since the abolishment of the milk quotas has removed a threshold that limits production, one might expect a shift in production choices, leading to large and intensive dairy farms. The associated Dairy Law, Order of Council and phosphate rights introduce new thresholds, after which producing becomes more expensive or requires the purchase of additional land or rights. These new thresholds might be expected to prevent a shift from occurring.

\section{Effects of cumulative effects, illustrated by innovations}

The adoption of an innovation, such as a new technology (e.g. an automatic milking system) or a new farming practice (e.g. on-farm processing of organic waste), can lead to land use change. Whether and when an innovation is adopted depends on multiple factors and their cumulative effects (Sinha \& Noble, 2008). There are multiple factors that might lead to innovation, but to illustrate the effect of cumulative effects we mention three. One factor that aids the diffusion of innovations is the existence of external economies of scale. External economies of scale exist when average costs decrease when the number of users of the innovation 
increases (Agnolucci \& McDowall, 2007). Another factor that will help the uptake of an innovation is the possibility to see the effects of the innovation demonstrated (Brown et al., 2016). Farms can learn about innovations by observing and interacting with other farms (Small, Brown \& Montes de Oca Munguia, 2016). A third factor that aids the spread of an innovation is social capital (Perman et al., 2011). The social norms and networks within the community can influence the values and beliefs of the farmer (Atwell, Schulte \& Westphal, 2009). Social norms establish the expectations on how one should behave, and thereby influence farm behaviour (Knight \& Ensminger, 1998).

When we consider the effects of the three mechanisms separately one might expect that although the innovation becomes more attractive, it does not become standard practice. However, the interaction between the mechanisms might lead to a higher uptake of the innovation. For example, if a few farmers innovate, the effects of the innovation are demonstrated, which might convince some other farmers to innovate as well. Then, because of these other farmers are now innovating, the costs go down due to external economies of scale. This might convince a few more farmers to innovate. At that stage the group of innovating farmers might have become big enough to socially influence other farmers, which might finally convince the remaining farmers to innovate. Thus, each of these factors might explain part of the adoption of an innovation, but to understand the complete picture we expect that it is necessary to take their cumulative effects into account as well.

\section{Effects of feedbacks and interactions, illustrated by Agri-Environmental Schemes}

Agri-environmental schemes (AES) have been introduced in an effort to prevent the negative environmental consequences of intensive farming practices. The AES are focused on environmental protection, nature conservation, and landscape enhancement (Primdahl et al., 2003). Farms can voluntarily join in an AES, in which payments are offered to farms that modify their farming practices to the benefit of the environment (Kleijn \& Sutherland, 2003). Within AES the environmental benefits achieved depend on the number of farms participating. However, the number of farm participating might also depend on the level of environmental benefits achieved in the region. This is an example of a feedback in the land use system. An extra feedback has been introduced in the Dutch AES system in 2016 when group application by farm collectives became compulsory. In this new system the farm collective is responsible for the application and the implementation of the AES on the regional level (Ministry of Economic Affairs, 2016). AES payments will only be available if the collective can submit a plan for a region that contains sufficient environmental benefits to the government. If not 
enough farms are willing to join in the AES the required environmental benefits cannot be promised and the AES payment will not be available. In turn, if AES payments are not available, it will be harder to develop a plan that contains sufficient environmental benefits. Therefore, we suspect that the collective application for AES will not always result in higher farm participation and biodiversity.

The collective AES system is also expected to result in a broader social support for the AES system (Portaal Natuur en Landschap, 2017; Stichting Collectief Agrarisch Natuurbeheer, 2016). Most members of the farm collectives feel connected to the collective. Farm collectives also organise activities like member meetings in which farmers can interact (Nieuwenhuizen et al., 2014). The increased farmer interaction might increase the social influence or peer pressure between farmers, causing farmers to adopt behaviours that comply with the social norm. Therefore, we expect that the introduction of a collective system might result in higher farm participation and biodiversity if social influence indeed increases as a result of this introduction.

\section{OBJECTIVE AND RESEARCH QUESTIONS}

In this thesis we aim to answer the following overarching research question:

Can thresholds, cumulative effects, feedbacks and interactions be responsible for unexpected system behaviour in land use systems?

By answering this research question our understanding of regime shifts and inertia in land use systems will be improved, thereby gaining further insights in the functioning of land use systems. To achieve this aim, the case of the Dutch dairy sector is taken as an example of a complex adaptive system. Due to its importance for land use in the Netherlands and the high level of policy intervention this sector is subject to, this case seems well suited for this purpose. In this thesis we define the following four sub questions:

1. Will the abolishment of the milk quotas lead to a shift towards larger and more intensive farms in the Netherlands?

2. How will the uptake of a new farming practice for processing of organic waste into compost in the "Friese Meren" in the Dutch province of Friesland be influenced by economies of scale, learning, and changing social norms?

3. What will be the effect on the resilience of the system of the shift from an individual to collective application for agri-environmental contracts in the 
Netherlands and how is the resilience of the land use system affected by the value farmers attach to biodiversity?

4. Does social influence due to the introduction of the collective AES system in the Netherlands result in a shift towards increased farm participation and a higher level of biodiversity?

Figure 1.1. shows an overview of the structure of this dissertation:

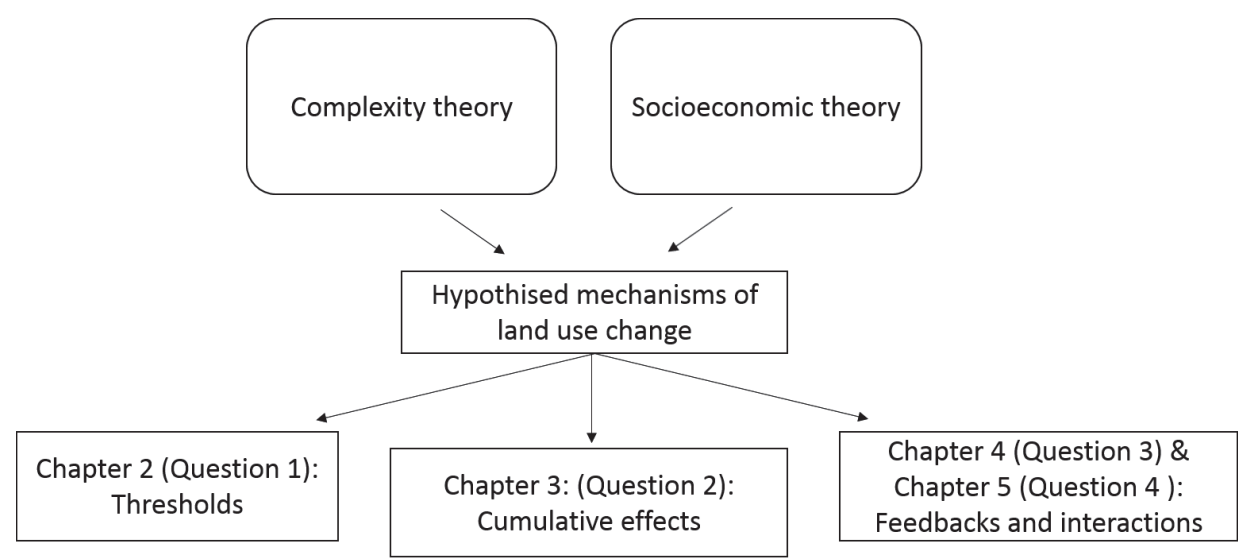

Figure 1.1. Overview of the structure in this dissertation

\section{DATA AND MODELS}

To answer the first research question on the abolishment of milk quotas we define 10 farm types, based on size. We assume that the farm types can be represented by 10 individual farms. To model the decisions of the individual dairy farm we apply mathematical programming. Mathematical programming models are commonly used to determine the optimal value of an objective function subject to a set of constraints. Mathematical programming models consist of a set of linear or nonlinear equations that determine the decision-making space (Kaiser \& Messer, 2011). In classical optimization theory usually an equality constraint is introduced. In contrast, mathematical programming techniques optimize an objective function subject to both equality and inequality constraints (Chiang, 1984). A possible non-linear relationship could result from multiple restrictions that are potentially binding. To answer the first research question we maximize farm profit given technological constraints like the use of inputs to produce milk and institutional constraints like milk quotas and Dutch manure laws. 
Data come from a wide variety of sources e.g. the BIN dataset (LEI Wageningen UR, 2015), the Quantitative Information Livestock Industry Report (KWIN 2014-2015 (Buisonje et al., 2014) and KWIN 2016-2017 (Blanken et al., 2016) and the handbook on the dairy sector (Remmelink et al., 2014; Remmelink et al., 2016). The BIN dataset contains economic data on a representative sample of Dutch dairy farms. The Quantitative Information Livestock Industry Report is an annual report containing up-to-date technical information on milk production (e.g. feed use of livestock). The Handbook on the dairy sector contains additional information on dairy farming such as manure production and composition, feed use and composition and data on soil quality.

To answer research question 2 on the uptake of on-farm processing of organic waste we use a mathematical programming model with multiple objectives. Goal programming was developed to deal with multiple objectives and is the most widely used multi-criteria decision making technique (Colapinto, Jayaraman \& Marsiglio, 2017). Goal programming models can be divided into lexicographic and weighted goal programming models. We develop a weighted programming model. In weighted programming models different goals receive different weights in the overall objective function (Colapinto, Jayaraman \& Marsiglio, 2017). To determine the weights we compare observed levels of each objective to the optimized level of each objective using a technique described by Manos et al. (2009). Data come from semi-structured interviews with a group of farmers that participated in a pilot project for the introduction of a new farming practice for processing of organic waste into compost. We combine farm-specific data with the data sources used for answering research question 1.

To answer research question 3 on the effects on farm participation and biodiversity of individual versus collective application for agri-environmental contracts in the Netherlands we again use a multi-objective goal programming model. The weights for the model are determined by asking farmers during semi-structured interviews to assign a weight to each farm objective. There are four farm objectives in our model, which are profit maximization, risk minimization, labour minimization and biodiversity maximization. To measure biodiversity we define key species, which are exemplary of the biodiversity in the region. Data come from the semi-structured interviews again in combination with the data sources used for answering research question 1.

To answer research question 4 on the effect of social influence on farm participation and a higher level of biodiversity we use the same mathematical programming model and data as for research question 3. However, to incorporate social influence the model is extended with an Opinion Dynamics Model module (Sun \& Müller, 2013). Moreover, the weights have been determined using the 
technique of Manos et al. (2009). Data sources used are the same as for answering research question 3 .

Our first research question is answered in chapter 2 , the second research question is answered in chapter 3 , the third research question is answered in chapter 4 and the fourth research question is answered in chapter 5 . In chapter 6 we present an overall conclusion and discussion. 


\section{Chapter 2}

The effect of milk quota abolishment on farm intensity: shifts and stability ${ }^{1}$

1 Paper by Groeneveld, A.N., Peerlings, J.H.M., Bakker, M.M., and Heijman, W.J.M. (2016). The effect of milk quota abolishment on farm intensity: shifts and stability. NJAS-Wageningen Journal of Life Sciences, 77, 25-37. 


\section{ABSTRACT}

We investigate whether milk quota abolition in the Netherlands is likely to lead to a shift towards more intensive farms, and whether the legislation introduced by the Dutch government to prevent this from happening is likely to be effective. To this end a mathematical programming model is developed and applied to ten Dutch dairy farms of varying size. The mathematical programming model allows us to calculate shadow prices, which we use to evaluate the stability or likelihood of a shift in the farmer decisions in our model. Our results suggest a strong increase in intensity for the largest farm type when milk quotas are abolished, while further intensification is limited for the smaller farm types. Although most farm types increase the number of cows on the farm, for the smaller ones this can only be achieved when the costs of expanding decrease considerably. The new legislation introduced by the Dutch government to prevent strong intensification appears to be successful. 


\subsection{INTRODUCTION}

Since 1984, the European Union (EU) has applied a supply quota for milk to prevent the overproduction that resulted from milk price support. This price support for milk was subject to critique, as it distorts global trade. In the 1990s, the World Trade Organisation urged the EU to abolish its system of price support (Binfield et al., 2004; NRC, 2015), in response to which the EU decided to gradually liberalise its dairy policy. From 2003 onwards, support prices were reduced and the supply quotas were enlarged in steps. In recent years, world market prices for dairy products increased strongly, decreasing the gap between EU prices and world market prices. It is therefore that the EU has decided to abolish the supply quotas for milk completely (NRC, 2014), per $1^{\text {st }}$ of April 2015 (European Commission, 2015). When production quotas such as those for milk are abolished, the industry structure (i.e. the number of farms and farm size distribution) is likely to be influenced (Boere et al., 2015; Buysse et al., 2012; Straeten et al., 2009), which may have important consequences for the land use and landscape in rural areas dominated by dairy farming, such as the Netherlands.

Within the Netherlands the abolishment of milk quotas has led to environmental concerns, as further intensification (i.e. number of livestock per hectare) is expected (Rijksoverheid, 2015b). Such intensification is likely to lead to an increase in the amounts of nitrogen and phosphate produced, which poses a major threat to the fragile natural ecosystems that are - in the Netherlands - often spatially interwoven into the agricultural area. Soon after the introduction of the milk quota, the Dutch government issued regulations to protect the environment (Hees, Rougoor, \& Schans, 2012) limiting the amount of nitrogen and phosphate from manure and artificial fertilizer that can be put on the land. Excesses of nitrogen and phosphate were to be removed from the farm (Buisonje et al., 2014), which led to a considerable trade in these excesses, among agricultural sectors and even with other countries. To prevent even larger excesses due to quota abolishment (the ceiling for the application of phosphate on land has remained unchanged), an additional law, referred to as the "Wet verantwoorde groei melkveehouderij" (law to ensure responsible growth of the dairy sector) or "Dairy law" (in Dutch Melkveewet), has been introduced in January 2015. Any phosphate surplus in excess of the amount prior to the milk quota abolishment has to be processed (Eerste Kamer der Staten Generaal, 2014), meaning considerable extra costs for the farmer.

Yet, more restrictions were deemed necessary. Although the Dairy law addresses environmental concerns by regulating potential phosphate surpluses, it still allows farms to grow and/or intensify. Intensive dairy farming has become a 
topic of societal debate for various reasons. Firstly, it is associated with cows that remain permanently indoors, which is considered to result in a loss of cultural ecosystem services (meadows with cows are considered esthetically pleasing) (Yarwood \& Evans, 2003). Secondly, animal welfare is considered to be at stake in high-intensity farms, also due to the fact that many cows never leave the stable (Shum et al., 2009; Stafford \& Gregory, 2008). Thirdly, many people consider the existence of very large farms (and large stables in particular) undesirable. Most people associate farming with family farms, and oppose the idea of industrialization of farming (Lagane, 2014). Whether or not these arguments are justified, the ministry of Economic Affairs accommodated them by implementing a further measure (i.e. the 'Order of Council') in September 2015 that imposes a restriction on the intensification of Dutch dairy farms (Rijksoverheid, 2015c). The measure specifically ensures land-based growth by demanding that - for intensive farms - further increases in the on-farm phosphate surpluses are only allowed when a certain amount of land is available (Rijksoverheid, 2015a; Rijksoverheid, 2015c). This means that most farmers who want to increase their dairy herd can only do so if they purchase additional farmland.

The objective of this paper is to investigate whether the abolition will lead to a shift towards larger and more intensive farms in the Netherlands. In addition, we explore the effectiveness of the Order of Council. We do this for a range of farm sizes, as we expect that responses to policy changes will differ strongly per size category. More specifically, we expect that large farms are more likely to intensify when milk quotas are abolished than small farms. This is because larger farms have higher economic and environmental efficiencies (Bos, Smit \& Schröder, 2013), have lower per-unit production costs, and are therefore more likely to invest in more animals. Taking into account this variability within the farm population is thus essential to reveal the potential impact of policy reforms.

A mathematical programming model is developed and applied to ten representative Dutch dairy farms of different size as measured by Standard Output (SO). $\mathrm{SO}$ is the average monetary value of the agricultural output at farm gate price, and is considered a good measure of the economic size of a farm (Eurostat, 2015). The model is used to analyse the likelihood of a shift towards a more intensive farm. We formulated three policy options: one reflects the situation with the milk quota still in place, the second reflects the situation in which milk quotas are abandoned but the Order of Council is not in effect, and the third captures the situation in which the Order of Council is introduced. Section 2 provides a short background. Section 3 discusses the methods we use. The results are presented in section 4. Section 5 provides a sensitivity analysis and sections 6 and 7 provide the discussion and conclusion. 


\subsection{BACKGROUND}

Agricultural land takes up about half of the total surface area in the Netherlands (CBS, 2016a; CBS, 2016b) and about 40 percent of agricultural land is used by dairy farms (CBS, 2015a). The majority of Dutch dairy farms is specialised in milk production (Westhoek et al., 2004). In 2014 there were around 17,000 dairy farms in the Netherlands (CBS, 2015a) which had an average SO of 339,000 euro. An average Dutch dairy farm as described by the Farm Accountancy Data Network (FADN) has 50 hectares of land and 90 dairy cows, which comes down to an average intensity of 1.8 cows per ha in 2014 (LEI Wageningen UR, 2015). Considering an average phosphate production of $45.5 \mathrm{~kg}$ per cow, and an allowed application rate of $95 \mathrm{~kg}$ phosphate on grassland (Buisonje et al., 2014), $1.8 \mathrm{cow}$ per ha would not require any manure to be exported off-farm. However, since most farms also apply artificial fertilizer, and keep young cattle which is not included in the average of 90 cows as recorded in the FADN, most dairy farms export or process manure. In 2014, 85.6 million $\mathrm{kg}$ of phosphate (Tweede kamer der Staten Generaal, 2015) and 257 million kg of nitrogen (CBS, 2016c) was produced by dairy farms. The Dutch government has made an agreement with the European Commission that allows farms to apply an additional amount of nitrogen to their land when at least 80 percent of their land is grassland. This is referred to as derogation and in exchange for the increased application of nitrogen allowed by the European Commission the Dutch government has to ensure that the total amounts of nitrogen and phosphate from manure stay below a so-called phosphate and nitrogen ceiling (Tweede kamer der Staten Generaal, 2015). In $201477 \%$ of the dairy farms had an excess of phosphate that had to be exported from the farm or processed (CBS, 2016c). If we consider the whole agricultural sector 172 million $\mathrm{kg}$ phosphate was produced of which 137 million $\mathrm{kg}$ could be applied on land, 28 million $\mathrm{kg}$ was exported to other countries, and 10 million $\mathrm{kg}$ was processed (CBS, 2016d).

As for the other issues around farm size and intensification, $69 \%$ of all dairy farms allow their cows to graze outside (CBS, 2015b). Within the Netherlands there is a general trend towards increasingly larger farms. This trend is also visible for the Dutch dairy sector. The number of farms with more than 250 cows has increased from 44 in 1980 to 355 in 2015. From 2011 onwards, the number of dairy farms in the Netherlands has decreased, while the number of dairy cows has increased. Thus, more cows are kept on bigger farms (CBS, 2015c). 


\subsection{METHOD}

\section{Mathematical programming}

Mathematical programming is a method for identifying an optimal allocation of resources (Mavrotas, Florios \& Vlachou, 2010). Within a mathematical programming model, an objective function is specified, which is maximized or minimized given a set of constraints. In this paper we assume that farms' main goal is to optimize their gross margin or profit. The assumption of profit maximization is in line with assumptions that are generally made in economic modelling (Pedersen et al., 2012), although it should be mentioned that in reality farms might have other objectives such as the minimization of labour use and risk or the environmental impact of farming as well (Berbel \& Rodriguez-Ocana, 1998; Rozakis, Sintori \& Tsiboukas, 2012; Sumpsi, Amador \& Romero, 1997; Willock et al., 1999). Mathematical programming allows us to study changes in the optimal farming decisions, which are the result of constraints becoming more or less binding.

In our model a farm maximizes gross margin given a set of technological and institutional constraints. These constraints can be both equality and inequality constraints. The basic structure of a mathematical programming model with only technological and inequality constraints is given in equation 1 .

$\max _{x_{i}} Z=\sum_{i=1}^{N}\left(p_{i} x_{i}-w_{i} x_{i}\right)$

Subject to:

$\sum_{i=1}^{N} a_{i k} x_{i} \leq b_{k} \quad \forall_{k}\left[\pi_{k}\right]$

$x_{i} \geq 0 \quad \forall i$

Where:

$Z$ is gross margin defined as total revenues minus total variable costs, $p_{i}$ refers to revenues per unit of activity $i, w_{i}$ is the variable costs per unit of activity $i, x_{i}$ is the level of activity $i, b_{k}$ is the total availability of a resource $k, a_{i k}$ is the quantity of resource $\mathrm{k}$ demanded by activity $i$, and $\pi_{k}$ is the shadow price of input $k$.

Equation 1 states that farms maximize gross margin by choosing the optimal activity levels under the assumption of exogenous output and input prices. Optimization takes place according to two types of restrictions. First, restriction 1a gives inequality restrictions, for example that the total use of fixed inputs should be less than or equal to the endowments of these inputs. Second, restriction $1 \mathrm{~b}$ states that activity levels cannot be negative. 


\section{Stability, regime shifts and shadow prices}

Models such as the one developed here, are commonly used to identify the optimal allocation of a set of resources under specific conditions and constraints. Their static nature does not - at first sight - qualify them for exploring temporal dynamics. However, we do think they can be used to reveal a potential disposition of a system for regime shifts. This is because these models typically reveal nonlinear responses of system properties (i.e. the resource allocation that leads to the highest profit) to prices and availability of the resources. The non-linear relationship between the availability of a factor and the optimal allocation of resources is the result of multiple factors that are potentially binding. If a mathematical programming model contains only two factors that influence the objective we can give a graphical presentation of the optimization problem (Figure 2.1.).

\section{a)}

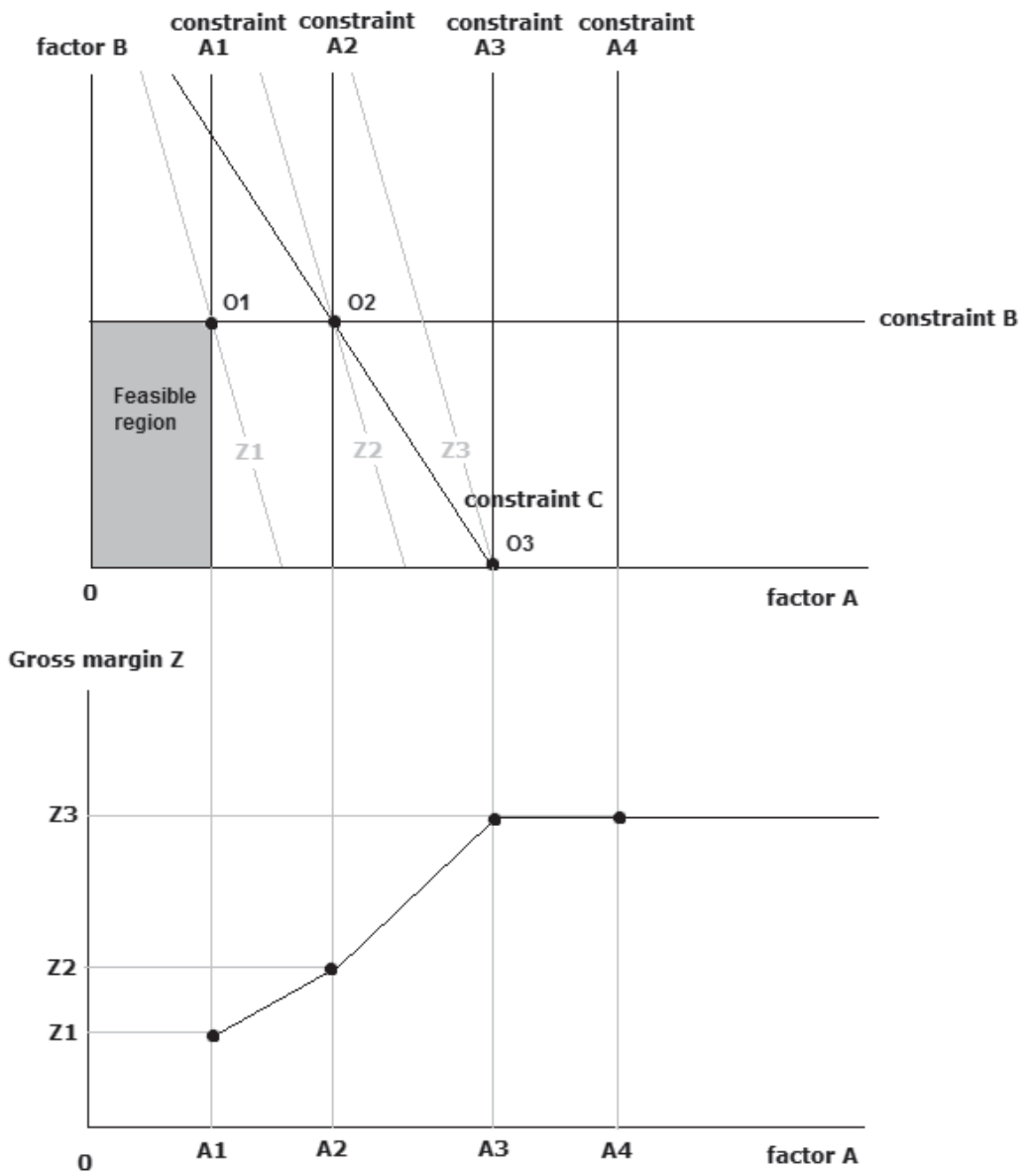

Figure 2.1. Graphical representation of the optimization problem, based on (Kaiser \& Messer, 2011) 
Panel (a) shows the two factors A and B that can be combined to reach a certain gross margin level $\mathrm{Z}$. In the initial situation constraint $\mathrm{A} 1, \mathrm{~B}$ and $\mathrm{C}$ are given, and all choices for the levels of $\mathrm{A}$ and $\mathrm{B}$ that are feasible form the feasible region. In the initial situation the feasible region is determined by the binding constraints $\mathrm{A} 1$ and $\mathrm{B}$, while constraint $\mathrm{C}$ is not binding. The light grey lines labelled $\mathrm{Z}$ are the iso-profit lines. These lines connect all the combinations of factor A and $\mathrm{B}$ for which the profit reaches the same level. In the initial situation the highest level of gross margin that can be obtained is Z1, where point O1 indicates the optimal amounts of factor $\mathrm{A}$ and $\mathrm{B}$ used in this case. Now imagine one more unit of factor A would become available, shifting the constraint from A1 to A2. This would mean that the feasible region grows and the highest level of gross margin that can now be obtained is $\mathrm{Z} 2$. The point $\mathrm{O} 2$ indicates the optimal amounts of factor $\mathrm{A}$ and $\mathrm{B}$ used in this case. The difference between $\mathrm{Z} 1$ and $\mathrm{Z} 2$ is the extra gross margin that results from having one more unit of factor $\mathrm{A}$ available, which is referred to as the shadow price of factor A. If the decision maker would have the opportunity to obtain an extra unit of factor $A$, the shadow price would be the maximum amount the decision maker would be willing to pay to do so. If we shift to constraint $A 3$, constraint $C$, which was previously not binding the optimal solution, now restricts the optimal level of gross margin that can be obtained. The point $\mathrm{O} 3$ indicates the optimal amounts of factor $\mathrm{A}$ and $\mathrm{B}$ used in this case. Shifting the constraint even further out to A4 would no longer result in extra gross margin, since constraint $C$ prevents this. In Panel (1b) we show the response of gross margin to an increase in the availability of factor $\mathrm{A}$, if we keep all other constraints fixed. Whenever binding factors change (i.e. the lines representing constraints in Panel (1a) change), the optimal solution and its associated resource allocation changes as well, but not in a linear way (Panel (1b)): As long as binding factors are relaxed or changed, the optimal solution will change as well; but once another constraint 'takes over' the binding role, the optimal solution will no longer respond to changes in the (now no longer binding) factor.

Hence, it is possible that the optimal solution does not change when we change the value of one of the constraints (say from A4 to A3 in Panel (1b)), but when we continue changing the constraint value, at some point (A3) a small extra change will be enough to result in a different optimal solution. This is a clear analogy with the concept of regime shifts as proposed by (Folke et al., 2004). Following this analogy, optimal solutions can be seen as domains of attraction, the range over which a constraint can change without affecting the optimal solution can be seen as resilience, while the shift from one optimal solution to another could be seen as a regime shift. Although in this case the regime shift does not result from complex system behaviour (e.g. interactions between individual building blocks, 
and feedbacks between scale levels), and the shift itself is not characterized by an (uncontrollable) cascade of positive feedbacks, there is a clear non-linear response that needs to be accounted for when anticipating the effects of a policy measure. In a mathematical programming model the stability or resilience of the optimal solution can be measured by its relative position within the range of optimality. This range indicates the maximum change that the system can absorb due to a change in a driver (e.g. the amount of manure that has to be processed) without changing the optimal solution (Kaiser \& Messer, 2011).

Since a graphical representation is only possible in the case with two constraining resources (and we have many more), a useful indicator for the degree to which a factor is binding, is the shadow price. A shadow price indicates what the value is of one more unit of a resource to the decision maker (Gass, 2003). For example, if a farm is constrained by the initial stable capacity (factor A) the shadow price indicates how much a farmer would be willing to pay to increase the stable capacity (shifting constraint A). If the shadow price is zero, the stable capacity is not constraining the production. If the shadow price is positive, but less than the actual investment costs, the farmer will not be willing to invest. Only when the shadow price equals or exceeds the investment costs the farmer would start investing in extra stable capacity. Hence, shadow prices allow us to quantify the likelihood of a shift in one of the constraints, and thus the optimal solution. We will use these concepts to interpret our results in terms of the likelihood of a shift or stability.

\section{Model}

Our model describes the decisions made by Dutch dairy farms. It is assumed that a farm maximizes gross margin given a set of constraints. Gross margin is the result of revenue from milk production and selling cows that are no longer suited for milk production against a fixed price, minus the maintenance costs of cows and young cattle, the costs of growing grass and maize, the costs of buying feed, the costs of removing phosphate $\left(\mathrm{P}_{2} \mathrm{O}_{5}\right)$, the costs of processing phosphate (which is higher than the costs of removing phosphate), the costs of hiring additional labour, the investment cost in additional stable capacity, the costs of raising or buying extra cows and the cost of renting extra land to a maximum of 20 ha. It is possible that the farm rents out some of its initial land, in which case the costs of renting extra land are negative and result in extra revenue. A mathematical presentation of our model can be found in appendix A.

The farm is restricted by its initial endowment of land, cows, stable capacity, own labour and policy regulations. There is a policy which limits the amount of phosphate that can be placed on land. In the situation where milk quotas are ap- 
plied policy restricts the amount of milk that can be sold. In the case where milk quotas are abandoned and the Dairy Law is introduced policy restricts the amount of phosphate that can be removed. In the case where milk quotas are abandoned and the Order of Council is introduced policy dictates a certain amount of land that needs to be bought when expanding production.

In our model there are three shadow prices of interest. First, the shadow price that indicates the value of extending the initial stable capacity with one more cow. This is relevant as we assume that there is a maximum farm size in terms of cow numbers (i.e. 500 cows) and the farm will only extend stable capacity when the shadow price is equal or higher than the yearly investment costs of additional stable capacity. Second, the shadow price indicating the value of one more hectare of land the farm can rent. This is relevant as we assume a farm cannot extend with more than 20 ha and the farm will only attract extra land if the shadow price is higher than the costs of renting extra land (1200 euro per ha). Third, the shadow price indicating the value of having one more hour of labour available. This is relevant as below an external wage (16.74 euro per hour) a farm will not hire external labour. Our model provides a more simplified and stylized version of a mathematical programming dairy model than for instance the model of Berentsen and Giesen (1995), to allow a stronger focus on the possibility of a shift.

Our model allows farms to rent up to 20 hectares of extra land, paying 1200 euro per hectare. Farms can increase the number of cows up to 500, which we consider to be the maximum number of cows that can still be managed on a family farm. Each farm has 7000 hours of own labour available, more labour from outside the farm can be hired, for which the farm pays a wage of 17 euro per hour. As mentioned before we present all results compared to the initial situation in the BIN data set.

\section{Data}

The costs of feed bought, the costs of removing phosphate, the costs of maintaining young cattle, the costs of extra cows, the yearly investment costs in the stable, the costs of hired labour, the amount of feed measured in KVEM (measure for energy content of feed) produced on a ha of grassland and maize land, the amount of young cattle needed for replacement of current dairy cows, the amount of phosphate allowed on a ha of grassland and maize land, and the percentage grassland needed to be able to apply for derogation are taken from the Quantitative Information Livestock Industry report KWIN 2014-2015 (Buisonje et al., 2014). The KVEM needed per cow, the KVEM needed for young cattle, and the amount of own labour hours available are taken from the 
handbook on the dairy farm sector 2014 (Remmelink et al., 2014). The $\mathrm{kg}_{2} \mathrm{O}_{5}$ per KVEM from grass, the $\mathrm{kg} \mathrm{P}_{2} \mathrm{O}_{5}$ per KVEM from maize, the $\mathrm{kg} \mathrm{P}_{2} \mathrm{O}_{5}$ per KVEM from feed bought, the $\mathrm{kg}_{2} \mathrm{O}_{5}$ bound in milk, $\mathrm{kg} \mathrm{P}_{2} \mathrm{O}_{5}$ bound in carrying cows and $\mathrm{kg} \mathrm{P}_{2} \mathrm{O}_{5}$ bound in young cattle are taken from the assistance report for calculating phosphate production on dairy farms by the Dutch government. The labour hours needed for milk production, for cultivating grass land and for cultivating maize land are taken from (Meetjesland, 2016), the land rent is based on (BoerenBusiness, 2014a) and the costs of cultivating a ha grass land and maize land are calculated using the "Kostenwijzer voedermiddelen" (Cost indicator for feedstuff) (Wageningen UR, 2015).

To be able to discuss the effect of milk quota abolition we defined 10 farm types based on SO, describing farms with increasingly larger SO. Our starting point in creating these different farm types was the BIN dataset (LEI Wageningen UR, 2015). This dataset provided us with information on the total farm area, the initial number of cows, the number of cows sold, the production per cow, the price of cows sold and the other costs of keeping cows for three different farm sizes.

The data from BIN provided us with the opportunity to calculate the percentage of the total farms represented by each of the three farm types based on SO. In 2013 a 0.1 share of the farms fell in the category 0 to 150,000 SO, a 0.2 share of the farms fell within the category $150,000-250,000$ and a 0.5 share of the farms fell within the 250,000-500,000 category. These shares do not add up to one, since there are farms that fall in the category larger than 500,000. Using this information we searched for a distribution that fitted our data and that we could calibrate to our data. We considered a normal distribution, a gamma distribution and a Weibull distribution. The distribution that we found fitted our data the closest was the Weibull distribution. The probability density function of a Weibull distribution has the following form:

$f(t)=\left(\frac{a}{B}\right)\left(\frac{t}{B}\right)^{a-1} * e^{\left[-\left(\frac{t}{B}\right)^{a}\right]}$

This distribution is positively skewed if the value of $a$ is smaller than 3.6 (Lai, 2014). The distribution we use is described by equation 2 .

$f(x)=\left(\frac{2.12}{439}\right) *\left(\frac{x}{439}\right)^{1.12} * e^{-\left(\frac{x}{439}\right)^{2.12}}$

Where:

$x$ size in $1000 \mathrm{SO}$. 
We then divided this distribution in intervals, looking at the SO of farms at the 10, 20, 30, 40, 50, 60, 70, 80 and 90 percent quantile. To present each group we took the average of SO of the farms at the beginning and end of each interval. For example, for the farm type in the 0-10 percent quantile SO was the average of $\mathrm{SO}$ at the 0 percent quantile and $\mathrm{SO}$ at the 10 percent quantile. In this way 10 farm types based on SO were created which each present an equal share of the farms.

The next step was to calculate the value of the exogenous variables that are used in the model. In order to do this the farm size in terms of SO was plotted against each exogenous variable. Using the three data points a trend line was fitted to the data. The resulting equation was then used to estimate the values of the exogenous variables for the different farm types.

The decisions made by the farm are influenced by policy, input prices and output prices. The values of the exogenous prices in the model can be found in Table 2.1. Some values differ between the different farm types in which case a price range is given, while others are the same for everyone. A further description of the data used in our model can be found in appendix B. Data were taken for the period 2013-2014.

\section{Table 2.1. Values for the prices and costs used in the model}

\begin{tabular}{ll}
\hline Price & Value \\
\hline Yearly maintenance costs in euro per cow on farm n & $234-509$ \\
Yearly maintenance costs in euro per young cattle on farm n & $45-97$ \\
Yearly costs in euro of growing one ha grass & 1440 \\
Yearly costs in euro of growing one ha maize & 1540 \\
Costs of feed bought in euro per KVEM & 0.14 \\
Costs of removing P2O5 in euro per kg & 9.33 \\
Costs of processing P2O5 in euro per kg & 10.83 \\
Costs of hired labour in euro per hour & 16.74 \\
Yearly investment costs additional stable capacity including young & \\
cattle capacity in euro per place for each extra cow & 354.80 \\
Yearly costs of raising or buying extra cows in euro per cow & 294 \\
Yearly costs of renting extra land in euro per ha & 1200 \\
Price of cows sold from the farm in euro per cow for farm n & $515-770$ \\
Milk price in euro per 100 kg & $42.18-43.78$ \\
\hline
\end{tabular}




\section{Policy options}

We ran our model for the following three policy options:

\section{P01: Milk quotas}

This policy option fits the situation before 1 April 2015. In this policy option, the farm maximizes gross margin but is constrained by the milk quota, which limits milk production and thus the number of cows.

\section{PO2: Milk quotas abolished, no Order of Council}

In this policy option, the farm maximizes gross margin, and is no longer constrained by the milk quota. The number of cows on the farm is now only limited by a supposed maximum amount of 500 cows that can be managed by a family farm; this assumption is based on (Boerderij, 2010; Gelderlander, 2015; Trouw, 2015). Any phosphate surplus in excess of the amount that already was exported off-farm prior to the milk quota abolishment in the reference year 2013, has to be either processed (against a considerable cost), applied on land (but up to limited amounts per hectare), or a combination of these two measures.

\section{PO3: Milk quotas are abolished and Order of Council is introduced}

In this policy option, the farm maximizes gross margin and is no longer constrained by the milk quota. However, the Order of Council is introduced, ensuring land-bound growth. Farms that have a phosphate surplus below $20 \mathrm{~kg}$ phosphate per hectare are excluded from the Order of Council and any phosphate surplus in excess of the amount that already was exported off-farm prior to the milk quota abolishment in the reference year 2013 has to be either processed, applied on land, or a combination of these two measures. If the farm has an on-farm phosphate surplus above $20 \mathrm{~kg}$ phosphate per hectare, a certain share of this has to be placed on additional land. Farms that have a phosphate surplus between 20-50 kg per hectare are obliged to place 25 percent of the additional phosphate production on land and farms that have a surplus above $50 \mathrm{~kg}$ per hectare are required to place 50 percent of the additional phosphate production on land, the rest of the additional phosphate surplus can be either processed, applied on land or a combination of these two measures.

Note that PO1 in a way reflects the situation of the recent past, which could allow us to use existing data rather than model outcomes. However, the initial situation as presented by the BIN data might not be the gross margin maximizing situation. In the model we allow for an increase in the amount of land rented and in the stable capacity on the farm, which is, in reality not always that simple, due to scarcity of land or the requirement to obtain building permits. To capture this, 
we compare the results from the three policy options with the actual situation as described by the BIN data.

\subsection{RESULTS}

Table 2.2. shows the amount of extra land rented by the 10 farm types for the three policy options (PO). The farms in quantile $0-10$ present the farms with the smallest SO and the farms in quantile 90-100 present the farms with the largest SO. The smallest farm type rents out one hectare of land for all policy options. With the number of cows on this farm no additional land is needed for placing a phosphate surplus. The other farm types rent some extra land under PO1, as it provides them with feed and the option to put phosphate on land. The number of cows under PO2 is higher than under PO1, leading to a higher demand for land as well. Under PO2 Farm types in the 10-100 percent quantiles rent all available extra land (i.e. up to 20 ha, see Model section). Under PO3 this is largely the same, but somewhat lower for the farm type in the 10-20 quantile, who has a slightly lower number of cows in this policy option.

Table 2.2. Extra hectares of land rented per farm type for the three policy options

\begin{tabular}{llll}
\hline Farm type/ extra land rented & $\begin{array}{l}\text { PO1: Milk } \\
\text { quota }\end{array}$ & $\begin{array}{l}\text { PO2: No milk } \\
\text { quota }\end{array}$ & $\begin{array}{l}\text { PO3: Order of } \\
\text { Council }\end{array}$ \\
\hline Quantile $0-10$ & -1 & -1 & -1 \\
Quantile 10-20 & 3 & 20 & 19 \\
Quantile 20-30 & 5 & 20 & 20 \\
Quantile 30-40 & 6 & 20 & 20 \\
Quantile 40-50 & 8 & 20 & 20 \\
Quantile 50-60 & 9 & 20 & 20 \\
Quantile 60-70 & 11 & 20 & 20 \\
Quantile 70-80 & 12 & 20 & 20 \\
Quantile $80-90$ & 14 & 20 & 20 \\
Quantile $90-100$ & 20 & 20 & 20 \\
\hline
\end{tabular}

Table 2.3. shows that the number of cows for all but the smallest farm type is higher under PO2 and PO3 compared to PO1, but less so under PO3 than in $\mathrm{PO} 2$. Increase in cows is constrained by different factors for different farm size types. Farm types in the 10-30 percent quantiles would - under PO2 - have to start paying for the removal or processing of excess phosphate when increasing 
the number of cows any further, while farm types in the 30-90 percent quantiles use all of their own labour, so that increasing the number of cows would result in more hired labour costs. Since the costs outweigh the extra gross margin, these farms will not expand their number of cows any further. Since the larger farm types have a larger initial endowment of land, they end up with more land than the smaller farm types. For the farm types limited by the availability of own labour the consequence is that more labour is spent cultivating land and less labour is available for the cows, explaining the decreasing number of cows with increasing farm size for those farms in the 30-90 quantiles of PO2. The number of cows is lower in PO3 for all farm types in the 10-100 percent quantiles than in PO2.

Table 2.3. Number of cows per farm type for the three policy options

\begin{tabular}{llll}
\hline Farm type/number of cows & $\begin{array}{l}\text { PO1: Milk } \\
\text { quota }\end{array}$ & $\begin{array}{l}\text { PO2: No } \\
\text { milk quota }\end{array}$ & $\begin{array}{l}\text { PO3: Order of } \\
\text { Council }\end{array}$ \\
\hline Quantile 0-10 & 24 & 24 & 24 \\
Quantile 10-20 & 45 & 71 & 69 \\
Quantile 20-30 & 57 & 83 & 83 \\
Quantile 30-40 & 68 & 168 & 99 \\
Quantile 40-50 & 78 & 165 & 112 \\
Quantile 50-60 & 88 & 161 & 126 \\
Quantile 60-70 & 99 & 158 & 140 \\
Quantile 70-80 & 112 & 154 & 154 \\
Quantile 80-90 & 129 & 149 & 149 \\
Quantile 90-100 & 215 & 500 & 276 \\
\hline
\end{tabular}

As a measure of intensity Table 2.4. presents the number of cows per hectare under the different policy options for the ten farm types. The number of cows per hectare for the farm types in the $0-20$ percent quantiles is not affected by the policy options. Even though the farm types in the 10-20 percent quantile increase their number of cows, they increase the amount of land accordingly. The farm types in the 10-100 percent quantiles all rent extra land under PO2 and PO3. PO3 is effective in terms of avoiding intensification for the farm types in the 30-70 and 90-100 quantiles as it results in a lower number of cows per ha. The farms in the 30-90 quantiles use all of their own labour available, limiting the total number of cows. Because larger farms have a larger initial land endowment, and because all farms in the 30-90 quantiles rent all available extra land when milk quotas are abolished, the number of cows per ha decreases when the farm size measured in $\mathrm{SO}$ increases under PO2. 
Table 2.4. Cows per hectare per farm type for the three policy options

\begin{tabular}{llll}
\hline Farm type/ number of cows per ha & $\begin{array}{l}\text { PO1: Milk } \\
\text { quota }\end{array}$ & $\begin{array}{l}\text { PO2: No } \\
\text { milk quota }\end{array}$ & $\begin{array}{l}\text { PO3: Order of } \\
\text { Council }\end{array}$ \\
\hline Quantile 0-10 & 1.5 & 1.5 & 1.5 \\
Quantile 10-20 & 1.5 & 1.5 & 1.5 \\
Quantile 20-30 & 1.5 & 1.6 & 1.6 \\
Quantile 30-40 & 1.5 & 2.9 & 1.7 \\
Quantile 40-50 & 1.5 & 2.6 & 1.8 \\
Quantile 50-60 & 1.5 & 2.4 & 1.8 \\
Quantile 60-70 & 1.5 & 2.1 & 1.9 \\
Quantile 70-80 & 1.5 & 1.9 & 1.9 \\
Quantile 80-90 & 1.5 & 1.7 & 1.7 \\
Quantile 90-100 & 1.6 & 3.8 & 2.1 \\
\hline
\end{tabular}

Table 2.5. shows that the phosphate surplus per hectare is larger for the farm types in quantiles 20-100 under PO2 and PO3 compared to PO1. Under PO2 and PO3 farm types 20-90 rent all extra land that is available. Larger farm types have a larger initial land endowment and a smaller number of cows due to the restriction on own labour available. This explains how larger farm types can have a smaller surplus per hectare. PO3 effectively lowers the phosphate surplus per hectare for farm types in the 30-70 and 90-100 quantiles.

Table 2.5. Phosphate surplus per ha per farm type for the three policy options

\begin{tabular}{llll}
\hline Farm type/ phosphate surplus per ha & $\begin{array}{l}\text { PO1: Milk } \\
\text { quota }\end{array}$ & $\begin{array}{l}\text { PO2: No } \\
\text { milk quota }\end{array}$ & $\begin{array}{l}\text { PO3: Order of } \\
\text { Council }\end{array}$ \\
\hline Quantile 0-10 & 0 & 0 & 0 \\
Quantile 10-20 & 0 & 0 & 0 \\
Quantile 20-30 & 0 & 5 & 5 \\
Quantile 30-40 & 0 & 113 & 15 \\
Quantile 40-50 & 0 & 89 & 20 \\
Quantile 50-60 & 0 & 68 & 25 \\
Quantile 60-70 & 0 & 49 & 29 \\
Quantile 70-80 & 0 & 31 & 31 \\
Quantile $80-90$ & 0 & 10 & 10 \\
Quantile 90-100 & 3 & 173 & 39 \\
\hline
\end{tabular}


The results show that the differences between farm types in costs and revenues in the model are determining the outcomes. Since small farms have higher maintenance costs per cow and a lower production per cow they are less likely to become big and very intensive when milk quotas are abolished. Only the largest farms found in the 90-100 percent quantile will increase the number of cows per hectare under PO2 significantly, since they can afford to pay the investment costs in stable capacity, the hired labour costs, the rent for extra land, and the costs of processing phosphate. More model results for the gross margin per farm type, the number of cows exceeding initial stable capacity per farm type, the phosphate processing costs per farm type, the hectares per farm type and the phosphate surplus per farm type can be found in appendix C.

\section{Stability and shifts within the model}

Table 2.6. shows the shadow prices for stable capacity for the different farm types in the different policy options. The shadow price for stable capacity indicates the extra gross margin a farm could achieve when having one more place in its initial stable capacity. If this amount is equal to the costs of investing in one more stable place (355 euro) the farm will choose to do so and there is no limit to the amount of extra stable places a farm can invest in. The shadow price tells us how far the price of stable capacity would have to go down for the farms to start investing in additional stable capacity. The shadow price can therefore be seen as an indicator for the distance to a tipping point where farms will no longer be kept from expanding due to the investment costs in stable capacity. Table 2.6. shows that this situation is reached for all farm types under PO2 and PO3 except the $0-10$ quantile.

Under PO2 and PO3 only the smallest farm type in quantile 0-10 is constrained by the investment costs in extra stable capacity. The shadow price shows that these costs would have to go down considerably before this decision would change and a shift towards investment in extra stable capacity would occur. Therefore, the choice made by the farm type in the $0-10$ quantile is quite stable with respect to investment costs for stable capacity. The other farm types are not constrained by the stable capacity (as under PO1) or the investment costs in stable capacity (as under PO2 and PO3). 
Table 2.6. Shadow prices (euro per cow) for stable capacity per farm type for the three policy options

\begin{tabular}{llll}
\hline $\begin{array}{l}\text { Farm type/shadow price stable } \\
\text { capacity }\end{array}$ & $\begin{array}{l}\text { PO1: Milk } \\
\text { quota }\end{array}$ & $\begin{array}{l}\text { PO2: No milk } \\
\text { quota }\end{array}$ & $\begin{array}{l}\text { PO3: Order of } \\
\text { Council }\end{array}$ \\
\hline Quantile 0-10 & 0 & 276 & 276 \\
Quantile 10-20 & 0 & 355 & 355 \\
Quantile 20-30 & 0 & 355 & 355 \\
Quantile 30-40 & 0 & 355 & 355 \\
Quantile 40-50 & 0 & 355 & 355 \\
Quantile 50-60 & 0 & 355 & 355 \\
Quantile 60-70 & 0 & 355 & 355 \\
Quantile 70-80 & 0 & 355 & 355 \\
Quantile 80-90 & 0 & 355 & 355 \\
Quantile 90-100 & 0 & 355 & 355 \\
\hline
\end{tabular}

The shadow price for land as presented in Table 2.7. measures what it would be worth to the farm if there would be 1 more ha of land that it could rent. Under PO2 all farms except those in quantile 0-10 and under PO3 all farms except those in quantile 0-20 rent the maximum allowed $20 \mathrm{ha}$ (see Table 2.2.). If the maximum amount of extra land available for rent to the farm is not constraining its production, the shadow price for extra land available for rent is 0 . The shadow price is zero when the gross margin increase (excluding the costs of buying land) of buying land is less than 1200 euros (i.e. the price of buying land) making the net gross margin increase of renting land negative. So, the farm does not buy land and the shadow price is zero. A shadow price of 151 results when the gross margin increase (excluding the costs of buying land) is 1351 making the net gross margin increase of renting land positive and equal to 151.

The shadow price for land shows that the farm types in the 10-100 percent quantiles in PO2 would be willing to rent extra land if it became available, thereby becoming less intensive. In PO3 the availability of extra land is constraining the gross margin for farm types in the 40-70 quantiles and 90-100 quantile even more. Especially for the largest farm type extra land for rent would result in a considerable increase in gross margin. The farm types with a shadow price larger than zero would rent extra land if it became available, resulting in a shift towards a less intensive farming practice. The high positive shadow prices indicate that the system is responsive, in the sense that this farm type will respond to extra land becoming available. 
Table 2.7. Shadow prices (euro per ha) for land per farm type for the three policy options

\begin{tabular}{llll}
\hline Farm type/shadow price land & $\begin{array}{l}\text { PO1: Milk } \\
\text { quota }\end{array}$ & $\begin{array}{l}\text { PO2: No milk } \\
\text { quota }\end{array}$ & $\begin{array}{l}\text { PO3: Order of } \\
\text { Council }\end{array}$ \\
\hline Quantile 0-10 & 0 & 0 & 0 \\
Quantile 10-20 & 0 & 151 & 0 \\
Quantile 20-30 & 0 & 291 & 291 \\
Quantile 30-40 & 0 & 339 & 347 \\
Quantile 40-50 & 0 & 326 & 347 \\
Quantile 50-60 & 0 & 313 & 347 \\
Quantile 60-70 & 0 & 299 & 347 \\
Quantile 70-80 & 0 & 285 & 285 \\
Quantile 80-90 & 0 & 266 & 266 \\
Quantile 90-100 & 38 & 227 & 1810 \\
\hline
\end{tabular}

The shadow price for labour in Table 2.8. indicates the extra gross margin a farm could achieve for having one more hour of own labour available. If the shadow price is equal to the hired labour wage, the farm will hire additional labour. Only if the shadow price for own labour is equal to the wage for hired labour (17 euro) the farm will hire additional labour. Table 2.8. shows that it is only attractive for the largest farm type to hire labour.

The shadow price for own labour costs shows that labour is not constraining for the farm types in the 0-90 quantile under PO1, for the farm types in the 0-30 quantile under PO2, and for the farm types in the 0-70 quantile under PO3. The wage for hired labour would have to decrease substantially before the farm types in the 30-90 quantile under PO2 and 70-90 quantile under PO3 would hire additional labour. Therefore, these farm types are quite stable in their choice not to hire labour. That said, under PO2 and PO3 a drop of 3 euros in the wage would result in a shift in farming decisions for the farms in the 80-90 percent quantile. 
Table 2.8. Shadow prices for labour (euro per hour) per farm type for the three policy options

\begin{tabular}{llll}
\hline Farm type/shadow price labour & $\begin{array}{l}\text { PO1: Milk } \\
\text { quota }\end{array}$ & $\begin{array}{l}\text { PO2: No } \\
\text { milk quota }\end{array}$ & $\begin{array}{l}\text { PO3: Order } \\
\text { of Council }\end{array}$ \\
\hline Quantile $0-10$ & 0 & 0 & 0 \\
Quantile 10-20 & 0 & 0 & 0 \\
Quantile $20-30$ & 0 & 0 & 0 \\
Quantile 30-40 & 0 & 1 & 0 \\
Quantile 40-50 & 0 & 3 & 0 \\
Quantile 50-60 & 0 & 5 & 0 \\
Quantile 60-70 & 0 & 7 & 0 \\
Quantile 70-80 & 0 & 9 & 9 \\
Quantile $80-90$ & 0 & 14 & 14 \\
Quantile 90-100 & 17 & 17 & 17 \\
\hline
\end{tabular}

\subsection{SENSITIVITY ANALYSIS}

The results we find depend strongly on the value of the prices that are used within our model. In this paper we use data from 2013-2014, a period in which the milk price was very high. To show how our results would change with a lower milk price, we ran our model using the expected long term milk price instead. The results from this analysis can be found in appendix D. Lowering the milk price makes dairy farming less profitable for all farm types. For smaller farm types it is more profitable to rent out their land and sell their cows than to use the cows and land on their own farm. None of the farm types will expand their number of cows to the maximum. However, it is good to keep in mind that we only changed the milk price in this policy option, but kept all other costs and prices at the 2013-2014 level. It can be expected that these will also change over the long term.

\subsection{DISCUSSION}

Our results suggest that the milk quota abolishment will have the largest impact for the largest farm type in the 90-100 percent quantile. When milk quotas are abolished and only the Dairy law is in place this will be the only farm type that reaches the maximum amount of cows that can be kept on a farm in our model. The other farm types are restricted by the investment costs of stable capacity and the wage rate of hired labour, or the costs of processing manure and will 
not become very intensive. The introduction of the Order of Council effectively limits the growth of the largest farm type in the 90-100 percent quantile.

The hypothesis that farms will grow when milk quotas are abolished seems to be supported by our results. Combined with a limitation on the land available for rent in the region this will also result in more intensive farms. The fear that intensive farms emerge if no additional legislation is introduced after quota abolishment seems to be realistic for the largest farm type. Whether a farm will change its farming practice to a larger scale with a more intensive farming style depends on the cost structure. Because larger farms can produce at lower costs, these are the farms that will grow and become more intensive. The expected shift towards larger farms is in line with the results found by Huettel and Jongeneel (2011) who found that a trend of increasing herd size is likely after milk quotas are abolished. Research by Louhichi et al. (2010) also indicated that herd size is likely to increase as a result of milk quota abolishment. Koeijer et al. (2014) considered several other options for land-based dairy farm growth, and concluded that land-based dairy farm growth is likely to increase the demand for land, and result in a higher land price. This is in line with the analysis performed by Rougoor and Schans (2013) and Rougoor and Schans (2014), who suggest that arable farms might choose to rent out their land to dairy farms due to the high value of land for the dairy sector. These results found by others are in line with the results we find in our model. Having extra land available for rent would be especially beneficial to those farms which are heavily constrained by the availability of land as indicated by the high shadow price for land.

The results from our sensitivity analysis suggest that some of the smaller farm types would achieve the highest gross margin by renting out most of their land and selling most of their cows when the milk price is equal to the long term expected milk price. The fact that they do not rent out all their land and sell all their cows is due to a restriction in our model that does not allow for having no land on the farm. In reality these farms might quit all together. Although our results do not demonstrate that small Dutch dairy farms will quit, research by Zimmermann and Heckelei (2012) showed that the probability of farm exit decreases when farm size increases.

In this paper, we explored the degree to which we could relate the non-linear response of the optimal situation to the availability of various resources (stable capacity, availability of extra land for rent and labour) to the concepts of shifts and stability. As pointed out in section 3, we are aware that a shift as described in this paper does not result from interactions between farmers, or from feedbacks between scale levels (which are considered to be typical complex system features (Mitchell, 2009)) and that the shift itself is not characterized by an (uncontrol- 
lable) cascade of positive feedbacks. However, we do point out that some developments are latent, such as a resource gradually moving towards the point where it becomes a constraint, and that the system will only respond to changes in this resource once a certain threshold is reached. Such latent developments were captured by shadow prices and were used by us as an indicator for the stability (or no-response) of the farming decisions to changes in resource availability. Shadow prices that approach investment prices indicate a non-linearity in the response curve as displayed in Figure 2.1. (bottom). Anticipating such non-linearities is useful for anticipating the effects of a policy measure. For instance, in the current situation an abolishment of the milk quotas has no effect on the number of cows kept by the smallest farm type, which may lead to the preliminary conclusion that the policy change has no detrimental effects for this farm type. However, if the investment costs of stable capacity would decrease continuously, at an investment cost of 276 this farm type might - in the absence of restricting quota - decide to increase its stable capacity. This is then a delayed effect of quota abolishment. In the same way, abolishment of the milk quota does not result in an increase to the maximum number of cows that can be kept on the farm for the farm type in the 80-90 percentile. However, the shadow price for labour indicates that a tipping point might be expected if the wage decreases and reaches a value of 14 euro per hour. Prior to this point, wages are the constraining factor, and only when this constraint is no longer present, further effects of quota abolishment on milk production could become visible.

Our analysis also has some caveats. First, the model used is rather simple focusing mainly on feed, labour, and phosphate. However, other factors play a role in farm growth, e.g. farmers' characteristics (e.g. age), preferences, financial variables, etc. For example, our model assumes that all farms are gross margin maximizers, while in reality farms are only partly driven by economic motives and might at times act more like satificers than maximizers (Schnabel, 2001; Willock et al., 1999). If farmers farm because they appreciate independence, because of family traditions, because they love their land, the countryside, their animals, etc., this may also explain why small farms are still in business while it would be more profitable to exit (Schnabel, 2001). Secondly, there are data limitations. We did not have economic and technical information for all farms producing milk in the Netherlands. The data at our disposal contained values for the average farm for some variables, or information for only three size categories. We then used this information to generate a distribution of ten farm types. The milk price in the period that is reflected by our data was very high. Our sensitivity analysis shows that a lower milk price changes our conclusions. However, simply changing the milk price to an expected long term value creates inconsistencies in our data, and 
so these results have to be interpreted with caution. Furthermore, our model allowed for an increase in the amount of land rented and stable capacity on the farm. However, in reality increasing the amount of land or stable capacity might not always be that simple, due to scarcity of land or the requirement to obtain building permits. Despite these caveats our analysis using a mathematical programming model contributes to understanding the effects of milk quota abolition in the Netherlands.

\subsection{CONCLUSIONS}

Our work shows that when milk quotas are abandoned the farm type in the 0-10 percent quantile will keep the number of cows and the number of hectares on the farm constant. An increase in production is prevented by the fact that the costs associated with extending the production will outweigh the revenues. The farms in the 10-90 percent quantiles will extend the number of cows and grow. However, they will not grow to the maximum number of cows that could be managed by a farm because they are constrained either by the costs of removing and processing phosphate or by the availability of own farm labour. Hiring additional labour is only profitable for the largest farm type in the 90-100 percent quantile. This farm type does grow until the maximum number of cows that could be managed on the farm is reached. The smaller farm types in the $0-20$ percent quantiles will not increase in intensity when milk quotas are abolished. However, farms in the 20-100 percent quantiles will become more intensive when milk quotas are abolished, especially the largest farm type in the 90-100 quantile. Introducing the Order of Council effectively prevents farms from becoming very intensive. Especially the largest farm type is limited in its intensity when the Order of Council is introduced. In that case this farm type is severely constrained by the availability of land for rent.

The response curve of a system's optimal configuration to the price or availability of a resource is often non-linear. We used the shadow prices of these resources (i.e. stable capacity, labour, and extra land available for rent) as indicators for the distance to tipping points, and therewith of stability or likelihood to shifts in farm structure. The shadow prices for stable capacity indicate that the yearly investment costs in stable capacity would have to go down from 355 euro to 276 euro per extra stable place before the smallest farm type in the 0-10 percent quantile would start to invest in additional stable capacity. The shadow price for the other farms indicates that they are already willing to invest in additional stable capacity. When milk quotas are abolished the shadow prices for land indicate 
that all but the smallest farm type would be willing to rent extra land if it was available, thereby becoming less intensive. The shadow prices for extra land for farm types in the 40-70 and 90-100 quantile indicate that the availability of land constrains them more when the Order of Council is introduced. This shadow price is especially high for the farm type in the 90-100 quantile. The positive shadow prices when the Order of Council is introduced for extra land for the farm types 20-100 indicate that these farm types would be willing to rent extra land if it was available. 


\section{APPENDIX 2A. MODEL DESCRIPTION}

\section{Objective:}

$$
\begin{aligned}
& \max \pi_{n}=\overline{x_{1 n}} * \overline{p_{1 n}}+x_{2 n} * \overline{e_{1 n}} * \overline{p_{2 n}}-\sum_{i=2}^{4} x_{i n} * \overline{w_{l n}}-\sum_{i=5}^{13} x_{i n} * \overline{w_{l}} \\
& n=1, \ldots, 10 ; i=1, \ldots 13
\end{aligned}
$$

\section{Subject to}

$$
\begin{aligned}
& x_{2 n}=\overline{e_{2 n}}+x_{12 n}-x_{1 n} \\
& x_{3 n}=x_{2 n} * \overline{e_{3}} \\
& x_{4 n}=x_{2 n} * \overline{e_{4}} \\
& x_{7 n}=x_{2 n} * \overline{e_{5}}+x_{3 n} * \overline{e_{6}}+x_{4 n} * \overline{e_{7}}-x_{5 n} * \overline{e_{8}}-x_{6 n} * \overline{e_{9}} \\
& x_{12 n}=x_{11 n}+x_{14 n} \\
& x_{15 n}=x_{8 n}+x_{9 n} \\
& x_{16 n}=x_{15 n}+x_{17 n} \\
& x_{16 n}=x_{18 n}-x_{19 n} \\
& x_{18 n}=\left(x_{5 n} * \overline{e_{8}} * \overline{e_{10}}+x_{6 n} * \overline{e_{9}} * \overline{e_{11}}+x_{7 n} * \overline{e_{12}}\right)- \\
& \left(x_{2 n} * \overline{e_{1 n}} * \overline{e_{13}}+x_{2 n} * \overline{e_{14}}+x_{3 n} * \overline{e_{15}}+x_{4 n} * \overline{e_{16}}\right) \\
& x_{19 n}=x_{5 n} * \overline{e_{17}}+x_{6 n} * \overline{e_{18}} \\
& x_{20 n}=\overline{e_{19}} * x_{2 n} * \overline{e_{1 n}}+\overline{e_{20}} * x_{5 n}+\overline{e_{21}} * x_{6 n} \\
& x_{20 n}=x_{21 n}+x_{10 n} \\
& x_{22 n}=x_{20 n}-\overline{e_{22}} \\
& x_{22 n}=x_{10 n}+x_{23 n} \\
& x_{24 n}=\overline{e_{23 n}}+x_{13 n} \\
& x_{24 n}=x_{5 n}+x_{6 n} \\
& x_{21 n} \leq e_{22} \\
& x_{5 n} \geq 0.8 * x_{24 n} \\
& x_{13 n} \leq \overline{e_{24}} \\
& x_{2 n} \leq \overline{e_{25}} \\
& x_{14 n} \leq \overline{x_{1 n}} \\
& \overline{e_{26 n}}=\left(\overline{e_{2 n}} * 45.5+\overline{e_{2 n}} * \overline{e_{3}} * 10.2+\overline{e_{2 n}} * \overline{e_{4}} * 23.5\right)- \\
& \left(\overline{e_{17}} * \overline{h g l_{n}}+\overline{e_{18}} * \overline{h m l_{n}}\right) \\
& \overline{w_{3 n}}=0.19 * \overline{w_{2 n}} \\
& \overline{w_{4 n}}=0.19 * \overline{W_{2 n}} \\
& \overline{e_{27 n}}=2.057797 * \overline{h g l_{n}}+1.520981 * \overline{h m l_{n}} \\
& \overline{e_{28 n}}=2.594614 * \overline{h g l_{n}}+2.057797 * \overline{h m l_{n}} \\
& x_{2 n}, x_{5 n}, x_{6 n}, x_{7 n}, x_{8 n}, x_{9 n}, x_{10 n}, x_{11 n}, x_{15 n}, x_{24 n}, \geq 0 \\
& x_{17 n}, x_{23 n} \leq 0
\end{aligned}
$$




\section{Extra constraints in policy options}

Policy option 1: milk quotas

$x_{2 n} * \overline{e_{1 n}} \leq \overline{e_{2 n}} * \overline{e_{1 n}}$

Policy option 2: milk quotas abolished, Dairy Law introduced

$x_{8 n} \leq \overline{e_{26 n}}$

\section{Policy option 3: milk quotas abolished, Order of Council introduced}

*If farm chooses a phosphate surplus less than or equal to $20 \mathrm{~kg}$ per hectare:

$x_{2 n} \leq \overline{e_{27 n}}$

$x_{8 n} \leq \overline{e_{26 n}}$

*If farm chooses a phosphate surplus between 20-50kg per hectare:

$x_{25 n}=x_{18 n} / x_{2 n}$

$x_{26 n}=\left(x_{25 n} * x_{12 n} * 0.25\right) /\left(0.8 * \overline{e_{17}} * \overline{e_{18}}\right)$

$x_{24 n} \geq \overline{e_{23 n}}+x_{26 n}$

$x_{2 n}>\overline{e_{27 n}}$

$x_{2 n}<\overline{e_{28 n}}$

$x_{8 n} \leq \overline{e_{26 n}}$

*If farm chooses a phosphate surplus larger than or equal to $50 \mathrm{~kg}$ per hectare:

$x_{25 n}=x_{18 n} / x_{2 n}$

$x_{26 n}=\left(x_{25 n} * x_{12 n} * 0.5\right) /\left(0.8 * \overline{e_{17}} * \overline{e_{18}}\right)$

$x_{24 n} \geq \overline{e_{23 n}}+x_{26 n}$

$x_{2 n} \geq \overline{e_{28 n}}$

$x_{8 n} \leq \overline{e_{26 n}}$

Exogenous variables are indicated by means of a bar. The meaning of the variables is given next in the order of appearance in the model.

Where:

$\pi_{n} \quad=$ gross margin in euros on farm $\mathrm{n}$

$p_{1 n}=$ price of cows sold in euros per cow for farm $\mathrm{n}$

$p_{2 n}=$ milk price in euros per $100 \mathrm{~kg}$ for farm $\mathrm{n}$

$x_{1 n}=$ number of cows sold by farm $\mathrm{n}$

$x_{2 n}=$ number of cows on farm $\mathrm{n}$

$x_{3 n}=$ number of young cattle $<1$ year on farm $\mathrm{n}$ 
$x_{4 n}=$ number of young cattle $>1$ year on farm $\mathrm{n}$

$x_{5 n}=$ ha grass on farm $\mathrm{n}$

$x_{6 n}=$ ha maize on farm $\mathrm{n}$

$x_{7 n}=$ KVEM of feed bought on farm $\mathrm{n}$

$x_{8 n}=\mathrm{kg} \mathrm{P}_{2} \mathrm{O}_{5}$ removed from farm $\mathrm{n}$

$x_{9_{n}}=\mathrm{kg} \mathrm{P}_{2} \mathrm{O}_{5}$ processed from farm $\mathrm{n}$

$x_{10 n}=$ positive hours of hired labour used on farm $\mathrm{n}$

$x_{11 n}=$ number of extra cows above stable capacity farm $\mathrm{n}$

$x_{12 n}=$ number of extra cows bought or raised on farm $\mathrm{n}$

$x_{13 n}=$ ha of extra land rented on farm $\mathrm{n}$

$x_{14 n}=$ number of extra cows that fit within the initial stable capacity of farm $\mathrm{n}$

$x_{15 n}=$ positive $\mathrm{kg} \mathrm{P}_{2} \mathrm{O}_{5}$ surplus on farm $\mathrm{n}$

$x_{16 n}=\mathrm{kg} \mathrm{P}_{2} \mathrm{O}_{5}$ surplus on farm $\mathrm{n}$

$x_{17 n}=$ negative $\mathrm{kg} \mathrm{P}_{2} \mathrm{O}_{5}$ surplus on farm $\mathrm{n}$

$x_{18 n}=\mathrm{kg} \mathrm{P}_{2} \mathrm{O}_{5}$ produced on farm $\mathrm{n}$

$x_{19 n}=\mathrm{kg} \mathrm{P}_{2} \mathrm{O}_{5}$ that can be placed on land farm $\mathrm{n}$

$x_{20 n}=$ total hours of labour needed on farm $\mathrm{n}$

$x_{21 n}=$ own labour hours used on farm $\mathrm{n}$

$x_{22 n}=$ hours of hired labour used on farm $\mathrm{n}$

$x_{23 n}=$ negative amount of labour hired

$x_{24 n}=$ total ha land on farm $\mathrm{n}$

$\mathrm{x}_{25 n}=\mathrm{kg} \mathrm{P}_{2} \mathrm{O}_{5}$ produced per cow on farm $\mathrm{n}$

$x_{26 n}=$ ha land that has to be rented due to Order of Council if farm $\mathrm{n}$ increases the phosphate surplus

$e_{1 n}=$ milk production per cow in $100 \mathrm{~kg}$ on farm $\mathrm{n}$

$e_{2 n}=$ initial number of cows on farm $\mathrm{n}$

$e_{3}=$ percentage young cattle $<1$ year per cow

$e_{4}=$ percentage young cattle $>1$ year per cow

$e_{5} \quad=$ KVEM needed per cow

$e_{6}=\mathrm{KVEM}$ needed per young cattle $<1$ year

$e_{7}=\mathrm{KVEM}$ needed per young cattle $>1$ year

$e_{8}=\mathrm{KVEM}$ produced on 1 ha of grass land

$e_{9}=\mathrm{KVEM}$ produced on 1 ha of maize land

$e_{10}=\mathrm{kg} \mathrm{P}_{2} \mathrm{O}_{5}$ per KVEM from grass

$e_{11}=\mathrm{kg} \mathrm{P}_{2} \mathrm{O}_{5}$ per KVEM from maize

$e_{12}=\mathrm{kg} \mathrm{P}_{2} \mathrm{O}_{5}$ KVEM from feed bought

$e_{13}=\mathrm{kg} \mathrm{P}_{2} \mathrm{O}_{5}$ bound in $100 \mathrm{~kg}$ milk

$e_{14}=\mathrm{kg} \mathrm{P}_{2} \mathrm{O}_{5}$ bound in carrying cows

$e_{15}=\mathrm{kg} \mathrm{P}_{2} \mathrm{O}_{5}$ bound in growth young cattle $<1$ year 
$e_{16}=\mathrm{kg} \mathrm{P}_{2} \mathrm{O}_{5}$ bound in growth cattle $>1$ year

$e_{17}=\mathrm{kg} \mathrm{P}_{2} \mathrm{O}_{5}$ allowed per ha grass land

$e_{18}=\mathrm{kg} \mathrm{P}_{2} \mathrm{O}_{5}$ allowed per ha maize land

$e_{19}=$ labour hours needed per $100 \mathrm{~kg}$ milk produced

$e_{20}=$ labour hours needed per ha grass land

$e_{21}=$ labour hours needed per ha maize land

$e_{22}=$ hours of own labour available

$e_{23 n}=$ initial ha land on farm $\mathrm{n}$

$e_{24}=$ total ha land available for rent to farm $\mathrm{n}$

$e_{25}=$ maximum number of cows on farm

$e_{26 n}=$ maximum $\mathrm{kg} \mathrm{P}_{2} \mathrm{O}_{5}$ that can be removed from farm $\mathrm{n}$

$e_{27 n}=$ number of cows for which phosphate surplus in initial situation is equal to 20 $\mathrm{kg} \mathrm{P}_{2} \mathrm{O}_{5}$ per ha

$e_{28 n}=$ number of cows on farm $\mathrm{n}$ for which phosphate surplus in initial situation is equal to $50 \mathrm{~kg} \mathrm{P}_{2} \mathrm{O}_{5}$ per ha

$w_{2 n}=$ yearly maintenance costs in euro per cow on farm $\mathrm{n}$

$w_{3 n}=$ yearly maintenance costs in euro per young cattle $<1$ year on farm $\mathrm{n}$

$w_{4 n}=$ yearly maintenance costs in euro per young cattle $>1$ year on farm $\mathrm{n}$ in euro

$w_{5}=$ yearly costs in euro of growing a ha grass

$w_{6}=$ yearly costs in euro of growing a ha maize

$w_{7}=$ costs of feed bought in euro per KVEM

$w_{8}=$ costs of removing $\mathrm{P}_{2} \mathrm{O}_{5}$ in euro per $\mathrm{kg}$

$w_{9}=$ costs of processing $\mathrm{P}_{2} \mathrm{O}_{5}$ in euro per $\mathrm{kg}$

$w_{10}=$ costs of hired labour in euro per hour

$w_{11}=$ yearly investment costs additional stable capacity including young cattle capacity in euro per place for each extra cow

$w_{12}=$ yearly costs of raising or buying extra cows in euro per cow

$w_{13}=$ yearly costs of renting extra land in euro

$h g i_{n}=$ initial ha grassland farm $\mathrm{n}$

$h m i_{n}=$ initial ha maize land farm $\mathrm{n}$ 
The objective of the farm (A1) is to maximize gross margin, which is the result of the revenue from milk production and selling cows no longer used in production minus the costs of maintenance of cows and young cattle, the costs of growing grass and maize, the costs of buying feed, the costs of removing phosphate, the costs of processing phosphate, the costs of hiring additional labour, the investment cost in additional stable capacity, the costs of raising or buying extra cows and the cost of renting extra land. The number of cows on the farm can be found by adding up the number of cows from the initial endowment and the extra number of cows in the optimal solution and subtracting the number of cows that have been sold (A2). If the farm decides to decrease the number of cows on the farm in the optimal solution the extra number of cows compared to the initial situation can be negative. The number of young cattle on the farm is determined by multiplying the number of cows with the percentage young cattle needed for replacement (A3) and (A4). Feed on the farm can be grown on the land in the form of grass and maize or be bought. The amount of feed bought is equal to the amount of feed needed for the cows and young cattle minus the amount of feed produced on the farm (A5). We assume each animal needs a certain amount of feed (expressed in KVEM) but we do not specify what that diet should consist of in terms of roughage and concentrate. The number of extra cows bought or raised on the farm can be divided in a part that fits within the initial stable capacity and a part that does not fit within the initial stable (A6). The positive phosphate surplus on the farm can be divided into a part that is removed from the farm and a part that has to be processed (A7). It is possible that a farm does not produce a positive phosphate surplus, in which case the phosphate surplus is negative. In (A8) we state that the phosphate surplus is equal to the sum of positive phosphate surplus and negative phosphate surplus. This is done to make sure the farm does not get a negative cost for phosphate removal, which would be a revenue. It is not realistic to assume that a farm would make as much revenue from having some room left for extra phosphate on its land as it would need to pay for removing extra phosphate. In case the phosphate surplus is negative the positive phosphate surplus is set to zero. The phosphate surplus on the farm can be found by subtracting the phosphate place of the farm from the phosphate produced on the farm (A9). The phosphate produced on the farm can be found by taking the amount of phosphate consumed by the cows and young cattle and subtracting the amount of phosphate that will be bound in the milk or growth of cattle (A10). The phosphate that can be placed on land can be found by multiplying the hectares of grass land by the amount of phosphate that can be placed on a ha of grass and adding the multiplication of the hectares of maize and the amount of phosphate that can be placed on a ha of maize (A11). 
The total hours of labour needed on the farm can be found by adding the labour needed for milk production and the labour needed for cultivating grass and maize (A12). The labour hours needed on the farm can be divided into own labour hours and positive hired labour hours (A13). The amount of labour hired is equal to the total amount of labour hours needed minus the endowment of own labour hours of the farm (A14). It is possible that the farm has more own labour hours than needed, in which case the labour hours hired are negative. To prevent that the farm would get a revenue from these negative labour hours hired equation (A15) is added, that distinguishes between a negative and a positive amount of labour hired. In the case that the amount of labour hired is negative the positive labour hours will be set to zero. The total amount of land used on the farm is equal to the initial land endowment plus the extra ha land rented (A16). We allow that the farm rents out some of its own land, in which case the extra land rented will be negative. The land on the farm can be divided into grassland and maize land (A17).

There are some restrictions in the model. The amount of own labour hours used has to be smaller than or equal to the amount of own labour that is available on the farm (A18). The amount of grassland has to be at least 80 percent, because only then the farm will receive derogation, which means the farm is allowed to place extra nitrogen on its land, which is often desired by Dutch dairy farms (A19). The amount of extra land rented should be less than or equal to the amount of land available for rent in the region which is $20 \mathrm{ha}$ (A20). The number of cows on the farm should be less than the maximum number of cows that could still be managed by a Dutch family farm (A21). This amount was based on the size of some very large dairy farms in the Netherlands (Boerderij, 2010; Gelderlander, 2015; Trouw, 2015). The number of cows that fit within the initial stable of the farm should be equal to or less than the amount of cows that have been sold (A22). The model also contains a number of variables that cannot become negative (A28) or positive (A29).

Finally, there are some constraints that are specific to each of the policy options. If the milk quotas are in place the milk production should not exceed the milk production in the initial situation (A30). When the milk quotas are abolished and the Dairy Law is introduced the amount of manure that can be removed should be less than a maximum amount that can be removed (melkveefosfaatreferentie) (A31, A33, A39, A44).

Under the Order of Council farms that have a phosphate surplus less than 20 $\mathrm{kg}$ per hectare are excluded, provided they process the extra phosphate produced. Farms with a phosphate surplus between 20 and $50 \mathrm{~kg}$ per hectare are obliged to place 25 percent of the extra phosphate production on newly acquired land. 
Farms with a phosphate surplus exceeding $50 \mathrm{~kg}$ per hectare are required to place 50 percent of the extra phosphate produced on land (Rijksoverheid, 2015a)

In our model, if the Order of Council is introduced the farm can choose between three categories, namely producing a phosphate surplus less than $20 \mathrm{~kg}$ per ha, in which case the number of cows cannot exceed beyond the number of cows for which the phosphate surplus is $20 \mathrm{~kg}$ per ha (A32). In this case no additional land has to be purchased. If the farm chooses a phosphate surplus between 20-50 $\mathrm{kg}$ per ha the number of cows on the farm is larger than the number which would result in a phosphate surplus of $20 \mathrm{~kg}$ per ha (A37) and less than the number of cows for which the phosphate surplus would be more than $50 \mathrm{~kg}$ per ha (A38). In this case the farm will have to purchase extra land on which to place 25 percent of the phosphate produced by the extra cows (A35). The phosphate produced per cow is given by (A34). The total amount of land on the farm should then be equal to or larger than the initial amount of land plus the amount of land that has to be bought for the phosphate surplus (A36). Finally, if the farm chooses to have more than $50 \mathrm{~kg}$ phosphate surplus the farm will have to purchase extra land on which to place 50 percent of the phosphate produced by the extra cows (A41). The total land on the farm must then be equal to or larger than the initial amount of land plus the amount of land needed to place the extra phosphate (A42). In this case the number of cows on the farm will exceed the number of cows for which the phosphate surplus is $50 \mathrm{~kg}$ per ha (A43). To maximise gross margin the farm will compare the three possible categories for the Order of Council and choose the one that will give him the highest gross margin. 


\section{APPENDIX 2B. DATA USED}

Table 2B.1. Values of exogenous parameters

\begin{tabular}{|c|c|c|c|c|c|}
\hline Parameter & Description & Value & Parameter & Description & Value \\
\hline$w_{5}$ & $\begin{array}{l}\text { Yearly costs in euro of } \\
\text { growing a ha grass }\end{array}$ & 1440 & $e_{10}$ & $\begin{array}{l}\mathrm{Kg} \mathrm{P}_{2} \mathrm{O}_{5} \text { per KVEM from } \\
\text { grass }\end{array}$ & 0.01 \\
\hline$w_{6}$ & $\begin{array}{l}\text { Yearly costs in euro of } \\
\text { growing a ha maize }\end{array}$ & 1540 & $e_{11}$ & $\begin{array}{l}\mathrm{Kg} \mathrm{P}_{2} \mathrm{O}_{5} \text { per KVEM from } \\
\text { maize }\end{array}$ & 0.005 \\
\hline$w_{7}$ & $\begin{array}{l}\text { Costs of feed bought in } \\
\text { euro per KVEM }\end{array}$ & 0.14 & $e_{12}$ & $\begin{array}{l}\mathrm{Kg} \mathrm{P}_{2} \mathrm{O}_{5} \mathrm{KVEM} \text { from } \\
\text { feed bought }\end{array}$ & 0.012 \\
\hline$w_{8}$ & $\begin{array}{l}\text { Costs of removing } \\
\mathrm{P}_{2} \mathrm{O}_{5} \text { in euro per } \mathrm{kg}\end{array}$ & 9.33 & $e_{13}$ & $\begin{array}{l}\mathrm{Kg} \mathrm{P}_{2} \mathrm{O}_{5} \text { bound in } 100 \\
\mathrm{~kg} \text { milk }\end{array}$ & 0.222 \\
\hline$w_{9}$ & $\begin{array}{l}\text { Costs of processing } \\
\mathrm{P}_{2} \mathrm{O}_{5} \text { in euro per kg }\end{array}$ & 10.83 & $e_{14}$ & $\begin{array}{l}\mathrm{Kg} \mathrm{P}_{2} \mathrm{O}_{5} \text { bound in } \\
\text { carrying cows }\end{array}$ & 0.522 \\
\hline$w_{10}$ & $\begin{array}{l}\text { Costs of hired labour in } \\
\text { euro per hour }\end{array}$ & 16.74 & $e_{15}$ & $\begin{array}{l}\mathrm{Kg} \mathrm{P}_{2} \mathrm{O}_{5} \text { bound in growth } \\
\text { young cattle }<1 \text { year }\end{array}$ & 4.619 \\
\hline$w_{11}$ & $\begin{array}{l}\text { Yearly investment } \\
\text { costs additional stable } \\
\text { capacity including } \\
\text { young cattle capacity in } \\
\text { euro per place for each } \\
\text { extra cow }\end{array}$ & 354.8 & $e_{16}$ & $\begin{array}{l}\mathrm{Kg} \mathrm{P}_{2} \mathrm{O}_{5} \text { bound in growth } \\
\text { cattle }>1 \text { year }\end{array}$ & 4.078 \\
\hline$w_{12}$ & $\begin{array}{l}\text { Yearly costs of raising } \\
\text { or buying extra cows in } \\
\text { euro per cow }\end{array}$ & 294 & $e_{17}$ & $\begin{array}{l}\mathrm{Kg} \mathrm{P}_{2} \mathrm{O}_{5} \text { allowed per ha } \\
\text { grass land }\end{array}$ & 95 \\
\hline$w_{13}$ & $\begin{array}{l}\text { Yearly costs of renting } \\
\text { extra land in euro }\end{array}$ & 1200 & $e_{18}$ & $\begin{array}{l}\mathrm{Kg} \mathrm{P}_{2} \mathrm{O}_{5} \text { allowed per ha } \\
\text { maize land }\end{array}$ & 65 \\
\hline$e_{3}$ & $\begin{array}{l}\text { Share young cattle }<1 \\
\text { year per cow }\end{array}$ & 0.64 & $e_{19}$ & $\begin{array}{l}\text { Labour hours needed per } \\
100 \mathrm{~kg} \text { milk produced }\end{array}$ & 0.5 \\
\hline$e_{4}$ & $\begin{array}{l}\text { Share young cattle }>1 \\
\text { year per cow }\end{array}$ & 0.29 & $e_{20}$ & $\begin{array}{l}\text { Labour hours needed per } \\
\text { ha grass land }\end{array}$ & 7.2 \\
\hline$e_{5}$ & KVEM needed per cow & 7197.8 & $e_{21}$ & $\begin{array}{l}\text { Labour hours needed per } \\
\text { ha maize land }\end{array}$ & 7.0 \\
\hline$e_{6}$ & $\begin{array}{l}\text { KVEM needed per } \\
\text { young cattle }<1 \text { year }\end{array}$ & 1277.5 & $e_{22}$ & $\begin{array}{l}\text { Hours of own labour } \\
\text { available }\end{array}$ & 7000 \\
\hline$e_{7}$ & $\begin{array}{l}\text { KVEM needed per } \\
\text { young cattle }>1 \text { year }\end{array}$ & 2555 & $e_{24}$ & $\begin{array}{l}\text { Total ha land available for } \\
\text { rent to farm } n\end{array}$ & 20 \\
\hline$e_{8}$ & $\begin{array}{l}\text { KVEM produced on } 1 \\
\text { ha of grass land }\end{array}$ & 11220 & $e_{25}$ & $\begin{array}{l}\text { Maximum number of } \\
\text { cows on farm }\end{array}$ & 500 \\
\hline$e_{9}$ & $\begin{array}{l}\text { KVEM produced on } 1 \\
\text { ha of maize land }\end{array}$ & 13720 & & & \\
\hline
\end{tabular}


Table 2B.2. Values for the farm type specific exogenous variables in the reference year 2013

\begin{tabular}{|c|c|c|c|c|c|c|c|c|c|}
\hline $\begin{array}{l}\text { Farm type } \\
\text { (quantile) }\end{array}$ & 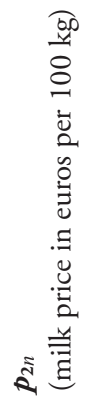 & 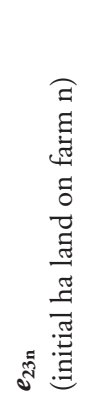 & 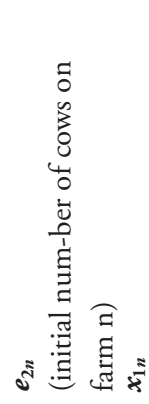 & 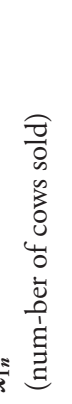 & 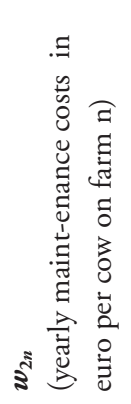 & 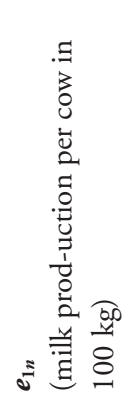 & 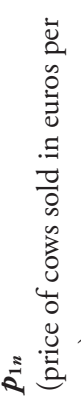 & 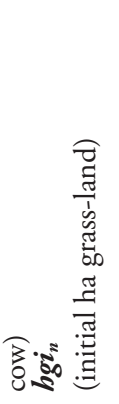 & 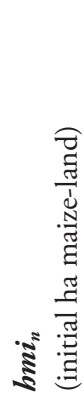 \\
\hline $0-10$ & 42.18 & 16 & 24 & 7 & 509 & 7291 & 774 & 15 & 1 \\
\hline $10-20$ & 42.73 & 27 & 45 & 12 & 488 & 7548 & 696 & 26 & 1 \\
\hline $20-30$ & 42.90 & 33 & 57 & 15 & 476 & 7692 & 671 & 32 & 1 \\
\hline $30-40$ & 43.02 & 38 & 68 & 18 & 465 & 7822 & 653 & 37 & 1 \\
\hline $40-50$ & 43.12 & 44 & 78 & 21 & 455 & 7945 & 639 & 43 & 1 \\
\hline $50-60$ & 43.21 & 49 & 88 & 23 & 445 & 8068 & 627 & 48 & 1 \\
\hline $60-70$ & 43.28 & 54 & 99 & 26 & 434 & 8199 & 616 & 53 & 1 \\
\hline $70-80$ & 43.36 & 60 & 112 & 29 & 421 & 8347 & 605 & 59 & 1 \\
\hline $80-90$ & 43.46 & 69 & 129 & 33 & 404 & 8554 & 592 & 68 & 1 \\
\hline $90-100$ & 43.79 & 112 & 215 & 55 & 317 & 9594 & 544 & 111 & 1 \\
\hline
\end{tabular}

\section{APPENDIX 2C. ADDITIONAL MODEL RESULTS}

Table 2C.1. Model result farm gross margin in euros per farm type for the three policy options

\begin{tabular}{llll}
\hline Farm type/ gross margin & $\begin{array}{l}\text { PO1: Milk } \\
\text { quota }\end{array}$ & $\begin{array}{l}\text { PO2: No } \\
\text { milk quota }\end{array}$ & $\begin{array}{l}\text { PO3: Order of } \\
\text { Council }\end{array}$ \\
\hline Quantile 0-10 & 36306 & 36306 & 36306 \\
Quantile 10-20 & 70999 & 73597 & 73459 \\
Quantile 20-30 & 93229 & 97952 & 97952 \\
Quantile 30-40 & 114926 & 124665 & 121631 \\
Quantile 40-50 & 137106 & 152502 & 146225 \\
Quantile 50-60 & 160498 & 179396 & 172451 \\
Quantile 60-70 & 187064 & 207471 & 202533 \\
Quantile 70-80 & 219254 & 238653 & 238653 \\
Quantile 80-90 & 267371 & 280463 & 280463 \\
Quantile 90-100 & 499098 & 585004 & 519508 \\
\hline
\end{tabular}


Table 2C.2. Model result number of extra cows that exceed initial stable per farm type for the three policy options

\begin{tabular}{llll}
\hline $\begin{array}{l}\text { Farm type/ extra cows that exceed initial } \\
\text { stable capacity }\end{array}$ & $\begin{array}{l}\text { PO1: Milk } \\
\text { quota }\end{array}$ & $\begin{array}{l}\text { PO2: No } \\
\text { milk quota }\end{array}$ & $\begin{array}{l}\text { PO3: Order of } \\
\text { Council }\end{array}$ \\
\hline Quantile 0-10 & 0 & 0 & 0 \\
Quantile 10-20 & 0 & 26 & 25 \\
Quantile 20-30 & 0 & 26 & 26 \\
Quantile 30-40 & 0 & 101 & 31 \\
Quantile 40-50 & 0 & 87 & 34 \\
Quantile 50-60 & 0 & 73 & 37 \\
Quantile 60-70 & 0 & 59 & 41 \\
Quantile 70-80 & 0 & 42 & 42 \\
Quantile 80-90 & 0 & 20 & 20 \\
Quantile 90-100 & 0 & 285 & 61 \\
\hline
\end{tabular}

Table 2C.3. Model result processing costs in euro per farm type for the three policy options

\begin{tabular}{llll}
\hline Farm type/ costs of processing phosphate & $\begin{array}{l}\text { PO1: Milk } \\
\text { quota }\end{array}$ & $\begin{array}{l}\text { PO2: No } \\
\text { milk quota }\end{array}$ & $\begin{array}{l}\text { PO3: Order of } \\
\text { Council }\end{array}$ \\
\hline Quantile 0-10 & 0 & 0 & 0 \\
Quantile 10-20 & 0 & 0 & 0 \\
Quantile 20-30 & 0 & 0 & 0 \\
Quantile 30-40 & 0 & 67632 & 5314 \\
Quantile 40-50 & 0 & 55651 & 8697 \\
Quantile 50-60 & 0 & 43902 & 11969 \\
Quantile 60-70 & 0 & 31470 & 15379 \\
Quantile 70-80 & 0 & 17473 & 17473 \\
Quantile 80-90 & 0 & & \\
Quantile 90-100 & 0 & 225621 & 34107 \\
\hline
\end{tabular}


Table 2C.4. Model result total hectare on farm per farm type for the three policy options

\begin{tabular}{llll}
\hline Farm type/ ha land used & $\begin{array}{l}\text { PO1: Milk } \\
\text { quota }\end{array}$ & $\begin{array}{l}\text { PO2: No } \\
\text { milk quota }\end{array}$ & $\begin{array}{l}\text { PO3: Order of } \\
\text { Council }\end{array}$ \\
\hline Quantile 0-10 & 16 & 16 & 16 \\
Quantile 10-20 & 30 & 47 & 46 \\
Quantile 20-30 & 38 & 53 & 53 \\
Quantile 30-40 & 45 & 58 & 58 \\
Quantile 40-50 & 51 & 64 & 64 \\
Quantile 50-60 & 58 & 69 & 69 \\
Quantile 60-70 & 65 & 74 & 74 \\
Quantile 70-80 & 72 & 80 & 80 \\
Quantile 80-90 & 83 & 89 & 89 \\
Quantile 90-100 & 132 & 132 & 132 \\
\hline
\end{tabular}

Table 2C.5. Model result phosphate surplus in kg P205 per farm type for the three policy options

\begin{tabular}{llll}
\hline Farm type/phosphate surplus & $\begin{array}{l}\text { PO1: Milk } \\
\text { quota }\end{array}$ & $\begin{array}{l}\text { PO2: No } \\
\text { milk quota }\end{array}$ & $\begin{array}{l}\text { PO3: Order of } \\
\text { Council }\end{array}$ \\
\hline Quantile 0-10 & 0 & 0 & 0 \\
Quantile 10-20 & 0 & 0 & 0 \\
Quantile 20-30 & 0 & 248 & 248 \\
Quantile 30-40 & 0 & 6615 & 861 \\
Quantile 40-50 & 0 & 5626 & 1290 \\
Quantile 50-60 & 0 & 4657 & 1708 \\
Quantile 60-70 & 0 & 3632 & 2146 \\
Quantile 70-80 & 0 & 2480 & 2480 \\
Quantile 80-90 & 0 & 905 & 905 \\
Quantile 90-100 & 365 & 22879 & 5195 \\
\hline
\end{tabular}




\section{APPENDIX 2D. SENSITIVITY ANALYSIS}

Results when milk price equals long term milk price of 35 euro per kg (KWIN, 2014-2015)

Table 2D.1. Extra hectares of land rented per farm type for the three policy options

\begin{tabular}{llll}
\hline Farm type/ extra land rented & $\begin{array}{l}\text { PO1: Milk } \\
\text { quota }\end{array}$ & $\begin{array}{l}\text { PO2: No } \\
\text { milk quota }\end{array}$ & $\begin{array}{l}\text { PO3: Order of } \\
\text { Council }\end{array}$ \\
\hline Quantile $0-10$ & -15 & -15 & -15 \\
Quantile 10-20 & -26 & -26 & -26 \\
Quantile 20-30 & -32 & -32 & -32 \\
Quantile 30-40 & -37 & -37 & -37 \\
Quantile 40-50 & 8 & 8 & 8 \\
Quantile 50-60 & 9 & 9 & 9 \\
Quantile 60-70 & 11 & 11 & 11 \\
Quantile 70-80 & 12 & 12 & 12 \\
Quantile $80-90$ & 14 & 14 & 14 \\
Quantile 90-100 & -29 & -29 & -29 \\
\hline
\end{tabular}

Table 2D.2. Number of cows per farm type for the three policy options

\begin{tabular}{llll}
\hline Farm type/number of cows & $\begin{array}{l}\text { PO1: Milk } \\
\text { quota }\end{array}$ & $\begin{array}{l}\text { PO2: No } \\
\text { milk quota }\end{array}$ & $\begin{array}{l}\text { PO3: Order of } \\
\text { Council }\end{array}$ \\
\hline Quantile $0-10$ & 1 & 1 & 1 \\
Quantile 10-20 & 2 & 2 & 2 \\
Quantile 20-30 & 2 & 2 & 2 \\
Quantile 30-40 & 2 & 2 & 2 \\
Quantile 40-50 & 78 & 78 & 78 \\
Quantile 50-60 & 88 & 88 & 88 \\
Quantile 60-70 & 99 & 99 & 99 \\
Quantile 70-80 & 112 & 112 & 112 \\
Quantile $80-90$ & 129 & 129 & 129 \\
Quantile 90-100 & 133 & 133 & 133 \\
\hline
\end{tabular}


Table 2D.3. Cows per hectare per farm type for the three policy options

\begin{tabular}{llll}
\hline Farm type/ number of cows per ha & $\begin{array}{l}\text { PO1: Milk } \\
\text { quota }\end{array}$ & $\begin{array}{l}\text { PO2: No } \\
\text { milk quota }\end{array}$ & $\begin{array}{l}\text { PO3: Order of } \\
\text { Council }\end{array}$ \\
\hline Quantile 0-10 & 1.5 & 1.5 & 1.5 \\
Quantile 10-20 & 1.5 & 1.5 & 1.5 \\
Quantile 20-30 & 1.5 & 1.5 & 1.5 \\
Quantile 30-40 & 1.5 & 1.5 & 1.5 \\
Quantile 40-50 & 1.5 & 1.5 & 1.5 \\
Quantile 50-60 & 1.5 & 1.5 & 1.5 \\
Quantile 60-70 & 1.5 & 1.5 & 1.5 \\
Quantile 70-80 & 1.5 & 1.5 & 1.5 \\
Quantile 80-90 & 1.5 & 1.5 & 1.5 \\
Quantile 90-100 & 1.6 & 1.6 & 1.6 \\
\hline
\end{tabular}

Table 2D.4. Shadow prices for stable capacity per farm type for the three policy options

\begin{tabular}{llll}
\hline Farm type/shadow price stable capacity & $\begin{array}{l}\text { PO1: Milk } \\
\text { quota }\end{array}$ & $\begin{array}{l}\text { PO2: No } \\
\text { milk quota }\end{array}$ & $\begin{array}{l}\text { PO3: Order } \\
\text { of Council }\end{array}$ \\
\hline Quantile 0-10 & 0 & 0 & 0 \\
Quantile 10-20 & 0 & 0 & 0 \\
Quantile 20-30 & 0 & 0 & 0 \\
Quantile 30-40 & 0 & 0 & 0 \\
Quantile 40-50 & 0 & 57 & 57 \\
Quantile 50-60 & 0 & 114 & 114 \\
Quantile 60-70 & 0 & 175 & 175 \\
Quantile 70-80 & 0 & 244 & 244 \\
Quantile 80-90 & 0 & 341 & 341 \\
Quantile 90-100 & 0 & 0 & 0 \\
\hline
\end{tabular}

The phosphate surplus is zero for all farm types in all three policy options, as is the shadow price for extra land for all farm types in all three policy options. The shadow price for labour is zero for all but the largest farm type in all three policy options. The largest farm type has a shadow price of 16 for labour, which is just below the costs of hiring additional labour (which is 17 euro per hour). 



\section{Chapter 3}

Complex dynamics in the uptake of new farming practices: a case study for organic waste application ${ }^{2}$

2 Paper by Groeneveld, A.N., Bakker, M.M., Peerlings, J.H.M., and Heijman, W.J.M. has been accepted by Journal of Environmental Planning and Management 


\section{ABSTRACT}

Adverse environmental effects of intensive agriculture, together with scarcity in phosphates and water, urge farmers to find more sustainable practices. An example of such a sustainable practice is on-farm processing of organic waste. This paper explores three mechanisms that can lead to a widespread uptake of this technique: (i) economies of scale, (ii) information sharing, and (iii) adjustment of social norms. Although each of these mechanisms has been studied before, this paper provides new insights by considering the interactions that might exist between the different mechanisms when they are applied to real life situations. Based on a pilot study, we developed a multicriteria mathematical programming model at individual farm level. We used this model to simulate the uptake of on-farm processing of organic waste, as a result of the three mechanisms and their interactions. Our results show that each mechanism results in an increased uptake, but is not likely to cause a widespread uptake. Interaction between the mechanisms, will lead to a much higher uptake. This result suggests that simultaneous consideration of multiple mechanisms is essential to understand the behaviour of socialecological systems. 


\subsection{INTRODUCTION}

After the Second World War agricultural practices became more intensive within Europe (Freemark, 2005; Kirschenmann, 2010). More intensive agriculture results in higher yields and economic development, but also in soil organic matter decline, soil erosion, biodiversity loss and ground water contamination (D'Hose et al., 2014; Guillem et al., 2015). Together with expected natural resource depletion this leads to a need to make agriculture more sustainable (Kassam et al., 2009). Sustainable practices are commonly stated to be environmentally sound, economically profitable, and socially just (Dale et al., 2013).

To achieve a situation in which sustainable agricultural practices are the norm, a regime shift has to take place. In general, regime shifts are the result of a combination of shocks, such as the introduction of a new technology, and gradual changes that diminish the strength of the prevailing processes. Once a threshold is passed another set of processes prevail and the system restructures towards a new regime (Biggs, Schluter \& Schoon, 2015; Peerlings, Polman \& Dries, 2014). Uptake of new agricultural techniques is a complex process, influenced by both monetary and non-monetary considerations (Clare et al., 2014). The adoption of innovations is positively influenced by external economies of scale (e.g. cost sharing, Agnolucci \& McDowall, 2007), when the usefulness can be demonstrated (Brown et al., 2016), and when the innovation is part of social capital (Perman et al., 2011). Besides these mechanisms other factors that may play a role are ease of operation, image, riskiness, visibility, voluntariness, divisibility and communicability (Kapoor, Dwivedi \& Williams, 2014). These mechanisms can lead to a gradually accelerating adoption of innovations, which can ultimately lead to a regime shift from unsustainable to sustainable farming practices.

On-farm processing of organic waste is an example of a sustainable farming practice. In this paper we analyse the potential of a regime shifts for two techniques for on-farm processing of compost from organic waste: the Controlled Microbial Compost (CMC) technique and the Bokashi technique (Janmaat, 2015). For both techniques municipalities deliver organic waste to a farm to be composted, and the end product can be used to fertilize the land of the farm. In the case of CMC organic waste material is put down in rows and micro-organisms are added. The material is then covered for six to eight weeks, during which the temperature and oxygen levels are regularly checked by the farmer. If these values exceed a certain range the material is turned in order to bring the temperature levels down and to add extra oxygen (Lanting, 2008). In the case of Bokashi a fermented compost is created, by adding layers of organic waste interspersed with calcium and micro-organisms (Jaramillo-López, Ramírez \& Pérez-Salicrup, 2015). The organic 
material is then covered and left for eight to ten weeks. Although the end product from both processes is slightly different, the most important distinctions between the processes are the labour intensity of the process and the investment costs. The CMC process is labour intensive and requires a high initial investment in the form of in a turning machine to control the oxygen and temperature levels during the composting process. This turning machine will generally last for 10 years. The variable costs for the $\mathrm{CMC}$ technique, on the other hand, are relatively low. The Bokashi technique is not as labour intensive, and does not require an initial investment. On the other hand, the variable costs of this process are relatively high. Both kinds of compost potentially increase the soil organic matter content and could have a positive effect on yields. Other benefits for the farmer are payments from municipalities, who will save processing and transport cost by this alternative for organic waste removal. CMC and Bokashi have not been applied on large scale in the Netherlands (Cupcompost, 2015; Diver, 2004; Melkvee.nl, 2014) but in recent years pilot projects have been implemented (EM vereniging Nederland, 2015; Ommermarke, 2015).

The goal of this paper is show how on-farm processing of organic waste might spread in the "Friese Meren" in the Dutch province of Friesland as a result of economies of scale, learning, and changing social norms. We investigate how these mechanisms individually lead to (partial) uptake of on-farm processing of organic waste, but also how interaction of these mechanisms contributes to achieving a regime shift towards on-farm processing of organic waste. These mechanisms reflect a combination of economic, psychology and sociology perspectives. Although each of these mechanisms has been studied before, this paper provides new insights by considering the interactions that might exist between the different mechanisms when they are applied to real life situations. We develop an Agent Based Model (ABM) -like methodology capturing feedbacks between the individual farmers and the overall system. However, we capture the individual decision making in a more sophisticated way by using a multi-criteria approach instead of simple rule-based decision making. By looking at interactions between these mechanisms and the feedbacks between the farmers in sharing costs and information, and adjusting social norms we take a Complex Adaptive System (CAS) approach. A CAS approach has also been taken by (Alexander et al., 2013) who reconstructed the uptake of perennial energy crops in the United Kingdom. Their model is well suited to explain and reconstruct the historical spread of energy crops, but is less suited for predictions due to a lack of specific empirical data on the individual farm level. In this paper we obtained an empirical basis using interviews with local farmers. Given that we were not able to interview all farmers in the region we created an artificial farmer-agent population. This 
artificial farmer-agent population was based on the interviewed farmers and used to simulate the uptake of on-farm processing of organic waste in the region. We analyse eight scenarios to show how a regime shift towards on-farm processing of organic waste might take place.

The farmer-agent decision-making process is captured in a multi-criteria mathematical programming model. Mathematical programming models have been widely used within bio-economic research. They are appealing due to the fact that they are straightforward in optimizing an objective, given technological, resource and institutional constraints (Buysse, Huylenbroeck \& Lauwers, 2007). Although mathematical programs are particularly suited to predict an individual farmer's decisions and less for simulating interactions between farmers, we implement the mathematical program in a CAS context. CAS consists of a network of actors such as farmers, with interactions taking place between actors and between actors and their environment. Actors get information from their surroundings, which is used to determine their course of action. The farmer decision depends on the decisions made by other farmers. In our model the CAS context is made explicit in the scenarios where farmer agents observe each other's actions and adjust their own actions accordingly. By taking this into account we are able to analyse the likelihood of an uptake of the new technology better than if we would ignore the linkages between the farmers.

In the next section we introduce our model and the experimental design used in this paper, as well as the scenarios we analyse. We also describe our study area in more detail and elaborate on the data we use as an input to our model. In section 3 we present our findings, and in sections 4 and 5 we provide a general discussion and conclusions.

\subsection{METHODS}

In this section we start by describing the developed model (section 2.1), followed by a description of the study area for which we calibrated the model (section 2.2). After that, we present the data collected for calibrating the model (section 2.3), and we end with a description of the model-experimental set-up that was used to explore the uptake of on-farm processing of organic waste in the study area (section 2.4).

\subsubsection{Model description}

Our conceptual model is illustrated in Figure 3.1. A community of farmers is shown, in which each individual can decide whether or not to adopt the practice 
of CMC or Bokashi (currently still a small minority). That decision is based on multiple criteria to which each individual attaches their own level of importance. At system level, the sum of individual decisions amount to emergent properties such as a certain social norm about the practices, a body of knowledge about the practices, and also of certain costs of possibly shared equipment for the practices. These emergent system properties may in turn affect the criteria and weights that determine the individual decisions. The model is dynamic, since what happens in one time step is dependent on the state of the system in the previous step. This approach is inspired by the work of amongst others Murray-Rust et al. (2011), Karali, Rounsevell \& Doherty (2011) and Valbuena et al. (2010). In the remainder of this chapter, we explain a) the individual decision module, b) the generation of the virtual farmer population and their criteria and weights, and c) how the emergent system properties are determined and how they influence the criteria and weights of the individuals.

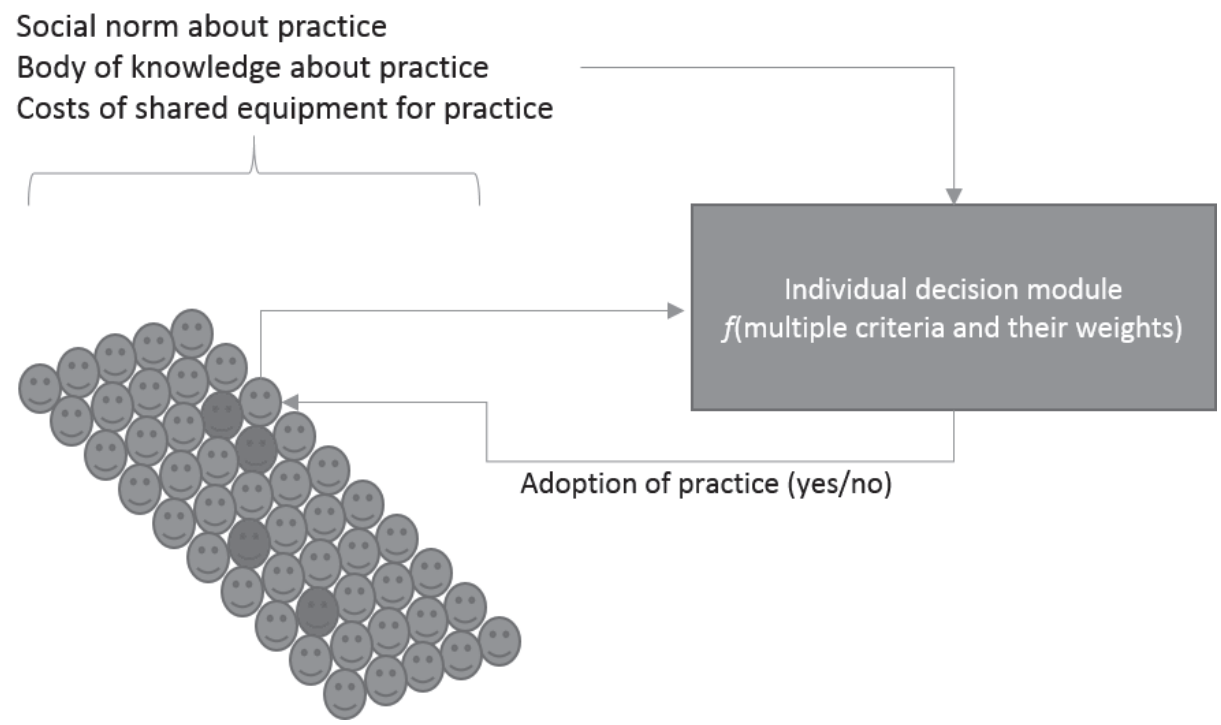

Figure 3.1. A community of farmers is shown of which a small minority (the green ones) adopt one of the two practices. Each farmer makes this decision based on a decision module that is fed by their specific characteristics (e.g. number of cows, size of farm, value attached to sustainable farming). The individual decisions are also influenced by emergent system properties that in turn evolve from the behaviour of the collective: social norms, body of knowledge and costs of equipment 


\subsubsection{Individual decision module}

The decision of each individual farmer-agent is determined in a multi-criteria mathematical programming model capturing the farmer-agents utility function. The advantage of this type of model is that it allows one to take into account various conflicting objectives that farmer-agents might have. The assumption that farmers have multiple criteria is in line with the assumptions made by Bournaris \& Manos (2012) and Tziolas, Manos \& Bournaris (2016) which have successfully developed multi-criteria models to describe farmer behaviour before.

To estimate the utility functions of the farmers we set a priori three farmers' objectives; profit maximization, environmental sustainability maximization, and the minimization of hired labour. The assumption of profit maximization in our model is in line with general assumptions in economic modelling (Pedersen et al., 2012; Peerlings \& Polman, 2009). The assumption of labour minimization is in line with the findings of Berbel \& Rodriguez-Ocana (1998), Paassen, Ridder \& Stroosnijder (2011), Rozakis, Sintori \& Tsiboukas (2012), and Sumpsi, Amador \& Romero (1997). Especially the CMC technique, which allows the farmer to process the largest amount of organic waste, is labour intensive. The assumption of environmental sustainability maximization is in line with the findings by Willock et al. (1999), Bernués, Clemetsen \& Eik (2016), Pereira et al. (2016), and Mandryk et al. (2014) that the use of sustainable and environmentally friendly farming practices might influence farmer decisions (Karali et al., 2014; Willock et al., 1999).

The levels of profit, environmental sustainability, and hired labour are determined as indicated in equations 1-3. Profit is operationalized as Gross Margin, sustainability is measured by the quantity of organic waste produced and hired labour as the amount of labour required minus the own labour endowment. In the baseline the farmer's decision is unrelated to the decisions made by other farmers. In the scenario analysis we introduce interaction between agents where the actions of other agents effect the farmer's decision. Profit is equal to the revenue from regular outputs (which may improve due to Bokashi/CMC application) and the revenue from processing organic waste (municipalities pay the farmers for taking the waste from them) minus the costs of producing the regular outputs, costs of processing organic waste, and labour costs (1). Farmers are not allowed to sell the compost they produce but have to use this on their own land. This assumption is based on the (concept) contracts between farmers and municipalities in which farmers are not allowed to sell the compost to avoid unfair competition in the markets for compost. As an indicator for environmental sustainability we use the amount of organic waste processed on the farm (2). The hired labour hours used on the farm are the labour hours needed which depends on the level of regular 
outputs and organic waste processed minus the initial labour endowment which is equal to the labour of the farm household applied on-farm (3).

$$
\begin{aligned}
\pi & =\max \left(\sum_{j=1}^{J} p_{j} y_{j}-\sum_{m=1}^{M} w_{m} x_{m}-\left(p_{o}-w_{o}\right) y_{o}-p_{L} L-I_{o}\right) \\
\mu & =\max y_{o} \\
L & =\max (L R-L I)
\end{aligned}
$$

\section{Subject to:}

$T\left(\boldsymbol{y}, \boldsymbol{x}, y_{0}, L R\right)$

$\boldsymbol{p}, \boldsymbol{w}, p_{o}, w_{o}, p_{L}>0$

Where:

$\pi$ profit, $p_{j}$ price per unit of regular output $\mathrm{j}, v_{j}$ quantity of regular output $\mathrm{j}, w_{m}$ price per unit of input $\mathrm{m}, x_{m}$ quantity of input $\mathrm{m}, p_{o}$ revenue per unit of processed organic waste, $w_{o}$ processing cost per unit of organic waste, $y_{o}$ quantity of organic waste processed, $p_{L}$ price per unit of hired labour, $L$ quantity of hired labour, $l_{o}$ yearly investment cost of organic waste, $\mu$ environmental sustainability, $L R$ labour required in the production process, $L I$ initial labour endowment, $T\left(y, x, y_{o}, L\right)$ technology set, $y, x$ vector of outputs and variable inputs respectively, $p, w$ vector of output and input prices respectively.

Within the farmer's utility function each of these objectives receives a weight. Following Manos et al. (2009) we distinguish four steps in the estimation of a farmer's utility function. First, we have to define a set of q objectives $f_{1}(z), f_{2}(z) \ldots f_{q}(z)$ that capture the objectives that are most important in farmers' decision making, here they are given in equation 1-3 (i.e. profit maximization, environmental sustainability maximization, and hired labour minimization). Here, $z$ are the constraints determining the value of an objective.

In the second step we have to obtain the pay-off matrix for the selected objectives. The pay-off matrix is set up in the following way:

Objectives/attributes $f_{1}(z), f_{2}(z) \ldots f_{q}(z)$

$\begin{array}{llll}f_{1}(z) & f_{1}^{*} & f_{12} & f_{1 q} \\ f_{2}(z) & f_{21} & f_{2}^{*} & f_{2 q} \\ \ldots & & & \\ f_{q}(z) & f_{q 1} & f_{q 2} & f_{q}^{*}\end{array}$


To obtain the elements of this matrix we optimize the objective in the top subject to the constraints $z$ of each column. The elements in the rows are then the value of the objective at the beginning of the row achieved in this optimization. For example, the element $f_{i j}$ is the value of objective $i$ when we optimize objective $f_{j}(z)$. The diagonal elements give the optimal value of each objective.

In the third step the weights that represent the farmers' preferences are determined. In order to obtain the weights we have to solve the following system of equations:

$\operatorname{Min} \sum_{i=1}^{q}\left(\left(n d_{i}+p d_{i}\right) \times \frac{1}{f_{i}}\right)$

$i=1,2, \ldots, q$

Subject to

$\sum_{j=1}^{q} g_{j} f_{i j}+n d_{i}-p d_{i}=f_{i}$

$\sum_{j=1}^{q} g_{j}=1$

Where:

$g_{j}$ is the weight attached to the $\mathrm{j}$-th objective $(\mathrm{j}=1,2, . ., \mathrm{q})$ of the farmer, $f_{i j}$ are the elements of the pay-off matrix and $f_{i}$ is the value of the $\mathrm{i}$-th objective that is actually observed in the current production plan of the farmer, $n d_{i}$ is the negative deviation from the observed and calculated value of the i-th objective (i.e. $f_{i}-f_{i}^{*}$ ), $p d_{i}$ is the positive deviation from the observed and calculated value of the $\mathrm{i}$-th objective.

In the fourth step the weights obtained in the third step are used to formulate the farmer's utility function. The utility function of a farmer has the following form:

$U=\sum_{j=1}^{q} g_{j} \times \frac{f_{j}}{f_{j}^{*}}$

Where:

$U$ is the utility of the farmer.

By combining this objective function with farm-specific and general farm data we create the individual farm model. Individual farm properties concern milk production per cow, number of young cattle younger than a year per cow, number of young cattle older than a year per cow, initial number of cows, initial number of hectares and the amount of labour available on farm. General system properties concern the costs of feed bought, the costs of removing phosphate, the costs of 
maintaining cattle, the amount of feed measured in KVEM (measure for energy content of feed) produced on a ha of grassland and maize land, the amount of phosphate $\left(\mathrm{P}_{2} \mathrm{O}_{5}\right)$ allowed on a ha of grassland and maize land, and the percentage grassland needed to be able to apply for derogation (i.e. a measure that allows to apply more minerals on land (Rijksoverheid, 2009), the KVEM needed per cow, the KVEM needed for young cattle, the $\mathrm{kg}_{2} \mathrm{O}_{5}$ per KVEM from grass, the $\mathrm{kg} \mathrm{P}_{2} \mathrm{O}_{5}$ per KVEM from maize, the $\mathrm{kg}_{2} \mathrm{O}_{5}$ per KVEM from feed bought, the $\mathrm{kg} \mathrm{P}_{2} \mathrm{O}_{5}$ bound in milk, $\mathrm{kg}$ P2O5 bound in carrying cows, $\mathrm{kg} \mathrm{P}_{2} \mathrm{O}_{5}$ bound in young cattle, the labour hours required for cultivating maize, the labour hours required for cultivating grass, the labour hours needed per cow, the labour hours needed per $\mathrm{m} 3$ organic and the costs of cultivating a hectare of grass and maize. See section 3.2 for more details on how we collected these data and how their corresponding variables have been included in the model.

Within this paper we model a limited number of dairy farms. The empirical model can be found in Appendix A.

\subsubsection{Creating the farmer-agent population}

As we have not been able to interview all farmers in the region we then created a virtual population of a hundred farmer-agents to simulate the uptake of processing organic waste using the $\mathrm{CMC}$ or Bokashi technique. Hereby we use the information obtained from interviews with five dairy farmers in the study area (see section 2.3) to generate a population that exhibits variability in terms of the above described criteria and weights. We assume that these five dairy farmers are representative for the whole region, except for the fact that they process organic waste. To generate the population, we take the properties of the five farms and create per farm 19 additional virtual farm-agents. Each variable (representing the individual farm properties) is a random number drawn from a normal distribution, with the mean equal to the parameter value of the original farm and a standard deviation of ten percent of the mean. This standard deviation is loosely based on standard deviations of farm parameters used in Ondersteijn et al. (2003) and Fanguiero et al. (2008). The characteristics of the initial farms can be found in appendix B.

To create the weights attached to profit maximization, environmental sustainability maximization and labour minimization we also start from the weights of the initial farmers. However, because these five farmers already adopted the practice, they likely care more for environmental sustainability than the "average" farmer in this region. The assumption that the farmers that are among the early adopters and included in the pilot project on processing organic waste care more about sustainability than the other farmers in the region seems reasonable, given the 
fact that they were willing to invest time in preparation of the pilot when benefits were still uncertain. Furthermore, during the interviews farmers often mentioned the environmental benefits of the project. Therefore, we draw the sustainability weight for the created farmer-agent population from a normal distribution with a mean that is equal to five percent of the weight of the original farmer and a standard deviation of ten percent. Obviously, these are crude estimations from our side, which cannot be substantiated with empirical data. Although the estimations affect the decision within the virtual farmer-agents population to adopt $\mathrm{CMC} /$ Bokashi in absolute terms, they do not affect the conclusions we ultimately draw about the mechanisms of uptake (and their relative importance), and how these interact. Based on the number of farmers involved in the CMC/Bokashi pilot projects and the total number of farmers in the study area we estimate that five percent of the farms in this area process organic waste. Although we focused on farmers that adopted the practice of $\mathrm{CMC} /$ Bokashi, we assume that they are representative for the whole region, except for their sustainability weight (below we describe how we dealt with that).

We determine the weights for profit and labour by drawing a random term from a normal distribution with a mean equal to the weight of the original farmer and a standard deviation of ten percent. However, if we decrease the weight attached to environmental sustainability we have to increase the weight for profit and labour, since the total weights have to add up to one. Therefore, we sum the three weights and determine the deviation from one. We add half of this deviation to the random term we found for profit and half to the random term we found for labour to arrive at the final weights for profit and labour. If we use the created farmer-agents population in the baseline model we find an initial uptake of around five percent of on-farm processing of organic waste.

\subsubsection{Emergent system properties}

Mechanism 1: Economies of scale

Economies of scale is often considered an important mechanism that enables the spread of new technologies (Agnolucci \& McDowall, 2007). Farmers can join in a network to reduce e.g. investment costs and therewith benefit from economies of scale (Perdomo et al., 2016). Other examples of the importance of economies of scale as a potential driver for innovation in the agricultural sector can be found in Vagneron, Faure \& Loeillet (2009), Hermans, Roep \& Klerkx (2016), Roest, Ferrari \&Knickel (2017), and Berger (2001).For this mechanism the investment costs for the CMC machinery can be shared with other farmer-agents (the machine can be attached to a tractor and can therefore easily be transported). The costs for Bokashi cannot be shared, since this technique does not require an investment in 
a specific machine. After each time step the number of farmer-agents investing in a $\mathrm{CMC}$ machine is evaluated. We assume the farmer-agents are able to observe the investment decision of all other farmer-agents in the system. In the next time step each of the farmer-agents that did not invest in CMC in the previous time steps considers investing in CMC if (s)he would be able to share the costs with the farmer-agents that invested in the previous time step. To determine the cost of the CMC machine farmer-agents apply the following formula (see eq. A23 in appendix A):

$I_{i, t}=\frac{T I}{n_{t-1}}$

Where $I_{i, t}$ is the average yearly investment cost of individual farmer-agent $i$ in time step $t, T I$ is the average yearly total investment costs of CMC machinery and $n_{t-1}$ is the number of farmer-agents that chose to invest in time step $t-1$.

The model takes into account that there is a maximum of 10 farmer-agents that could share a machine. If this number is exceeded a new machine would be needed, for which costs could again be shared. This mechanism is incorporated in the model. The assumption that farmers are able to share the machinery seems plausible given the fact that two farmers in one of the pilot projects already shared the machine. We assume that the maximum of 10 farmers is not dependent on farm size, as most material to be composted will be delivered by the municipality. Moreover, we assume that the amount of organic waste within the municipality is sufficiently large as not to limit the farmer's decision whether or not to process organic waste on farm.

\section{Mechanism 2: Learning}

Adoption of new agricultural knowledge and practice is more likely after farmers are able to see them successfully demonstrated (Brown et al., 2016). Examples of the importance of learning as a potential driver for innovation in the agricultural sector can be found in Marra, Pannell \& Ghadim (2003), Panell et al. (2006), Hogarth (2017), Olde, Carsjens \& Eilers (2017), Dogliotti et al. (2014), and Šumane et al. (2017). When a new technique is introduced, the effects of this technique are uncertain. In general, application of compost can potentially enhance soil structure, increase water holding capacity, improve soil fertility (Cozzolino et al., 2015; Steel et al., 2010), improve soil biodiversity (Mbau, Karanja \& Ayuke, 2015), reduce carbon emissions and nutrients leakage (Lanting, 2008), and reduce need for artificial pesticide (Saxena et al., 2015). Negative effects by pathogens and unwanted seed plants have also been reported (Insam, Franke-Whittle, \& Goberna, 2010; Montemurro et al., 2015). For the farmers it is very difficult to 
estimate the effect of applying Bokashi or CMC to their land, and whether or not this will have an effect on yield ex ante. Furthermore, the observation of the actual yield increase due to compost application tends to get obscured by the overall variability in yields caused by a range of other factors, many of them being stochastic (weather, mostly). The learning mechanism captures this yield uncertainty and the effect of learning. Yields are subject to a small positive effect of CMC and Bokashi, but with a considerable stochastic variability, so that an agent may not necessarily experience a positive response to compost application. To incorporate this in the scenarios reflecting this mechanism, a normal distribution with a mean of four percent and a standard deviation of two percent was used to generate the stochastic effect on yields when compost is applied. In each of the consecutive time steps the farmer-agents are able to observe the yields of the farmer-agents that invested in the previous time steps. They will adapt their yield expectation based on these observed yields and take this into account when making the decision to invest. Farmers do so by applying the following formula (see eq. A24 in appendix A):

$y_{i, t}^{e}=\sum_{i=1}^{K} \frac{y_{i, t-1}}{m_{t-1}}$

Where $\mathrm{y}_{i, t}^{\mathrm{e}}$ is the expected yield increase of farmer-agent $i$ in time step $t$ when applying compost, $y_{i, t-1}$ is the yield increase for farmer-agent $i$ when applying compost in time step $t-1 m_{t-1}$ is the number of farmer-agents that applied compost in time step $t-1$.

We assume the farmers within the region can all observe each other, and thereby learn from each other. All farmer-agents in our model have similar learning capacity. This means that distance or personal relationships between the farmers do not explicitly influence learning in our model.

\section{Mechanism 3: Changing social norms}

The third mechanism shows the effect of changing social norms and values. Social norms and networks are thought to influence micro-scale values and beliefs of individuals and households (Atwell, Schulte \& Westphal, 2009). Examples of the importance of changing social norms as a potential driver for innovation in the agricultural sector can be found in Cohen et al. (2016), Martínez-García, Dorward \&Rehman (2013) and Fleury et al. (2015) . Initially a farmer might not care much about environmental sustainability. However, when more and more farmers start to process organic waste it might become the norm, influencing the weight a farmer attaches to environmental sustainability. For this mechanism we show the effect of an increase in the weight attached to environmental sustainability, 
as a response to decisions made by other farmer-agents in previous time steps. After each time step the number of farmer-agents that process organic waste is evaluated. For every five farmer-agents that apply organic waste the weight for environmental sustainability increases by 0.0025 percent in the next time step for the entire population. This means that the farmer will increase the value he attaches to environmental sustainability by 1 percent for each 20 farmers that adopt on-farm processing of organic waste. The weights for profit and labour are decreased proportionally by the same amount, according to the following formulas (see eq. A25-A27 in appendix A):

$$
\begin{aligned}
& w b_{i, t}=w b_{i, t-1}+0.0025 \times \frac{m_{t-1}}{5} \\
& w p_{i, t}=w p_{i, t-1}-\frac{w p_{i, t-1}}{w p_{i, t-1}+w l_{i, t-1}} \times 0.0025 \times \frac{m_{t-1}}{5} \\
& w l_{i, t}=w l_{i, t-1}-\frac{w l_{i, t-1}}{w p_{i, t-1}+w l_{i, t-1}} \times 0.0025 \times \frac{m_{t-1}}{5}
\end{aligned}
$$

Where wbi,t is the weight farmer-agent $i$ attaches to sustainability in time step $t, w p_{i, t}$ is the weight farmer-agent $i$ attaches to profit in time step $t, w l_{i, t}$ is the weight farmer-agent $i$ attaches to labour in time step $t$.

The weights of the objective of all farmer-agents in the system change by the same amount, and is not dependent on their initial values. The value of 0.0025 reflects the degree of social cohesion within a farmers' community. Our choice of 0.0025 is a fairly arbitrary one, which would require further calibration in future studies. We assume the farmers within the region can all observe each other, and each extra farmer processing organic waste will have the same impact on the weight for environmental sustainability.

More detailed information about how the mechanisms were implemented in the model can be found in Appendix A.

\subsubsection{Study Area}

Our study area is called the "Friese Meren" and is situated in the Southwest of the province of Friesland. It encompasses an area of 55,000 ha of land and is inhabited by around 51,000 persons (Overheid in Friesland, 2016). The land use is dominated by agriculture, with some big lakes and smaller villages and cities in between. The soil consists of peat, sand and light sandy clay (Bodematlas, 2016). Within the Friese Meren there are 362 dairy farms with on average 97 dairy cows. There are 132 farms with more than 100 cows (BoerenBusiness, 2014b; Melkvee. $\mathrm{nl}$, 2016). Figure 3.2. shows a map of the area. Currently organic municipal waste (often from the roadsides) is collected into a central point and processed, which 
is a costly activity for the municipality. The quality of the processed organic waste is often very low and rarely used in the agricultural sector. By setting up a system of on-farm processing of organic waste municipalities save processing and transport costs. Even though farmers receive a payment from the municipality for the organic waste they process the municipality will reduce their costs for processing organic waste. On top of that, since farmers are expected not to sell their compost but to use it on their own land, important nutrients from the organic waste will remain within the region (Lanting, 2008).

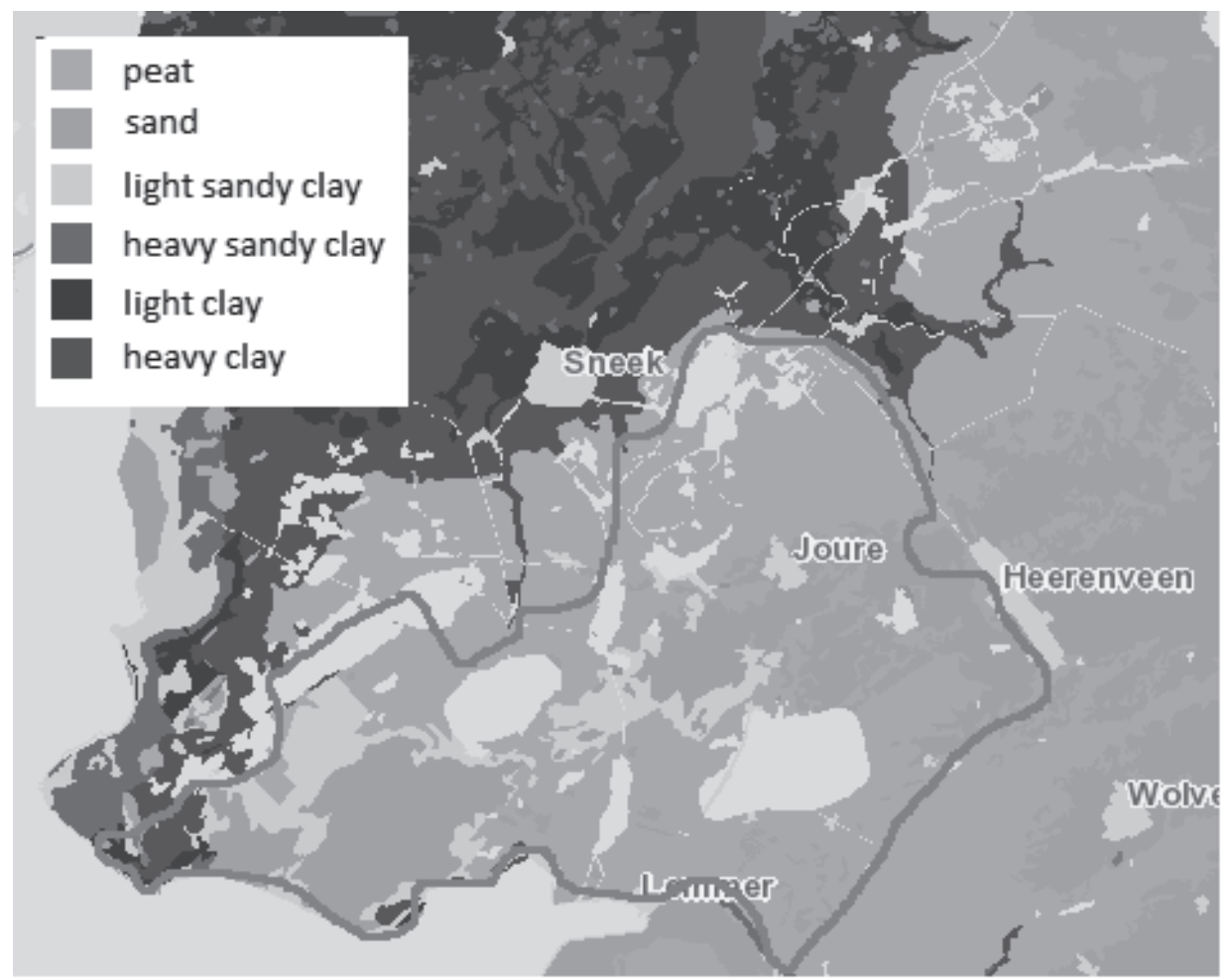

Figure 3.2. Soil types in the Friese Meren, Source: (Bodematlas, 2016)

\subsubsection{Data}

In the "Friese Meren" ten farmers have been involved in two pilot projects for on-farm processing of organic waste. One project has been finished in 2015, in this 2015 project two farmers were involved, and both are now applying the CMC compost technique. We interviewed one of the farmers in this 2015 pilot project, since the other farmer had a mixed farm instead of a dairy farm.

The other pilot project is still running, in this current pilot eight farmers participate and evaluate the decision to start CMC or Bokashi. Most of these farmers 
do not yet apply the technique, but revealed an intention to take up either CMC or Bokashi in the next year. We interviewed six of the farmers in the current pilot project; two of the farmers were not willing to participate. We performed all interviews in 2016, using semi-structured interviews to gather part of the data for the model. Table 3.1. gives an overview of the farmers in the pilot projects and the farmers we interviewed.

Table 3.1. Overview of farmers in pilot projects and farmers interviewed

\begin{tabular}{lll}
\hline & Total farmers & Farmers interviewed \\
\hline Current pilot project & 8 & 6 \\
2015 pilot project & 2 & 1 \\
Total & 10 & 7 \\
\hline
\end{tabular}

For each farm we asked about the number of cows, the number of young cattle $<1$ year, the number of young cattle $>1$ year, the total amount of milk produced, the total amount of land on the farm, the amount of grassland, the amount of maize land, whether they (are going to) produce $\mathrm{CMC}$ or Bokashi including the amount of organic waste (that will be) processed on the farm, the number of persons working on the farm and the hours of agricultural contractors hired. Two of the seven farmers had an organic farm. Since our model is based on regular dairy farms to capture the majority of the farmers in the Friese Meren we used the interviews with the organic farmers to gain background information on the $\mathrm{CMC}$ and Bokashi techniques. The interviews with the remaining five farmers were used to collect input data for our model.

Appendix B shows the values of the parameters used in the model. Table 3B.1. in appendix B gives an overview of the individual farmer data used in our model. For the farmers that did not yet process organic waste we use the expected level of investments and costs indicated by the farmers, unless they were unable to estimate these costs. In that case we base ourselves on the values indicated in the report on the 2015 pilot project (Holster, 2015). In the interviews we asked each of the farmers to indicate the price (s)he expected to receive from the municipality for each $\mathrm{m}^{3}$ of organic waste that was processed on farm. Different farmers expected different prices per $\mathrm{m}^{3}$ of organic waste processed. Since negotiations were still going on we do not report the individual expectations here. We determine farmer's utility functions given the investment costs and processing benefits as expected by the farmers, regardless whether these investment costs and benefits were realistic. However, when we analyse the possible uptake of this practice we will need to take the "real" investment costs and prices into account. Based on the conversations we had on this topic with different people involved 
in the pilot projects we assume that the real price for most farmers will eventually be somewhere around $7 € / \mathrm{m}^{3}$.

The investments indicated also differed for each farmer. The two farmers in the current pilot project managed to buy a second-hand machine together, lowering their investment costs considerably. They already invested in this machine, even though the contract with the municipality specifying the amount of organic waste to be processed and the price for organic waste was not yet concluded. For the other farmers we use the investment costs as indicated in the report from the 2015 pilot project. The variable costs of processing organic waste were hard to estimate for the farmers at the time of the interviews. Based on the answers of the farmers we found that they expected a variable cost of around $5.7 € / \mathrm{m}^{3}$ organic waste in the CMC process and around 6. $/ € \mathrm{~m}^{3}$ for the Bokashi process. These are the prices that farmers expected and that we used in determining utility functions. In the time since we did the interviews with the farmers the organizers of the current pilot project had research done that indicated that the real variable costs of the farmers were $5 € / \mathrm{m}^{3}$ for $\mathrm{CMC}$ and $11.78 € / \mathrm{m}^{3}$ for Bokashi (Bosma, 2016); these are the prices that we use to analyse the uptake. The total costs of hiring labour of about $33 € / \mathrm{hr}$ we base on the report of the 2015 pilot project (Holster, 2015) and the interviews with the farmers. This number is in accordance with the labour costs mentioned for agricultural contractors in the Quantitative Information Livestock Industry report (KWIN) 2014-2015 (Buisonje et al., 2014).

Our model also contains general farm data. From the KWIN 2014-2015 (Buisonje et al., 2014) we extracted information on the costs of feed bought, the costs of removing phosphate, the costs of maintaining cattle, the amount of feed measured in KVEM (measure for energy content of feed) produced on a ha of grassland and maize land, the amount of phosphate $\left(\mathrm{P}_{2} \mathrm{O}_{5}\right)$ allowed on a ha of grassland and maize land, and the percentage grassland needed to be able to apply for derogation (i.e. a measure that allows to apply more minerals on land (Rijksoverheid, 2009). The handbook on the dairy farm sector 2014 (Remmelink et al., 2014) states the KVEM needed per cow and the KVEM needed for young cattle. The $\mathrm{kg} \mathrm{P}_{2} \mathrm{O}_{5}$ per KVEM from grass, the $\mathrm{kg} \mathrm{P}_{2} \mathrm{O}_{5}$ per KVEM from maize, the $\mathrm{kg} \mathrm{P}_{2} \mathrm{O}_{5}$ per KVEM from feed bought, the $\mathrm{kg} \mathrm{P}_{2} \mathrm{O}_{5}$ bound in milk, $\mathrm{kg} \mathrm{P}_{2} \mathrm{O}_{5}$ bound in carrying cows and $\mathrm{kg} \mathrm{P}_{2} \mathrm{O}_{5}$ bound in young cattle can be found in a report for calculating phosphate production on dairy farms by the Dutch government (RVO, 2010). The labour hours required for cultivating maize and for cultivating grass are extracted from (Meetjesland, 2016), while the labour hours needed per cow and per $\mathrm{m}^{3}$ organic waste are based on the interviews. Finally, the costs of cultivating a hectare of grass land and maize are calculated 
from information from the "Kostenwijzer voedermiddelen" (Cost indicator for feedstuff) (WageningenUR, 2015).

\subsubsection{Model-experimental set-up}

In order to explore if and how a regime shift towards wide-scale uptake of on-farm organic waste processing could take place, as a result of the proposed mechanism, the following experimental design was chosen. First, we explore a baseline in which none of the mechanisms occur, and only the individual decision module is in effect. Secondly, we explore three scenarios in which each individual mechanism is taking place. Third, we explore four scenarios in which all possible combinations of the three mechanisms are simulated.

For each scenario we run the model a 100 times. For each of these 100 model runs we create a random farmer-agent population as described in the section "creating the farmer-agent population". Each of the 100 model runs contains ten time steps. In each time step the farmer-agent observes the actions of its neighbours in the previous time step and makes its own decision accordingly. This allows us to determine the average number of farmer-agents who process organic waste over 100 model runs in each of the ten time steps.

Table 3.2. shows which mechanisms are implemented in each of the scenarios and the baseline.

Table 3.2. Mechanisms implemented in each of the scenarios and the baseline

\begin{tabular}{llll}
\hline Scenario/mechanism & $\begin{array}{l}\text { Economies of } \\
\text { scale }\end{array}$ & Learning & $\begin{array}{l}\text { Changing social } \\
\text { norm }\end{array}$ \\
\hline Baseline & x & x & x \\
Economies of scale & $\checkmark$ & x & X \\
Learning & x & $\checkmark$ & x \\
Changing social norm & X & x & $\checkmark$ \\
Interaction all & $\checkmark$ & $\checkmark$ & $\checkmark$ \\
Interaction no economies of scale & X & $\checkmark$ & $\checkmark$ \\
Interaction no learning & $\checkmark$ & $x$ & $\checkmark$ \\
Interaction no social norm & $\checkmark$ & $\checkmark$ & x \\
\hline
\end{tabular}




\subsection{RESULTS}

\section{Initial utility functions}

The actual value of gross margin, total amount of organic waste processed and the total labour hours hired on the farm when optimizing each of the farmers objectives are depicted in Table 3.3 .

Table 3.3. Simulated and actual gross margin in euros, $\mathrm{m} 3$ organic waste processed and hours of hired labour by farmer

\begin{tabular}{|c|c|c|c|c|}
\hline Farmer & Max profit & $\begin{array}{l}\text { Max } \\
\text { environmental } \\
\text { sustainability }\end{array}$ & Min hired labour & Actual \\
\hline \multicolumn{5}{|l|}{ Farm 1} \\
\hline Gross margin & 160,106 & 155,950 & 119,173 & 147,610 \\
\hline Total org. waste & 3,960 & 4,950 & 0 & 2,917 \\
\hline Hired labour hours & 1,634 & 1,935 & 0 & 2,301 \\
\hline \multicolumn{5}{|l|}{ Farm 2} \\
\hline Gross margin & 198,998 & 197,268 & 168,074 & 198,960 \\
\hline Total org. waste & 2,680 & 3,350 & 0 & 1,916 \\
\hline Hired labour hours & 855 & 1,059 & 0 & 793 \\
\hline \multicolumn{5}{|l|}{ Farm 3} \\
\hline Gross margin & 201,707 & 184,072 & 168,074 & 189,165 \\
\hline Total org. waste & 0 & 4,060 & 0 & 2,000 \\
\hline Hired labour hours & 751 & 1,122 & 0 & 1,119 \\
\hline \multicolumn{5}{|l|}{ Farm 4} \\
\hline Gross margin & 126,024 & 115,412 & 126,024 & 88,807 \\
\hline Total org. waste & 0 & 2,500 & 0 & 600 \\
\hline Hired labour hours & 0 & 0 & 0 & 1,183 \\
\hline \multicolumn{5}{|l|}{ Farm 5} \\
\hline Gross margin & 310,950 & 299,206 & 171,494 & 274,733 \\
\hline Total org. waste & 0 & 6,250 & 0 & 2,500 \\
\hline Hired labour hours & 3,754 & 4,254 & 0 & 4,849 \\
\hline
\end{tabular}


By applying the technique as described by Manos et al. (2009) which minimizes the deviations between the scenarios and reality we find the utility functions (9) to (14) for each of the five farmers (we determined these using equations 4 to 8 ).

$U_{1}=0.119 \times \frac{\pi_{1}}{\pi_{1}^{*}}+0.588 \times \frac{\mu_{1}}{\mu_{1}^{*}}-0.293 \times \frac{l_{1}}{l_{1}^{*}}$

$U_{2}=0.715 \times \frac{\pi_{2}}{\pi_{2}^{*}}-0.285 \times \frac{l_{2}}{l_{2}^{*}}$

$U_{3}=0.507 \times \frac{\pi_{3}^{2}}{\pi_{3}^{*}}+0.493 \times \frac{\mu_{3}}{\mu_{3}^{*}}$

$U_{4}=0.760 \times \frac{\pi_{4}}{\pi_{4}^{*}}+0.240 \times \frac{\mu_{4}}{\mu_{4}^{*}}$

$U_{5}=0.693 \times \frac{\pi_{5}}{\pi_{5}^{*}}+0.307 \times \frac{\mu_{5}}{\mu_{5}^{*}}$

Where $U_{i}$ is utility of farmer $i, \pi_{i}$ is profit of farmer $i, \pi_{i}^{*}$ is maximum potential profit of farmer $i, \mu_{i}$ is environmental sustainability of farmer $i, \mu_{i}^{*}$ is maximum potential environmental sustainability farmer $i, l_{i}$ is hired labour hours by farmer i, $l_{i}^{*}$ minimum hired labour hours used by farmer $i$.

Farmer 1 is the only farmer that attaches weight to all three objectives. Farmer 2 does not attach value to environmental sustainability, whereas farmer 3, 4 and 5 do not value hired labour minimization.

The utility functions for the artificially created farmer population resulted from the weights we created as described in the section "creating the farmer-agent population". These weights can be found in appendix D.

\section{Baseline}

In the baseline each farmer determines his/her optimal choice without taking the choices made by other farmers into account. In the baseline on average five farmers (5.15) choose to process organic waste (i.e. 5\%).

Three important parameters that influence the decisions in our model are the wage, the milk price and the price received for processing organic waste. In the sensitivity analysis in appendix $C$ we show how the optimal decisions of the initial five farmers change with these prices. The sensitivity analysis shows that the farmer choices are robust with respect to price changes.

\section{Results Scenarios}

Figure 3.3. shows the average number of farmers who process organic waste over a 100 model runs in each of the ten time steps for the economies of scale, learning and social norm scenarios. 


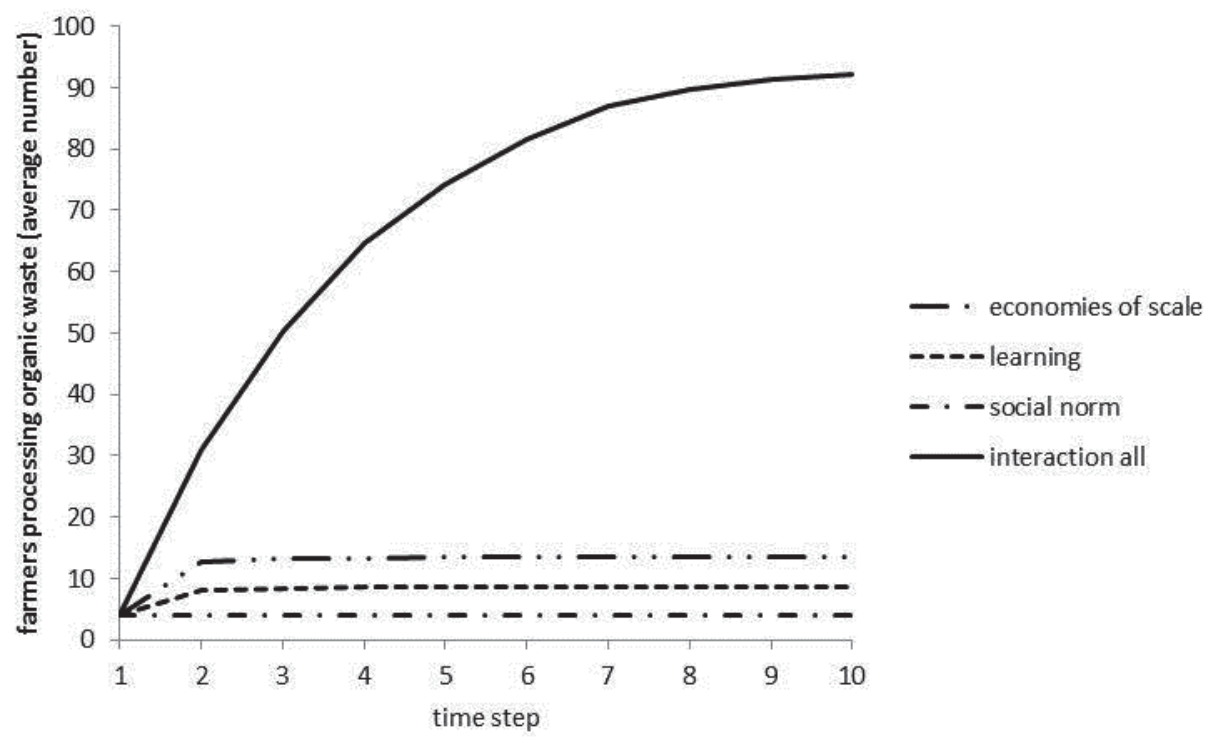

Figure 3.3. Average number of farmers processing organic waste in each time step in the economies of scale, learning, social norm and interaction all scenarios

Figure 3.3. shows that the average number of farmers that process organic waste in the $10^{\text {th }}$ time step is no higher than in the baseline in the scenario changing social norms (4), but this may be ascribed to our - fairly arbitrarily chosen parameter indicating how the behaviour of individual farmers affect the overall social norm. The economies of scale scenario (13) and the learning scenario take an intermediate position (9). The average number of farmers increases initially, but after a certain time the average number of farmers stays constant in each of these scenarios However, the final uptake is substantially higher if the mechanisms from the first three scenarios are combined in the scenario interaction (92).

Figure 3.4. shows the average number of farmers processing organic waste in the different interaction scenarios. 


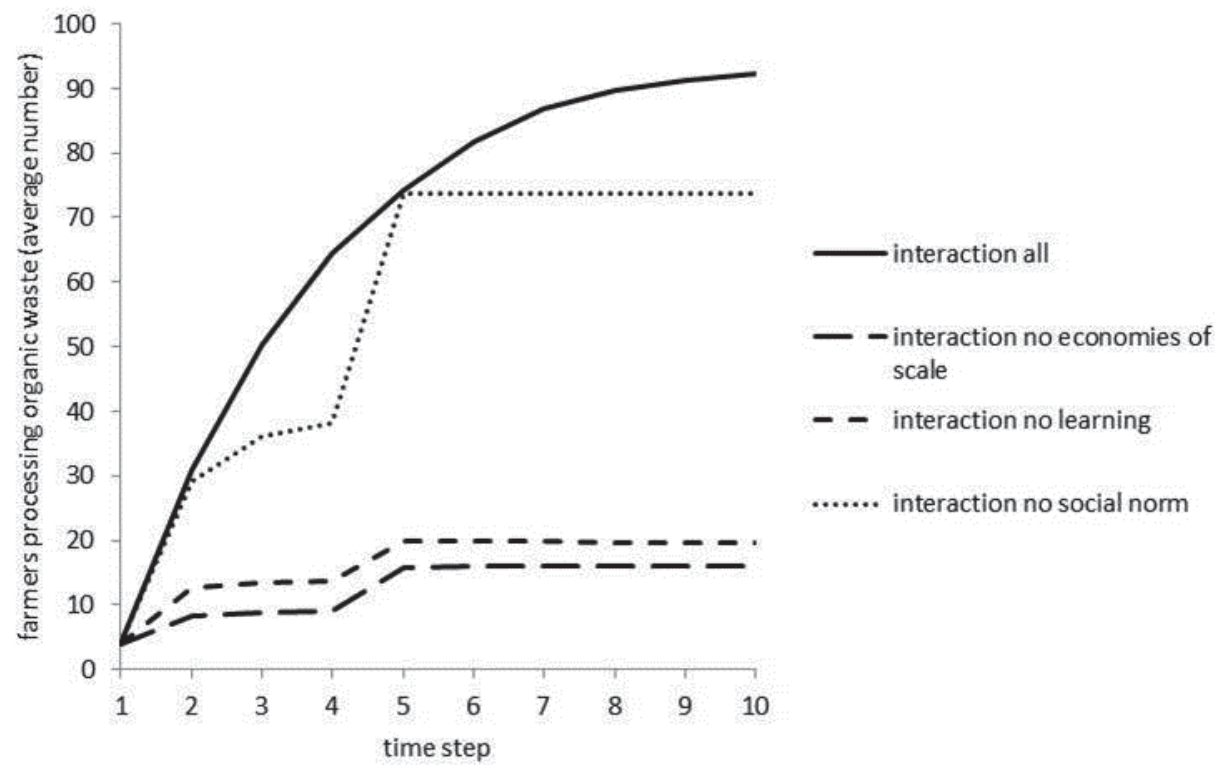

Figure 3.4. Average number of farmers processing organic waste in each time step in the interaction scenarios

Figure 3.4. shows the effect of dropping one of the mechanisms from the interaction scenario. If we consider the combined effect of a changing social norm and learning (16) and combined effect of a changing social norm and economies of scale (20) the average number of farmers processing organic waste after ten time steps is considerably lower than if we consider the effect of the three mechanisms combined (92). The average number of farmers after ten time steps if we combine the effect of economies of scale and learning (74) takes an intermediate value. Furthermore, the average number of farmers processing organic waste stays constant after the fifth time step in the scenarios combining only two mechanisms, but keeps increasing in the scenario combining all three mechanisms.

For each of the 100 model runs we determined the number of farmers processing organic waste. This information is presented in the histograms in Figure 3.5. The frequency in these histograms indicates how many times the number of farmers indicated on the horizontal axis were processing organic waste at the end of the model run. For example, in the histogram economies of scale the frequency of 11 farmers processing organic waste is 23 . This means that out of a 100 model runs we found 23 times that the final number of farmers processing organic waste was 11 . 

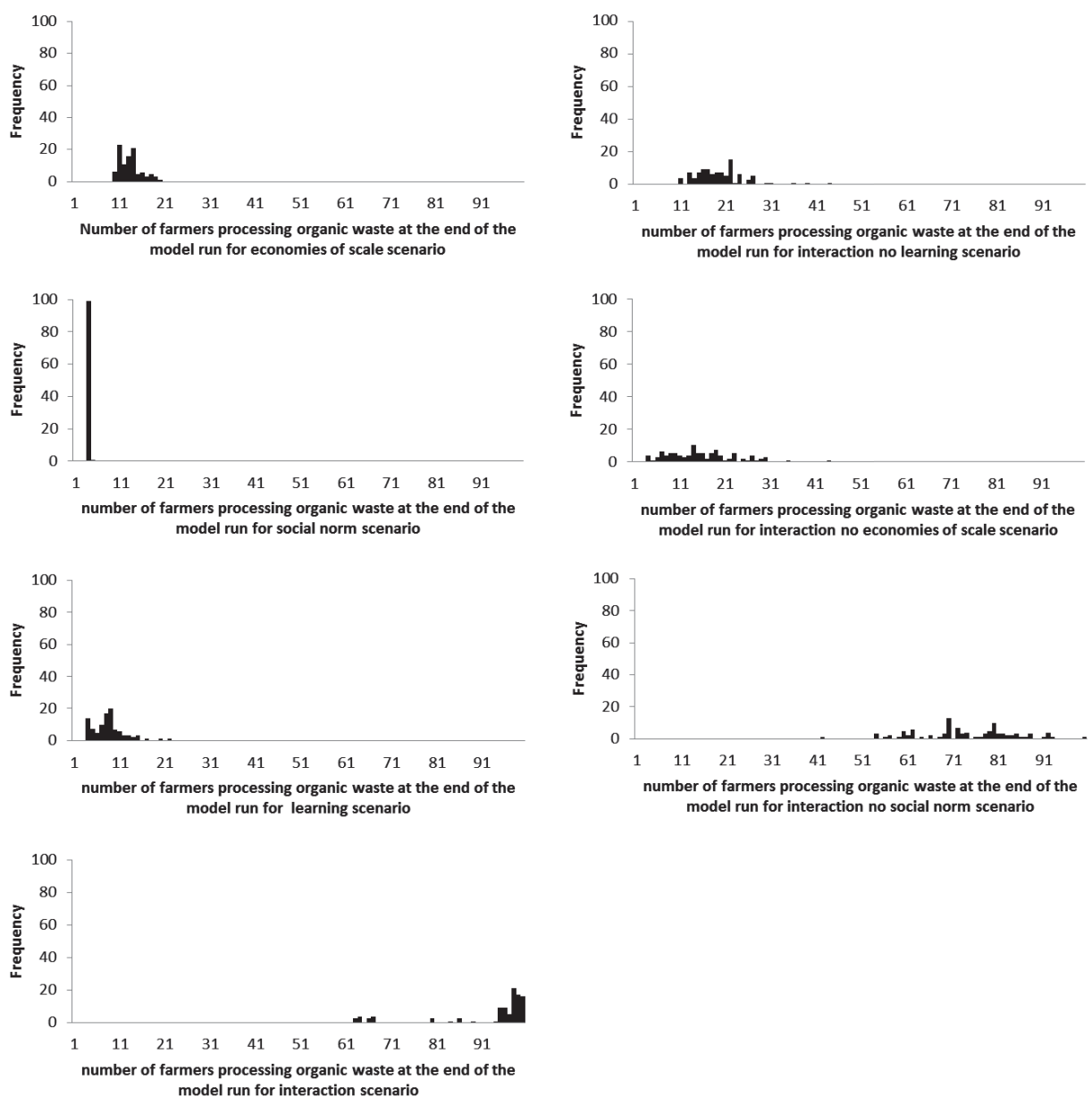

Figure 3.5. Histograms for each scenario

In the economies of scale scenario the number of farmers processing organic waste in the final time step ranges from 10 to 20. Initially there are possible gains from sharing costs, but at a certain point the gains and the spread of the new technology is halted due to the fact that there is a maximum number of farmers that can share the costs of one machine. In the learning scenario the number of farmers processing organic waste in the final time step ranges from 4 to 22 . Learning about yields changes the expected benefits and will cause some farmers to take up the practice, but the increase in yields is not so large that it will make processing organic waste attractive for everyone. In the changing social norms scenario the number of farmers processing organic waste in the final time step 
ranges is always 4 . The initial number of farmers is too small to change the weight for sustainability significantly.

In the interaction scenarios the interaction between the mechanisms creates a kind of momentum. If the uptake due to the first mechanism is coming to a standstill, the increasing number of farmers participating due to the second mechanism can activate the first mechanism again. If we combine only two mechanisms, the number of farmers processing organic waste at the end of the model run ranges from 4 to 44 for the interaction without economies of scale, from 11 to 44 for the scenario without learning and from 42 to 100 for the scenario without a changing social norm. In the interaction between all mechanisms scenario the number of farmers processing organic waste at the end of the model run ranges from 63 to 100. The histograms show that the number of farmers processing organic waste is in general much larger if all three mechanisms interact. Although a feedback loop starts in the interaction scenarios with only two mechanisms, this feedback loop does not always lead to a regime shift towards processing organic waste, when the effect of both mechanisms is exhausted and no new impulse is provided. When a third mechanism is added, this can provide the new impulse necessary to set the feedback loop in motion again, leading to a full shift towards processing organic waste. Due to random variations in the population processing organic waste is taken up by almost the entire farmer-agent population in some cases, while not in others. The results also show that uptake of on-farm processing organic waste can even occur when the weight for sustainability is zero, as long as on-farm processing of organic waste is profitable. This implies that a policy maker could stimulate the use of this sustainable farming practice even in areas where farmers do not attach a large weight on sustainability. Furthermore, the results suggest that in order to promote the uptake of a sustainable farming practice, such as the use of organic waste, a policymaker should take into account all three mechanisms of innovation. Ideally, all three mechanisms could be stimulated, in which case the effect on the uptake of organic waste would be biggest.

\subsection{DISCUSSION}

We analysed how economies of scale, learning, and changing social norms can influence the decision to invest in CMC and Bokashi. We showed how the techniques can spread in some situations, and remain a niche in other situations. Random variations in yield and farmer-agent population can explain why in some instances a threshold is reached resulting in a shift towards processing organic waste and not in others. This helps to explain to policy makers the puzzling result 
of why policies can have a large effect in one area and no effect in another area. When we consider the effects of the three mechanisms separately it might seem that although processing organic waste on farm becomes somewhat more popular, it is unlikely to become a standard practice in the region. However, the interaction between the mechanisms leads to a higher uptake. When the effect of the first mechanism is exhausted, the increasing number of farmers participating due to the second mechanism can set the first mechanism in motion again. For instance, if more than ten farmers invest in CMC the machine cannot be shared by more farmers. Therefore, the eleventh farmer will not be able to share the costs, even if (s)he would want to. However, if more farmers want to take up the processing of organic waste due to learning about yields, the eleventh farmer is able to share the costs with these farmers, again starting a feedback loop of decreasing investment costs. Although other studies have already shown the individual effects of each of these three mechanisms, we show that only by combining the three mechanisms in one scenario a shift towards processing organic waste can be achieved.

We are aware of limitations in our research. First, even though the farmers in our model prefer CMC, in the interviews two farmers indicated their preference for Bokashi. This can be explained by the fact that our model considers yearly investment costs and does not consider the possible difficulty that farmers might experience when they need to finance the whole investment at the beginning of the period. Second, the exact effect on yields of using CMC and Bokashi are still largely unknown (Álvarez-Solís et al., 2010; D’Hose et al., 2016; ILVO, 2016; Kahn, Payton \& Graetz, 2012; Lee, 2012; Ndona et al., 2011). Our assumption that yields instantly react to CMC or Bokashi application (albeit modestly and obscured by general yield volatility) is a simplification of reality, in which it may take many years before any improvement can be observed, if at all. Other limitations pertain to the fact that our empirical observations were obtained from farmers that participated in a pilot project. Lastly, the empirical grounding of the model was based on only a limited set of interviews, which were also conducted for a subset of farmers who were interested in the practice. The lack of awareness of these technologies in the wider farming populations made it difficult to extend the number of interviews.

The results from our paper show a high uptake of on-farm processing of organic waste, which might at first glance seem unrealistic. However, if one realises the favourable circumstances for on-farm processing of organic waste created in the pilot project, the results are much more understandable. In the pilot project a contract with the municipality was arranged, in which a fixed price was guaranteed to the farmers for processing organic waste during a couple of years. Therefore, in our model this price is offered by the municipality to any farmer willing to 
process organic waste. Outside the pilot project arranging such a contract might be more difficult. If municipalities would not be willing to pay the uptake would be much lower. Furthermore, in our model we assume that the farmers believe the municipalities will keep offering these contracts, while in reality farmers might be afraid that the contracts will not be renewed. So, to facilitate a shift towards on-farm processing of organic waste policy makers should create a transparent and constant policy, offering farmers a secure contract for processing organic waste.

To overtake the limitations of our research, one would first need to decide which direction to take: towards a more applied-sciences model, which can be used by policymakers to predict uptake of the practice in response to certain policy options; or towards a more academic model that allows the development of theory around the scientific questions of how regime shifts in land use systems can be brought about. For the former purpose, the model would have to be better calibrated in terms of decision-making processes in farmers, of yield responses to $\mathrm{CMC} /$ Bokashi applications, and one may want to include more real-world mechanisms such as regulations preventing the uptake (due to e.g. heavy metal pollution risk). On the other hand, to move towards more elaborated theory development one would need to filter out the "empirical noise" and increase the number of agents in the model to arrive at a more stylized output and conduct more experiments to explore e.g. hysteresis, bifurcations, and other phenomena related to the notion of regime shifts. Nevertheless, our research shows how the mechanisms of economies of scale, learning about yields, and changing social norms can each lead to (partial) uptake of on-farm processing of organic waste. We also show the importance of interaction between these mechanisms. It demonstrates how a regime shift towards on-farm processing of organic waste as a standard practice can only explained by the interaction of these mechanisms. This realisation provides us with more insights on the mechanisms that underlie the uptake of sustainable farming practices and might aid policymakers in the design of more effective policies to promote these farming practices.

We find that taking a farmer perspective that is broader than profit maximization allows us to explain farmer decisions on the uptake of on-farm processing of organic waste. Our work is related to the work of Sengupta et al. (2005) who uses an agent-based model to describe farmer enrolment in the Conservation Reserve Program in the USA, and emphasize the need to focus on more than just profit maximizing to capture agent decisions accurately. We took a CAS perspective in studying the uptake of on-farm waste processing of the farmers in our model, which allows us to explain the mechanisms that can lead to uptake of sustainable farming techniques. This is in line with results found by Bale et al. (2014) who 
developed a method to model the diffusion of energy-efficiency innovations in a social network of heterogeneous households. Their results suggest that a complexity based approach is required to understand the decision making of the households.

In their paper Zeweld et al. (2017) used insights from the theory of planned behaviour to reveal that attitudes and normative issues can explain the possible adoption of sustainable farming practices. Furthermore, they found that perceived usefulness, social capital and perceived ease of operation have an effect on adoption decisions (Zeweld et al., 2017). Our paper shows a practical application of the effect of perceived usefulness and ease of operation through the learning mechanism, as well as a practical application of the effect of social capital in the form of the social pressure mechanism. Gebrezgagher et al. (2015) studied the likelihood of adoption of manure separation of Dutch dairy farmers, and found that farmer attitudes towards technology play a role in explaining adaptation. The attitudes of the farmers in our model are reflected in the weights assigned to different farmer objectives.

In traditional Agent Based Modelling approaches the individual decision making is rule-based. In this paper we show a more sophisticated way of capturing individual decision making, while still maintaining the advantages of ABM in terms of capturing interactions and feedbacks, in a system of heterogonous agents. This paper also contributes to the understanding of feedbacks in land use systems, an area which is relatively unexplored as pointed out by Chen et al. (2016a).

\subsection{CONCLUSIONS}

Although achieving a shift towards more sustainable farming practices is desirable, in reality the uptake of these practices is often limited and unsatisfactory. As we have shown in this paper, the uptake of sustainable practices is often dependent on a combination of multiple mechanisms. If one of these mechanisms is not in place, the momentum might be lost and the sustainable practice might remain a niche practice. This brings interesting policy implications, for when planning to implement a sustainable practice, all these mechanisms have to be taken into account.

\section{Acknowledgements}

Special thanks to Henri Holster (Wageningen University and Research) and Sake Bosma for their help, as well as the farmers who were willing to participate in interviews. This work was supported by the Complex Adaptive Systems program of Wageningen University. 


\section{APPENDIX 3A. FARM MODEL}

\section{Basic model:}

\section{Objective}

$\max U_{i r t}=g 1_{i r} * \frac{\pi_{i r t}}{\pi_{i r t}^{*}}+g 2_{i r} * \frac{\mu_{i r t}}{\mu_{i r t}^{*}}-g 3_{i r} * \frac{l_{i r t}}{l_{i r t}^{*}}$

$\mathrm{i}=1, \ldots, 10$

$\mathrm{r}=1, \ldots, 100$

$\mathrm{t}=1, \ldots, 10$

Subject to:

$$
\begin{aligned}
& \pi_{\text {irt }}=x 1_{\text {irt }} * e 1_{\text {ir }} * p 1+x 9_{\text {imrt }} * p 2_{i}-\sum_{n=1}^{8} x_{\text {nirt }} * w_{n} \\
& -x 9_{\text {imrt }} * w 9_{m}-w 10_{\text {imt }} \\
& \mathrm{m}=1 \text { or } 2 \\
& \mu_{\text {irt }}=x 9_{\text {imrt }} \\
& x 8_{\text {irt }}=\max \left(\left(l_{\text {irt }}-e 2_{\text {ir }}\right), 0\right) \text {; } \\
& x 4_{\text {irt }}=x 1_{\text {irt }} * e 3+x 2_{\text {irt }} * e 4+x 3_{\text {irt }} * e 5-x 13_{\text {irt }} * e 6 * e 27 \\
& -x 14_{\text {irt }} * e 6-x 15_{\text {irt }} * \quad e 7 * e 27-x 16_{\text {irt }} * e 7 \\
& x 10_{\text {irt }}=x 13_{\text {irt }} * e 6 * e 27 * e 8+x 14_{\text {irt }} * e 6 * e 8+x 15_{\text {irt }} * e 7 * e 27 * e 9 \\
& +x 16_{\text {irt }} * e 7 * e 9+x 4_{\text {irt }} * e 10-x 1_{\text {ir }} * e 1_{\text {ir }} * e 11 \\
& -x 1_{\text {irt }} * e 12-x 2_{\text {irt }} * e 13-x 3_{\text {irt }} * e 14 \\
& x 11_{\text {irt }}=x 5_{\text {irt }} * e 15+x 6_{\text {irt }} * e 16 \\
& x 7_{\text {irt }}=\max \left(\left(x 10_{\text {irt }}-x 11_{\text {irt }}\right), 0\right) \\
& l_{\text {irt }}=x 1_{\text {irt }} * e 17+x 5_{\text {ir }} * e 18+x 6_{\text {irt }} * e 19+x 9_{\text {imrt }} * e 20_{m} \\
& x 5_{\text {irt }}=0.8 *\left(x 5_{\text {irt }}+x 6_{\text {irt }}\right) \\
& x 12_{\text {irt }}=x 5_{\text {irt }}+x 6_{\text {irt }} \\
& x 2_{\text {irt }}=x 1_{\text {irt }} * e 22_{\text {irt }} \\
& x 3_{\text {ir }} t=x 1_{\text {irt }} * e 23_{\text {irt }} \\
& x 1_{\text {irt }} \leq e 24_{\text {ir }} \\
& x 5_{\text {irt }}+x 6_{\text {irt }} \leq e 25_{\text {ir }} \\
& x 9_{\text {imrt }} \leq e 21_{\text {imr }} * x 12_{\text {irt }} \\
& x 1_{\text {irt }}, x 5_{\text {irt }}, x 6_{\text {irt }}, x 7_{\text {irt }} x 9_{\text {imrt }}, x 8_{\text {irt }}, x 12_{\text {irt }} \geq 0 \\
& \pi_{\text {irt }} \geq e 26 \\
& x 5_{\text {irt }}=x 13_{\text {irt }}+x 14_{\text {irt }} \\
& x 6_{\text {irt }}=x 15_{\text {irt }}+x 16_{\text {irt }} \\
& x 17_{\text {irt }}=x 13_{\text {irt }}+x 15_{\text {irt }} \\
& x 17_{\text {irt }}=x 9_{\text {imrt }} / e 21_{\text {im }}
\end{aligned}
$$


Where:

$x 1_{\text {irt }}=$ number of cows on farm $\mathrm{i}$

$x 2_{\text {irt }}=$ number of young cattle $<1$ year on farm $\mathrm{i}$

$x 3_{\text {irt }}=$ number of young cattle $>1$ year on farm $\mathrm{i}$

$x 4_{\text {irt }}=$ KVEM feed purchased

$x 5_{\text {irt }}=$ ha grassland on farm $\mathrm{i}$

$x \sigma_{\text {irt }}=$ ha maize land on farm $\mathrm{i}$

$x 7_{\text {irt }}=\mathrm{kg}$ phosphate surplus farm $\mathrm{i}$

$x 8_{\text {irt }}=$ labour hours hired on farm $\mathrm{i}$

$x 9_{\text {imrt }}=\mathrm{m} 3$ organic waste material processed on farm $\mathrm{i}$ with technique $\mathrm{m}$

$x 10_{\text {irt }}=\mathrm{kg}$ phosphate produced on farm $\mathrm{i}$

$x 11_{\text {irt }}=\mathrm{kg}$ phosphate that can be placed on land farm $\mathrm{i}$

$x 12_{\text {irt }}=$ total ha land on farm $\mathrm{i}$

$x 13_{\text {irt }}=$ ha grass with compost

$x 14_{\text {irt }}=$ ha grass without compost

$x 15_{\text {irt }}=$ ha maize with compost

$x 16_{\text {irt }}=$ ha maize without compost

$x 17_{\text {irt }}=$ total ha with compost

$p 1=$ price milk in euro per $100 \mathrm{~kg}$

$p 2_{i}=$ price organic waste in euro per $\mathrm{m} 3$

$w 1=$ maintenance costs in euro per cow

$w 2=$ maintenance costs in euro per young cattle $<1$ year

$w 3=$ maintenance costs in euro per young cattle $>1$ year

$w 4=$ costs per KVEM feed in euro

$w 5=$ costs of maintaining a ha of grass in euro

$w 6=$ costs of maintaining a ha of maize in euro

$w 7=$ costs of removing a $\mathrm{kg}$ of excess phosphate

$w 8=$ costs of hiring one hour of labour in euro

$w 9_{m}=$ costs of processing one $\mathrm{m} 3$ organic waste with technique $\mathrm{m}$

$w 10_{i m}=$ yearly investment costs of technique $\mathrm{m}$ in euro

$e 1_{i r}=100 \mathrm{~kg}$ milk produced per cow on farm $\mathrm{i}$

$e 2_{i r}=$ own labour hours available on farm $\mathrm{i}$

e3 $=$ KVEM needed per cow

e4 $=$ KVEM needed per young cattle $<1$ year

e5 $=$ KVEM needed per young cattle $>1$ year

e6 $=\mathrm{KVEM}$ produced on a ha of grassland

e7 $=\mathrm{KVEM}$ produced on a ha of maize land

e $=\mathrm{kg}$ phosphate in a KVEM from grassland 
e9 $=\mathrm{kg}$ phosphate in a KVEM from maize land

$e 10=\mathrm{kg}$ phosphate in a KVEM purchased

e11 = $\mathrm{kg}$ phosphate in $100 \mathrm{~kg}$ milk

e12 = $\mathrm{kg}$ phosphate in a carrying cow

e13 = $\mathrm{kg}$ phosphate in a young cattle $<1$ year

e14 = $\mathrm{kg}$ phosphate in a young cattle $>1$ year

e15 = $\mathrm{kg}$ phosphate allowed on a ha of grassland

e16 $=\mathrm{kg}$ phosphate allowed on a ha of maize land

e17 = labour hours needed per cow

e18 = labour hours needed per ha grassland

e19 = labour hours needed per ha maize land

$e 20_{m}=$ labour hours needed per $\mathrm{m} 3$ organic waste with technique $\mathrm{m}$

$e 21_{m}=$ maximum $\mathrm{m} 3$ organic waste processed with technique $\mathrm{m}$ that can be placed on a ha of land

$e 22_{i r}=$ number of young cattle $<1$ year per cow on farm $\mathrm{i}$

$e 23_{i r}=$ number of young cattle $>1$ year per cow on farm $\mathrm{i}$

$e 24_{i r}=$ initial number of cows on farm $\mathrm{i}$

$e 25_{i r}=$ initial ha of land on farm $\mathrm{i}$

e26= subsistence income farmers

$e 27=$ expected increase in yields when applying compost

$g 1_{\text {ir }}=$ weight attached to profit maximization by farmer $\mathrm{i}$

$g 2_{i r} \quad=$ weight attached to environmental sustainability maximization by farmer $\mathrm{i}$

$g 3_{i r}=$ weight attached to labour minimisation by farmer $\mathrm{i}$

$l_{\text {irt }}=$ labour hours needed on farm $\mathrm{i}$

$\mu_{i r t}=$ environmental sustainability on farm $\mathrm{i}$

$\pi_{i r t} \quad=$ profit on farm i

$\pi_{i r}{ }^{*} \quad=$ maximum value for profit for farm $\mathrm{i}$

$\mu_{i r}{ }^{*} \quad=$ maximum value for environmental sustainability for farm $\mathrm{i}$

$l_{i r}^{*} \quad=$ minimum value for labour hours on farm $\mathrm{i}$.

The farmer aims to maximize his utility (A1), which depends on the level of profit (A2), environmental sustainability (A3) and hired labour (A4). Profit equals the revenue from milk and municipal waste processed minus the maintenance costs of cattle, the costs of feed, the costs of growing grass and maize, the costs of removing excess manure, the costs of processing organic waste, the costs of hired labour, and the investment costs in CMC or Bokashi (A2). The environmental sustainability equals the amount of organic waste processed on the farm (A3). The hired labour used on the farm is the result of the labour hours needed minus own labour hours, there cannot be a negative amount of labour hours hired (A4). 
The amount of feed purchased by the farmer is equal to the number of cows times the feed needed per cow plus the number of young cattle times the feed needed per young cattle minus the amount of feed produced on the farm (A5). The phosphate produced on farm equals the KVEM from grass consumed times the phosphate in a KVEM of grass plus the KVEM from maize consumed times the phosphate in a KVEM of maize plus the KVEM bought consumed times the phosphate in a KVEM bought minus the phosphate in milk, the phosphate in carrying cows and the phosphate in young cattle (A6). The phosphate that can be placed on land is equal to the ha of grass times the phosphate allowed per ha of grass plus the phosphate allowed per ha of maize times the phosphate allowed per ha of maize (A7).The phosphate surplus is then the result of the total phosphate production minus the amount of phosphate that can be placed on land, there cannot be a negative phosphate surplus (A8). The total hours of labour needed can be found by multiplying the number of cows with the time needed per cow, the ha of grass with the time needed per ha of grass, the ha of maize with the time needed per ha of maize and the $\mathrm{m} 3$ organic waste times the amount of time needed to process a $\mathrm{m} 3$ organic waste (A9). In order to be viable for derogation (permission to place more manure on land) the farm has to maintain at least 80 percent grass land (A10). The total area of farm land exists of grassland and maize land (A11). The number of young cattle younger than one year is found by multiplying the number of cows by the number of young cattle younger than one year kept per cow (A12). The number of young cattle older than one year is found by multiplying the number of cows by the number of young cattle older than one year kept per cow (A13). The number of cows kept in the model cannot exceed the number of cows kept in the initial situation (A14). The amount of grass plus the amount of maize is equal to or less than the total amount of land in the initial situation (A15). The amount of organic waste processed on the farm cannot be more than the maximum amount of organic waste per ha times the number of ha on the farm (A16). Export of processed organic waste is not possible in the model, since that would mean the farmer has to take additional legislation into account. All the farmers in the pilot studies indicated that they would not produce more compost than could be used on their own farm. The number of cows, the feed purchased, the ha of grass, the ha of maize, the phosphate surplus, the organic waste processed, and the hired labour hours and the total amount of land cannot be negative (A17). The profit of the farm has to reach a certain level to guarantee the farmer a subsistence income (A18). Grassland can be divided in grassland on which compost is applied and grassland on which no compost is applied (A19). Similarly, maize land can be divided in maize land on which compost is applied on maize land on which no compost is applied (A20). The hectares of grassland with compost and the hectares of maize land with compost 
together form the total amount of land on which compost is used (A21). The total amount of land on which compost is used is equal to the amount of compost produced divided by the amount of compost that can be put on a ha of land (A22).

Scenario 1: Costs sharing

To determine the shared costs we add the following equation to the base model: $w 10_{m=1, r}=e 28 / e 29_{r}$

Where:

$e 28=$ yearly investment costs of CMC machine in euro

$e 29_{r}=$ number of farmers that chose to invest in CMC in the previous step

Equation (A23) specifies that the yearly investment costs are equal to the yearly investment costs of a CMC machine divided by the number of farmers that chose to invest.

Scenario 2: Learning

Step 2: Add the following equation to the base model:

$e 27=\sum_{i=1}^{k} e 30_{k r} / e 31_{r}$

Where:

$e 30_{k r}=$ increase in yields for the farmer $\mathrm{k}$ using compost

$e 31_{r}=$ the number of farmers that used compost in the previous step.

The average increase in yields when using compost is equal to the sum of increased compost for each farmer $\mathrm{k}$ that applies compost, divided by the $\mathrm{k}$ farmers that apply compost (A24).

\section{Scenario 3: Social norms}

The weight $g 2_{i r}$ in the model is replaced by $x g 2_{i r}$, the weight $g 1_{i r}$ in the model is replaced by $x g 1_{i r t}$ and the weight $g 3_{i r}$ is replaced by $x g 3_{i r}$. The following equations need to be added to the base model.

$x g 2_{\text {irt }}=g 2_{\text {ir }}+0.0025 * e 31_{r} / 5$

$x g 1_{\text {ir }}=g 1_{\text {ir }}-\left(\frac{g 1_{\text {ir }}}{g 1_{\text {ir }}+g 3_{\text {ir }}}\right) * 0.0025 * e 31_{r} / 5$

$x g 3_{i r}=g 3_{i r}-\left(\frac{g 3_{i r}}{g 1_{i r}+g 3_{i r}}\right) * 0.0025 * e 31_{r} / 5$ 


\section{APPENDIX 3B. EXOGENOUS VALUES FOR DETERMINING UTILITY FUNCTIONS}

Table 3B.1. Exogenous farmer specific parameter values

\begin{tabular}{|c|c|c|c|c|c|c|}
\hline \multicolumn{2}{|c|}{ Parameter } & \multirow{2}{*}{$\begin{array}{l}\text { Farmer 1 } \\
81\end{array}$} & \multirow{2}{*}{$\begin{array}{l}\text { Farmer } 2 \\
95\end{array}$} & \multirow{2}{*}{$\begin{array}{l}\text { Farmer } 3 \\
96\end{array}$} & \multirow{2}{*}{$\begin{array}{l}\text { Farmer } \mathbf{4} \\
86.7\end{array}$} & \multirow{2}{*}{$\begin{array}{l}\text { Farmer } 5 \\
96.15\end{array}$} \\
\hline $\mathrm{e} 1_{i}$ & $\begin{aligned}= & 100 \mathrm{~kg} \text { milk produced per } \\
& \text { cow on farm i }\end{aligned}$ & & & & & \\
\hline $\mathrm{e} 2_{i}$ & $\begin{aligned}= & \text { Own labour hours available } \\
& \text { on farm }\end{aligned}$ & 2,237 & 2,237 & 2,237 & 2,237 & 2,237 \\
\hline $\mathrm{e} 22_{i}$ & $\begin{aligned}= & \text { Number of young cattle }<1 \\
& \text { year per cow on farm } \mathrm{i}\end{aligned}$ & 0.32 & 0.31 & 0.36 & 0.35 & 0.29 \\
\hline$e 23_{i}$ & $\begin{aligned}= & \text { Number of young cattle }>1 \\
& \text { year per cow on farm i }\end{aligned}$ & 0.32 & 0.27 & 0.28 & 0.35 & 0.29 \\
\hline$e 24_{i}$ & $\begin{aligned}= & \text { Initial number of cows on } \\
& \text { farm i }\end{aligned}$ & 190 & 130 & 125 & 100 & 260 \\
\hline $\mathrm{e} 25_{i}$ & $=$ Initial ha of land on farm i & 102.5 & 67 & 81.2 & 50 & 125 \\
\hline e26i & $\begin{aligned}= & \text { Max } \mathrm{m} 3 \text { organic waste that } \\
& \text { can be placed on farm }\end{aligned}$ & 4,950 & 3,350 & 4,060 & 2,500 & 6,250 \\
\hline$l_{i}$ & $\begin{aligned}= & \text { Actual labour hours hired on } \\
& \text { farm i }\end{aligned}$ & 2,301 & 793 & 1,119 & 1,183 & 4,849 \\
\hline$\mu_{i}$ & $\begin{aligned}= & \text { Actual } \mathrm{m} 3 \text { organic waste } \\
& \text { processed on farm } \mathrm{i}\end{aligned}$ & 2,917 & 1,916 & 2,000 & 600 & 2,500 \\
\hline$w 10_{i m=1}$ & $\begin{aligned}= & \text { Yearly investment costs } \\
& \mathrm{CMC} \text { in euro }\end{aligned}$ & 2,600 & 1,000 & 7,650 & 7,650 & 3,306 \\
\hline$w 10_{i m=2}$ & $\begin{aligned}= & \text { Yearly investment costs } \\
& \text { Bokashi in euro }\end{aligned}$ & 1,000 & 1,000 & 1,000 & 1,000 & 1,000 \\
\hline
\end{tabular}


Table 3B.2. Exogenous parameters

\begin{tabular}{|c|c|c|c|}
\hline \multicolumn{3}{|c|}{ Variable } & \multirow{2}{*}{$\begin{array}{l}\text { Values in baseline } \\
\text { scenario } \\
35\end{array}$} \\
\hline p1 & $=$ & Output price per $100 \mathrm{~kg}$ milk in euro & \\
\hline$w 1$ & $=$ & Maintenance costs per cow in euro & 432 \\
\hline w2 & $=$ & Maintenance cost per young cattle $<1$ year in euro & $432 \times 0.19$ \\
\hline$w 3$ & $=$ & Maintenance costs per young cattle $>1$ year & $432^{*} 0.19$ \\
\hline w4 & $=$ & Costs in euro per KVEM bought & 0.14 \\
\hline w5 & $=$ & Costs of maintaining a ha of grass in euro & 1,440 \\
\hline w6 & $=$ & Costs of growing a ha maize in euro & 1,540 \\
\hline w7 & $=$ & costs of removing $\mathrm{P}_{2} \mathrm{O}_{5}$ in euro per $\mathrm{kg}$ & 11.78 \\
\hline$w 8_{1}$ & $=$ & Costs of processing $\mathrm{m} 3$ organic waste $\mathrm{CMC}$ in euro $/ \mathrm{m} 3$ & 5 \\
\hline$w 8_{2}$ & $=$ & Costs of processing $\mathrm{m} 3$ organic waste Bokashi in euro $/ \mathrm{m} 3$ & 6.5 \\
\hline w9 & $=$ & Costs of hired labour in euro per hour & 33 \\
\hline e3 & $=$ & KVEM needed per cow & 7197.8 \\
\hline e4 & $=$ & KVEM needed per young cattle $<1$ year & 1277,5 \\
\hline e5 & $=$ & KVEM needed per young cattle $>1$ year & 2555 \\
\hline e6 & $=$ & KVEM produced on a ha of grassland & 11220 \\
\hline e7 & $=$ & KVEM produced on a ha of maize land & 13720 \\
\hline e8 & $=$ & $\mathrm{Kg} \mathrm{P}_{2} \mathrm{O}_{5}$ per KVEM from grass & 0.01 \\
\hline e9 & $=$ & $\mathrm{Kg} \mathrm{P}_{2} \mathrm{O}_{5}$ per KVEM from grass & 0.01 \\
\hline e10 & $=$ & $\mathrm{Kg} \mathrm{P}_{2} \mathrm{O}_{5}$ per KVEM from feed bought & 0.012 \\
\hline e11 & $=$ & $\mathrm{Kg} \mathrm{P}_{2} \mathrm{O}_{5}$ bound in $100 \mathrm{~kg}$ milk & 0.222 \\
\hline $\mathrm{e} 12$ & $=$ & $\mathrm{Kg} \mathrm{P}_{2} \mathrm{O}_{5}$ bound in carrying cows & 0.522 \\
\hline e13 & $=$ & $\mathrm{Kg} \mathrm{P}_{2} \mathrm{O}_{5}$ bound in growth cattle $<1$ year & 4.619 \\
\hline e14 & $=$ & $\mathrm{Kg} \mathrm{P}_{2} \mathrm{O}_{5}$ bound in growth cattle $>1$ year & 4.078 \\
\hline e15 & $=$ & $\mathrm{Kg} \mathrm{P}_{2} \mathrm{O}_{5}$ allowed per ha grass land & 95 \\
\hline e16 & $=$ & $\mathrm{Kg} \mathrm{P}_{2} \mathrm{O}_{5}$ allowed per ha maize & 65 \\
\hline e17 & $=$ & Labour hours needed per cow & 19.6 \\
\hline e18 & $=$ & Labour hours needed per ha grassland & 7.2 \\
\hline e19 & $=$ & Labour hours needed per ha of maize land & 7.0 \\
\hline $\mathrm{e} 20_{1}$ & $=$ & Labour hours needed per $\mathrm{m} 3$ organic waste CMC & 0.08 \\
\hline $\mathrm{e} 2 \mathrm{O}_{2}$ & $=$ & Labour hours needed per m3 organic waste Bokashi & 0.024 \\
\hline $\mathrm{e} 21_{1}$ & $=$ & Maximum $\mathrm{m} 3$ organic waste for CMC per ha & 50 \\
\hline $\mathrm{e} 21_{2}$ & $=$ & Maximum $\mathrm{m} 3$ organic waste for Bokashi per ha & 40 \\
\hline
\end{tabular}




\section{APPENDIX 3C. SENSITIVITY ANALYSIS}

Three important parameters that influence the decisions of the farmers in our model are the wage, the milk price and the price received for processing organic waste. In this sensitivity analysis we show how the optimal decisions of the farmers change with these prices.

\section{Changing wage}

We change the hired labour costs from minus $50 \%$ to plus 50 percent and observe the effect on the farmers decision with respect to the selection of processing organic waste or not. Changing the wage within this range does not change the farmer decisions.

If the price for hired labour becomes too high to hire labour, less milk will be produced and more of the own labour will be used for producing CMC.

\section{Changing milk price}

We change the milk price from minus 50 percent to plus 50 percent and observe the farmers' decisions whether or not to produce organic waste.

The optimal decision to use CMC or not does not change for the farms when the milk price changes within this range, but if the price more than $-40 \%$ farm 2 will exit farming and if the price drops more than 50\% farm 3 will exit because the farms are no longer able to earn the subsistence income in those cases.

\section{Changing organic waste price}

We do not observe a change in the optimal decision to process organic waste or not when organic waste prices are changed from minus $50 \%$ to plus $50 \%$. Even though processing organic waste is costly to the farmers, they appreciate the environmental sustainability aspect and take this into account when maximizing their utility. Farmer 2 does not care about environmental sustainability and does not chose to process organic waste not even when the organic waste price is 50 percent higher. 
APPENDIX 3D. WEIGHTS FOR PROFIT, SUSTAINABILITY AND LABOUR

Table 3D.1. Weights for profit sustainability and labour in the first model run

\begin{tabular}{|c|c|c|c|}
\hline Farm & Weight profit & Weight sustainability & Weight labour \\
\hline Farm1 & 0.12 & 0.59 & 0.29 \\
\hline Farm2 & 0.39 & 0.03 & 0.58 \\
\hline Farm3 & 0.38 & 0.03 & 0.59 \\
\hline Farm4 & 0.40 & 0.03 & 0.57 \\
\hline Farm5 & 0.42 & 0.03 & 0.56 \\
\hline Farm6 & 0.39 & 0.03 & 0.59 \\
\hline Farm7 & 0.41 & 0.03 & 0.56 \\
\hline Farm8 & 0.40 & 0.02 & 0.57 \\
\hline Farm9 & 0.41 & 0.03 & 0.56 \\
\hline Farm10 & 0.41 & 0.03 & 0.56 \\
\hline Farm11 & 0.42 & 0.03 & 0.55 \\
\hline Farm12 & 0.41 & 0.04 & 0.55 \\
\hline Farm13 & 0.40 & 0.03 & 0.57 \\
\hline Farm 14 & 0.42 & 0.03 & 0.55 \\
\hline Farm15 & 0.43 & 0.03 & 0.54 \\
\hline Farm16 & 0.42 & 0.03 & 0.55 \\
\hline Farm17 & 0.40 & 0.03 & 0.57 \\
\hline Farm18 & 0.38 & 0.03 & 0.59 \\
\hline Farm19 & 0.42 & 0.03 & 0.56 \\
\hline Farm20 & 0.41 & 0.03 & 0.56 \\
\hline Farm 21 & 0.72 & 0.00 & 0.29 \\
\hline Farm22 & 0.77 & 0.00 & 0.23 \\
\hline Farm23 & 0.77 & 0.00 & 0.23 \\
\hline Farm 24 & 0.67 & 0.00 & 0.33 \\
\hline Farm25 & 0.68 & 0.00 & 0.32 \\
\hline Farm26 & 0.74 & 0.00 & 0.26 \\
\hline Farm 27 & 0.73 & 0.00 & 0.27 \\
\hline Farm28 & 0.72 & 0.00 & 0.28 \\
\hline Farm29 & 0.65 & 0.00 & 0.35 \\
\hline Farm30 & 0.72 & 0.00 & 0.28 \\
\hline Farm31 & 0.65 & 0.00 & 0.35 \\
\hline Farm32 & 0.66 & 0.00 & 0.34 \\
\hline Farm33 & 0.72 & 0.00 & 0.28 \\
\hline Farm34 & 0.78 & 0.00 & 0.22 \\
\hline Farm35 & 0.79 & 0.00 & 0.21 \\
\hline
\end{tabular}


Table 3D.1. Weights for profit sustainability and labour in the first model run (continued)

\begin{tabular}{|c|c|c|c|}
\hline Farm & Weight profit & Weight sustainability & Weight labour \\
\hline Farm36 & 0.71 & 0.00 & 0.29 \\
\hline Farm37 & 0.74 & 0.00 & 0.26 \\
\hline Farm38 & 0.70 & 0.00 & 0.30 \\
\hline Farm39 & 0.68 & 0.00 & 0.32 \\
\hline Farm 40 & 0.77 & 0.00 & 0.23 \\
\hline Farm41 & 0.51 & 0.49 & 0.00 \\
\hline Farm42 & 0.77 & 0.02 & 0.21 \\
\hline Farm43 & 0.73 & 0.03 & 0.25 \\
\hline Farm44 & 0.74 & 0.03 & 0.23 \\
\hline Farm45 & 0.74 & 0.03 & 0.23 \\
\hline Farm46 & 0.78 & 0.03 & 0.19 \\
\hline Farm47 & 0.78 & 0.02 & 0.20 \\
\hline Farm 48 & 0.74 & 0.02 & 0.23 \\
\hline Farm49 & 0.71 & 0.03 & 0.26 \\
\hline Farm 50 & 0.77 & 0.02 & 0.21 \\
\hline Farm51 & 0.71 & 0.02 & 0.26 \\
\hline Farm52 & 0.72 & 0.02 & 0.25 \\
\hline Farm53 & 0.77 & 0.02 & 0.20 \\
\hline Farm54 & 0.72 & 0.02 & 0.25 \\
\hline Farm55 & 0.75 & 0.02 & 0.23 \\
\hline Farm56 & 0.75 & 0.03 & 0.22 \\
\hline Farm57 & 0.74 & 0.02 & 0.24 \\
\hline Farm58 & 0.70 & 0.03 & 0.28 \\
\hline Farm59 & 0.73 & 0.02 & 0.25 \\
\hline Farm60 & 0.71 & 0.02 & 0.27 \\
\hline Farm61 & 0.76 & 0.24 & 0.00 \\
\hline Farm62 & 0.85 & 0.01 & 0.14 \\
\hline Farm63 & 0.91 & 0.01 & 0.07 \\
\hline Farm64 & 0.91 & 0.01 & 0.08 \\
\hline Farm65 & 0.83 & 0.01 & 0.16 \\
\hline Farm66 & 0.84 & 0.01 & 0.15 \\
\hline Farm67 & 0.91 & 0.01 & 0.08 \\
\hline Farm68 & 0.88 & 0.01 & 0.11 \\
\hline Farm69 & 0.87 & 0.01 & 0.12 \\
\hline
\end{tabular}


Table 3D.1. Weights for profit sustainability and labour in the first model run (continued)

\begin{tabular}{|c|c|c|c|}
\hline Farm & Weight profit & Weight sustainability & Weight labour \\
\hline Farm70 & 0.89 & 0.01 & 0.10 \\
\hline Farm71 & 0.88 & 0.01 & 0.11 \\
\hline Farm72 & 0.89 & 0.01 & 0.10 \\
\hline Farm73 & 0.94 & 0.01 & 0.05 \\
\hline Farm74 & 0.86 & 0.01 & 0.13 \\
\hline Farm75 & 0.91 & 0.01 & 0.07 \\
\hline Farm76 & 0.87 & 0.01 & 0.12 \\
\hline Farm77 & 0.85 & 0.01 & 0.14 \\
\hline Farm78 & 0.79 & 0.01 & 0.20 \\
\hline Farm79 & 0.90 & 0.01 & 0.09 \\
\hline Farm80 & 0.89 & 0.01 & 0.10 \\
\hline Farm81 & 0.69 & 0.31 & 0.00 \\
\hline Farm82 & 0.85 & 0.02 & 0.13 \\
\hline Farm83 & 0.88 & 0.01 & 0.11 \\
\hline Farm84 & 0.82 & 0.01 & 0.16 \\
\hline Farm85 & 0.85 & 0.02 & 0.13 \\
\hline Farm86 & 0.83 & 0.01 & 0.15 \\
\hline Farm87 & 0.85 & 0.02 & 0.13 \\
\hline Farm88 & 0.80 & 0.01 & 0.19 \\
\hline Farm89 & 0.87 & 0.02 & 0.11 \\
\hline Farm 90 & 0.79 & 0.02 & 0.20 \\
\hline Farm 91 & 0.81 & 0.02 & 0.17 \\
\hline Farm92 & 0.83 & 0.02 & 0.15 \\
\hline Farm93 & 0.83 & 0.01 & 0.15 \\
\hline Farm 94 & 0.85 & 0.01 & 0.14 \\
\hline Farm95 & 0.85 & 0.01 & 0.14 \\
\hline Farm96 & 0.90 & 0.02 & 0.09 \\
\hline Farm97 & 0.84 & 0.01 & 0.14 \\
\hline Farm98 & 0.79 & 0.02 & 0.20 \\
\hline Farm 99 & 0.87 & 0.02 & 0.12 \\
\hline Farm100 & 0.86 & 0.02 & 0.13 \\
\hline
\end{tabular}




\section{Chapter 4}

Effects on participation and biodiversity of reforming the implementation of agri-environmental schemes in the Netherlands ${ }^{3}$

3 Paper by Groeneveld, A.N., Peerlings, J.H.M., Bakker, M.M., Polman, N.B.P. and Heijman, W.J.M. Submitted to a peer-reviewed journal. 


\section{ABSTRACT}

To prevent further biodiversity loss as a result of intensive agricultural practices, Agri-Environmental Schemes (AES) have been implemented on European farmland. Unfortunately, these AES have not always been effective in terms of biodiversity and farmer participation. In an effort to improve the AES programme the Dutch government switched from an individual application system to a collective application system for AES payments in 2016. The goal of this paper is to analyse how the resilience of the land use system in terms of farmer participation in the AES and biodiversity is affected by the value farmers attach to biodiversity, and whether the shift from an individual to collective AES will affect the resilience of the land use system. We constructed a multi-objective mathematical programming model in which farmers maximise utility. Farmers are linked through their common effect on biodiversity. In the collective application system payments are only available when the biodiversity in the region is above a certain threshold. Simulation results show no difference in farmer participation and biodiversity between the individual application system and the collective application system when biodiversity weights are high. The land use system loses its resilience in terms farmer participation in the AES and biodiversity if we lower the biodiversity weights, this effect is stronger in the collective AES programme. 


\subsection{INTRODUCTION}

Agricultural intensification has resulted in a loss of biodiversity within Europe (Stoate et al., 2001). To prevent further biodiversity loss, Agri-Environmental Schemes (AES) have been implemented on European farmland (van Dijk et al., 2015). AES offer payments to farmers that modify their farming practice to obtain environmental benefits (Kleijn \& Sutherland, 2003). Sufficient farmer participation is vital for achieving the aims of the AES programmes (Lastra-Bravo et al., 2015). Unfortunately, participation of farmers in AES is often low, resulting in inadequate conservation areas and poor biodiversity results (Kuhfuss et al., 2016; Mckenzie et al., 2013; Whittingham, 2007). These disappointing results combined with the high costs of AES schemes (Kleijn \& Sutherland, 2003) have motivated policymakers to try to improve the AES programme.

To this effect the 2014 EU Rural Development Regulation (Regulation (EU) No 1305/2013, Article 28) was introduced, which made it possible to apply for AES as a group, but left the option for individual farm applications as well. The Dutch government took this a step further and changed the implementation of the Dutch AES programme to allow only joint applications by farmer collectives from 2016 onwards. Only if the farmer collective can offer sufficient nature conservation its application will be approved and payment will become available. If the promised nature conservation is not realized, the payment to the collective will be penalized or withdrawn (Ministry of Economic Affairs, 2016). The collective programme is believed to result in a more effective and efficient realisation of nature conservation goals, with lower execution costs, and a higher and more sustainable participation of farmers (Portaal Natuur en Landschap, 2016). However, it is possible that farmers who in first instance receive AES payments, will no longer be able to obtain these payments due to insufficient participation of their neighbours in the collective AES programme. If no payments are available in the AES programme we might encounter a shift towards low farmer participation and a loss of resilience leading to lower biodiversity in the ecological system.

Land use systems can be viewed as a social ecological system, characterised by interactions and feedbacks between socio-economic elements such as farming methods and biophysical components such as biodiversity (Mitchell et al., 2015; Müller et al., 2014; Schouten et al., 2013). Developing policies for land use systems can be challenging because they exhibit many characteristics of a complex system, with nonlinear responses (Chen et al., 2016a). The result is that sometimes the resilience of a system is influenced by a policy measure, while at other times the system shows no response to a policy change at all. Therefore, this complex nature should be taken into account when analysing policy measures 
such as the change in the AES programme. Central elements of complex systems are feedbacks, which should be incorporated in land use models to accomplish integration of the social and biophysical system (Verburg, 2006). In both the individual and collective AES application programme there is a feedback from biodiversity. Biodiversity in the region depends on conservation measures taken by farmers, but the amount of conservation measures taken also depends on the level of biodiversity in the region. This is because farmers attach value to biodiversity and a single farmer will not be able to reach a high biodiversity level on his/her own. In the collective AES programme an additional feedback is introduced via the availability of maintenance payments, whereby the AES payment depends on a sufficient biodiversity level, in contrast to the individual AES programme. A feedback between land use and prices has also been described by Drechsler (2017) who shows how cost feedbacks affect the ecological effectiveness of conservation instruments.

Some farmers are more biodiversity-minded than other farmers. The value farmers attach to biodiversity might have an effect on the resilience of biodiversity in the land use system. The goal of this paper is to analyse how the resilience of the land use system in terms of farmer participation in the AES and biodiversity is affected by the value farmers attach to biodiversity, and whether the shift from an individual to collective application for agri-environmental contracts will affect the resilience of the land use system. We test this for a case study area containing high nature value farmland due to the presence of hedgerows. Biodiversity depends on the farmers' efforts to maintain hedgerows (Boer, 2003), for which AES payments are offered. To measure biodiversity we calculate a biodiversity score, based on three indicator species with different key areas needed to maintain a sustainable population. We incorporate feedback mechanisms in a multi-objective mathematical programming model in which farmers maximise utility and where famers' utility is influenced by the choices made by other farmers. Farmers are linked through their mutual effect on biodiversity and agri-environmental payments.

Section 2 discusses the methods, including our theoretical framework, the case study area, the conceptual model and the mathematical model. Section 3 presents the data and section 4 presents the experimental design. The results are presented in section 5. Section 6 concludes and discusses. 


\subsection{METHODS}

\section{Theoretical framework}

Farmers work with scarce resources (land, labour, inputs), which justifies taking an economic perspective to their decision making. However, although financial incentives play a role in farmer decisions on nature conservation, they do not only apply for AES on the basis of economic profit (van Dijk et al., 2015; Lokhorst et al., 2011). Farmer willingness to support biodiversity and farmer interactions also influence conservation choices and behaviour (Runhaar et al., 2017). Therefore, we apply a mathematical programming model containing a multi-criteria decision making (MCDM) principle, in which multiple conflicting objectives can be combined (Calker et al., 2006). Farmer decisions depend on several weighted farmer objectives in a utility maximization framework. This allows us to step outside the traditional reductionist economic approaches in which farmer choices are purely based on the profit maximization paradigm, but still model a rational-decisionmaking process (Jongeneel, Polman \& Slangen, 2008). Since the change from the individual to collective AES programme is a new policy measure, data on this change are not yet available. This makes an econometric analysis problematic. By using a mathematical programming model we can simulate the change without the need for time-series data.

\section{Case study area}

The study area Noordelijke Friese Wouden (NFW) is situated in the province of Friesland, in the northern part of the Netherlands. The NFW is a 25,000 ha rural area specialized in dairy farming with some villages in between, where farming parcels are separated by hedgerows of alder belts and wooded banks (Oosterveld, 2013; van der Ploeg, Strijker \& Hoofwijk, 2010). Alder belts are rows of trees next to ditches, mostly alder trees, while wooded banks exist of a sand ridge that is overgrown by trees, bushes and herbs (Oosterveld, 2013). Hedgerows offer home and refuge to many species that are threatened by intensive agricultural practices (Besnard \& Secondi, 2014). The hedgerows stem from the time before barbed wire was introduced, and served to prevent livestock from roaming. Given its historical value the NFW is a national park (Oosterveld, 2013). Because of the cultural and biodiversity value of this landscape the farmers in this area are offered AES payments of 0.3 euro per $\mathrm{m}^{2}$ to maintain their hedgerows. If a farmer does not join the AES (s)he is free not to maintain his hedgerows, but (s)he is not allowed to remove the trees. Within this area the farmer collective of the NFW plays an important role in nature and landscape conservation. The NFW submits a proposal for nature conservation to the Dutch government and is responsible 
for the implementation of these plans. This collective has around 800 members in several municipalities spread over an area of 53,551 hectares. The area covered by the collective contains $971 \mathrm{~km}$ alder belts and 103 hectares of wooded banks (Noordelijke Friese Wouden, 2017). An average parcel in our sample will have four neighbours and $285 \mathrm{~m}^{2}$ hedgerows. An average farm in our sample contains 0.91 ha of hedgerows and has 144 neighbouring parcels. The total amount of hedgerows in our sample is 8.19 ha.

\section{Conceptual model}

Our model describes a landscape made up of nine individual farmers and 288 parcels. Farmers decide on the maintenance of hedgerows on their own farming parcels. It is possible for the farmers in our model to maintain only part of the hedgerows on the farm. Although each farmer maximizes his/her own utility, farmers are connected through their mutual effect on biodiversity and the availability of AES payments.

The farmer-decision module describes a typical farm in the area: a dairy farm with hedgerows, eligible for financial support from the AES program. These hedgerows are located on the farms parcels, and contribute to the biodiversity level in the region provided they are maintained. Properly maintaining hedgerows entails some yearly work like checking and some bigger work like pruning or cutting down trees every few years. In practice, farmers tend to alternate the large maintenance work for different hedgerows, ensuring that only a part of the hedgerows needs major maintenance every year. Therefore, the model considers just the average amount of work needed every year for maintaining hedgerows. Well-maintained hedgerows take up space and create shade resulting in a lower grass or maize production. Although most farmers that are not in the AES scheme do some maintenance work, we assumed that farmers who will not properly maintain their hedgerows have negligible maintenance costs, area reduction, and shade effects.

Farmers strive for maximizing their utility. Utility depends on several weighted farmer objectives which are captured by an additive utility function. Farmer objectives and weights have been determined during interviews. We grouped the objectives into the following categories: profit maximization, labour minimization, risk minimization and biodiversity maximization. Profit equals the sum of revenues from milk, revenue from selling cows, and AES payments minus costs of farming and costs of hedgerow maintenance. Labour equals the sum of the labour needed for each of the farm tasks. We measured price risk as the variance in milk prices (see e.g. Berentsen, Kovacs \& van Asseldonk., 2012; Kaiser and Messer, 2011; Schmit, Boisvert \& Tauer, 2001). If a farmer attaches a value to 
the risk minimization objective, (s)he will be risk averse. We assume there is no price risk to the AES programme, once the contract is agreed, as contracts are concluded for a period of 6 years. Biodiversity is measured by a biodiversity score, depending on three indicator species (see also the next section on measuring resilience).

There are two feedbacks in our model, as illustrated in Figure 4.1. The feedback through biodiversity takes place in both the individual and the collective AES programme: The overall biodiversity level in the region has an effect on the individual farmer's decision (arrow 1); the individual farmer's decision determines the amount of hedgerows maintained on the farm (arrow 2); which influences the overall biodiversity level (arrow 3). The payment feedback takes place only in the collective AES programme: The availability of AES payments depends on sufficient overall biodiversity in the region (arrow 4); the individual farmer's decision depends on the availability of payment (arrow 5); the individual farmer's decision determines the amount of hedgerows maintained on the farm (arrow 2); which has an effect on the overall biodiversity (arrow 3).

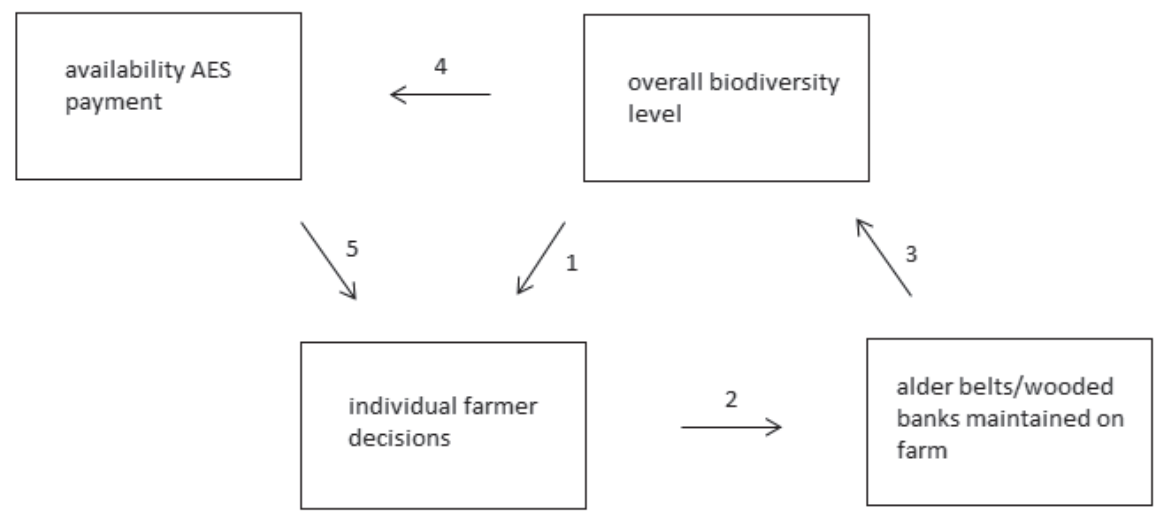

Figure 4.1. Schematic representation of the biodiversity feedback (arrow 1, 2, 3) and payment feedback (arrow 4, 5, 2, 3) in the model

\section{Measuring resilience}

To determine the resilience of the hedgerow landscape we analyse how the farmer participation in the AES scheme and the biodiversity score in the region depend on the level of the biodiversity weights and the AES programme. 


\section{Farmer participation in the AES}

Farmer participation is measured as the number of farmers that maintain hedgerows. We hereby assumed that each farmer maintaining hedgerows does so within the AES scheme.

\section{Biodiversity}

Biodiversity is a broad concept, and can include numerous animal and plant species. For the purpose of this paper we selected a number of key species characterised by their key area and dispersion capacity, which together represent the biodiversity in the NFW. The minimum or key area of a species is the total amount of habitat area that is needed to maintain a sustainable population of that species (Reijnen et al, 2007). The dispersion capacity of an organism refers to the extent to which it is able to move from one habitat patch to another (Reijnen et al., 2001). All maintained hedgerows that are within a distance equal to the dispersion capacity are added to calculate the key area. Key areas and dispersion capacity have also been used to analyse and measure biodiversity by e.g. Grashof-Bokdam et al. (2009), Reijnen et al., (2001), Reijnen et al., (2007), Elands et al. (2005) and Kwakernaak, de Lange \& Hartgers (2015).

False oat-grass (Arrhenatherum elatius) is a plant species that occurs in the hedgerow landscape in the NFW (expert judgement and Floron, 2017). It has a key area of $1000 \mathrm{~m}^{2}$ and a dispersion capacity of $100 \mathrm{~m}$, and is therewith an example of a species for which the biodiversity is dependent on a small scale key area. The key area indicates that a sustainable population could not survive on the hedgerows of a single parcel. However, the dispersion capacity suggests that the species could reach the hedgerows on the neighbouring parcels. On average the amount of hedgerows on a parcel plus its neighbouring parcels is sufficient to support a sustainable population of this species when these hedgerows are maintained.

The purple hairstreak (Favonius quercus) is a butterfly that occurs in wooded banks (Vlindernet, 2017). The key area of this species is 5 ha and the dispersion capacity is $100 \mathrm{~m}$, and is therewith an example of a species with a medium scale key area. The key area needed for this species cannot be provided on one farm; however the amount of hedgerows on the farm plus its neighbouring parcels is sufficient to support a sustainable population of this species when these hedgerows are maintained.

The Large-flowered Hemp-nettle (Galeopsis speciosa) is a plant species that occurs in the hedgerow landscape (expert judgement and Dijkstra, 2017). The key area of this species is $10 \mathrm{ha}$, and is therewith an example of a species with a large scale key area. All the hedgerows in the region need to be maintained to support a sustainable population of this species. 
In our case study the key area of a small scale species matches the average size of a parcel plus it's neighbouring parcels, the key area for a medium scale species matches the average size of a farm plus its neighbouring parcels, and the key area of a large scale species matches the size of the whole region. However, it is possible that only part of the hedgerows in the key area is maintained. To calculate the effect on biodiversity of maintaining only part of the hedgerows in the key area we use a logistic function. This function is specified in such a way that it implies that when the maintained amount of hedgerows is low, the score is close to zero and when a certain threshold is passed the score is close to one. A logistic function was also used by (Natuhara \& Imai, 1999) to predict species richness by environmental variables such as habitat area.

\section{Mathematical model}

In this section we present the general structure of our mathematical model. The exact equations and restrictions are presented in appendix A.

Each farmer maximizes utility as defined in equation 1, subject to the constraints presented in equations $1 \mathrm{a}-1 \mathrm{c}$.

maximize $U=\sum_{n=1}^{N} g_{n} O_{n}\left(r_{1}, \ldots, r_{Z}\right)$

Subject to:

$\sum_{z=1}^{Z} a_{z k} r_{z} \leq b_{k} \quad \forall_{k} \quad\left[\pi_{k}\right]$

$\sum_{z=1}^{Z} c_{z l} r_{z}=d_{l} \quad \forall_{l}$

$r_{z} \geq 0$

Where:

$U$ is utility; $g_{n}$ is the weight attached to objective n; $o_{n}\left(r_{z}\right)$ is the normalized value of objective $\mathrm{n}$ depending on activity level $z ; r_{z}$ is the level of activity $z, b_{k}$ is the total availability of a resource $\mathrm{k} ; a_{z k}$ is the quantity of resource $\mathrm{k}$ demanded by activity $z ; \pi_{k}$ is the shadow price of resource $\mathrm{k} ; d_{l}$ is the total available quantity of resource $1 ; c_{z l}$ is the quantity of resource 1 demanded by activity $z$.

The way we define the objectives is presented in equations 2-5.

$$
\begin{aligned}
O_{1} & =\sum_{j=1}^{J} p_{j} y_{j}-\sum_{m=1}^{M} w_{m} x_{m}+\left(p_{o}-w_{o}\right) y_{o}-w_{L}(L R-L I) \\
O_{2} & =L R \\
O_{3} & =e v_{1} y_{1}^{2} \\
O_{4} & =\frac{\sum_{b=1}^{b \mu_{b}}}{3}
\end{aligned}
$$


Subject to:

$T\left(\boldsymbol{y}, \boldsymbol{x}, y_{o}, L R\right)$

$\boldsymbol{p}, \boldsymbol{w}, p_{o}, w_{o}, w_{L}>0$

Where:

$O_{l}$ profit; $p_{j}$ price of regular output $j ; y_{j}$ quantity of regular output $\mathrm{j} ; w_{m}$ price of input $\mathrm{m} ; x_{m}$ quantity of input $\mathrm{m} ; p_{o}$ AES payment hedgerows; $w_{o}$ cost of maintaining hedgerows; $y_{o}$ quantity of hedgerows maintained; $w_{L}$ costs of hired labour; $O_{2}$ quantity labour used on the farm; $L R$ labour required in the production process; $L I$ initial labour endowment; $O_{3}$ risk taken by the farmer; $e$ risk aversion coefficient; $v_{l}$ variance milk price; $y_{1}$ amount of milk produced; $O_{4}$ overall biodiversity score; $\mu_{1}$ small scale biodiversity score; $\mu_{2}$ medium scale biodiversity score; $\mu_{3}$ large scale biodiversity score; $T\left(\boldsymbol{y}, \boldsymbol{x}, y_{o}, L\right)$ technology set; $\boldsymbol{y}, \boldsymbol{x}$ vector of outputs and variable inputs respectively; $\boldsymbol{p}, \boldsymbol{w}$ vector of output and input prices respectively.

We calculate a biodiversity score using a logistic function. The advantage of a logistic function is that despite the abrupt switch we still have a continuous function which makes solving the model feasible. Equations 6 and 7 show how we calculated the biodiversity scores:

$\mu_{b}=\frac{1}{1+e^{-z}} \quad b=1,2,3$

$z \stackrel{\text { and }}{=} \alpha * \frac{y_{o b}}{y_{o b}{ }^{*}}-\beta$

Where:

$\mu_{b}$ is the biodiversity score of biodiversity type $\mathrm{b} ; y_{o b}$ is the amount of maintained hedgerows that contributes to biodiversity type $\mathrm{b} ; y_{o b}{ }^{*}$ is the maximum amount of hedgerows that contributes to biodiversity type $\mathrm{b}$ and can be maintained, $\alpha$ is the speed parameter and $\beta$ the biodiversity parameter.

By manipulating $\alpha$ we determine the speed at which the biodiversity score switches from close to 0 to close to 1 , the higher $\alpha$ the faster. We select here arbitrarily 30 implying a fast transition. By manipulating $\beta$ we can determine where the switch takes place. For example, with a biodiversity parameter $\beta$ equal to $\underline{y_{\dot{o} b}}$ the biodiversity score will drop rapidly to a value close to zero for a ratio $\frac{y_{o b}{ }^{*}}{y^{*}}$ smaller than 0.8 . With a higher ratio $\frac{y_{o b}}{y_{o b}{ }^{*}}$ the biodiversity score lies between 0.8 and 1. So, a higher biodiversity parameter implies that the switch occurs at higher ratios and with a lower parameter the switch takes place at lower ratios. Figure 4.2. shows how the biodiversity score differs depending on $\alpha$ and the $\frac{y_{o b}}{y_{o b}{ }^{*}}$ ratio. Figure 4.3. shows how the biodiversity score differs depending on $\beta$ and the $\frac{y_{o b}}{y_{o b}{ }^{*}}$ ratio. 


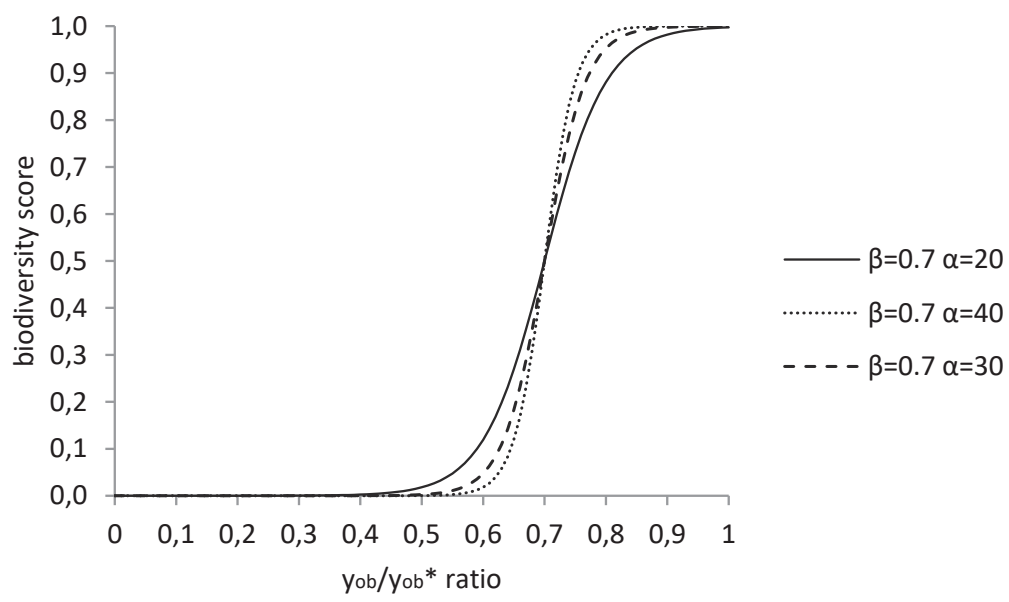

Figure 4.2. Biodiversity score depending on $\alpha$ and $\frac{y_{o b}}{y_{o b}{ }^{*}}$ ratio

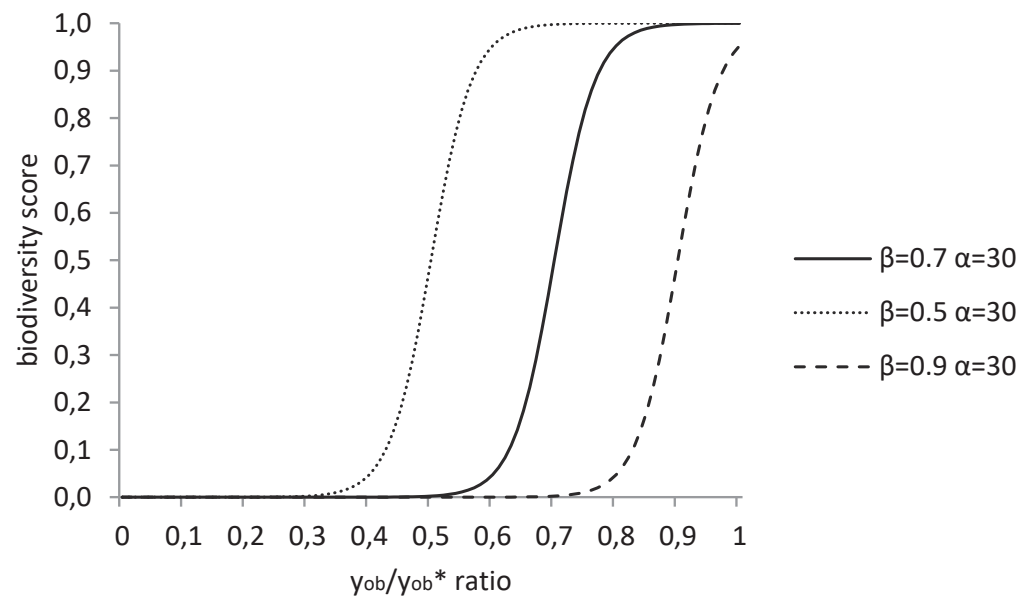

Figure 4.3. Biodiversity score depending on $\beta$ and $\frac{y_{o b}}{y_{o b}{ }^{*}}$ ratio

The biodiversity scores were determined for the species with small scale, medium scale and large scale key areas. An average of these scores was taken to calculate the overall biodiversity score as shown in equation 8. Equation 9 shows how the availability of payments in the collective AES depends on the achieved biodiversity level:

Overall biodiversity score $=\frac{\sum_{b=1}^{3} \mu_{b}}{3}$ 
If $\frac{\sum_{b=1}^{3} \mu_{b}}{3}>b t \quad$ AES payment is available

If $\frac{\sum_{b=1}^{3} \mu_{b}}{3} \leq b t \quad$ AES payment is not available

Where $b t$ is the biodiversity threshold.

As long as the biodiversity score remains close to one if there is a change in biodiversity weights or AES application system we say that the system is resilient to the change. However, if the biodiversity score drops below the threshold the biodiversity score will be close to zero and the system is no longer resilient in terms of biodiversity.

\subsection{DATA}

\section{Available data}

The model requires general farm data which is largely unavailable. Therefore we used data for the average Dutch farm that were available from different sources (Blanken et al., 2016; Meetjesland, 2016; Remmelink et al., 2016; RVO, 2010; Wageningen UR, 2015) for the following variables: costs of feed bought; costs of removing phosphate surpluses; costs of maintaining cattle; amount of feed produced on grassland; amount of feed produced on arable land (fodder maize); limits for phosphate application on grassland and maize land; milk price; labour costs; percentage cows to be replaced; price of new cows; price of slaughter cows; variance of the milk price; feed requirements per cow, cattle younger than one year and cattle between one and two years; phosphate content of grass, maize, feed bought, bound in milk, bound in carrying cows and bound in young cattle; labour hours needed for cultivating maize or grass; costs of cultivating silage maize and grass.

\section{Data collection}

Farm-specific information was collected from in-depth interviews with nine farmers in the NFW. The sample was selected by the farmer collective in the NFW, who ensured that both farmers with positive, negative, and neutral attitudes concerning AES were included. All of the farmers in the sample had hedgerows on their land, but not all participated in the AES scheme and maintained their hedgerows accordingly. An overview of the income, maintenance, and payments 
received for each farmer is presented in Table 4.1. The farmer income has to be shared by all family members that work on the farm.

Table 4.1. Income, maintenance and payments per farmer

\begin{tabular}{lllllll}
\hline Farmer & $\begin{array}{l}\text { Number of } \\
\text { parcels }\end{array}$ & $\begin{array}{l}\text { Total } \mathbf{m}^{2} \\
\text { hedgerows }\end{array}$ & $\begin{array}{l}\mathbf{M}^{2} \\
\text { hedgerows } \\
\text { maintained }\end{array}$ & $\begin{array}{l}\text { Income } \\
\text { farmer in } \\
\text { euro }\end{array}$ & $\begin{array}{l}\text { AES } \\
\text { payments } \\
\text { received }(\boldsymbol{\epsilon})\end{array}$ & $\begin{array}{l}\text { Share of } \\
\text { payments } \\
\text { in income }\end{array}$ \\
\hline 1 & 15 & 2335 & 0 & 82676 & 0 & 0.00 \\
2 & 92 & 33152 & 33152 & 228710 & 9946 & 0.04 \\
3 & 7 & 1988 & 784 & 96289 & 235 & 0.00 \\
4 & 22 & 7517 & 7517 & 98022 & 2255 & 0.02 \\
5 & 25 & 12920 & 12920 & 156870 & 3876 & 0.02 \\
6 & 21 & 10273 & 0 & 60060 & 0 & 0.00 \\
7 & 14 & 5086 & 0 & 89732 & 0 & 0.00 \\
8 & 38 & 800 & 0 & 205687 & 0 & 0.00 \\
9 & 54 & 7917 & 7273 & 66800 & 2182 & 0.03 \\
Total & 288 & 81988 & 61646 & 1084846 & 18494 & \\
\hline
\end{tabular}

We asked each farmer about his/her farming objectives and their relative importance. In addition, facts concerning the type of farm, whether or not the farm was certified as organic, the number of cows and young cattle, the amount of milk produced on the farm, the amount of land, the different crops, the labour hours worked on farm, the amount of hedgerows, the location hedgerows, and the maintenance of hedgerows were collected. Moreover, for all farms we had a map showing the exact size and location of all their parcels. Out of the nine farmers one farmer no longer had dairy cows, but still owned and maintained his/her land. For this farmer we took the average milk production per cow and the average number of dairy cows in the region, since we assumed every farmer needed to be able to earn a subsistence income. We realise our small sample may not be representative of the whole region. However, it allows us to show how a small sample such as this can be used to create an artificial region which is suitable for running model simulations. In this way we are able to capture the mechanisms that are important in the collective AES programme. In theory more farmers could be included in our model, but this would make solving the model more complex. To see how the farmers that we included compare to the general farming population in the Netherlands and in the province of Friesland we offer a comparison on the number of cows, the milk production and the amount of land in Table 4.2. The averages are reported for 2016. 
Table 4.2. Number of cows, milk production and land in sample and on average (CBS, 2017b; CRV, 2016)

\begin{tabular}{llll}
\hline & Number of cows & $\begin{array}{l}\text { Milk production per } \\
\text { cow }\end{array}$ & Ha of land on farm \\
\hline Sample NFW & 129 & 8243 & 77 \\
The Netherlands & 97 & 8500 & 52 \\
Friesland & 114 & 8500 & 66 \\
\hline
\end{tabular}

\section{Data reconstruction}

The farmers we interviewed were all located within the NFW. Their parcels are distributed over the NFW, mixed with parcels of other farmers. For simulating biodiversity, however, we needed a contiguous area, so we created an artificial region containing only these nine farms and their 288 parcels. For each individual farm we have a map showing its parcels of land, and how these parcels are located relative to each other. We used this information to create an artificial region, with the 288 parcels that belong to the nine individual farmers. Since there is no reason to assume a specific spatial configuration, we calculated for each parcel $\mathrm{k}$ the probability that it neighboured parcel $\mathrm{j}$ of farm $\mathrm{i}$ in the sample. For the parcels $\mathrm{k}$ that belong to the same farm as parcel $\mathrm{j}$ this probability is either 1 or 0 as we know their exact location relative to parcel j. For the parcels $k$ that belong to the other farms we calculated the probability by determining the number of potential neighbours. For example, imagine parcel 1 of farm a has 3 unknown neighbours and parcel 4 of farm b has two unknown neighbours. Parcel 4 could then be located at any of the 3 unknown sides of parcel 1 with either of its two unknown sides. Furthermore, assume that in this example in total all the parcels not belonging to farm a have 100 unknown neighbours. Then parcel 4 of farm $b$ has a probability of $\frac{1}{100} \times 3 \times 2=\frac{6}{100}$ to neighbour parcel 1 of farm 1 . We used the probabilities to calculate an expected amount of maintained hedgerows by multiplying the probability with the amount of hedgerows on each potentially neighbouring parcel and the parcel itself. One should note here that the effect of maintaining hedgerows on a single parcel on biodiversity is less extreme when one considers expected amounts. By multiplying the probability that each parcel is a neighbour times the amount of maintained hedgerows we take some kind of average over all the parcels that could potentially be a neighbour, thereby smoothening the effect of maintaining the hedgerows on a single parcel. 


\subsection{EXPERIMENTAL DESIGN}

We ran the model for 10 time steps in order to reach a stable outcome, for two policy scenario and various settings of biodiversity weights. It is important to notice here that time steps do not refer to specific time units, but to the time needed for the famers to respond to each other's actions in the previous time step. The response time is dependent on how long it takes for the farmer to determine the actions of other farmers, either by observing the effects (this could be months) or by gathering information during the interaction with other farmers or the farmer collective (this could be days). When making a decision, the farmer takes the actions of the other farmers in the previous time step as given. In the first time step the actions of the other farmers are as indicated during the interviews. A sensitivity analysis of our results can be found in appendix B.

\subsubsection{Policy scenarios}

\section{Baseline: individual AES Programme}

In this scenario AES payments are available if the farmer properly maintains the hedgerows. The biodiversity feedback (arrow 1, 2, 3 in Figure 4.1.) is in effect, but the payment feedback (arrow 4,5 in Figure 4.1.) is not included. This scenario allows us to determine what the biodiversity and participation in the AES are in the individual AES programme.

\section{Collective AES programme}

In this scenario the first time step is equal to the baseline scenario. In each time step farmers choose whether or not to maintain their hedgerows. The AES payment is only available if the overall biodiversity score in the previous time step exceeds 0.8 (the range for this biodiversity score is $0-1$ ). Both the biodiversity feedback and payment feedback are included. This scenario allows us to determine what happens to biodiversity and participation in AES when the collective AES programme is introduced.

\subsubsection{Biodiversity weights}

During the interviews we asked farmers to indicate the weight they attached to each of the farmer objectives. The farmers in our case study were situated in a landscape that was designated as a national park. Farmers seemed to be very aware of the special quality of the landscape in the NFW. However, it is likely that farmers in other parts of the Netherlands are less biodiversity-minded and have lower biodiversity weights. Therefore, in this model-experiment we consider the effect of the switch from the individual to collective AES programme in a 
situation where farmers attach less value to biodiversity. We consider biodiversity weights that are in the range $0-100 \%$ of the original weight and for each of these weights we run the baseline scenario and the collective AES programme scenario. When we lower the biodiversity weight, we increase the other weights proportionally to assure the weights will add up to one.

\subsection{RESULTS}

\subsubsection{Results policy scenarios}

\section{Baseline Scenario: individual AES Programme}

Figure 4.4 shows the biodiversity scores in each time step of the model for the baseline scenario.

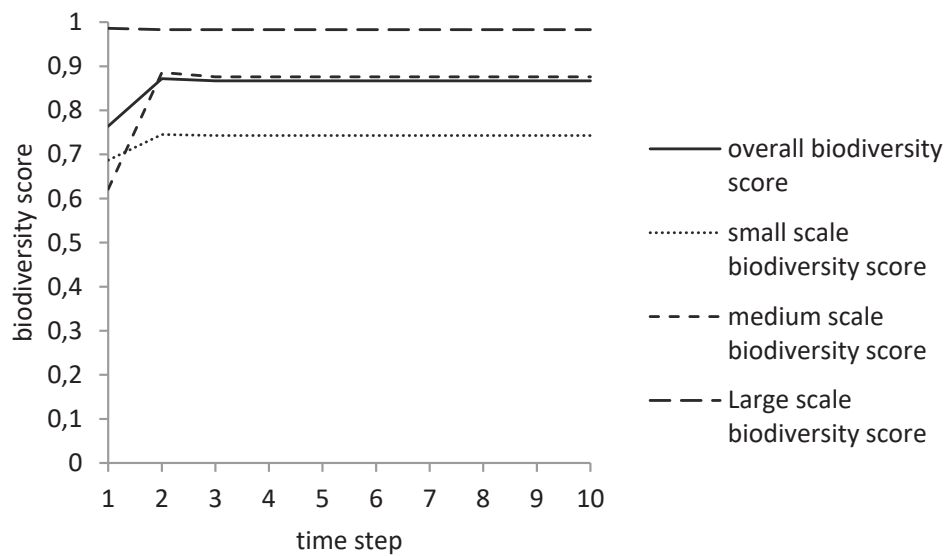

Figure 4.4. Overall, small scale, medium scale and large scale biodiversity scores in the baseline scenario

In the model farmers consider a trade-off. On the one hand, by maintaining hedgerows they obtain AES payments, achieve higher biodiversity, and have a lower price risk. On the other hand, maintaining hedgerows also results in production loss due to the shade of hedgerows and extra labour hours spend on maintenance. Farmers will choose to maintain the amount of hedgerows that will give them the highest utility. In the baseline scenario six farmers participate in the AES maintaining $68,531 \mathrm{~m}^{2}$ of hedgerows. The overall biodiversity score stabilizes at 0.867 . The highest biodiversity score is for large scale biodiversity, the lowest biodiversity score is for small scale biodiversity. 


\section{Collective AES programme}

The results at the end of the model run for the collective programme are the same as the results in the baseline scenario. Biodiversity does not drop below the threshold and the system remains resilient in terms of biodiversity and farmer participation. A difference between farmers' decisions in the baseline scenario and the collective programme can be expected when there is a change in maintenance payment, which will occur if the biodiversity score drops below the threshold. This is apparently not the case here.

\subsubsection{Results model experiments}

\section{Biodiversity weights}

Figure 4.5. shows the number of farmers enrolled in the individual and the collective AES programme for different biodiversity weights. In Figure 4.5. we show the farmer participation in the AES programme for biodiversity weights in the range $0-30 \%$ of the original weight.

If the biodiversity weight is zero, the system is not resilient and only two farmers are maintaining their hedgerows at the onset of the model run. They are not motivated by the biodiversity effects of maintaining these hedgerows but by the profit or low risk that is associated with the AES payments. In the individual AES programme this payment is available in each time step, and thus these two farmers do not change their maintenance during the model run. In the collective AES programme the biodiversity score in the first time step is below the threshold, and the AES payment is not be available in the following time steps of the collective AES programme. Therefore, in the collective programme the number of farmers in the AES will drop to zero. If the biodiversity weight is equal to 10 percent of the original weight, six farmers participate in the AES at the onset of the model run. In the individual programme this does not change over time. However, since the biodiversity score is below the threshold, payments are not available in the collective AES programme and the system loses its resilience. In the second time step two farmers still choose to maintain their hedgerows, because they are not primarily driven by the AES payment but by the perception of biodiversity around them. However, when they notice the low overall biodiversity score due to the low maintenance by the other farmers in the second round they no longer maintain their own hedgerows in the third round, since they will receive a higher utility by not maintaining hedgerows if the overall biodiversity score is very low. If the biodiversity weight is equal to $20 \%$ of the original weight, six farmers participate in the AES at the onset of the model run. The number of farmers in the AES is stable in the individual programme. Since the biodiversity score is below the threshold, no payment is available in the collective AES programme. Therefore, 
the system shows no resilience, and the number of farmers participating in the AES in the collective programme drops, and alternates between three and four farmers that keep responding to each other by maintaining small amounts of hedgerows. When the biodiversity weight is equal to $30-100 \%$ of the original biodiversity weight there are six farmers participating in the AES and we do not see a drop in farmer participation for either the individual or collective AES programme, as both systems are resilient in terms of farmer participation.

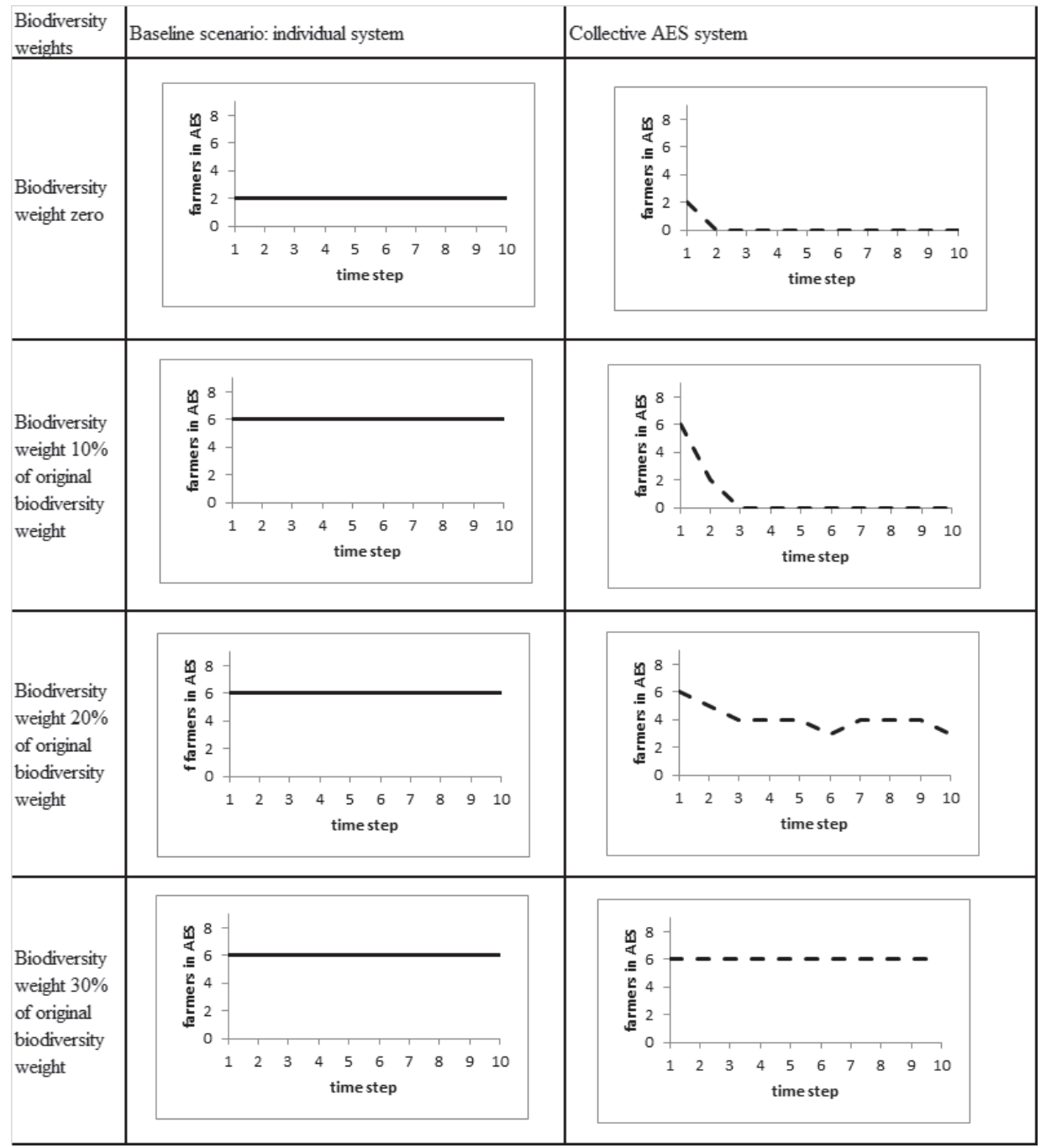

Figure 4.5. Farmer participation in the individual and collective programme depending on biodiversity weights 
Figure 4.6. shows how the overall biodiversity score changes due to the change from the individual AES programme to the collective AES programme.

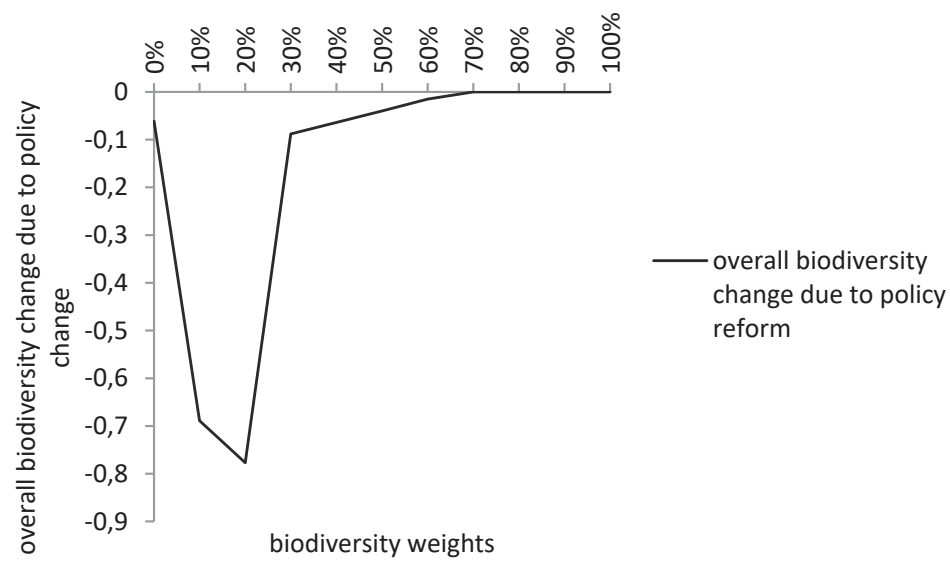

Figure 4.6. Change in overall biodiversity score due to switching from an individual AES programme to a collective AES programme

If the biodiversity weights are zero (thus equal to $0 \%$ of the original biodiversity weights) there is a low biodiversity score in both the individual and collective AES programme. The individual AES programme is slightly more resilient to the change in the biodiversity weight, as the overall biodiversity score is slightly higher. If the biodiversity weights are $10 \%$ or $20 \%$ of the original weight the biodiversity score in the collective AES programme is much lower than the individual AES programme. In this case the change in overall biodiversity score due to the new policy is substantial, and the collective AES programme shows less resilience to changing the biodiversity weights than the individual AES programme. If the biodiversity weights are $30-60 \%$ of the original biodiversity weight farmer participation does not differ between the two AES programmes, but the biodiversity score is slightly lower in the collective AES programme. Thus, in the range $30-60 \%$ of the original biodiversity weight the collective AES programme is slightly less resilient to a change in biodiversity weights than the individual AES programme. In the range $70-100 \%$ of the original biodiversity weight there is no difference in the overall biodiversity score in the individual AES programme and the collective AES programme. 


\subsection{CONCLUSIONS AND DISCUSSION}

The goal of this paper is to analyse how the resilience of the land use system in terms of farmer participation in the AES and biodiversity is affected by the value farmers attach to biodiversity, and whether the shift from an individual to collective application for agri-environmental contracts will affect the resilience of the land use system. Our results show that the individual AES programme is quite resilient to changes in the biodiversity weight, only if the biodiversity weight drops to zero the farmer participation and biodiversity score are low. The collective AES programme is less resilient to changes in the biodiversity weight, especially for situations in which farmers do not value biodiversity very highly. If the biodiversity weight is 20 percent of the original weight or less the biodiversity scores and farmer participation are low.

Thus, although the Dutch policy makers assume that the introduction of the collective AES programme will result in a higher biodiversity level and more farmer participation due to social interaction, in this paper we show that the introduction of the collective AES programme also brings a risk of a collapse of the biodiversity and farmer participation.

Whether or not the system will be resilient to the policy change depends on the level of the biodiversity weights. If farmers have high biodiversity weights, some farmers will maintain their hedgerows even when no payment is available, and no loss of resilience occurs when the collective AES programme is introduced. This finding is in line with research by van Dijk et al. (2016), who found that on-farm nature conservation is only to some extent determined by payments. If biodiversity weights are low, the introduction of the collective AES programme might result in a loss of resilience and a shift towards low farmer participation and biodiversity level.

This shift in the land use system due to a loss of resilience can be explained from the feedbacks in the system. The shift starts due to the payment feedback, where payment is no longer available if the biodiversity score in the region is below a certain threshold. The lack of payments influences farmer decisions which result in a low level of biodiversity in the region. Due to the biodiversity feedback this lower level of biodiversity causes other farmers to stop their maintenance efforts as well. Melman et al. (2016) find that a moderately positive ecological effect for meadow birds is expected due to the collective AES programme. In the light of our results this suggests that no shift towards low farmer participation is to be expected. Melman et al. (2016) did not take the economic efficiency and farmers' support for the collective programme into account. 
The reported results are determined in a model simulation based on a small sample, and caution should be applied when generalizing these results. To place our model in context we provided a comparison against the average number of cows, milk production per cow and amount of land in the Netherlands and in Friesland. On average the farmers in our model have more cows and land, and a lower milk production. The differences are not very large. To provide some validation to our results we showed the results of this research to representatives of the farmer collective, who thought the results were reasonable. The possibility that the collective programme will lead to a lower resilience seems to be supported by findings from the theory on threshold public goods. For example, Dannenberg et al. (2015) found that a negative effect (such as a loss of biodiversity) can occur when a certain contribution threshold needs to be passed to obtain a common benefit and the individual agent cannot pass this threshold on its own. McBride (2006) shows that low farmer participation can prevent the provision of a public good. Luo and Miller (2017) analysed the possibility of starting a biofuel factory, which would only be economically viable once enough farmers participate. They also show that farmer participation can be high in some circumstances but low in others.

Our research shows how a model with information on a small sample of farmers can offer insights in the mechanisms that drive the decision whether or not to participate in the AES programme. We believe this is a valuable contribution, since collecting information on a large sample is often costly and time consuming. It is not just the time and costs sacrificed by the researcher, sample subjects must also be found willing to invest their time in being interviewed. Since our goal is not to show a significant effect, but to explore the impact of the introduction of the collective AES programmes and the associated feedback effects in the case study, this small sample approach seems appropriate.

We realise our model has limitations, we mention four. First, we do not allow the total amount of hedgerows to increase beyond the current amount of maintained plus unmaintained hedgerows in the NFW. This assumption is based on the fact that none of the farmers indicated a willingness to plant more trees, due to the restrictions on removing trees. Second, we use stated farmer objectives, which might differ from the actual weights farmers might apply in their day to day decisions. When a question is asked in a hypothetical way, farmers do not need to take market and personal constraints into account or can be sensitive to the elicitation format used (Azevedo, Herriges \& Kling, 2003; Woldu et al., 2016). Third, biodiversity is measured in quite a crude way. We capture only the effect of maintaining three specific species in small, medium and large key areas and their dispersion capacities. Therefore, our biodiversity scores should be inter- 
preted only as an indication of the effect on biodiversity. Finally, we considered the success of the collective AES programme from the perspective of farmer participation and biodiversity scores. We did not score the collective programme on its performance in other areas, such as the possible cost savings or reduction in monitoring efforts for the Dutch government. Neither did we look at the social influence that might result in the collective programme, which might increase farmer participation.

However, despite the caveats we think this paper contributes to the discussion on the implementation and effects of AES payments for maintaining wildlife and landscapes. We show how the value farmers attach to biodiversity affects the resilience of the land use system and how the switch from an individual to a collective AES programme can have a negative effect on the resilience of the land use system.

\section{Acknowledgements}

I would like to thank the farmer collective of the Noordelijke Friese Wouden for their help, as well as the farmers who were willing to participate in interviews. A special thanks to Rene Jochem, Wieger Wamelink and Carla Grashof for their help and support. This work was supported by the Complex Adaptive Systems program of Wageningen University. 


\section{APPENDIX 4A. GAMS MODEL}

The model describes the behaviour of the dairy farmers in the "Noordelijke Friese Wouden". It is assumed that the farm maximizes utility (A1). Utility equals the sum of the weights the farmer attaches to each of the farmer objectives times the normalized value of each objective. The farmer objectives are profit maximization (A2), labour minimization (A3), risk minimization (A4) and biodiversity maximization (A5). In the model utility is maximized subject to constraints (A2-A35).

Objective:

maximize $U_{i}=\sum_{n=1}^{2} g_{i n} \frac{o_{i n}}{O_{i n}{ }^{*}}-g_{i 3} \frac{o_{i 3}}{O_{i 3}{ }^{*}}-g_{i 4} \frac{o_{i 4}}{O_{i 4}{ }^{*}}$

$n=1, \ldots, 4 ; i=1, \ldots, 9$

Subject to:

$$
\begin{aligned}
& O_{i 1}=p_{1} y_{i 1}+p_{2} x_{i 22}+p_{o} x_{i 7}-\sum_{m=1}^{8} w_{m} x_{i m}-w_{9} O_{i 2}-w_{10} x_{i 24} \\
& m=1, \ldots, 10 \\
& O_{i 2}=L R_{i} \\
& O_{i 3}=v_{1} y_{i 1}^{2} \\
& O_{i 4}=\frac{\sum_{b=1}^{3} \mu_{i b}}{3} \\
& y_{i 1}=x_{i 1} * e_{i 4} \\
& x_{i 4}=\sum_{m=1}^{3} x_{i m} e_{m}-x_{i 11} e_{11}-x_{i 12} e_{12}-x_{i 13} e_{31}-x_{i 14} e_{32} \\
& x_{i 5}=\max \left(0, x_{i 15}-x_{i 16}\right) \\
& x_{i 15}=x_{i 11} e_{11} e_{13}+x_{i 12} e_{12} e_{13}+x_{i 13} e_{31} e_{14}+x_{i 14} e_{32} e_{14}+x_{i 4} e_{15}-x_{i 1} e_{i 4} e_{16}-x_{i 1} e_{17} \\
& x_{i 2} e_{18}-x_{i 3} e_{19} \\
& x_{i 16}=x_{i 8} e_{20}+x_{i 6} e_{21} \\
& L R_{i}=x_{i 1} e_{5}+\sum_{m=6}^{8} x_{i m} e_{m} \\
& x_{i 18}=\sum_{h=1}^{H} e_{h i 22}-e_{i 23} \\
& h=1, \ldots, H \\
& x_{i 18}=x_{i 8}+x_{i 6} \\
& e_{i 23}=x_{i 7}+x_{i 9} \\
& x_{i 8}=x_{i 11}+x_{i 12} \\
& x_{i 6}=x_{i 13}+x_{i 14} \\
& x_{i 12}+x_{i 14}=x_{i 7} * e_{10} \\
& x_{i 7} \leq e_{i 23} \\
& x_{h i 10}=x_{h i 25}+\sum_{a=1}^{A} e_{a} * x_{h a 19} \\
& x_{i n}
\end{aligned}
$$




$$
\begin{aligned}
& a=1, \ldots, A \\
& x_{i 21}=\sum_{h=1}^{H} x_{h i 25}+\sum_{c=1}^{C} e_{c} * x_{h c 20} \\
& c=1, \ldots, C
\end{aligned}
$$

$$
\begin{aligned}
& \mu_{i 1}=\frac{\sum_{h=1}^{H}\left(\frac{1}{\left.\left(1+e^{\left(-\alpha *\left(\left(\frac{x_{h i 10}}{e_{h i 33}}\right)-\beta\right.\right.}\right)\right)}\right)}{)} / e_{i 35} \\
& \mu_{i 2}=\frac{1}{\left(1+e^{\left(-\alpha *\left(\left(\frac{x_{i 21}}{e_{i 34}}\right)-\beta\right)\right)}\right)}
\end{aligned}
$$

$$
\mu_{i 3}=\frac{1}{\left(1+e\left(-\alpha *\left(\left(\frac{\Sigma_{i=1}^{9} x_{i 7}}{e_{i 24}}\right)-\beta\right)\right)\right)}
$$

$x_{i 7}=\sum_{h=1}^{H} x_{h i 25}$

$$
x_{\text {hi25 }} \leq e_{\text {hi28 }}
$$

$x_{i 1}, x_{i 2}, x_{i 3}, x_{i 4}, x_{i 5}, x_{i 6}, x_{i 7}, x_{i 8}, x_{i 9}, x_{i 11}, x_{i 12}, x_{i 13}, x_{i 14}, x_{i 18}, x_{i 22}, x_{i 23}, x_{i 24} \geq 0$

$x_{i 8} \geq x_{i 18} * 0.8$

$x_{i 2}=e_{i 25} x_{i 1}$

$x_{i 3}=e_{i 26} x_{i 1}$

$x_{i 1} \leq e_{i 27}$

$x_{i 22} \geq e_{9} * e_{i 27}$

$x_{i 23}=e_{i 30} * e_{i 27}+x_{i 17}$

$x_{i 1}=e_{i 27}-x_{i 22}+x_{i 23}$

$O_{i 1} \geq e_{29}$

Add for the collective AES system setting:

If $\left(\frac{\sum_{i=1}^{9} \mu_{i 1}}{9}+\frac{\sum_{i=1}^{9} \mu_{i 2}}{9}+\frac{\sum_{i=1}^{9} \mu_{i 3}}{9}\right) / 3>e_{36}$ then $p_{o t=2}=p_{o}$

If $\left(\frac{\sum_{i=1}^{9} \mu_{i 1}}{9}+\frac{\sum_{i=1}^{9} \mu_{i 2}}{9}+\frac{\sum_{i=1}^{9} \mu_{i 3}}{9}\right) / 3 \leq e_{36}$ then $p_{o t=2}=0$ 
Where:

$U_{i}=$ utility of farmer i

$O_{i 1}=$ profit farmer $\mathrm{i}$ in euros

$O_{i 2}=$ labour hours used on farm i

$O_{i 3}=$ risk taken by farmer i

$O_{i 4}=$ overall biodiversity score

$O_{i 1}{ }^{*}=$ maximum profit in euros farmer $\mathrm{i}$ could obtain

$O_{i 2}{ }^{*}=$ minimum labour hours that could be used on farm $\mathrm{i}$

$O_{i 3}{ }^{*}=$ minimum risk that could be taken by farmer $\mathrm{i}$

$O_{i 4}{ }^{*}=$ max overall biodiversity score farmer i could obtain

$g_{i l}=$ weight attached to profit maximization by farmer $\mathrm{i}$

$g_{i 2}=$ weight attached to labour minimization by farmer $\mathrm{i}$

$g_{i 3}=$ weight attached to risk minimization by farmer $\mathrm{i}$

$g_{i 4}=$ weight attached to biodiversity maximization by farmer $\mathrm{i}$

$L R_{i}=$ labour hours required on farm $\mathrm{i}$

$L I_{i}=$ initial labour hours available on farm $\mathrm{i}$

$\alpha \quad=\quad$ speed parameter

$\beta=$ biodiversity parameter

$v_{l}=$ variance milk price

$\mu_{i l}=$ biodiversity score small scale biodiversity type for farmer $\mathrm{i}$

$\mu_{i 2}=$ biodiversity score medium scale biodiversity type for farmer $\mathrm{i}$

$\mu_{i 3}=$ biodiversity score large scale biodiversity type

$y_{i 1}=$ milk produced on farm i (in $100 \mathrm{kgs}$ )

$p_{1}=$ price milk in euro per $100 \mathrm{~kg}$

$p_{2}=$ price old cows in euro per cow

$p_{o}=$ price maintained hedgerows in euro per $\mathrm{m}^{2}$

$p_{o t=2}=$ price maintained hedgerows in euro per $\mathrm{m}^{2}$ in second time step

$w_{1}=$ maintenance costs in euro per cow

$w_{2}=$ maintenance costs in euro per young cattle $<1$ year

$w_{3}=$ maintenance costs in euro per young cattle $>1$ year

$w_{4}=$ costs per KVEM feed in euro

$w_{5}=$ costs of removing a $\mathrm{kg}$ of excess phosphate in euro

$w_{6}=$ costs of maintaining a $\mathrm{m}^{2}$ of maize in euro

$w_{7}=$ costs of maintaining a $\mathrm{m}^{2}$ hedgerows in euro

$w_{8}=$ costs of maintaining a $\mathrm{m}^{2}$ of grass in euro

$w_{9}=$ costs of hiring an hour of labour in euro

$w_{10}=$ costs of buying one more cow in euro per cow

$x_{i 1}=$ number of cows on farm $\mathrm{i}$ 


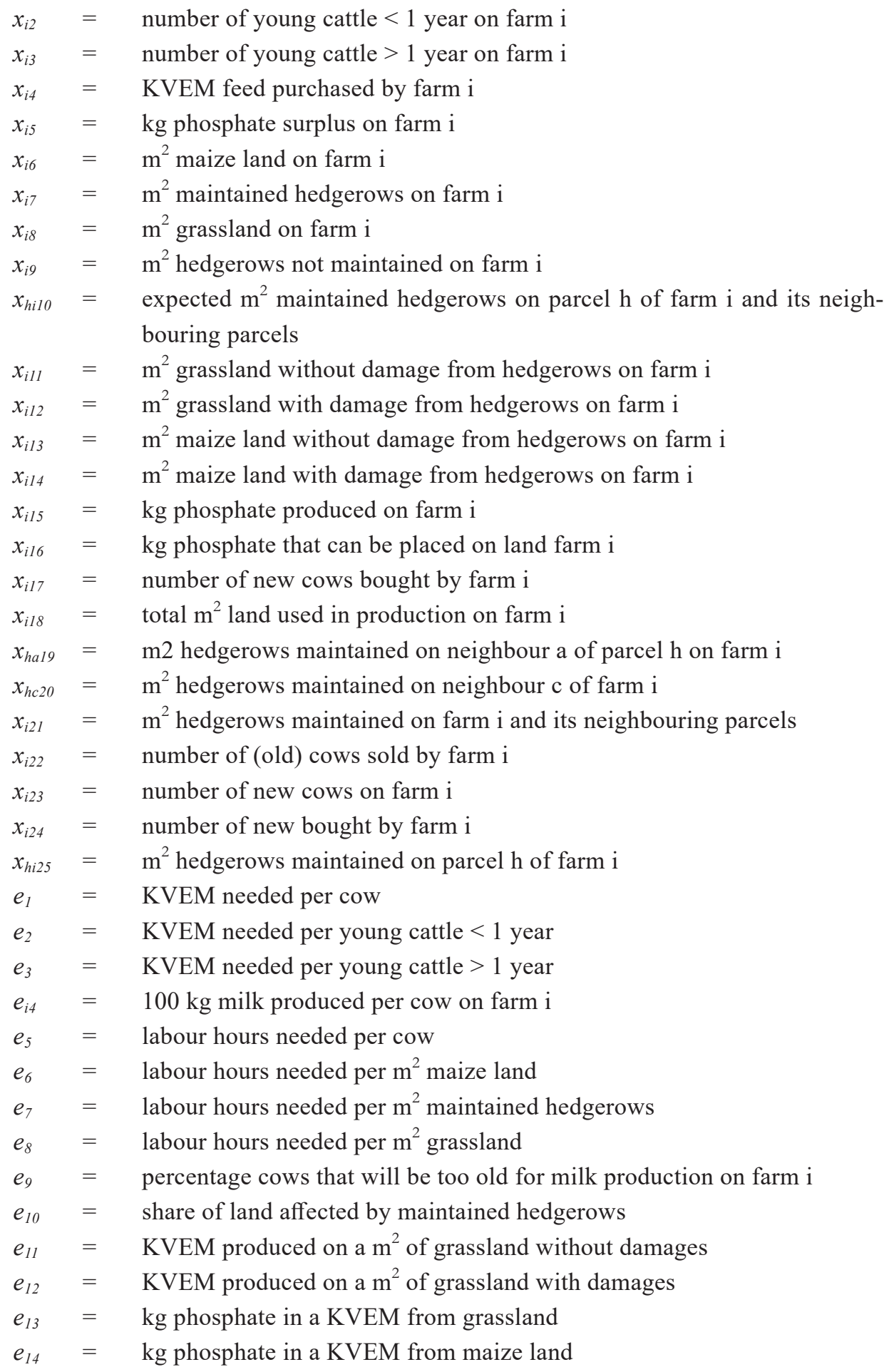




$$
\begin{aligned}
& e_{15}=\quad \mathrm{kg} \text { phosphate in a KVEM purchased } \\
& e_{16}=\mathrm{kg} \text { phosphate in } 100 \mathrm{~kg} \text { milk } \\
& e_{17}=\mathrm{kg} \text { phosphate in a carrying cow } \\
& e_{18}=\mathrm{kg} \text { phosphate in a young cattle }<1 \text { year } \\
& e_{19}=\mathrm{kg} \text { phosphate in a young cattle }>1 \text { year } \\
& e_{20}=\mathrm{kg} \text { phosphate allowed on } \mathrm{a}^{2} \text { of grassland } \\
& e_{21}=\mathrm{kg} \text { phosphate allowed on } \mathrm{a}^{2} \text { of maize land } \\
& e_{\text {hi22 }}=\mathrm{m}^{2} \text { area parcel } \mathrm{h} \text { on farm } \mathrm{i} \\
& e_{i 23}=\text { initial } \mathrm{m}^{2} \text { land used for hedgerows on farm } \mathrm{i} \\
& e_{i 24}=\text { maximum } \mathrm{m}^{2} \text { of hedgerows that could be maintained in the region } \\
& e_{i 25}=\text { number of young cattle }<1 \text { year per cow on farm } \mathrm{i} \\
& e_{i 26}=\text { number of young cattle }>1 \text { year per cow on farm } \mathrm{i} \\
& e_{i 27}=\text { initial number of cows on farm } \mathrm{i} \\
& e_{28 h i}=\text { maximum amount of hedgerows that could be maintained on parcel } \mathrm{h} \text { of } \\
& \text { farm i } \\
& e_{29}=\text { subsistence income farmers } \\
& e_{i 30}=\text { percentage cows that can be replaced by young cattle farm } \mathrm{i} \\
& e_{31}=\text { KVEM produced on } \mathrm{a}^{2} \text { of maize land without damages } \\
& e_{32}=\text { KVEM produced on } \mathrm{a}^{2} \text { of maize land with damages } \\
& e_{\text {hi33 }}=\text { maximum expected } \mathrm{m}^{2} \text { hedgerows that could be maintained on parcel } \mathrm{h} \text { of } \\
& \text { farm I and its neighbouring parcels } \\
& e_{i 34}=\text { maximum expected } \mathrm{m}^{2} \text { hedgerows that could be maintained on farm I and } \\
& \text { its neighbouring parcels } \\
& e_{i 35}=\text { number of groups of parcels and neighbours on which hedgerows occur } \\
& e_{36}=\text { threshold overall biodiversity score } \\
& e_{a}=\text { probability parcel } \mathrm{a} \text { is a neighbour of parcel } \mathrm{h} \text { of farm } \mathrm{i} \\
& e_{c}=\text { probability parcel } \mathrm{c} \text { is a neighbour of farm } \mathrm{i}
\end{aligned}
$$

Within this model the farmer aims to maximize his/her utility, as depicted by equation (A1). Utility depends on four farming objectives; profit maximization, labour minimization, risk minimization and biodiversity maximization. Whether or not a farmer attaches value to each of these objectives depends on the weights for the farmer objectives. If a farmer does not care about an objective, this objective will obtain a weight of zero.

Profit is the result of the revenue from milk production, the revenue from selling cows that are no longer productive and AES payments, minus the costs of normal production including the costs of maintaining hedgerows, the costs of labour and the costs of buying new cows (A2). Labour used on the farm is equal to the amount of labour hours needed for all of the farms activities (A3). 
Risk depends on the variance of the milk price (A4). The overall biodiversity score depends on the biodiversity score for the small scale biodiversity type, the medium scale biodiversity type, and the large scale biodiversity type (A5).

There are two commodities that are produced on the farm: milk and biodiversity. The revenue from milk depends on the milk production, which is the result of the number of cows times the milk production per cow (A6). Of course, cows need to be fed. Feed can be produced on farm, and feed needed in excess of the on-farm production can be purchased from the market (A7). Feed production depends on the type of crop grown (grass or maize) and possible damages to production due to shade from the hedgerows. If more phosphate is produced on farm than can be placed on farm land, there is a phosphate surplus that has to be removed from the farm (A8). Phosphate produced on farm results from phosphate included in the feed minus the phosphate captured in the milk, cows and young cattle (A9). Phosphate that can be placed on land is determined by multiplying the allowed amount of phosphate per $\mathrm{m}^{2}$ of grass or maize with the $\mathrm{m}^{2}$ of grass and maize on the farm (A10). The labour required on the farm is sum of the labour needed for feeding and milking the cows, the labour needed to work the farm land and the labour needed to maintain the hedgerows (A11). The total amount of land that can be used in production is the land available on the parcels of the farm minus the land needed for hedgerows (A12). The amount of land used in production can be used for growing grass or growing maize (A13). Land used by hedgerows can either be maintained or not maintained (A14). Grassland can be divided into grassland with and without damages from hedgerows (A15). Maize land can be divided into maize land with and without damages (A16). The total amount of land with damages can be calculated as equal to a share of the land used by maintained hedgerows (A17). The total amount of maintained hedgerows cannot exceed the initial amount of hedgerows (A18).

In our model we translate the amount of maintained hedgerows for the small scale, medium scale and large scale types of biodiversity in a biodiversity score. The basis for calculating this score is to compare the amount of maintained hedgerows in the model with the maximum amount of hedgerows that could be maintained. For the small scale biodiversity type we consider for each parcel the amount of hedgerows that is maintained on the parcel and its direct neighbours. For the medium scale biodiversity type we compare the amount of hedgerows that are maintained on the own parcels of the farm plus the amount of hedgerows that are maintained on the neighbouring parcels of the farm. For the large scale biodiversity we compare the amount of hedgerows that are maintained in the total region. We use the information on the parcels of the individual farms to create an artificial region. We calculate for each parcel the probability that it neighbours 
parcel $h$ of farm $i$ in the sample. For the parcels $h$ of farm $i$ this probability is either 1 or 0 as we now their exact location. For the parcels of the other farms we calculate the probability by determining the number of potential neighbours. We then use the probabilities to calculate an average expected amount of hedgerows maintained on each parcel and its direct neighbours by multiplying the probability that parcel A neighbours parcel $h$ with the amount of hedgerows on each potentially neighbouring parcel and add the hedgerows maintained on the parcel itself (A19). We multiply the probability that parcel $\mathrm{C}$ neighbours farm $\mathrm{i}$ with the amount of hedgerows on each potentially neighbouring parcel of farm $i$ and add the hedgerows maintained on farm $i$ itself to calculate the expected amount of hedgerows on the farm and its neighbouring parcels (A20). Using these expected amounts of hedgerows we can calculate the biodiversity scores for small scale, medium scale and large scale biodiversity. We calculate the biodiversity scores by a logistic function, and the score depends on the ratio of maintained hedgerows and the maximum amount of hedgerows that could be maintained for that type of biodiversity (A21, A22, and A23).

Of course, the sum of the hedgerows maintained on each of the parcels of the farmer is equal to the total amount of hedgerows maintained by the farmer (A24). The amount of maintained hedgerows on each parcel cannot exceed the amount of hedgerows on that parcel (A25).

The number of cows, number of young cattle younger than 1 year, number of young cattle older than 1 year, the amount of feed purchased, the phosphate surplus, the $\mathrm{m}^{2}$ of maize, the $\mathrm{m}^{2}$ of hedgerows maintained and not maintained, the $\mathrm{m}^{2}$ of grass, the $\mathrm{m}^{2}$ of grass without damages, the $\mathrm{m}^{2}$ of grass with damages, the $\mathrm{m}^{2}$ of maize without damages, the $\mathrm{m}^{2}$ of maize with damages, the total amount of land used in production, the number of old cows sold, the number of new cows on farm and the number of new cows bought cannot be negative (A26).

Cows produce manure, which contains minerals. To prevent environmental damages due to a surplus of these minerals used on land, the EU formulated regulations that place a limit on the amount of minerals from manure that can be placed on land. The Dutch farmers and government have successfully argued that it is safe to put a bit more of these minerals on the Dutch soil type. This has resulted in an EU agreement called derogation, which allows for applying more minerals on land if a farm has at least 80 percent grassland. In order to be viable for derogation the farms in our model have to maintain at least 80 percent grassland (A27). The number of young cattle younger than 1 year and young cattle older than 1 year are estimated by taking a share of the number of cows, where the share taken was determined in the farmer interviews and differs for each farmer (A28 and A29). The number of cows cannot exceed the initial number of cows 
(A30). The number of cows sold is larger than or equal to the number of cows that is too old for production (A31). The number of new cows on farm equals the number of new cows coming from young cattle and the number of new cows bought (A32). The number of cows on the farm is the result of the initial number of cows, minus the cows sold plus the new cows (A33). In order for the farm to survive the farmer has to reach a certain subsistence income (A34).

To model the collective AES system the price paid for maintaining hedgerows depends on biodiversity achieved in the previous time step (A35).

\section{APPENDIX 4B. SENSITIVITY ANALYSIS}

\section{Sensitivity analysis labour}

During the interviews, farmers found it difficult to indicate the amount of labour needed to maintain hedgerows. The estimates given covered a wide range. An estimation of 0.2 hours per $10 \mathrm{~m}^{2}$ per year seemed reasonable to us given the farmers estimates, but we performed a sensitivity analysis to provide insight in the effect of using different amounts of labour needed in the model. One would expect that when the labour needed for maintenance of hedgerows is increased sufficiently, the farmer will stop maintaining his/her hedgerows. At some point it will either be too expensive to hire additional labour, or the negative effect of using hired labour on the farmer's utility will become too large. Figure 4B.1. shows the number of farmers in the AES for different amounts of labour needed to maintain hedgerows and Figure 4B.2. shows the overall biodiversity score for different amounts of labour needed to maintain hedgerows.

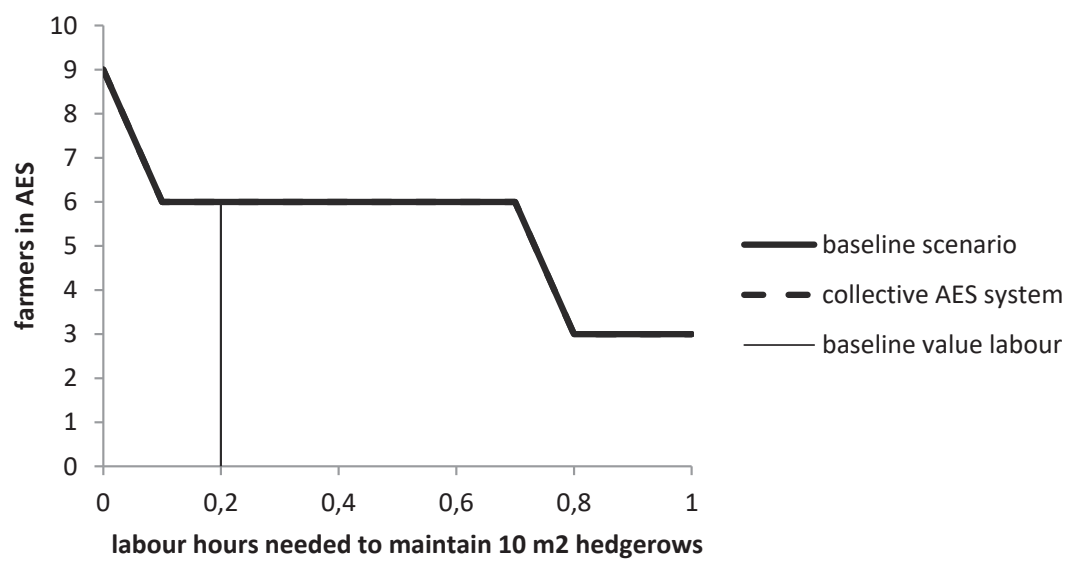

Figure 4B.1. Farmers in AES at the end of the model run for different amounts of labour needed for maintenance of hedgerows 


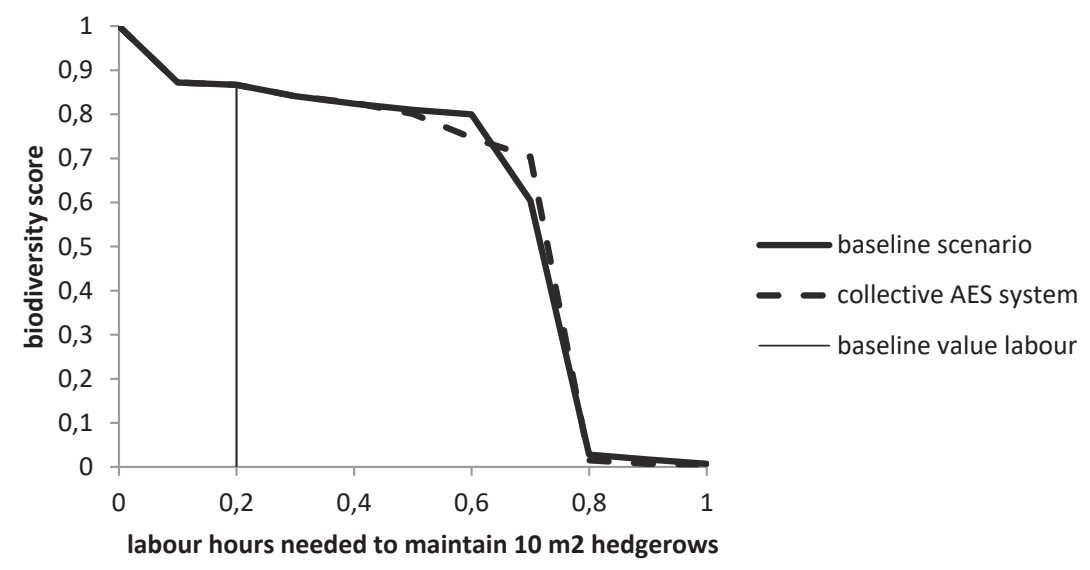

Figure 4B.2. Overall biodiversity score at the end of the model run for different amounts of labour needed for maintenance of hedgerows

When we ran the model for different amounts of labour required we found no stable solution for the biodiversity score in the labour range 0.3-0.7 hours per $10 \mathrm{~m}^{2}$, because farmers kept changing their actions in response to each other's actions. However, the number of farmers participating in this labour range stayed constant over the different time steps, and the difference in biodiversity score between the final time steps was very small. If no labour would be needed to maintain hedgerows all farmers would participate in the AES and the maximum biodiversity score would be reached. The amount of labour needed does not influence the number of farmers that maintains hedgerows in the range 0.1-0.7 hours per $10 \mathrm{~m}^{2}$. If the amount of labour required reaches 0.8 hours per $10 \mathrm{~m}^{2}$ a tipping point is reached and the number of farmers that maintains hedgerows suddenly goes down to three. Even though the number of farmers is constant in the range $0.1-0.7$ hours per $10 \mathrm{~m}^{2}$ the overall biodiversity score decreases gradually in this range until it also reaches the tipping point at 0.8 hours per $10 \mathrm{~m}^{2}$ and the overall biodiversity score drops sharply. At this point the negative effect of using extra labour on the utility of the farmer outweighs the positive effect of having a higher biodiversity on the utility of the farmer. In terms of farmer participation in the AES there is no difference between the baseline scenario and the collective AES system, but in terms of overall biodiversity score the collective system performs slightly worse when no AES payment is available. If no payment is available, there will not only be a negative effect on utility through using more hired labour when maintaining hedgerows, but also on profit since the costs made for maintaining hedgerows will not be compensated. 
Figure 4B.3. and Figure 4B.4. show the biodiversity scores for the different biodiversity types in both the baseline scenario and the collective system.

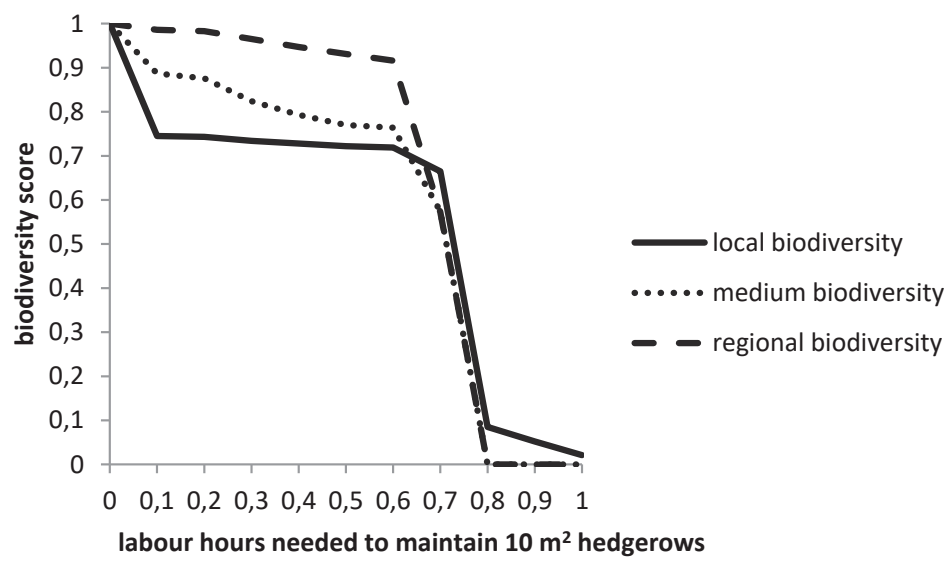

Figure 4B.3. Small scale, medium scale and large scale biodiversity score at the end of the model run in the baseline scenario

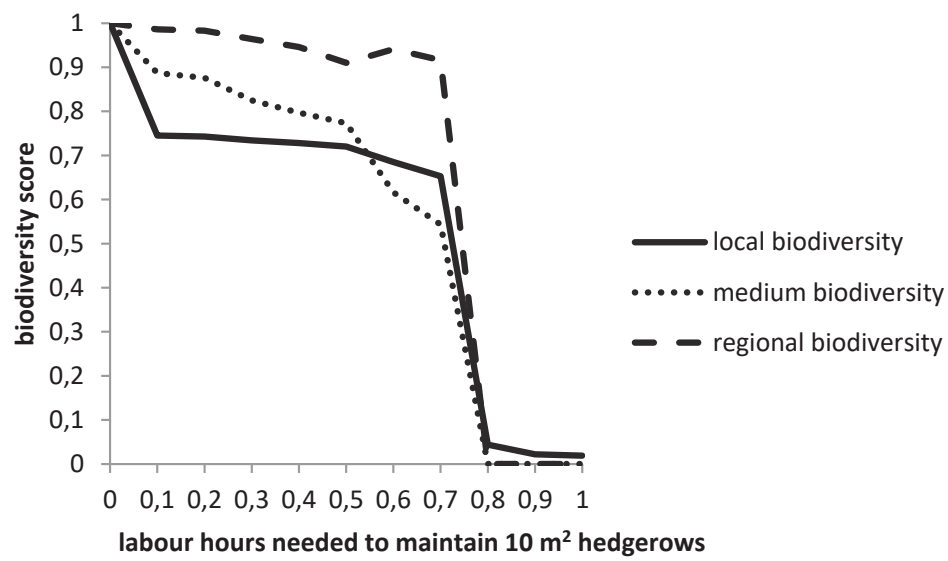

Figure 4B.4. Small scale, medium scale scale and large scale biodiversity score at the end of the model run in the collective AES system

\section{Sensitivity analysis maintenance price}

The AES payment for maintaining hedgerows is 0.3 euro per $\mathrm{m}^{2}$. For this payment six farmers are willing to maintain their hedgerows. To see how farmers respond to a changing compensation we perform a sensitivity analysis. Figure 4B.5. shows the number of farmers in the AES for different maintenance payments and Figure 4B.6. shows the overall biodiversity score for different maintenance payments. 


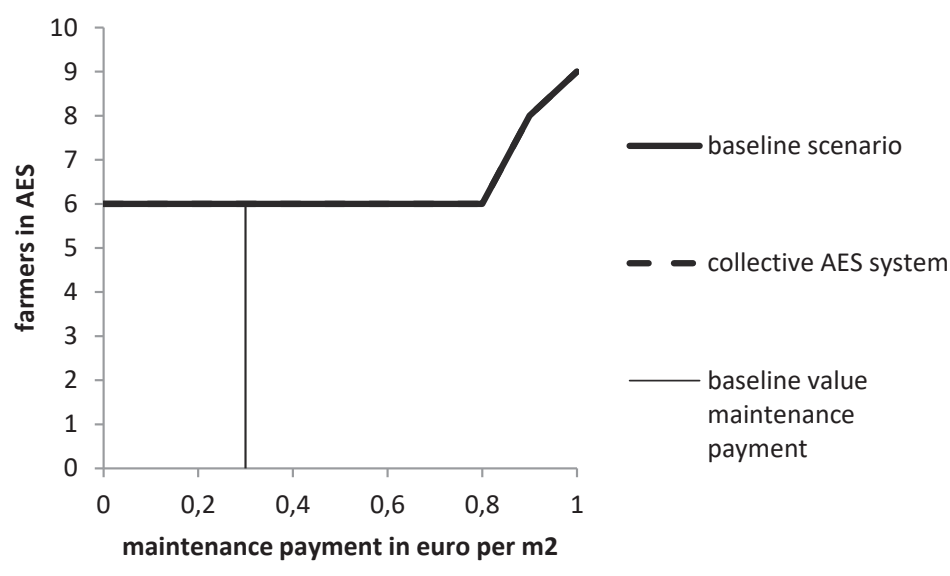

Figure 4B.5. Farmers in the AES at the end of the model run for different maintenance payments

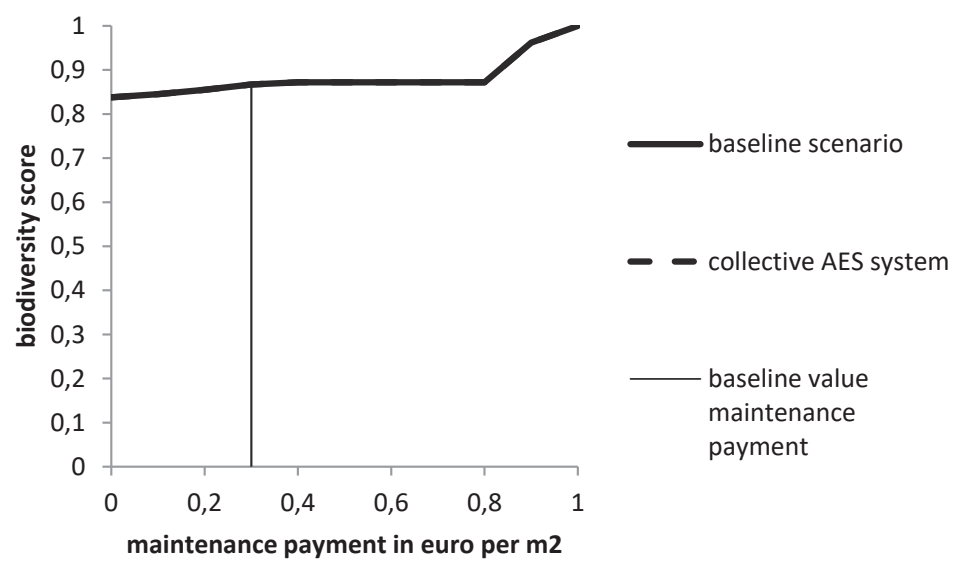

Figure 4B.6. Overall biodiversity score at the end of the model run for different maintenance payments

Our sensitivity analysis shows that six farmers are willing to maintain hedgerows even if they do not receive a payment at all. A maintenance payment below 0.3 euro per $\mathrm{m}^{2}$ results only in a slightly lower amount of hedgerows that are maintained. If we increase the payment for maintaining hedgerows, the amount of farmers maintaining hedgerows remains stable in the range $0-0.8$ euro per $\mathrm{m}^{2}$. If the price is 0.9 euro per $\mathrm{m}^{2}$ the number of farmers maintaining hedgerows increases to eight. If we increase the price to 1 euro per $\mathrm{m}^{2}$ all farmers will choose to maintain their hedgerows and the maximum biodiversity score will be achieved. 
This suggests that there is a possibility to differentiate payments, shifting payments for the farmers that attach a high utility to biodiversity to the farmers that do not attach (a high) utility to biodiversity for maintaining hedgerows.

\section{Sensitivity analysis milk prices}

The milk price in our model is the expected average milk price until 2026, which is equal to $€ 34.50$ per $100 \mathrm{~kg}$ milk. However, milk prices vary over time. Therefore, we analysed the effect of a 10 and 25 percent increase or decrease of the milk price on the biodiversity score. If we run the scenario with a 10 percent lower milk price there are six farmers in the AES, and a small scale biodiversity score of 0.745 , a medium scale biodiversity score of 0.887 , a large scale biodiversity score of 0.986 and an overall biodiversity score of 0.872 is reached. These biodiversity scores are slightly higher than in the baseline scenario. Lowering the milk price with 25 percent does not increase the biodiversity score further. Apparently, if the milk price goes down, spending more time on maintaining hedgerows becomes a more attractive option, but this effect is limited. If the milk price increases by 10 percent there are six farmers in the AES and a small scale biodiversity score of 0.740 , a medium scale biodiversity score of 0.860 , a large scale biodiversity score of 0.979 and an overall biodiversity score of 0.860 is reached. These biodiversity scores are slightly lower than in the baseline scenario. If the milk price increases with 25 percent there are six farmers in the AES and a small scale biodiversity score of 0.737 , a medium scale biodiversity score of 0.845 , a large scale biodiversity score of 0.974 and an overall biodiversity score of 0.852 is reached. Apparently, if the milk price goes up, spending less time on maintaining hedgerows becomes a more attractive option. Since the overall biodiversity score is above the threshold there is no difference between the results in the individual and collective AES system.

\section{Differentiated payments}

A larger number of farmers can be convinced to participate in the AES if we differentiate payments. In this model experiment we first asked what the minimum payment needed to be for each farmer to be in the AES. The lowest compensation for each farmer to be in the AES is zero for six farmers, 0.9 euro per $\mathrm{m} 2$ for two farmers and one euro per $\mathrm{m} 2$ for one farmer. The total compensation paid for maintaining hedgerows would then be 11954 euro. A small scale biodiversity score of 0.955 , a medium scale biodiversity score of 0.999 , a large scale biodiversity score of 0.909 and an overall biodiversity score of 0.954 will be reached. This is an improvement compared to the situation without differentiated payments, as in the baseline scenario in total 20559 euro is paid for maintaining the hedgerows 
which results in a biodiversity score of 0.867 . The second question in this scenario was what the minimum payment needed to be for each farmer to reach the maximum biodiversity score. To ensure the maximum biodiversity score at the lowest cost we should pay one farmer no maintenance price, one farmer 0.3 euro per $\mathrm{m} 2$, one farmer 0.4 euro per $\mathrm{m} 2$, one farmer 0.5 euro per $\mathrm{m} 2$, one farmer 0.7 euro per $\mathrm{m} 2$, three farmers 0.9 euro per $\mathrm{m} 2$ and one farmer 1 euro per $\mathrm{m} 2$. The total amount paid for maintaining hedgerows is then 39009 euro. 



\section{Chapter 5}

Effects of changing social influence on participation and biodiversity in agri-environmental schemes in the Netherlands ${ }^{4}$

4 Paper by Groeneveld, A.N., Peerlings, J.H.M., Bakker, M.M., and Heijman, W.J.M. Submitted to a peerreviewed journal. 


\section{ABSTRACT}

The Dutch government expects that the recently introduced collective application system for agri-environmental schemes (AES) will create a broader social support for AES since farmers no longer deal with a large and anonymous government but with the farmer collective in their region. The goal of this paper is to analyse whether a change in social influence due to the introduction of the collective AES programme results in a shift towards increased farmer participation and a higher level of biodiversity. To answer the research question, we use data from a small sample of farmers in the area of the Noordelijke Friese Wouden in the Netherlands. The data are used as input for a model that captures individual and collective farm behaviour and includes biodiversity and social influence. Our results show that the introduction of the collective AES programme in combination with social influence does not necessarily improve AES participation or biodiversity. Apparently, it is important to create the correct kind of social influence if biodiversity is to be increased. 


\subsection{INTRODUCTION}

To protect the environment from the negative effects of intensive agricultural practices, payments in the form of agri-environmental schemes (AES or AECS) have been offered to European farmers that adjust their farming practices (van Dijk et al., 2015; Kleijn \& Sutherland, 2003). However, due to insufficient farmer participation, the effects of these AES have been unsatisfactory (Kuhfuss et al., 2016; Lastra-Bravo et al., 2015; McKenzie et al., 2013; Whittingham, 2007). In an effort to improve the AES programme the 2014 EU Rural Development Regulation (Regulation (EU) No 1305/2013, Article 28) was developed. This regulation introduced the option of group applications for AES, while maintaining the possibility to apply on an individual basis as well. In 2016 the Dutch government introduced even stricter regulations, by exclusively allowing for joint applications by farmer collectives (Ministry of Economic Affairs, 2016).

The Dutch government expects that the collective AES programme will result in more effective nature conservation and lower implementation costs (Ministry of Economic Affairs, 2016). The expected increase in biodiversity should result from an improved selection of potential conservation areas and larger farmer participation due to increased social support. The government assumes that the collective structure will create a broader social support for AES since farmers no longer deal with a large and anonymous government but with the farmer collective in their region (Portaal Natuur en Landschap, 2017; Stichting Collectief Agrarisch Natuurbeheer, 2016). Due to an increase in collaboration within the farmer collective farmers might increase their social interaction and a stronger "feeling of belonging" might develop (Prager, 2015). During member events of the farmer collective farmers will be able to interact and have the possibility to encourage each other to participate in nature conservation (Nieuwenhuizen et al., 2014). In other words, an increase in social influence on the decision to participate in the AES is expected in the collective, more than in the individual AES programme.

Scientific literature, including social-psychological models such as the theory of planned behaviour (Ajzen,1991; Lalani et al., 2016) and the value-belief-norm theory (López-Mosquera \& Sánchez, 2012) stresses that farmers rarely make isolated decisions, as they are (socially) influenced by others. Social influence or peer pressure reflects the wish to conform to the opinions of the group and can persuade people to change their behaviour (van Dijk et al., 2015; Vargas et al., 2016). Research by Josefsson et al. (2017) indeed showed that perceived social pressure can motivate farmers to participate in nature conservation. Not everyone is equally sensitive to social influence; people with extreme opinions are thought to be less likely to change their opinions in order to comply with the group (Sun 
\& Müller, 2013). Furthermore, in society there are some people that will have a larger social influence on the opinions of others; these people are referred to as opinion leaders (Chen et al., 2016b). In general, people are more likely to comply with others that are socio-culturally closer (Estrada \& Vargas-Estrada, 2013) and from their own network or "in-group" (Leach et al., 2008).

This interconnectedness of farmers is reflected in the complex character of the land use system. Land use systems are coupled human environment systems that exhibit feedbacks between different scale levels and subsystems and interactions between land users (Mitchell et al., 2015; Schouten et al., 2013; Verburg, 2006). For instance, a feedback might exist between the biodiversity level and the individual farmer decisions. Biodiversity in the region is the combined result of the individual nature conservation decisions of farmers. On the other hand, the effect of individual nature conservation decisions might depend on the overall biodiversity level in the region. An example of interactions between land users can be observed in the collective AES programme, where farmers interact within the farmer collective. The stronger presence of social influence caused by the increased farmer interactions is an important distinction from the individual AES programme.

The goal of this paper is to analyse whether an increase in social influence due to the introduction of the collective AES programme could result in a shift towards increased farmer participation and a higher level of biodiversity. Here we assume a priori that the increase in social influence as expected by the Dutch government indeed takes place. To answer the research question we use data from a small sample of farmers in the Noordelijke Friese Wouden, an area in the North of the Netherlands. The data are used as input for a model that captures individual and collective farm behaviour and includes biodiversity and social influence. Within our model farmers maximize their utility and are linked to other farmers through the mutual effect of all farmers on biodiversity and through social influence. Utility maximization takes place in the multi-objective mathematical programming part of our model (Calker et al., 2006). The increased social influence is captured in the opinion dynamics part of the model, where the weights of the farmer objectives are socially influenced and three scenarios capture different types of social influence. In section 2 we discuss the modelling framework. In section 3 the study area is introduced, while we describe the method and data in section 4. Section 5 introduces the model equations and section 6 outlines the scenarios capturing three types of social influence. The results are presented in section 7 . Finally, we conclude and discuss in section 8. 


\subsection{MODELLING FRAMEWORK}

The landscape in our model exists of parcels that belong to individual farmers, who can be influenced by the (wider) farming community. Although each farmer makes an individual decision on nature conservation decisions on his/her land, (s)he is affected by the surrounding environment as shown in Figure 5.1.

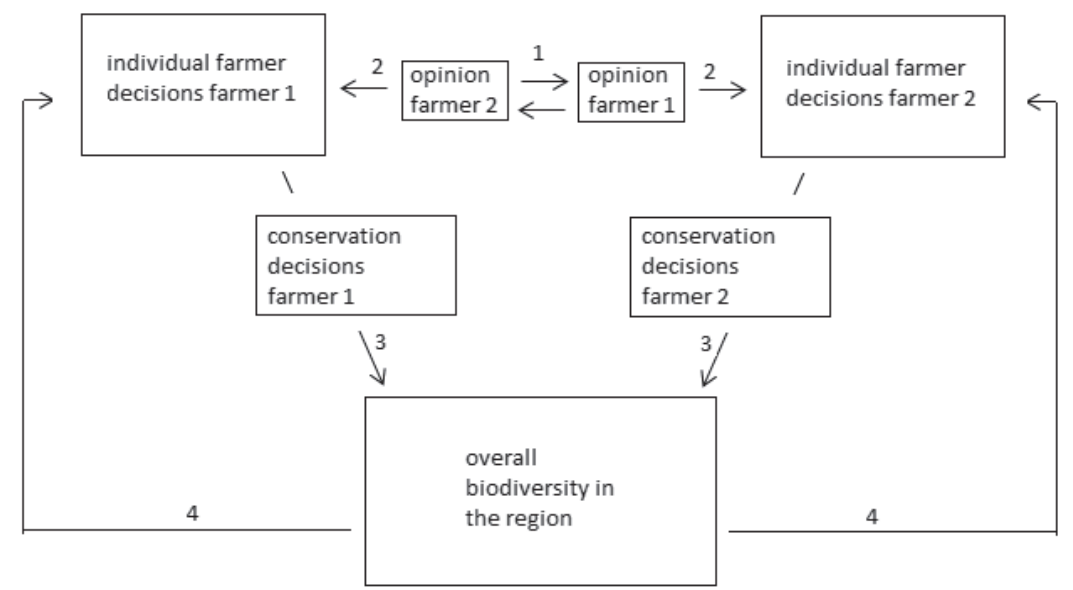

Figure 5.1. Modelling framework

The value farmers attach to different farming objectives is captured by farmer opinions. The farmer opinions are socially influenced by the opinions of other farmers (arrow 1). The decisions of the individual farmer depend on the values the farmer attaches to different farming objectives (arrow 2). The individual farmer decisions determine nature conservation decisions which have an impact on the overall biodiversity in the region (arrow 3). The overall biodiversity in the region in turn influences the individual farmer decisions (arrow 4).

\subsection{STUDY AREA}

In the northern Dutch province of Friesland there is a 25,000 ha rural area referred to as the Noordelijke Friese Wouden (NFW). The farmers in this area are mostly dairy farmers, and the area is well-known for its typical hedgerow landscape consisting of alder belts and wooded banks that divide the farming parcels (Oosterveld, 2013; van der Ploeg, Strijker \& Hoofwijk, 2010). The quality of the hedgerow landscape is dependent on the maintenance performed by farmers, which impacts the biodiversity level in the region (De Boer, 2003; Besnard 
\& Secondi, 2014). To compensate farmers for the costs of maintaining these hedgerows AES payments are available. Within the NFW a farmer collective exists that promotes and organizes landscape and nature conservation. If farmers want to apply for the collective AES programme they have to become a member of this collective. The collective contains about 800 members and is tasked with the organization and implementation of the AES. The farmer collective organizes meetings and working groups and sends around newsletters and updates. A commission formed by members of the farmer collective assesses whether farmers are performing adequate maintenance of landscape elements (Noordelijke Friese Wouden, 2017).

\subsection{METHOD AND DATA}

\subsubsection{Model procedure}

We develop a hybrid modelling framework that integrates a multi-objective mathematical programming model containing biodiversity feedbacks and an opinion dynamics model. The model procedure and the input and output for each model part are shown in Figure 5.2.

Farmers can have multiple farming objectives, such as profit maximization, risk minimization, labour minimization, and biodiversity maximization. Since the weights a farmer attaches to these objectives differ from one farmer to another, individual farmer decisions differ as well. The initial weights for these objectives are determined by the technique described by Manos et al. (2009) in the next section (model part 1). Next, the effect of social influence (arrow 1 in Figure 5.1.) is incorporated in the calculated weights in model part 2. If a farmer is not affected by the increase in social influence, the weights in model part 1 and model part 2 are the same; if a farmer is affected, the weights change. The final weights are added into the utility functions of the individual farmers, which form the objectives of the mathematical programming models of the individual farmers in model part 3. In the mathematical models the feedback from the overall biodiversity level is included (arrow 4 in Figure 5.1.). The mathematical programming models run for 10 time steps, each farmer takes the overall biodiversity in the previous time step as given when determining his/her farming decisions. Within the mathematical programming models biodiversity scores are calculated and the total farmer participation is determined. Each of the model parts is described below. The set of equations that form the model are presented in section 5 . 


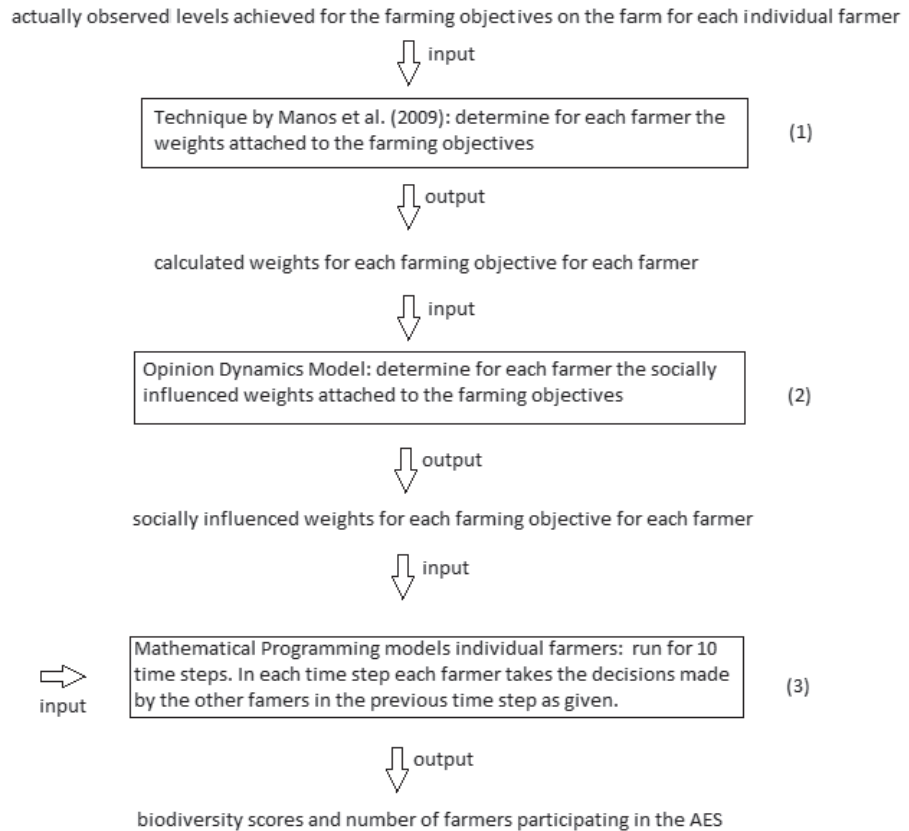

Figure 5.2. Model procedure

\section{Model part 1: determining farmer objectives and calculating weights}

The weights for the farmer objectives are determined in three steps using the method of Manos et al. (2009). Following Manos et al. (2009) we first define the set of objectives that are most important to farmers in their decision making. These objectives were elicited by asking the farmers in our sample about their objectives and can be grouped into the categories of profit maximization, labour minimization, risk minimization and biodiversity maximization. Second, we obtain the pay-off matrix for the objectives. In the payoff matrix the levels of each objective that will be achieved when optimizing each objective are compared to the actual levels of the objectives as observed on the farm. In the final step the weights that represent the farmers' preferences are determined using the information in the pay-off matrix. We choose the weights in such a way that the deviations between the model outcomes and actually observed amounts of each objective are minimized. The mathematical expression of this minimization can be found in appendix A. If a farmer does not care about an objective, the weight we find for this objective will be zero. A more elaborate description of the method including the equations used in determining the weights can be found in appendix A. 


\section{Model part 2: Opinion Dynamics Model}

With an Opinion Dynamics Model (ODM) it is possible to describe social influence. Social influence captures the effect of peer pressure or peer influence. Within ODM opinions develop during a diffusion process in which members of a social system interact (Ligtenberg \& Bregt, 2014). People take the judgments and actions of people around them into account and their own expressed opinions or behaviours might change accordingly (Huang, Tzou \& Sun, 2011). In an ODM an opinion is represented by a number. The model can be discrete, in which case the number is taken from a limited integer set, or continuous in which case the number is taken from a continuous real set between zero and one (Huang, Tzou \& Sun, 2011). Examples of discrete opinion dynamics models can be found in Crokidakis and Forgerini (2010), Galam (2002) and Galam (2003), Javarone (2014), and Sood and Redner (2005). Examples of continuous opinion dynamics models can be found in Hegselmann and Krause (2002), Deffuant et al. (2002), and Weisbuch, Deffuant and Amblard (2005). Our model is based on the continuous model developed by Sun and Müller (2013). In this model each person starts with an initial opinion, which is influenced by interactions with other persons. Whether or not someone chooses to adjust his/her opinion depends on the difference between the own opinion and the opinion of the person with which the interaction takes place (Sun \& Müller, 2013). The amount by which someone adjusts his/her opinion depends on how strong the social influence is. In our research we consider the weights that farmers assign to different objectives as opinions. When a farmer interacts with another farmer or group of farmers, his/ her opinion on the importance of the farmer objectives might be influenced. In this paper we consider three types of social influence, which are described in more detail in the scenarios in section 6 . The procedure of the collective is to discuss the possibility of the AES with all farmers in the region. Therefore, we assume that social influence is applied to all farmers, irrespective of whether they are in the AES.

\section{Model part 3: Mathematical programming models}

The individual farmer decisions are captured by multi-objective mathematical programming models as described in Groeneveld et al. (2017). The models describe a dairy farm which converts inputs like cows, feed, land, and labour into outputs such as milk, meat, manure, and hedgerows. The model includes hedgerows that are located on the farm parcels and can be (partly) maintained in return for AES payments. Properly maintaining hedgerows is labour intensive and reduces roughage production due to shade but will have a positive effect on farm income and the biodiversity level in the region. We assume that the loss in 
production and the maintenance costs are negligible when the farmer does not maintain hedgerows. Hedgerows can either be maintained or not maintained, but it is not possible to increase the amount of hedgerows on the farm. We choose to apply this assumption because farmers specified an unwillingness to plant more trees during the farm interviews. Profit is defined as the revenue from milk, cows, and AES payments minus the costs associated with farming and maintaining hedgerows. The amount of labour used on farm equals the sum of the amount of labour needed for each farm task. The variance in milk prices is used to capture risk (see e.g. Berentsen, Kovacs \& van Asseldonk, 2012; Kaiser \& Messer, 2011; Schmit, Boisvert \& Tauer, 2001). AES payments are agreed on for a period of 6 years, therefore once the contract is signed there is no price risk. We make the assumption that any farmer that maintains his/her hedgerows is in the AES scheme.

A biodiversity score, based on three indicator species with different key areas (area needed to maintain a sustainable population of the species) is used to capture biodiversity in our models. Biodiversity scores for an indicator species with a small, medium and large scale key area are calculated using a logistic function. This function contains the ratio of maintained to total amount of hedgerows in the key area. If the ratio is low the biodiversity score is close to zero, if the ratio is high the biodiversity score is close to one. To find the overall biodiversity score we take the average of the small, medium and large scale biodiversity scores as described in Groeneveld et al. (2017). More information on the indicator species and the biodiversity score calculations can be found in appendix B.

\subsubsection{Data}

\section{Available data}

General farm data was taken from RVO (2010), Wageningen UR (2015), Blanken et al. (2016), Meetjesland (2016) and Remmelink et al. (2016). Information was collected on: costs of feed bought; costs of removing a possible phosphate surplus; costs of maintaining cattle; amount of feed produced on grassland; amount of feed produced on maize land; limits for phosphate application on grassland and maize land; milk price; labour costs; percentage cows to be replaced; price of new cows; price of slaughter cows; variance of the milk price; feed requirements per cow, cattle younger than one year and cattle between one and two years; phosphate content of grass, maize, feed bought, bound in milk, bound in carrying cows and bound in young cattle; labour hours needed for cultivating maize or grass; costs of cultivating silage maize and grass. 


\section{Data collection}

We interviewed nine farmers in the NFW, whose details were provided by the farmer collective. Not all of these farmers were involved in the AES scheme for maintaining hedgerows, but all farmers had hedgerows separating their farming parcels. During each interview we asked the farmer to define his/her farming objectives. We brought a map of each farm and asked the farmer to indicate which parcels belonged to his/her farm, what was grown on these parcels, the amount and maintenance of hedgerows on the parcels, and the location of hedgerows on the parcels. Furthermore, we asked about the type of farm, whether or not the farm was certified as organic, the number of cows and young cattle, the amount of milk produced on the farm, the amount of land, the different crops, and the labour hours worked on farm. One farmer was now out of business and no longer kept cows, but he still owned and maintained his land as he had before. In the model we assume this farmer has the average milk production and average number of cows in the region. Table 5.1. shows for each farmer the number of parcels, the amount of hedgerows on the farm, the amount of hedgerows that are maintained on the farm, the total income of the farmer and the AES payments the farmer receives.

Table 5.1. Data farmers (Groeneveld et al., 2017)

\begin{tabular}{lllllll}
\hline Farmer & $\begin{array}{l}\text { Number of } \\
\text { parcels }\end{array}$ & $\begin{array}{l}\text { Total } \mathbf{m} 2 \\
\text { hedgerows }\end{array}$ & $\begin{array}{l}\mathbf{M}^{\mathbf{2}} \\
\text { hedgerows } \\
\text { maintained }\end{array}$ & $\begin{array}{l}\text { Modelled } \\
\text { income } \\
\text { farmer } \\
\text { in euro }\end{array}$ & $\begin{array}{l}\text { Total } \\
\text { payments } \\
\text { received in } \\
\text { euro }\end{array}$ & $\begin{array}{l}\text { Share of } \\
\text { payments } \\
\text { in income }\end{array}$ \\
\hline 1 & 15 & 2335 & 0 & 82676 & 0 & 0 \\
2 & 92 & 33152 & 33152 & 228710 & 9946 & 0.04 \\
3 & 7 & 1988 & 784 & 96289 & 235 & 0.00 \\
4 & 22 & 7517 & 7517 & 98022 & 2255 & 0.02 \\
5 & 25 & 12920 & 12920 & 156870 & 3876 & 0.02 \\
6 & 21 & 10273 & 0 & 60060 & 0 & 0.00 \\
7 & 14 & 5086 & 0 & 89732 & 0 & 0.00 \\
8 & 38 & 800 & 0 & 205687 & 0 & 0.00 \\
9 & 54 & 7917 & 7273 & 66800 & 2182 & 0.03 \\
total & 288 & 81988 & 61646 & 1084846 & 18494 & 0.02 \\
\hline
\end{tabular}

The total income of the farmer is calculated by the model as income of all family members working at the farm, which explains why the incomes mentioned are relatively high. 
The number of farmers in our sample is small, but with the number of parcels belonging to these farmers (288) making a spatial configuration already quite intricate. Our goal is not statistical significance, but to explore the impact of the change in social influence due to the introduction of the collective AES programme. For this purpose the sample size for the mathematical programming part of the model (part 3) is sufficient. For the opinion dynamics part of the model (part 2) the number of farmers that interact is small. Therefore, we create artificially additional farmers which represent the wider farming community with which the farmers in our sample interact in the opinion dynamics part of the model, as described in the section on creating additional farmer interactions.

\section{Creating an artificial landscape}

As described in Groeneveld et al. (2017) the farmers we interviewed did not own a contiguous area, which we needed for our simulations. Therefore, we created an artificial landscape out of the 288 parcels belonging to these nine farmers. We only have information on the neighbour of a parcel if this neighbour belongs to the same farmer, since we know how parcels belonging to the same farmer are located relative to each other. A specific spatial configuration of all the parcels in the region cannot be expected, therefore we specified for each parcel $\mathrm{k}$ the probability that it neighboured parcel $j$ of farm $i$ in the sample. If two parcels belong to the same farmer we know whether or not they are neighbours and the probability is either 1 or 0 . If two parcels belong to different farms we calculate the probability by looking at the number of potential neighbours. For instance, assume a parcel of farm 1 has two unknown neighbours and a parcel of farm 2 has three unknown neighbours. The parcel of farm 2 could then be situated on any of the two unknown sides of the parcel of farm 1, with any of its three unknown sides. If there are 100 options to add an unknown neighbour that does not belong to farm 1, the probability of the parcel of farm 2 to be situated next to farm 1 is $\frac{1}{100} \times 2 \times 3=\frac{6}{100}$. These probabilities are then multiplied with the amount of hedgerows maintained on each potential neighbour, thereby determining the expected amount of maintained hedgerows. This expected amount of maintained hedgerows is an average amount of maintained hedgerows on all possible neighbours, thereby diminishing the impact of maintaining a hedgerow on a specific parcel (Groeneveld et al., 2017).

\section{Mimicking interactions with the wider farm community}

Generally, an ODM would be run on a large group of farmers. In each time step a farmer randomly interacts with one of the other farmers in the farming community. If the difference in opinion between the two farmers is sufficiently small, 
both farmers will adjust their opinions. This is repeated over many time steps. Our sample is too small for such interactions, as farmers would quite often interact with the same farmers. To mimic interactions with the wider farm community we construct a normal distribution with a mean equal to the average biodiversity weight of our sample and a standard deviation equal to the standard deviation of the biodiversity weights in our sample. From this distribution we randomly draw 31 biodiversity weights. To ensure that the weights are between zero and one, we set the weight to zero if the random draw is negative and to one if the random draw exceeds one. If the weight is already between zero and one no adjustment is made. These biodiversity weights are then combined with the weights of the original farmers. These 40 weights are then used to mimic interaction with farmers from the wider farmer community. The interaction takes place during 10 time steps. In each time step each of the 40 farmers interact with a randomly chosen other farmer, choosing each time whether or not to changes their own weights. In this way we determine the socially influenced weights of the farmers in part 2 of the model (see Figure 5.2.).

\subsection{MODEL}

\section{Model part 1: Determining farmer objectives and calculating weights}

To determine the weights attached to each of these objectives, we follow the procedure as described by Manos et al. (2009) in which we choose the weights in such a way that we minimize the deviations between the observed and calculated value of each objectives. A more detailed description and the equations of the Manos technique can be found in appendix A.

\section{Model part 2: Opinion Dynamics Model}

Each farmer $\theta$ starts with an initial weight for objective $\mathrm{n} g_{n}$, which is continuous and lies between zero and one. A threshold $\delta(\delta \varepsilon[0,1])$ captures the farmers openness to other opinions. A convergence parameter $\mu(\mu \varepsilon[0,1])$ is defined which captures how strong the social influence is. A farmer $s$ who has weight $\left(g_{n s}(t)\right)$ for objective $\mathrm{n}$ in time step $\mathrm{t}$ has the following social influence on the weight for objective $\mathrm{n}$ of farmer $\theta$ in time step $\mathrm{t}\left(g_{n \theta}(t)\right)$ equals:

$$
\begin{aligned}
& g_{n \theta}(t+1)=g_{n \theta}(t)+\mu\left(g_{n s}(t)-g_{n \theta}(t)\right) \text { if }\left|g_{n s}(t)-g_{n \theta}(t)\right|<\delta \\
& g_{n \theta}(t+1)=g_{n \theta}(t) \text { if }\left|g_{n s}(t)-g_{n \theta}(t)\right| \geq \delta
\end{aligned}
$$


When we adjust the weight for biodiversity, other weights have to be adjusted as well, in order for the weights to add up to one. To do this, we change the other weights depending on their relative size. The new weight is equal to the amount the biodiversity weight changed multiplied by the ratio of the old weight to the sum of the old weight for profit, labour and risk.

\section{Model part 3: Mathematical programming models}

To describe the mathematical programming models we show the general modelling structure. A more elaborated description of the mathematical programming models can be found in appendix C. In our mathematical programming models the aim of each farmer is to maximize utility as presented in equation (2), which is optimized given the constraints described by equations $(2 a)-(2 c)$.

maximize $U=\sum_{n=1}^{N} g_{n} O_{n}\left(r_{1}, \ldots, r_{Z}\right)$

Subject to:

$\sum_{z=1}^{Z} a_{z k} r_{z} \leq b_{k} \quad \forall_{k} \quad\left[\pi_{k}\right]$

$\sum_{Z=1}^{Z} c_{z l} r_{z}=d_{l} \quad \forall_{l}$

$r_{z} \geq 0 \quad \forall \forall_{Z}$

Where:

$U$ is utility; $g_{n}$ is the weight attached to objective n; $o_{n}\left(r_{z}\right)$ is the normalized value of objective $\mathrm{n}$ depending on activity level $z ; r_{z}$ is the level of activity $z, b_{k}$ is the total availability of a resource $\mathrm{k} ; a_{s k}$ is the quantity of resource $\mathrm{k}$ demanded by activity $\mathrm{z} ; \pi_{k}$ is the shadow price of resource $\mathrm{k} ; d_{l}$ is the total available quantity of resource $1 ; c_{z l}$ is the quantity of resource 1 demanded by activity $z$.

Utility depends on four farmer objectives, which are profit maximization, risk minimization, labour minimization and biodiversity maximization. These objectives are defined in equations (3)-(6).

$O_{1}=\sum_{j=1}^{J} p_{j} y_{j}-\sum_{m=1}^{M} w_{m} x_{m}+\left(p_{o}-w_{o}\right) y_{o}-w_{L}(L R-L I)$

$\mathrm{O}_{2}=L R$

$O_{3}=e v_{1} y_{1}^{2}$

$O_{4}=\frac{\sum_{b=1}^{3} \mu_{b}}{3} \quad b=1,2,3$

\section{Subject to:}

$T\left(\boldsymbol{y}, \boldsymbol{x}, y_{o}, L R\right)$

$\boldsymbol{p}, \boldsymbol{w}, p_{o}, w_{o}, w_{L}>0$ 
Where:

$O_{l}$ profit; $p_{j}$ price of regular output $\mathrm{j} ; v_{j}$ quantity of regular output $\mathrm{j} ; w_{m}$ price of input $\mathrm{m} ; x_{m}$ quantity of input $\mathrm{m} ; y_{o}$ AES payment hedgerows; $w_{o}$ cost of maintaining hedgerows; $y_{o}$ quantity of hedgerows maintained; $w_{L}$ costs of hired labour; $\mathrm{O}_{2}$ quantity labour used on the farm; $L R$ labour required in the production process; $L I$ initial labour endowment; $O_{3}$ risk taken by the farmer; $e$ risk aversion coefficient; $v_{I}$ variance milk price; $y_{1}$ amount of milk produced; $O_{4}$ overall biodiversity score; $\mu_{1}$ small scale biodiversity score; $\mu_{2}$ medium scale biodiversity score; $\mu_{3}$ large scale biodiversity score; $T\left(\boldsymbol{y}, \boldsymbol{x}, y_{o}, L\right)$ technology set; $\boldsymbol{y}, \boldsymbol{x}$ vector of outputs and variable inputs respectively; $\boldsymbol{p}, \boldsymbol{w}$ vector of output and input prices respectively.

\subsection{SCENARIOS}

Each model run in the mathematical programming model (model part 3) contains ten time steps, which refer to the time needed for the farmers to react to each other's biodiversity decisions in the previous time step. In each time step a farmer takes the maintenance decision made by the other farmer in the previous time step as given in order to calculate the effect of his/her own decisions on the overall biodiversity score. At the start of the model run the maintenance decisions of the other farmer are as specified during the interviews. The biodiversity feedback is included in all scenarios. In all the scenarios containing social influence we assume that the convergence parameter is equal to 0.5 .

\section{No social influence scenario}

In this scenario there is no social influence. This means the weights do no change in part 2 of the model and the farmers maintain their original weight in the mathematical programming models in model part 3.

\section{Basic social influence scenario}

In this scenario we assume that farmers will maintain the same threshold $\delta$ and convergence parameter $\mu$ for the interaction with each of the other farmers in the community. We report results for a low threshold (0.25), an intermediate threshold (0.5) and a high threshold (0.75). If the threshold is low, farmers will only adjust their opinion if the difference in opinions is small (when they interact with like-minded farmers). If the threshold is large farmers will also adjust their opinion if the difference in opinions is large. 


\section{Follow-the-leader scenario}

In this scenario the farmers care most about the opinion of a specific farmer who is the opinion leader of the group. This specific farmer is chosen from our original sample, and not from the distribution that we created. In this scenario the farmer will maintain a threshold and convergence parameter of 0.75 for the opinion leader, and a threshold and convergence parameter of 0.25 for the other farmers. This means that the farmer is more likely to adjust his/her opinion when (s)he interacts with the opinion leader than with another farmer. Also, the amount by which the farmer adjusts his/her opinion is larger when the farmer interacts with the opinion leader.

\section{Network scenario}

In this scenario we consider the effect of social influence if it is applied through a network structure. Farmers care only about the opinions of their network or "in-group". Farmers that are small in terms of the number of cows (100 cows or more) form a network, as well as farmers that are large in terms of the number of cows (less than 100 cows). For farmers that are not in the in-group of the farmer the threshold is set to zero, which means the farmer will not adjust his/ her opinion after interacting with someone outside his/her network. For farmers that are in the in-group of the farmer we present the results if farmers maintain a small $(0.25)$, medium $(0.5)$ or large $(0.75)$ threshold.

\subsection{RESULTS}

\section{No social influence scenario}

If there is no social influence, five farmers are participating in the AES and the overall biodiversity score is 0.723 . Each of the farmers faces a trade-off between contributing to biodiversity plus receiving AES payments and the labour needed for AES plus the decrease in roughage production. Farmers choose the optimal choice that results in the highest utility.

\section{Basic social influence scenario}

The average number of farmers in the collective AES programme for different levels of the threshold are shown in Figure 5.3. The threshold reflects the difference between the farmers own opinion and the opinion of the farmer with whom the interaction takes place, for values below the threshold the farmer will adjust his/her opinion. 


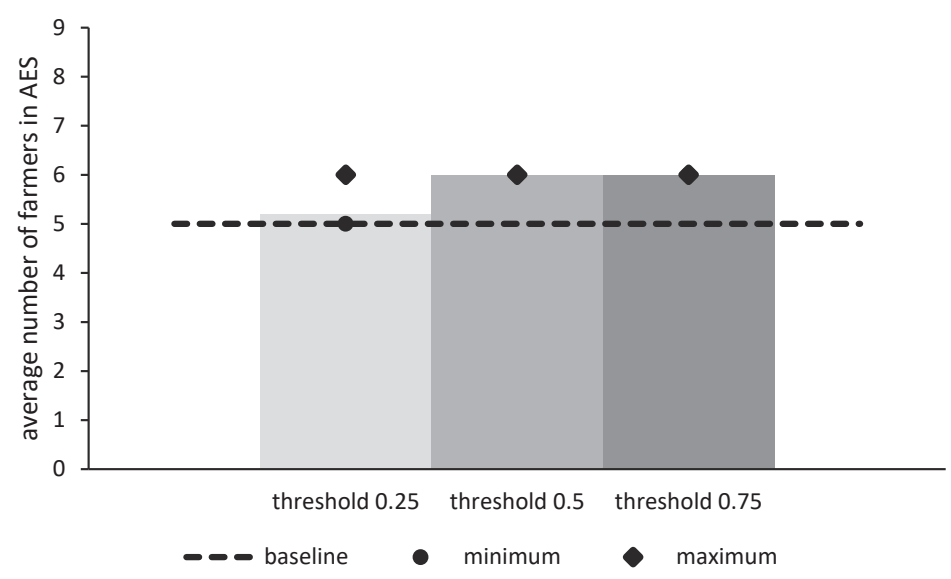

Figure 5.3. Average number of farmers in the AES programme in the basic social influence scenario over ten model runs at the end of time step ten for different threshold values

If the threshold is 0.25 the change in weights is very small and the optimal choice of the farmer only changes a little compared to the situation without additional social influence due to the introduction of the collective AES programme. If the threshold is 0.5 or 0.75 on average one more farmer participates in the AES programme due to the additional social influence. Due to the change in his/her weights the optimal decision of this farmer changes, and the highest utility can be achieved by participating in the AES. The fact that in this scenario one more farmer will participate due to social influence is due to the relatively high average biodiversity weight in the sample on which we base the farmer interactions. Since the farmers are randomly assigned other farmers they interact with, the resulting number of farmers in the AES might differ over the different model runs. The minimum number and maximum number of farmers over all the model runs are indicated by a dot and a square in Figure 5.3. A more detailed indication of the variety in the different runs is provided in appendix $\mathrm{D}$.

Figure 5.4. shows the average overall biodiversity score at the end of the model run. 


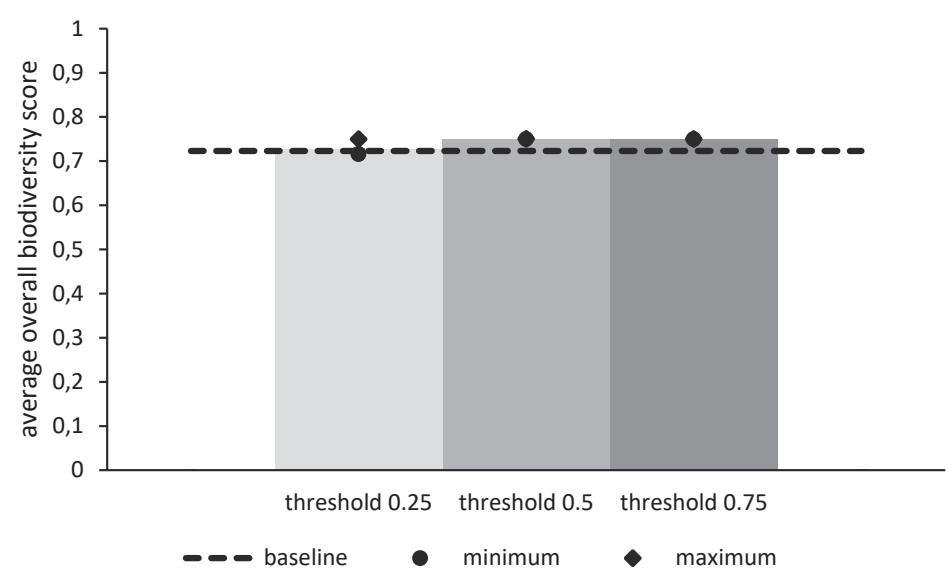

Figure 5.4. Average overall biodiversity score in the basic social influence scenario over ten model runs at the end of time step ten for different threshold values

When the threshold is 0.25 there is only a very small change in the farmers' objective weights, resulting in only a slightly higher average overall biodiversity score. This slight increase is caused by a slight increase in maintenance of farmers that already participated in the AES when there was no social influence. If the threshold is 0.5 or 0.75 the average overall biodiversity score is a bit higher than if there is no social influence. This increase is caused by the maintenance of the additional farmer that joins the AES due to social influence. The variation for the overall biodiversity score in the different model runs for the same threshold value is small, as shown by the minimum and maximum biodiversity score over all the model runs.

\section{Follow-the-leader scenario}

In Figure 5.5. we show the average number of farmers in the AES at the end of time step ten for different opinion leaders. 


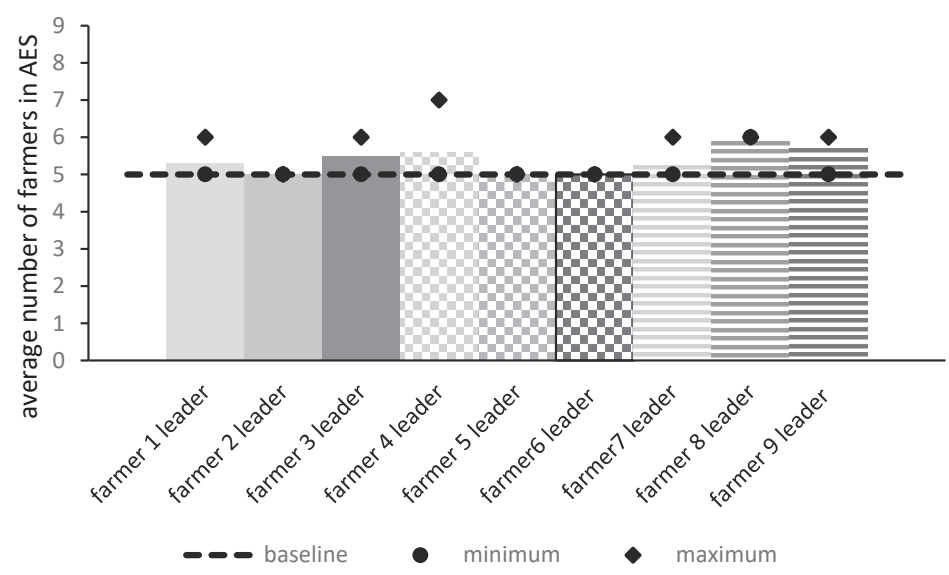

Figure 5.5. Number of farmers in the AES in the follow-the-leader scenario at the end of time step ten for different opinion leaders

The average number of farmers in the AES at the end of time step ten is slightly higher than in the baseline scenario if the opinion leader is farmer 1, 3,4,7,8 or 9. If one of the other farmers is the opinion leader the average number of farmers in the AES does not change compared to the baseline scenario. However, there is variation in between the different model runs when farmer $1,3,4,7,8$ or 9 is selected as opinion leader. The minimum number and maximum number of farmers over all the model runs are indicated by a dot and a square in Figure 5.5.

In Figure 5.6. we show the average overall biodiversity score at the end of time step ten for different opinion leaders.

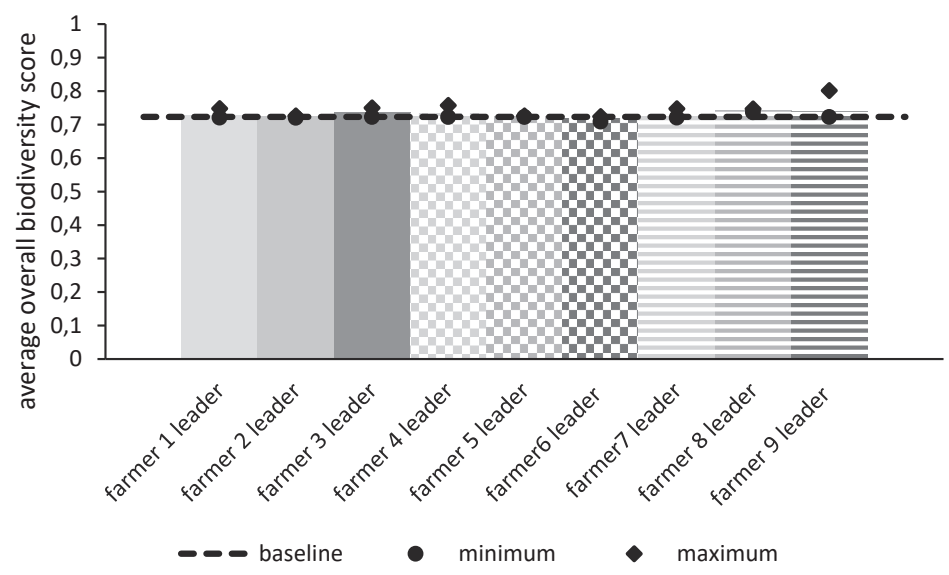

Figure 5.6. Overall biodiversity score in the follow-the-leader scenario at the end of time step ten for different opinion leaders 
The average overall biodiversity score increases slightly if there is interaction with an opinion leader, except when farmer 6 is selected as the opinion leader. If farmer 6 is selected there is a small decrease in the average overall biodiversity score. The minimum number and maximum biodiversity score over all the model runs are indicated by a dot and a square in Figure 5.6., as one can see the variation is small.

The number of farmers in the AES or the overall biodiversity score is not always exactly the same if the biodiversity weight of the opinion leader are the same. This is caused by a difference in the other weights of the opinion leaders, which also influences the optimal decisions of the farmer.

\section{Network scenario}

The average number of farmers in the collective AES programme for different levels of the threshold are shown in Figure 5.7.

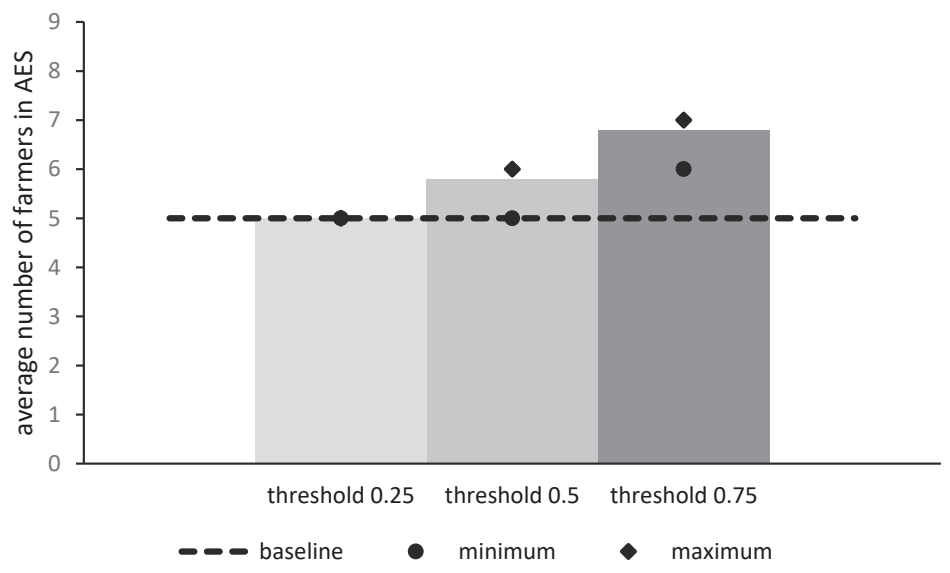

Figure 5.7. Average number of farmers in the AES programme in the network scenario over ten model runs at the end of time step ten for different threshold values

The average number of farmers in the AES does not increase due to social influence when the threshold is set to 0.25 . However, if the threshold is set to 0.5 or 0.75 the average number of farmers in the AES does increase. The minimum number and maximum number of farmers over all the model runs are indicated by a dot and a square in Figure 5.7. It is important to realise that these results depend on the formation of the in-group and the weights of the farmers in our sample. The average overall biodiversity score is shown in Figure 5.8. 


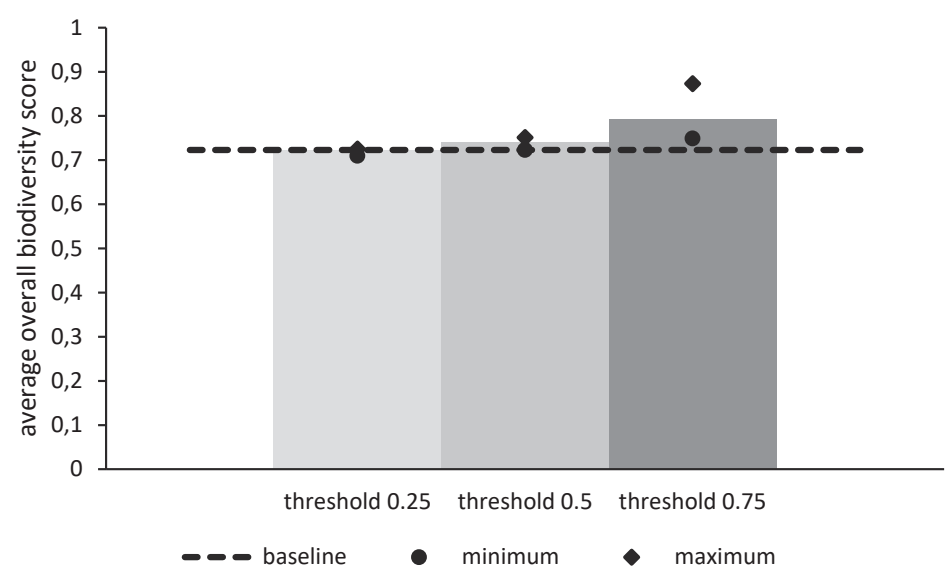

Figure 5.8. Average overall biodiversity score in the network scenario over ten model runs at the end of time step ten for different threshold values

The average overall biodiversity score is almost equal to the baseline scenario if the threshold is 0.25 . If the threshold is 0.5 or 0.75 the average overall biodiversity score is higher in the network scenario, due to the increase in social influence. The minimum and maximum biodiversity score over all the model runs are indicated by a dot and a square in Figure 5.8.

\section{Weights farmer objectives}

The weights we determined using the technique of Manos et al. (2009) are presented in appendix E. As a check, we also asked the farmers about the weights that they would attach to the farming objectives. These weights differed from the weights we calculated as can be seen in appendix E. Although the calculated weights also have a higher standard deviation, on average the calculated and reported weights are quite similar as shown in Table 5.2.

Table 5.2. Difference between calculated and reported weights, standard deviations in brackets

\begin{tabular}{lcccc}
\hline Average weights & $\begin{array}{c}\text { Weight } \\
\text { profit }\end{array}$ & $\begin{array}{c}\text { Weight } \\
\text { risk }\end{array}$ & $\begin{array}{c}\text { Weight } \\
\text { labour }\end{array}$ & $\begin{array}{c}\text { Weight } \\
\text { biodiversity }\end{array}$ \\
\hline Calculated & 0.381 & 0.082 & 0.140 & 0.397 \\
& $(0.45)$ & $(0.10)$ & $(0.33)$ & $(0.41)$ \\
& & & & \\
Reported & 0.356 & 0.057 & 0.277 & 0.310 \\
& $(0.17)$ & $(0.04)$ & $(0.10)$ & $(0.27)$ \\
\hline
\end{tabular}




\subsection{CONCLUSIONS AND DISCUSSION}

Our results show that if the introduction of the collective AES programme leads to social influence farmer participation and biodiversity might be positively affected, but the effect might be small or non-existent as well. The exact effect cannot be told beforehand and depends on the strength of the social influence, the like-mindedness of farmers and the type of social influence that is applied. However, the effect of social influence seems to be rather small, especially in terms of biodiversity.

Apparently, it is important to create the correct kind of social influence if biodiversity is to be increased. If farmers only change their opinions if they interact with like-minded farmers, there is likely no effect of the collective AES programme. On the other hand, if farmers are very open to the opinions of other farmers and there are enough biodiversity loving farmers in the region the collective AES programme might have a small positive effect. These findings have some interesting implications for policy design. Promoting a system with more social influence is not necessarily beneficial and there is a good chance that the effect of social influence is limited. Promoting social influence seems only worthwhile if farmers are open to other opinions and enough farmers in the region care for biodiversity already.

The possibility that social influence might play a role in farmer efforts to conserve nature is in line with results found by Josefsson et al. (2017). Similarly, van Dijk et al. (2015) and Runhaar et al. (2017) found that social capital, shared norms, relations of trust and social pressure will influence farmers' intention to cooperate and to participate in AES. The necessity of taking both personal characteristics and feedbacks from the environment into account when modelling people's decision-making, as we have done in our model, is confirmed by research of Phipps et al. (2013) and Johnstone and Hooper (2016).

The sample considered in our model is quite small, and the biodiversity weights we find are considerable. To check these weights we also asked the farmers outright about the weights they would attach to each of the farmer objectives. The reported weights differ from the calculated weights, but both the average reported biodiversity weight $(0.31)$ and the average calculated biodiversity weight $(0.40)$ are relatively high. This could be explained by the fact that our sample exists of farmers in an area that is known for its biodiversity and cultural values. This could very well mean that the weights we found for biodiversity are higher than the average weights one would expect from farmers in the Netherlands. This would mean that farmers in our sample are more likely to participate in the AES. 
However, the mechanisms for social influence as shown in the paper would not change if the objective weights are different.

We are aware that there are limitations to our results. First, our biodiversity measure is a crude approximation of real biodiversity; therefore our biodiversity scores should only be seen as an indication of the effect on biodiversity and be interpreted with care. Second, we show the mechanisms of social influence, but we are aware of the fact that the precise extent of social influence is hard to determine and therefore the strength of the social influence we assumed could deviate from reality. Finally, the sample considered in our research is small, and one should be careful in generalizing these results. Nevertheless, despite these limitations we think this paper adds to the debate on the effects and implementation of AES payments. 


\section{APPENDIX 5A. DETERMINING THE WEIGHTS OF THE FARMER}

\section{Objectives}

To determine the weights attached to each of these objectives, we follow the procedure as described by Manos et al. (2009). We calculate the weights in three steps. In the first step we define a set of $\mathrm{n}$ objectives $f_{l}(q), f_{2}(q) \ldots f_{n}(q)$ by asking the farmers in the sample about their farming objectives. Here q represents the constraints a farmer encounters when setting the level of the objective.

The next step is to define the pay-off matrix for the objectives. The pay-off matrix shows the value of each objective when optimizing each of the objectives and has the following set up:

Objectives / attributes $f_{l}(q), f_{2}(q) \ldots f_{n}(q)$

$f_{1}(q) \quad f_{1}^{*} \quad f_{12} \quad f_{1 n}$

$f_{2}(q) \quad f_{21} \quad f_{2}^{*} \quad f_{2 n}$

$f_{n}(q) \quad f_{n 1} \quad f_{n 2} \quad f_{n}^{*}$

The objective mentioned at the top of the column is optimised subject to $\mathrm{q}$. The levels achieved by the different objectives when optimizing the objective at the top are listed in the column below. Thus, the element $f_{i v}$ can be interpreted as the value of objective $i$ when we optimize objective $f_{v}(q)$. The optimal value for each objective can be found on the diagonal of the pay-off matrix.

The last step in obtaining the weights is to solve the following system of equations: $\operatorname{Min} \sum_{i=1}^{n}\left(\left(n d_{i}+p d_{i}\right) \times \frac{1}{f_{i}}\right)$

$i=1,2, \ldots, n$

\section{Subject to}

$\sum_{v=1}^{n} g_{v} f_{i v}+n d_{i}-p d_{i}=f_{i}$

$\sum_{v=1}^{n} g_{v}=1$

Where:

$f_{i v}$ are the elements of the pay-off matrix and $f_{i}$ is the value of the $\mathrm{i}$-th objective that is actually observed in the current production plan of the farmer, $n d_{i}$ is the negative deviation from the observed and calculated value of the $i$-th objective (i.e. $\left.f_{i}-f_{i}^{*}\right), p d_{i}$ is the positive deviation from the observed and calculated value of the i-th objective. 


\section{APPENDIX 5B. INDICATOR SPECIES AND BIODIVERSITY SCORES}

As a measure of biodiversity we calculate biodiversity scores based on three example species. These three species are used to represent the biodiversity in the area and are chosen in such a way that the size of the area needed to maintain a sustainable population (key area) of each species differs. The key area can be divided over different habitat areas (maintained hedgerows) as long as these hedgerows are within the dispersion capacity of the species. The dispersion capacity indicates the distance over which an organism is able to move from one habitat area to the next (Reijnen et al., 2001; Reijnen et al., 2007). To determine the total area that is available to a species, the habitat areas that are within dispersion capacity of each other are summed up. If this total area is equal to or larger than the key area a sustainable population of the species can be maintained. Grashof-Bokdam et al. (2009), Reijnen et al. (2001), Reijnen et al. (2007), Elands et al. (2005) and Kwakernaak et al. (2015) have analysed biodiversity using the concepts of key areas and dispersion capacity before.

We focus on the plant species false oat-grass (Arrhenatherum elatius), the butterfly species purple hairstreak (Favonius quercus) and the plant species largeflowered hemp-nettle (Galeopsis speciosa). Each of these species can occur in well-maintained hedgerows (Floron, 2017; Vlindernet, 2017; Dijkstra, 2017). False oat grass has a small scale key area of $1,000 \mathrm{~m}^{2}$, the purple hairstreak has a medium scale key area of 5 ha and the large-flowered hemp-nettle has a large scale key area of $10 \mathrm{ha}$. The dispersion capacity of these species is such that they are able to move between the hedgerows in our study area (expert judgement). Due to its small scale key area a sustainable population of false oat can already be maintained on a single farming parcel plus its direct neighbours. To maintain a sustainable population of the purple hairstreak maintaining the hedgerows on an area equal to the farm size plus its directly neighbouring parcels is sufficient. Due to its large scale key area a sustainable population of the large-flower hemp nettle can only result from maintaining all the hedgerows in the region. In reality, one can imagine that only a part of the hedgerows in each key area is maintained. The ratio of maintained to total hedgerows in the defined key areas (i.e. parcel plus neighbours, farm plus neighbours, all parcels in region) is translated in a biodiversity score using a logistic function. We specify the logistic function in such a way that the biodiversity score will be relatively high before a certain threshold and relative low below a certain threshold. To find the overall biodiversity score we take the average of the small, medium and large scale biodiversity scores. 


\section{APPENDIX 5C. MATHEMATICAL PROGRAMMING MODELS}

The model simulates the decisions of nine dairy farmers in the "Noordelijke Friese Wouden". We assume that the farmer optimizes utility (C1). Utility is calculated as the sum of the weights the farmer attaches to each of the objectives times the normalized value of each objective. The objectives of the farmer are profit maximization (C2), labour minimization (C3), risk minimization (C4) and biodiversity maximization (C5). Utility is maximized subject to constraints (C2C35).

Objective:

maximize $U_{i}=\sum_{n=1}^{2} g_{i n} \frac{o_{i n}}{O_{i n}{ }^{*}}-g_{i 3} \frac{o_{i 3}}{O_{i 3}{ }^{*}}-g_{i 4} \frac{o_{i 4}}{O_{i 4}{ }^{*}}$

$n=1, \ldots, 4 ; i=1, \ldots, 9$

Subject to:

$O_{i 1}=p_{1} y_{i 1}+p_{2} x_{i 22}+p_{o} x_{i 7}-\sum_{m=1}^{8} w_{m} x_{i m}-w_{9} O_{i 2}-w_{10} x_{i 24}$

$m=1, \ldots, 10$

$O_{i 2}=L R_{i}$

$O_{i 3}=v_{1} y_{i 1}^{2}$

$O_{i 4}=\frac{\sum_{b=1}^{3} \mu_{i b}}{3}$

$y_{i 1}=x_{i 1} * e_{i 4}$

$x_{i 4}=\sum_{m=1}^{3} x_{i m} e_{m}-x_{i 11} e_{11}-x_{i 12} e_{12}-x_{i 13} e_{31}-x_{i 14} e_{32}$

$x_{i 5}=\max \left(0, x_{i 15}-x_{i 16}\right)$

$x_{i 15}=x_{i 11} e_{11} e_{13}+x_{i 12} e_{12} e_{13}+x_{i 13} e_{31} e_{14}+x_{i 14} e_{32} e_{14}+x_{i 4} e_{15}-x_{i 1} e_{i 4} e_{16}-x_{i 1} e_{17}-$

$x_{i 16}=x_{i 8} e_{20}+x_{i 6} e_{21}$

$L R_{i}=x_{i 1} e_{5}+\sum_{m=6}^{8} x_{i m} e_{m}$

$x_{i 18}=\sum_{h=1}^{H} e_{h i 22}-e_{i 23}$

$h=1, \ldots, H$

$x_{i 18}=x_{i 8}+x_{i 6}$

$e_{i 23}=x_{i 7}+x_{i 9}$

$x_{i 8}=x_{i 11}+x_{i 12}$

$x_{i 6}=x_{i 13}+x_{i 14}$

$x_{i 12}+x_{i 14}=x_{i 7}$

$x_{i 7} \leq e_{i 23}$ 


$$
\begin{aligned}
& x_{\text {hi10 }}=x_{\text {hi25 }}+\sum_{a=1}^{A} e_{a} * x_{\text {ha19 }} \\
& a=1, \ldots, A \\
& x_{i 21}=\sum_{h=1}^{H} x_{h i 25}+\sum_{c=1}^{C} e_{c} * x_{h c 20} \\
& c=1, \ldots, C \\
& =\sum_{h=1}^{H}\left(\frac{1}{\left.\left(1+e^{\left(-\alpha *\left(\left(\frac{x_{h i 10}}{e_{h i 3}}\right)-\beta\right)\right.}\right)\right)}\right) / e_{e_{i 35}} \\
& \mu_{i 2}=\frac{1}{\left(1+e^{\left(-\alpha *\left(\left(\frac{x_{i 21}}{e_{i 34}}\right)-\beta\right)\right)}\right)} \\
& \mu_{i 3}=\frac{1}{\left(1+e^{\left.\left(-\alpha *\left(\left(\frac{\sum_{i=1}^{9} x_{i 7}}{e_{i 24}}\right)-\beta\right)\right)\right)}\right)} \\
& x_{i 7}=\sum_{h=1}^{H} x_{h i 25} \\
& x_{\text {hi25 }} \leq e_{\text {hi28 }} \\
& x_{i 1}, x_{i 2}, x_{i 3}, x_{i 4}, x_{i 5}, x_{i 6}, x_{i 7}, x_{i 8}, x_{i 9}, x_{i 11}, x_{i 12}, x_{i 13}, x_{i 14}, x_{i 18}, x_{i 22}, x_{i 23}, x_{i 24} \geq 0 \\
& x_{i 8} \geq x_{i 18} * 0.8 \\
& x_{i 2}=e_{i 25} x_{i 1} \\
& x_{i 3}=e_{i 26} x_{i 1} \\
& x_{i 1} \leq e_{i 27} \\
& x_{i 22} \geq e_{9} * e_{i 27} \\
& x_{i 23}=e_{i 30} * e_{i 27}+x_{i 17} \\
& x_{i 1}=e_{i 27}-x_{i 22}+x_{i 23} \\
& O_{i 1} \geq e_{29}
\end{aligned}
$$

\section{Add for the collective AES programme setting:}

If $\left(\frac{\sum_{i=1}^{9} \mu_{i 1}}{9}+\frac{\sum_{i=1}^{9} \mu_{i 2}}{9}+\frac{\sum_{i=1}^{9} \mu_{i 3}}{9}\right) / 3>e_{36}$ then $p_{o t=2}=p_{o}$

If $\left(\frac{\sum_{i=1}^{9} \mu_{i 1}}{9}+\frac{\sum_{i=1}^{9} \mu_{i 2}}{9}+\frac{\sum_{i=1}^{9} \mu_{i 3}}{9}\right) / 3 \leq e_{36}$ then $p_{o t=2}=0$ 
Where:

$U_{i}=$ utility of farmer i

$O_{i 1}=$ profit farmer $\mathrm{i}$ in euros

$O_{i 2}=$ labour hours used on farm i

$O_{i 3}=$ risk taken by farmer i

$O_{i 4}=$ overall biodiversity score

$O_{i 1}{ }^{*}=$ maximum profit in euros farmer $\mathrm{i}$ could obtain

$O_{i 2}{ }^{*}=$ minimum labour hours that could be used on farm $\mathrm{i}$

$O_{i 3}{ }^{*}=$ minimum risk that could be taken by farmer $\mathrm{i}$

$O_{i 4}{ }^{*}=\quad$ max overall biodiversity score farmer i could obtain

$g_{i l}=$ weight attached to profit maximization by farmer $\mathrm{i}$

$g_{i 2}=$ weight attached to labour minimization by farmer $\mathrm{i}$

$g_{i 3}=$ weight attached to risk minimization by farmer $\mathrm{i}$

$g_{i 4}=$ weight attached to biodiversity maximization by farmer $\mathrm{i}$

$L R_{i}=$ labour hours required on farm $\mathrm{i}$

$L I_{i}=$ initial labour hours available on farm $\mathrm{i}$

$\alpha=$ speed parameter

$\beta=$ biodiversity parameter

$v_{l}=$ variance milk price

$\mu_{i 1}=$ biodiversity score small scale biodiversity type for farmer $\mathrm{i}$

$\mu_{i 2}=$ biodiversity score medium scale biodiversity type for farmer $\mathrm{i}$

$\mu_{i 3}=$ biodiversity score large scale biodiversity type

$y_{i 1}=$ milk produced on farm i (in $100 \mathrm{kgs}$ )

$p_{1}=$ price milk in euro per $100 \mathrm{~kg}$

$p_{2}=$ price old cows in euro per cow

$p_{o}=$ price maintained hedgerows in euro per $\mathrm{m}^{2}$

$w_{1}=$ maintenance costs in euro per cow

$w_{2}=$ maintenance costs in euro per young cattle $<1$ year

$w_{3}=$ maintenance costs in euro per young cattle $>1$ year

$w_{4}=$ costs per KVEM feed in euro

$w_{5}=$ costs of removing a $\mathrm{kg}$ of excess phosphate in euro

$w_{6}=$ costs of maintaining a $\mathrm{m}^{2}$ of maize in euro

$w_{7}=$ costs of maintaining a $\mathrm{m}^{2}$ hedgerows in euro

$w_{8}=$ costs of maintaining a $\mathrm{m}^{2}$ of grass in euro

$w_{9}=$ costs of hiring an hour of labour in euro

$w_{10}=$ costs of buying one more cow in euro per cow

$x_{i 1}=$ number of cows on farm $\mathrm{i}$

$x_{i 2}=$ number of young cattle $<1$ year on farm $\mathrm{i}$ 







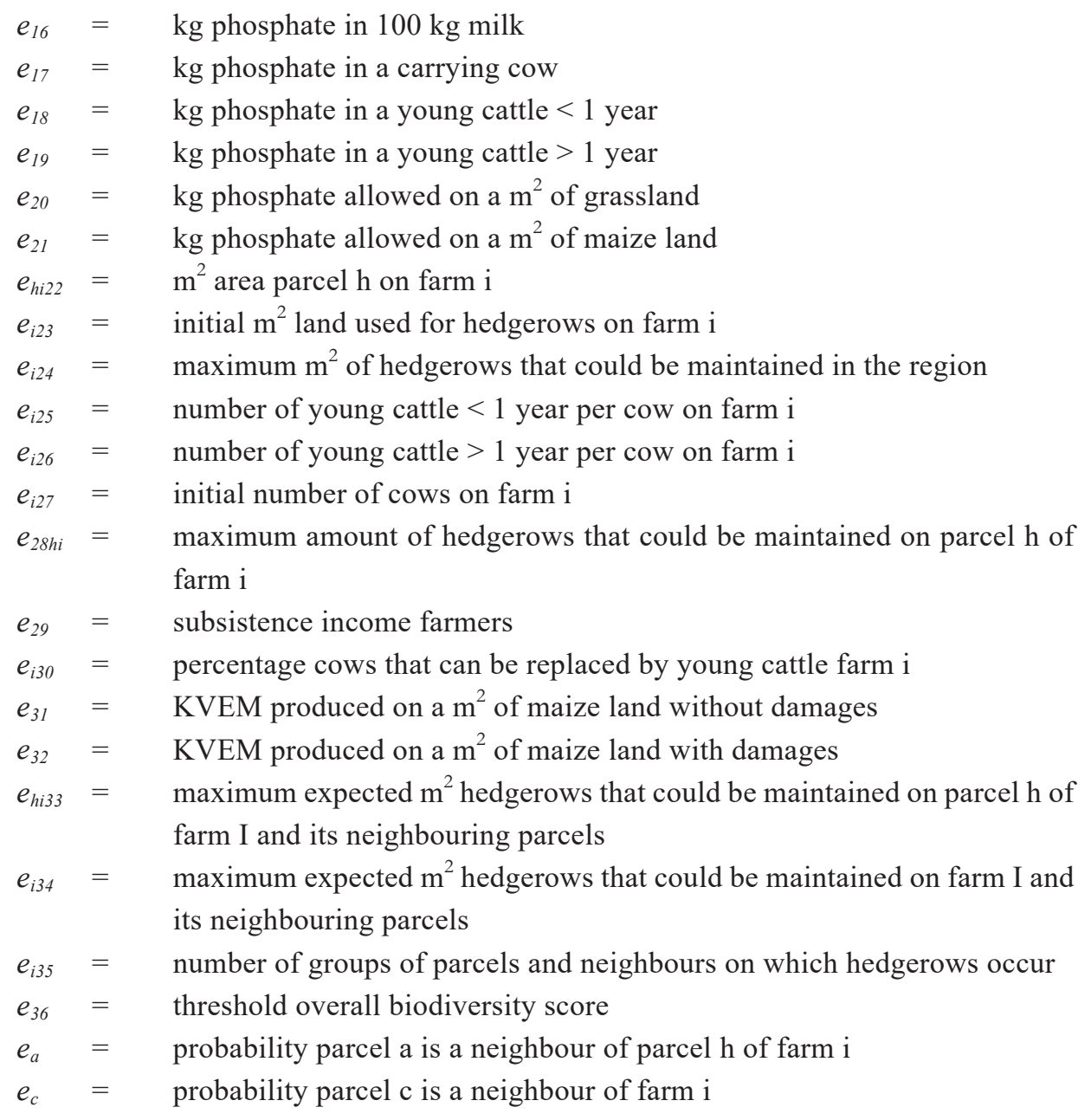

The farmer objective is to optimize his/her utility, as described by equation (C1). Four farmer objectives are included in the utility function, profit maximization, labour minimization, risk minimization and biodiversity maximization. If a farmer does not value one of these objectives, this objective will receive a zero weight.

Profit is calculated as revenue minus costs (C2). Revenue results from milk production, selling cows too old for production and AES payments. Costs are determined as the costs of normal production plus the costs of maintaining hedgerows. If we add the labour needed for each of the farmer objectives we find the total amount of labour used on the farm (C3). To calculate risk we look at the variance of the milk price (C4). We add the score for the small scale, medium scale and large scale biodiversity type to find the overall biodiversity score (C5). 
The farm produces milk and biodiversity. By multiplying the number of cows times the milk production per cow we find the total milk production (C6). Grass and maize grown on the farm can be used as feed; if more feed is needed than produced the rest of the feed can be purchased from the market (C7). The amount of feed produced on the farm depends on the type of crop that is planted and the amount of damage to the crops due to shade resulting from the hedgerows. A certain amount of phosphate is allowed on farm land, any phosphate in excess of this amount has to be removed from the farm (C8). The total amount of phosphate on the farm is the sum of phosphate in the feed minus the phosphate bound in milk, cows and young cattle (C9). The amount of phosphate allowed on land is found by multiplying the phosphate allowed per $\mathrm{m}^{2}$ grass or maize with the $\mathrm{m}^{2}$ grass and maize on the farm (C10). By adding the amount of labour required for feeding and milking the cows, working on the land and maintaining the hedgerows we find the farms total labour requirement (C11). Land available for production is the result of deducting the land needed for hedgerows from the land available on the parcels of the farm (C12). Land can either be used in the production of maize or the production of grass (C13). Hedgerows can be divided in maintained and unmaintained hedgerows (C14). Grass land and maize land are separated in land with and without damages from hedgerows (C15 and C16). A share of the land used by maintained hedgerows is used to determine the amount of land with damages (C17). It is not possible to increase the amount of maintained hedgerows above the initial amount of hedgerows (C18).

We determine the ratio of maintained to total hedgerows as the basis for calculating biodiversity scores. For the small scale biodiversity score this ratio compares the maintained to total hedgerows on a farming parcel and its direct neighbours. For the medium scale biodiversity score this ratio compares the maintained to total hedgerows on a farm plus its direct neighbouring parcels. For the large scale biodiversity score this ratio compares the maintained to total hedgerows in the whole region. The biodiversity score in our model is determined by a logistic function. A logistic function has been used before by Natuhara and Imai (1999) to link environmental variables to species richness. The logistic function captures an abrupt switch from a high to a low biodiversity score in a continuous way; thereby making it is possible to solve the model. In our function a high ratio of maintained to total hedgerows is translated in a biodiversity score close to one. A small ratio is translated to a biodiversity score close to zero. The biodiversity scores are determined in equations (C21, C22, C23). The speed parameter $\alpha$ regulates how quickly the biodiversity score changes from close to zero to close to one, a higher $\alpha$ means a faster switch. In the model we arbitrarily set the speed parameter to 30, which means the transition from a low to a high biodiversity score will be 
fast. The biodiversity parameter $\beta$ regulates at what ratio of maintained to total hedgerows the switch from a high to a low biodiversity score takes place. The biodiversity parameter is set to 0.7 , which means that the biodiversity score will be low for a ratio smaller than 0.8 .

To create an artificial region we combine the information on the parcels on the individual farms. For each parcel the chance that it neighbours parcel h of farm $i$ is determined. For all parcels h of farm $i$ we know exactly how they are located relative to each other, and the probability is either 0 or 1. For parcels that do not belong to farm $i$ we determine the potential neighbours and use this information to calculate the probability. The average expected amount of maintained hedgerows on the parcels a neighbouring parcel $\mathrm{h}$ is then determined by summing the multiplication of the probability that each parcel a neighbours parcel $h$ and the amount of hedgerows on each parcel a. We add the amount of hedgerows maintained on parcel $h$ itself to this expected amount to find the amount of hedgerows maintained on parcel ha and its direct neighbouring parcels (C19). Likewise we multiply the probability that each parcel c neighbours farm i with the hedgerows maintained on each parcel c to calculate the expected amount of hedgerows maintained on the direct neighbours of farm i. To this amount we add the hedgerows maintained on farm i to calculate the amount of hedgerows maintained on farm $\mathrm{i}$ and its direct neighbouring parcels (C20). If we add the hedgerows maintained on each of the farms parcels we find the total amount of hedgerows maintained by the farmer (C24). One cannot maintain more hedgerows on the parcel than are available on that parcel (C25).

The amount of cows, young cattle younger than 1 year, young cattle older than 1 year, feed purchased, phosphate surplus, maize, hedgerows maintained and not maintained, grass, grass without damages, grass with damages, maize without damages, maize with damages, land used in production, old cows sold, new cows on farm and new cows bought cannot be negative (C26).

Minerals are contained within the manure produced by cows. In order to avoid environmental damages as a result of a surplus of these minerals used on land, the EU designed regulations that limit the amount of minerals from manure that is allowed on land. After the Dutch farmers and government successfully claimed that more minerals could be put on the Dutch farm land without hurting the environment the EU agreed to derogation. This allows the Dutch farmers to place more minerals on land as long as the farm has at least 80 percent grassland. Therefore we assume that the farms in our model need to have at least 80 percent grassland (C27). For a certain percentage of the number of cows young cows should be kept to replace them, this percentage was solicited during the farm interviews (C28 and C29). It is not possible to exceed the initial number of cows 
(C30). Cows can be sold, the number of cos sold is larger than or equal to the amount of old cows (C31). New cows can either be bought or come from the young cattle raised to replace old cows (C32). The final number of cows on the farm is equal to the initial cows minus the cows sold plus the new cows (C33). If the farm wants to survive a certain subsistence income is necessary (C34).

\section{APPENDIX 5D. VARIATION IN MODEL RUNS}

Basic social influence scenario

Histogram threshold 0.25

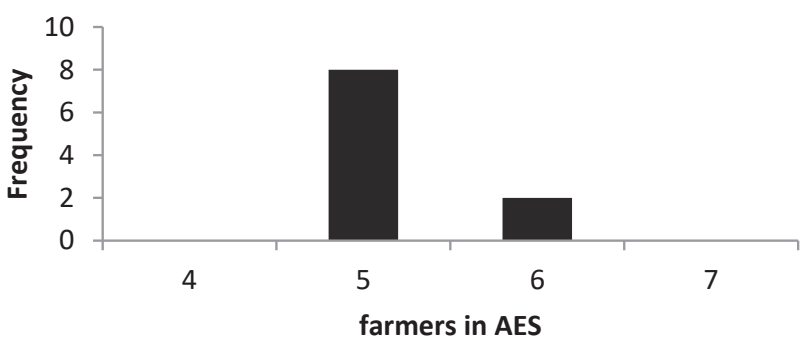

Histogram threshold 0.5

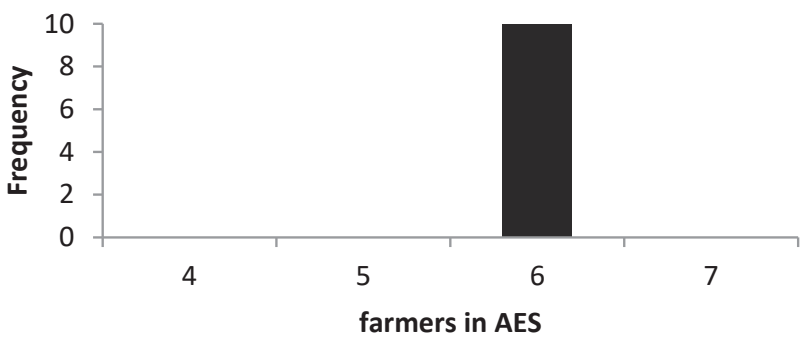

Histogram threshold $\mathbf{0 . 7 5}$

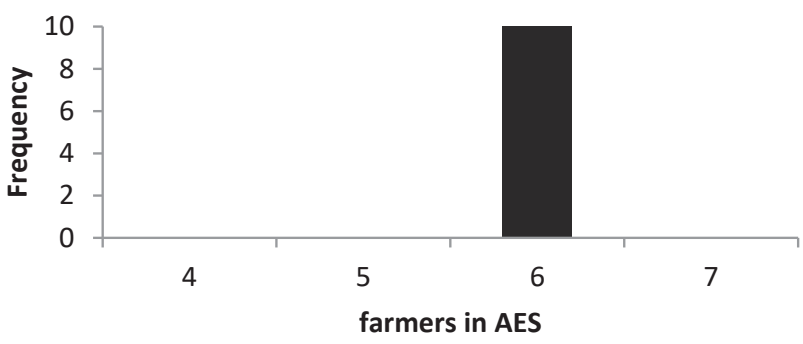

Figure 5D.1. Histograms basic social influence scenario 
Follow-the-leader scenario
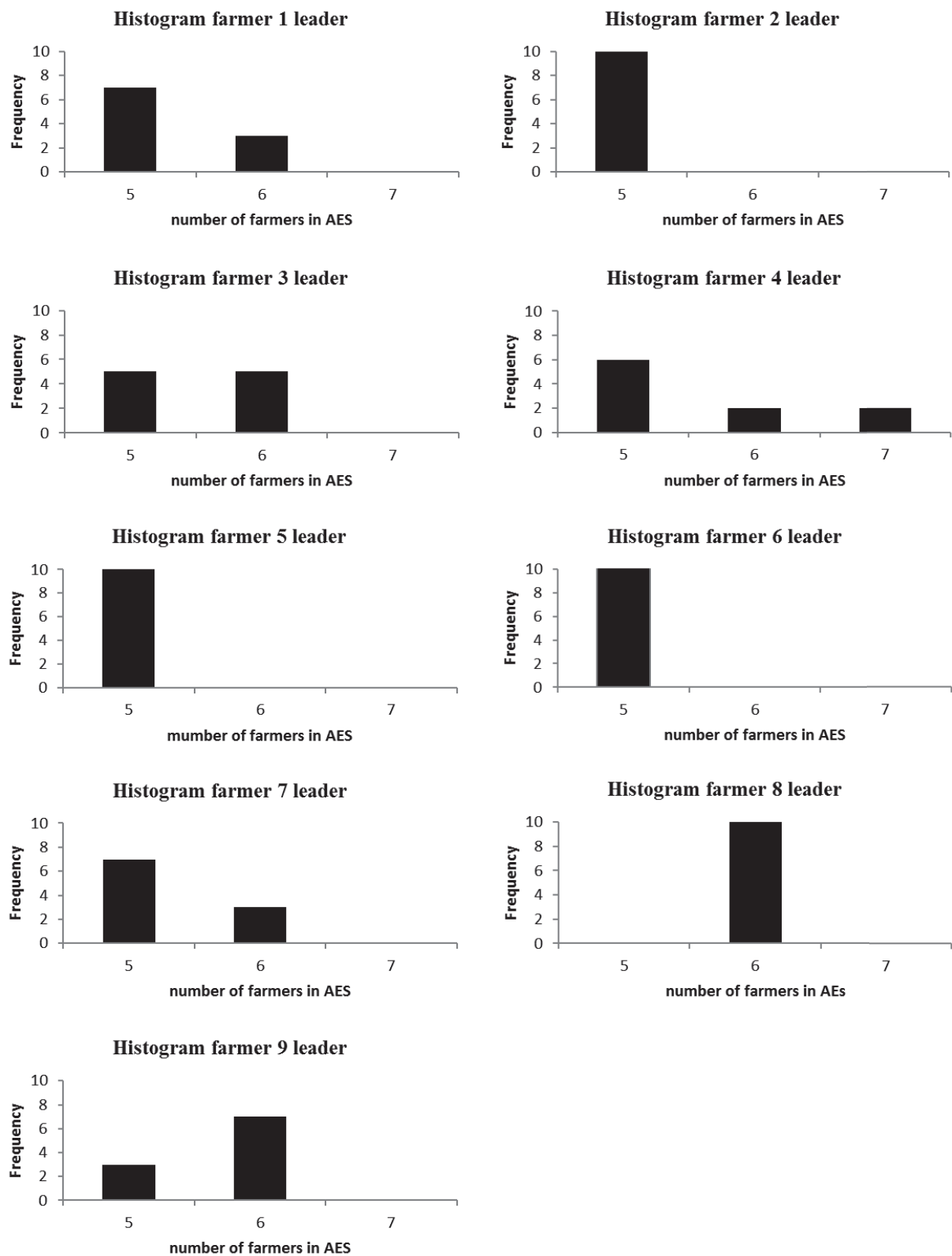

Figure 5D.2. Histograms follow-the-leader scenario 
Network scenario

Histogram threshold 0.25

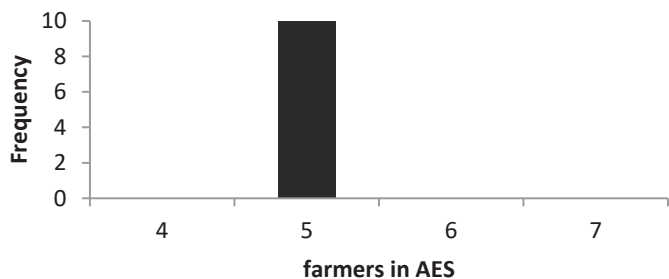

Histogram threshold 0.5

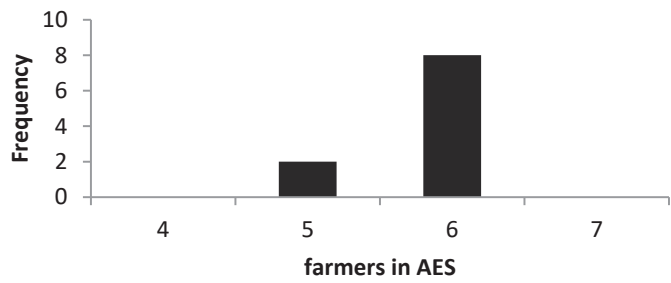

Histogram threshold 0.75

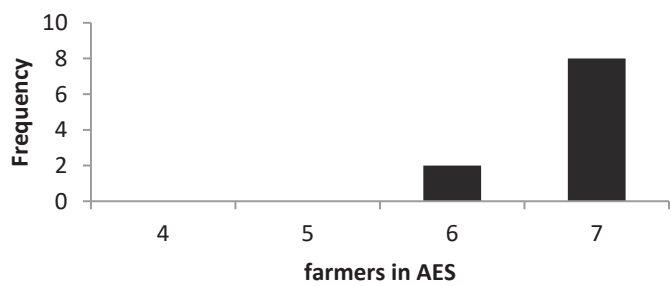

Figure 5D.3. Histograms network scenario 


\section{APPENDIX 5E. INITIAL WEIGHTS}

Table 5E.1. Initial objective weights calculated by the technique of Manos et al. (2009)

\begin{tabular}{llllll}
\hline Farmer & $\begin{array}{l}\text { Weight } \\
\text { profit }\end{array}$ & Weight risk & $\begin{array}{l}\text { Weight } \\
\text { labour }\end{array}$ & $\begin{array}{l}\text { Weight } \\
\text { biodiver-sity }\end{array}$ & $\begin{array}{l}\text { Sum of } \\
\text { weights }\end{array}$ \\
\hline 1 & 0.000 & 0.000 & 1.000 & 0.000 & 1.000 \\
2 & 0.000 & 0.106 & 0.000 & 0.894 & 1.000 \\
3 & 0.606 & 0.032 & 0.000 & 0.362 & 1.000 \\
4 & 0.000 & 0.264 & 0.000 & 0.736 & 1.000 \\
5 & 0.000 & 0.141 & 0.000 & 0.859 & 1.000 \\
6 & 0.740 & 0.000 & 0.260 & 0.000 & 1.000 \\
7 & 1.000 & 0.000 & 0.000 & 0.000 & 1.000 \\
8 & 1.000 & 0.000 & 0.000 & 0.000 & 1.000 \\
9 & 0.081 & 0.194 & 0.000 & 0.725 & 1.000 \\
\hline
\end{tabular}

Table 5E.2. Initial objective weights reported during the interviews

\begin{tabular}{llllll}
\hline Farmer & $\begin{array}{l}\text { Weight } \\
\text { profit }\end{array}$ & Weight risk & $\begin{array}{l}\text { Weight } \\
\text { labour }\end{array}$ & $\begin{array}{l}\text { Weight } \\
\text { biodiver-sity }\end{array}$ & $\begin{array}{l}\text { Sum of } \\
\text { weights }\end{array}$ \\
\hline 1 & 0.300 & 0.000 & 0.300 & 0.400 & 1.000 \\
2 & 0.200 & 0.200 & 0.200 & 0.400 & 1.000 \\
3 & 0.670 & 0.000 & 0.330 & 0.000 & 1.000 \\
4 & 0.273 & 0.180 & 0.273 & 0.273 & 1.000 \\
5 & 0.330 & 0.130 & 0.270 & 0.270 & 1.000 \\
6 & 0.500 & 0.000 & 0.500 & 0.000 & 1.000 \\
7 & 0.000 & 0.000 & 0.000 & 1.000 & 1.000 \\
8 & 0.600 & 0.000 & 0.400 & 0.000 & 1.000 \\
9 & 0.330 & 0.000 & 0.220 & 0.450 & 1.000 \\
\hline
\end{tabular}





\section{Chapter 6}

Conclusions and Discussion 

The objective of this thesis was to determine if thresholds, cumulative effects, and feedbacks and interactions can be responsible for unexpected system behaviour in land use systems. To do so, the Dutch dairy sector was taken as an example of a complex adaptive system. Four sub questions were formulated, each looking at one of the hypothesized mechanisms of land use change. We will first discuss the findings for each of these sub questions separately, followed by a synthesis and discussion of these findings.

The first sub question in chapter 2 concerned thresholds and asked whether the abolishment of the milk quotas would lead to a shift towards larger and more intensive farms in the Netherlands. For this sub question the Dutch dairy farms and their environment were considered as the land use system. We showed that a sudden shift towards intensive dairy farming can occur when milk quotas are abolished, but only if a threshold in farm size is passed. The second sub question in chapter 3 concerned cumulative effects and asked how the uptake of a new farming practice for processing of organic waste into compost in the "Friese Meren" in the Dutch province of Friesland was influenced by economies of scale, learning, and changing social norms. In this case the dairy farms in the "Friese Meren" and their environment was considered as the land use system. Our findings were that a large uptake of organic waste could only be explained by a combination of economies of scale, learning and changing social norms. The third sub question in chapter 4 concerned feedbacks and asked what the effect would be on the resilience of the system of the shift from an individual to collective application for agri-environmental contracts in the Netherlands and how the resilience of the land use system was affected by the value farmers attach to biodiversity. In this case the land use system studied encompasses the dairy farms in the "Noordelijke Friese Wouden" and their environment. We showed that the introduction of the collective AES programme results in a loss of resilience of the hedgerow landscape, in the sense that a shift towards low biodiversity in the Noordelijke Friese Wouden might be intensified due to the biodiversity and payment feedback that are in place in the collective AES programme. The decrease in resilience is stronger when biodiversity is valued less by the farmers. Finally, the fourth sub question in chapter 5 concerned interactions and asked whether social influence due to the introduction of the collective AES system in the Netherlands would result in a shift towards increased farm participation and a higher level of biodiversity. Again, the land use system studied consisted of the dairy farms in the "Noordelijke Friese Wouden" and their environment. We illustrated how the participation of farms in the AES programme to maintain hedgerows in the Noordelijke Friese Wouden might be subject to social influence, but that 
an increase in social influence does not necessarily result in a shift towards higher farmer participation or more biodiversity.

These findings show that thresholds, cumulative effects, and feedbacks and interactions can be responsible for unexpected system behaviour in land use systems. Thresholds might explain both regime shifts and inertia in the land use system. If the system is close to a threshold a small change in the environment can be the onset of a shift, while a system that is far from the threshold will be much more resilient. The relevance of thresholds is also pointed out by Marston (2015) who uses an historical perspective and identifies examples of the thresholds that led to the adoption of sustainable agricultural practices. Unexpected system behaviour might also be due to the existence of cumulative effects of different drivers of the land use system. In order to properly understand land use systems, all drivers of the system and their interaction need to be considered. Looking at each driver separately may result in a skewed perception of the system and lead to wrong predictions on system behaviour. This is in accordance with findings from Morris \& Rowe (2014) who point out how cumulative effects of human influences change the vegetation in the great basin in the United States. Feedbacks have the potential to explain unexpected system behaviour as well. Feedbacks from higher scale levels influence individual farm decisions, and these individual farm decisions in turn send a signal to the higher scale levels. Positive feedbacks can increase the effect of a driver of land use change, being self-reinforcing. Negative feedbacks can prevent changes from happening, by reinforcing the current state of the system. The importance of understanding feedbacks in the land use system is also pointed out by Verburg (2006). An analysis on research of feedbacks in land use systems performed by Chen et al. (2016a) further confirms the importance of including feedbacks in the analysis of land use systems. Finally, we found that interactions between the agent of a land use system have the potential to explain unexpected system behaviour. Social influence created by farmers' interaction can increase the uptake of an innovation or policy measure. On the other hand, social influence also has the potential to decrease the shift, making the land use system more resilient. In their research Miyasaka et al. (2017) also indicate the complex character of human environment (i.e. land use) systems caused by feedback loops between agents and their environment and interaction between the agents. However, although we showed that each of the mechanisms can be responsible for unexpected system behaviour, we also showed that this is not always the case, and depends on the specific characteristics of the land use system under consideration.

By taking into account the possible effects of thresholds, cumulative effects, and interactions and feedbacks policy makers might be better prepared for unex- 
pected system behaviour. The effect of abolishing or introducing a production limitation on farmers behaviour might be much better anticipated if the role of thresholds in farming choices are understood. As long as the farm is far from the threshold, its decisions will not be constrained by the limitations and its decisions with and without the production limitations do not differ. If the farm produces at a level above the threshold, its decisions will differ between the situation with and without limitations. Promoting a new farming practice might be much easier if cumulative effects can be generated, for instance by both reducing the costs of the new practice and by creating opportunities for farmers to learn from each other. Anticipating the effect of a new type of agri-environmental schemes is aided by considering feedbacks and interactions, and simulating the right type of social influence might even result in better results of the new scheme. Thus, taking complexity elements into account can help to predict how land use systems will react to policies and global change, thereby offering insights to improve policy design. If complexity is not taken into account one might be surprised by seemingly unexpected responses of the land use system see e.g. Mandemaker et al. (2014), who states that real world agricultural land use systems can only be meaningfully described by looking at complex system behaviour. Likewise, Temu, Rudebjer \& Chakeredza (2010), Li et al. (2010), Ligmann-Zielinska \& Sun (2010), and Strapasson (2015) use a complex systems approach to analyse land use dynamics. The exact way these complexity elements should be taken into account during the policy making process was not explicitly studied in this thesis, this would be an interesting topic for further research. Further research might also investigate how often these unexpected system responses actually occur, given the fact that current policies already aim for smooth transitions and are often implemented in small steps.

The results of this thesis are impacted by the choices we made when performing our research. We discuss a number of these choices and their implications. We first discuss some theoretical issues, followed by a discussion on the data and a discussion on the mathematical programming models used in this research.

\section{Theory}

In this thesis we analyse different mechanisms of land use change in the Dutch dairy sector. We do not incorporate all mechanisms in each of the papers, but concentrate on one or a few mechanisms at the time. By not including all of the mechanisms at the same time, we miss the effects and emergent behaviour that might occur from the interaction and combination of the different mechanisms. With the abolishment of the milk quotas in chapter 2 we have an example of the role thresholds can play in land use systems. We realise we take a limited view on 
complexity in this chapter, as the modelled shift does not result from interactions between farms or from feedbacks between scale levels, but only from the thresholds formed by the constraints. However, the contribution of this chapter is to show that that the system (i.e. farm) will only respond to changes once a certain threshold is reached. Moreover, the abolishment of the milk quota system can be regarded as part of a complex system on a high scale in which member states of the EU, the EU and other countries and the WTO interact via policy and market. In the introduction of an innovation we see an example of cumulative effects. These cumulative effects are studied for the uptake of on-farm processing of organic waste in chapter 3 . We realise that the mechanisms that drive innovation in our research are not exhaustive and other mechanisms might play a role as well, potentially changing our results. In the introduction of a collective AES system we see an example of the role feedbacks can play in land use systems, as well as an example of interactions as described in chapters 4 and 5 . We focus on the feedbacks and interactions of the farms within our case study, but we don't take the effect of other land users into account. Feedbacks or social influence from the wider community could potentially impact the farm decisions as well.

The models developed in this thesis are normative models, designed to understand the mechanisms of land use change. In this normative approach we are concerned with the actions that should be taken to maximize a certain specified objective (Frisvold, Bagavathiannan \& Norsworthy, 2017). The model shows the effects of mechanisms assuming they are important, but it does not prove or test the existence of these mechanisms in land use systems in a CAS setting. The existence and importance of these mechanisms have been discussed by other authors. For instance, Shi, Yin \& Lv (2017) show the impact of interactions and feedbacks on forest cover change. Besides explaining the importance of feedbacks and interactions, Miyasaka et al. (2017) show how a threshold can lead to an abrupt land use change. Morris \& Rowe (2014) point at the importance of cumulative effects due to human influence, while Nogueira Terra \& Ferreira dos Santos (2012) develop a method to measure the cumulative effects on a landscape.

The utility function applied in our research is an additive utility function. We assume each objective included in the utility function has a weight which does not vary with the level of the objectives. This implies for example an absolute coefficient of risk-aversion. Within our utility function, an agent will be equally risk averse for a low income and a high income. Examples of other models with an absolute risk aversion coefficient are Arata et al. (2017) and Cortignani \& Severini (2012). However, since the income consequences of risk taken in our model are relatively small compared to the total income, this seems an appropriate assumption. 
We viewed the Dutch dairy sector as an example of a complex adaptive system. This seems to be a reasonable choice given the characteristics of the dairy sector: individual dairy farms each make their own decisions, which together determine the characteristics of the sector. There are interactions between dairy farms and feedbacks from the higher scale level, for instance through the milk price. Global demand for milk products has increased, while the number of farms has decreased. The sector has to deal with increasing volatility and uncertainty in the prices paid for farming products and ongoing technological change. Furthermore there is an increasing societal pressure for sustainable farming practices (Klerkx \& Nettle, 2013). This makes the dairy sector a dynamic sector, and interesting from a complexity point of view. In our research we showed that the possibility of a shift does exist. However, one should keep in mind that the Dutch dairy sector is heavily regulated, which might limit the possibility of shifts, i.e. make the dairy sector resilient. The dairy sector might not be completely representative for all types of land use systems, but we still think that the results from this thesis have the potential to increase our understanding of responses of land use systems in general.

\section{Data}

Two commonly used sources of farm data are the FADN and the farm structure data of Statistics Netherlands. Unfortunately, the FADN data is only representative at the national level. Therefore, it cannot automatically be assumed it is representative for our regional case studies. Moreover, the data is not always publicly available, and not all the variables of interest in this thesis are included in the database. Therefore we used farm interviews and data from other sources as inputs for our models. Monte Carlo-like procedures were used to extent the number of farmer or farmer interactions in chapters 3 and 5.

Because of the small data samples the results from our model should be interpreted with caution, and extrapolation would require running our model for a larger number of empirical observations. However, this thesis focuses on new developments in policies or innovations. This automatically implies that data are scarce. By focusing on small sample groups we are able to give an indication of what might happen due to these changes and offer insights in the mechanisms of land use change.

The samples in this thesis might suffer from sample selection bias, due to the way they are constructed. Selection bias occurs when the subjects included in the sample differ in a systematic way from the subjects that are not included in the sample. For example, in chapter 3 we only selected farms that indicated they are interested in composting ignoring other farms. There are several methods of 
constructing a sample. The most basic method is the random sampling technique, in which participants are selected from the population in such a way that the sample is equally likely to contain every possible combination of participants. Ideally, we would have liked to include random samples in our model.

The sample in chapter 3 contains farms that are in a pilot study for on-farm processing of organic waste. It might very well be that the farms that are participating in this pilot are not representative for the average farm in the region. On the other hand, the farms in the pilot are the farms that are aware of the existence of the technique and have the necessary information to make a decision. In the fourth and fifth chapter the farms in our sample are collected by the Noordelijke Friese Wouden. Even though we asked the collective to not only include farms that were strongly nature oriented, it is possible that the farms in our sample are selected because they had strong ties to the farm collective. This would then result in another sample selection bias. In future research we could consider ways to deal with sample selection bias e.g. via collecting more farm data, linking our samples with others (e.g. farm accountancy data or farm survey data) or using adjusted methods (e.g. farm weighing).

Table 6.1 presents an overview that compares the number of cows, the milk production and the amount of land in our samples to the averages for the Netherlands and Friesland. The table shows that the sampled farms are relatively large.

Table 6.1. Number of cows, milk production and land in sample and on average in 2016 (CBS, 2017b; CRV 2016)

\begin{tabular}{llll}
\hline & Number of cows & $\begin{array}{l}\text { Milk production } \\
\text { per cow in } \mathbf{~ k g}\end{array}$ & Ha of land on farm \\
\hline Sample organic waste & 161 & 9071 & 85 \\
Sample NFW & 129 & 8243 & 77 \\
The Netherlands & 97 & 8500 & 52 \\
Friesland & 114 & 8500 & 66 \\
\hline
\end{tabular}

\section{Model}

In all of our chapters we apply mathematical programming. Mathematical programming models are quite intuitive, and therefore appealing to policymakers and other stakeholders. Using mathematical programming models allows us to incorporate real-life constraints, and to simulate changes in these constraints. In mathematical models a clear connection between economic, bio-physical and ecological aspects of the farm can be made (Buysse, Huylenbroeck \& Lauwers, 2007). Mathematical programming models can be used to calculate responses to policy and technological changes. Examples of studies where mathematical 
programming models are used for policy analysis are Doole \& Pannell (2011), Sweeney et al. (2017) and Viaggi, Raggi \& Gomez y Paloma (2010). Examples of mathematical models that are used to study technological change are Schneider, McCarl \& Schmid (2007) and Johnson, Masters \& Preckel (2006). By definition a model is a simplification of reality, and can never capture all of the aspects of reality. Mathematical programming models are generally used for the identification of optimal decisions subject to constraints. Although it is not standard practice, we think mathematical programming models can be used to reveal a potential disposition of a land use system for regime shifts. These models could potentially reveal non-linear responses of system properties to prices and availability of resources, and shadow prices that can be calculated within the model could be used to determine tipping points.

The downside of the mathematical programming technique as applied in this thesis is the fact that the current situation is not necessarily the outcome of our normative mathematical programming models i.e. the models are not calibrated to historical data. However, this also implies that basic knowledge of the farming system is sufficient to construct the model (Buysse, Huylenbroeck \& Lauwers, 2007) and the relatively low data requirement suits our small samples. Although the model is less suited to formulate exact predictions on the level of farming objectives, we can still show the mechanisms at work and the trends that can be expected. The model could be calibrated to the original situation using positive mathematical programming (PMP) techniques (Helming, 2005; Howitt, 1995); however, this would make the model no longer suitable to study regime shifts as PMP would make the model outcomes continuous (Buysse, Huylenbroeck \& Lauwers, 2007). In many instances this is a desirable property, but in this thesis we are looking for regime shifts and tipping points and our model should be able to reflect "jumpy" behaviour.

When studying complex adaptive systems mathematical programming models might not be the most obvious choice, and alternatives are available. Econometric models are well suited to determine the elements of a land use change. A combination of a mathematical programming model and an econometric model could also be used, as illustrated by Peerlings \& Polman (2009). Unfortunately, these models require large datasets with historic data or stated behaviour, which makes their use problematic in situations when data is scarce as is the case when evaluating a new policy or innovation. Another alternative would be to use Agent Based Modelling (ABM). ABM provides a way to simulate the actions of individual agents, who each follow relatively simple behavioural rules. These rules typically take the form of if-else statements, where agents carry out certain behaviour if a specified condition is met (Crooks \& Heppenstall, 2012). ABM is often used 
to analyse a system with real-world entities, and can test and represent social theory which cannot easily be described by mathematical formulas. Agent Based Models can be computationally quite intensive, and are very sensitive to small variations in interaction rules. Although we think ABM could have been used for the analysis in this thesis as well, we prefer to use the mathematical programming models since they are well suited to create a detailed representation of the farming system management (Shrestha, Barnes \& Ahmadi, 2016). In this thesis we show how mathematical programming models can offer a more sophisticated way of capturing individual decision making, while still maintaining the advantages of $\mathrm{ABM}$ in terms of capturing interactions and feedbacks, in a system of heterogonous agents. As a recommendation for further research one could consider the possibility to combine ABM and mathematical programming models, the research of Schouten (2013) could be considered as a good start for this.

Another recommendation for further research is to further investigate the possibilities for estimation and validation of the models. The best approach for further estimation and validation depends on the purpose of the model. For a more applied-sciences model, which can be used by policymakers to predict the effect of different policy options the model would have to be better calibrated to the actual decision-making processes of land users. Alternatively, if one is interested in a model that is better suited for theory development the "empirical noise" would have to be eliminated and the number of agents in the model would have to be increased. This would result in a more stylized output, allowing for experiments to further explore regime shift phenomena.

For a policy maker it would be interesting to understand the signals that might indicate eminent regime shifts, as well as measures that could be taken to prevent or promote regime shifts. This thesis contains exploratory research, using normative models to systematically analyse feedbacks, cumulative effects, feedbacks and interactions as mechanisms of land use change. This provides some initial indications for understanding signals of regime shifts and policy measures, but further research e.g. using experiments and econometric analysis is needed to extend this knowledge.

Despite the limitations of this research, we showed that considering thresholds, cumulative effects, and feedbacks and interactions in land use systems can help to understand the occurrence of inertia and regime shifts in these systems. 
References 

Agnolucci, P., \& McDowall, W. (2007). Technological change in niches: Auxiliary power units and the hydrogen economy. Technological Forecasting and Social Change, 74(8), 1394-1410.

Ajzen, I. (1991). The theory of planned behaviour. Organizational behaviour and human decision processes, 50(2), 179-211.

Alexander, P., Moran, D., Rounsevell, M. D., \& Smith, P. (2013). Modelling the perennial energy crop market: the role of spatial diffusion. Journal of the Royal Society Interface, 10(88), 20130656.

Álvarez-Solís, J., Gómez-Velasco, D., León-Martínez, N., \& Gutiérrez-Miceli, F. (2010). Integrated management of inorganic and organic fertilizers in maize cropping. Agrociencia, 44(5), 575-586.

Arata, L., Donati, M., Sckokai, P., \& Arfini, F. (2017). Incorporating risk in a positive mathematical programming framework: a dual approach. Australian Journal of Agricultural and Resource Economics, 61(2), 265-284.

Atwell, R. C., Schulte, L. A., \& Westphal, L. M. (2009). Landscape, community, countryside: linking biophysical and social scales in US Corn Belt agricultural landscapes. Landscape Ecology, 24(6), 791-806.

Azevedo, C. D., Herriges, J. A., \& Kling, C. L. (2003). Combining Revealed and Stated Preferences: Consistency Tests and Their Interpretations. American Journal of Agricultural Economics, 85(3), 525-537.

Bakker, M.M., Govers, G., Kosmas, C., Vanacker, V., Van Oost, K., \& Rounsevell, M. (2005). Soil erosion as a driver of land-use change. Agriculture, Ecosystems \& Environment, 105(3), 467-481.

Bakker, M.M., Kuhlman, T., Ligtenberg, A., \& Bregt, A. (2012). IPOP proposal Tipping Points and Regime Shifts in Land Use Systems.

Bale, C., McMullen, N., Foxon, T., Rucklidge, A., \& Gale, W. (2014). Modelling diffusion of energy innovations on a heterogeneous social network and approaches to integration of real-world data. Complexity, 19(6), 83-94.

Bell, A.V., \& Hernandez, D. (2017). Cooperative Learning Groups and the Evolution of Human Adaptability. Human Nature, 28(1), 1-15.

Berbel, J., \& Rodriguez-Ocana, A. (1998). An MCDM approach to production analysis: An application to irrigated farms in Southern Spain. European Journal of Operational Research, 107,108-118.

Berger, T. (2001). Agent-based spatial models applied to agriculture: a simulation tool for technology diffusion, resource use changes and policy analysis. Agricultural economics, 25(2-3), 245-260.

Berentsen, P.B.M., \& Giesen, G.W.J. (1995). An environmental-economic model at farm level to analyse institutional and technical change in dairy farming. Agricultural Systems, 49, 153-175.

Berentsen, P. B. M., Kovacs, K., \& Asseldonk, M. A. P. M. van (2012). Comparing risk in conventional and organic dairy farming in the Netherlands: An empirical analysis. Journal of Dairy Science, 95(7), 38033811.

Bernués, A., Clemetsen, M., \& Eik, L. O. (2016). Seeing Northern European Fjord and Mountain Agriculture Through Farmers' Eyes: A Critical Step in Promoting Sustainability. Mountain Research and Development, 36(3), 276-285.

Besnard, A.G., \& Secondi, J. (2014). Hedgerows diminish the value of meadows for grassland birds: Potential conflicts for agri-environment schemes. Agriculture, Ecosystems \& Environment, 189, 21-27.

Biggs, R., Schluter, M., \& Schoon, M. L. (2015). Principles for Building Resilience: Sustaining Ecosystem Services in Social-Ecological Systems. United Kingdom: Cambridge University Press.

Binfield, J., Donnellan, T., Hanrahan, K. F., Hart, C. E., \& Westhoff, P. C. (2004). CAP reform and the WTO: Potential impacts on EU agriculture. University of Missouri-Columbia, Food and Agricultural Policy Research Institute (FAPRI).

Blanken, K., Buisonje, F., Evers, A., Ouweltjes, W., Schooten, H. van, Verkaik, J., Vermeij, I., \& Wemmenhove H. (2016). Kwantitatieve Informatie Veehouderij 2016-2017 [Quantitative Information Livestock 20162017]. Wageningen University \& Research, Wageningen Livestock Research. 
BodemAtlas (2016). Bodematlas [Soil atlas]. Retrieved September 2, 2016, from http://www. fryslan.frl $/$ kaarten $/$ kaart.html? $\mathrm{t}=$ BodemAtlas $\& \mathrm{e}=117000,530000,226000,620000 \& 1=$ nazca _i; $0 ; 100 ; 1$,dinomap;0;100,bodematlas; $1 ; 60 ; 1 ; 3 ; 5 ; 8 ; 9 ; 10 ; 11 ; 12 ; 14 ; 16 ; 20 ; 29 ; 30 ; 31 ; 32 ; 34 ; 37 ; 38$;$39 ; 40 ; 41 ; 42 ; 43 ; 44 ; 47 ; 48 ; 49 ; 50 ; 51 ; 52 ; 53 ; 54 ; 55 ; 58 ; 62 ; 63 ; 64 ; 65 ; 68 ; 70 ; 75 ; 79 ; 80 \& b=b m k$.

Boer de, J.J. (2003). Veldgids landschapselementen Noardlike Fryske Wâlden [Fieldguide landscape elements Noardlike Fryske Wâlden]. Beesterswaag: Landschapsbeheer Friesland.

Boere, E., Peerlings, J., Reinhard, S., \& Heijman, W. (2015). The dynamics of dairy land use change with respect to the milk quota regime. European Review of Agricultural Economics, 42(4), 651-674.

BoerenBusiness (2014a). Hoge pachtprijs van 2751 euro per ha geboden [High land rent of 2751 euro offered]. Retrieved February 20, 2016 , from http://www.boerenbusiness.nl/grondmarkt/artikel/10858340/ hoge-pachtprijs-van-2-751-euro-per-ha-geboden.

BoerenBusiness (2014b). Waar zitten de 100 plus melkveebedrijven? [Where are the 100- plus dairy farms?]. Retrieved September 2, 2016, from http://www.boerenbusiness.nl/top5/artikel/10863551/Waarzitten-de-100-plus-melkveebedrijven.

Boerderij (2010). Zelfbedachte megastal voor 500 koeien [Self-invented mega-barn for 500 cows]. Retrieved February 20, 2016, from http://www.boerderij.nl/Rundveehouderij/Foto-Video/2010/8/Zelfbedachte-megastal-voor-500-koeien-BOE018133W.

Bos, J.F.F.P., Smit, A.L., \& Schröder, J.J., (2013). Is agricultural intensification in The Netherlands running up to its limits? NJAS - Wageningen Journal of Life Sciences, 66, 65-73.

Bosma, S. (2016). Onderzoeksrapport Businessplan Agrarische Groenstations. Unpublished thesis, van Hall Larenstein, Leeuwarden, the Netherlands.

Bournaris T., \& Manos., B. (2012). European union agricultural policy scenarios' impacts on social sustainability of agricultural holdings. International Journal of Sustainable Development and World Ecology, 19(5), 426-432.

Brandt, J.S., Haynes, M.A., Kuemmerle, T., Waller, D.M., \& Radeloff, V.C. (2013). Regime shift on the roof of the world: Alpine meadows converting to shrublands in the southern Himalayas. Biological Conservation, 158, 116-127.

Brown, P., Hart, G., Small, B., \& Oca Munguia, O. M. de, (2016). Agents for diffusion of agricultural innovations for environmental outcomes. Land Use Policy, 55, 318-326.

Buisonje, F. de, Blanken, K., Evers, A., Ouweltjes, W., Schooten, H. van, Schuiling, E., Stormink, H., Verkaik, J., Vermeij, I., \& Wemmenhove, H. (2014). Kwantitatieve Informatie Veehouderij 2014-2015 [Quantitative Information Livestock 2014-2015]. Wageningen University \& Research, Wageningen Livestock Research.

Buysse, J., Straeten, B. van der, Nolte, S., Claeys, D., \& Lauwers L. (2012). Optimisation of implementation policies of environmental quota trade. European Review of Agricultural Economics, 39(1), 95-114.

Buysse, J., Van Huylenbroeck, G., \& Lauwers, L. (2007). Normative, positive and econometric mathematical programming as tools for incorporation of multifunctionality in agricultural policy modelling. Agriculture, Ecosystems and Environment, 120(1), 70-81.

Calker, K.J., Berentsen, P.B.M., Romero, C., Giesen, G.W.J., \& Huirne, R.B.M. (2006). Development and application of a multi-attribute sustainability function for Dutch dairy farming systems. Ecological Economics, 57(4), 640-658.

CBS (2015a). Landbouw; economische omvang naar omvangsklasse, bedrijfstype [Agriculture, economic size in size category and business type]. Available from CBS Web site: http://statline. cbs.nl/Statweb/publication $/ ? \mathrm{DM}=\mathrm{SLNL} \& \mathrm{PA}=80785 \mathrm{NED} \& \mathrm{D} 1=2 \& \mathrm{D} 2=0 \& \mathrm{D} 3=\mathrm{a} \& \mathrm{D} 4=0,5,8-$ $14 \& H D R=G 3 \& S T B=T, G 1, G 2 \& V W=T$, (accessed 10.05.2015). 
CBS (2015b). Weidegang van melkvee; weidegebied [Grazing of dairy cattle, grazing area]. Available from CBS Web site: http://statline.cbs.nl/Statweb/publication/?DM=SLNL\&PA=70736ned\&D1=0-1\&D2=0\& D3 $=1 \& H D R=T \& S T B=G 1, G 2 \& V W=T$, (accessed 20.02.2016).

CBS (2015c). Steeds grotere landbouwbedrijven [Increasingly bigger agricultural companies]. Retrieved February 20, 2016 from http://www.cbs.nl/nl-NL/menu/themas/landbouw/publicaties/artikelen/ archief/2015/steeds-grotere-landbouwbedrijven.htm.

CBS (2016a). Bodemgebruik; uitgebreide gebruiksvorm per gemeente [Land use, extensive land use by municipality]. Available from CBS Web site: http://statline.cbs.nl/Statweb/publication/?DM=SLNL\&PA=70 262ned $\& D 1=0 \& D 2=0 \& D 3=a \& H D R=T \& S T B=G 1, G 2 \& V W=T$, $($ accessed 20.02.2016).

CBS (2016b). Landbouw; gewassen, dieren en grondgebruik naar omvangsklasse en regio [Agriculture; crops, animals and land use by size category and region]. Available from CBS Web site: http://statline. cbs.nl/Statweb/publication/?DM=SLNL\&PA=80787ned\&D1=0-18,38-98,160-196,234-264,296$332 \& \mathrm{D} 2=0-4 \& \mathrm{D} 3=14 \& \mathrm{VW}=\mathrm{T}$, (accessed 20.02.2016).

CBS (2016c). Dierlijke mest; productie en mineralenuitscheiding; bedrijfstype, regio [Animal manure; production and mineral excretion; business type, region]. Available from CBS Web site: http://statline.cbs.nl/ Statweb/publication $/ ? \mathrm{DM}=\mathrm{SLNL} \& \mathrm{PA}=82506$ ned $\& \mathrm{D} 1=0,13,17,19 \& \mathrm{D} 2=0,2,4,8 \& \mathrm{D} 3=0 \& \mathrm{D} 4=21 \& \mathrm{H}$ $\mathrm{DR}=\mathrm{T} \& \mathrm{STB}=\mathrm{G} 1, \mathrm{G} 2, \mathrm{G} 3 \& \mathrm{VW}=\mathrm{T},($ accessed 20.02.2016).

CBS (2016d). Dierlijke mest; productie, transport en gebruik; kerncijfers [Animal manure, production, transport and use]. Available from CBS Web site: http://statline.cbs.nl/Statweb/publication/?DM=SLNL\&PA= 82504NED\&D1 $=0-1,8,11,14,16,18,20,22 \& D 2=0-1,3,7,12,22,24,35-37 \& H D R=G 1 \& S T B=T \& V W=T$, (accessed 20.02.2016).

CBS (2016e). Minder landbouw, meer natuur [Less agriculture, more nature]. Retrieved February 20, 2016 from https://www.cbs.nl/nl-nl/nieuws/2016/08/minder-landbouw-meer-natuur.

CBS (2017a). Landbouw; gewassen, dieren en grondgebruik naar omvangsklasse en regio [Agriculture; crops, animals and land use by size category and region]. Retrieved February 20, 2017, from http://statline. cbs.nl/Statweb/publication/?DM=SLNL\&PA=80783ned\&D1=0,101-112\&D2=0,4\&D3=0\&D4=1\& $\mathrm{HDR}=\mathrm{G} 2, \mathrm{G} 3 \& \mathrm{STB}=\mathrm{T}, \mathrm{G} 1 \& \mathrm{VW}=\mathrm{T}$.

CBS (2017b). Landbouwtelling 2016. Centraal Bureau voor de Statistiek.

Chen, Y., Bakker, M. M., Ligtenberg, A., \& Bregt, A.K. (2016a). How Are Feedbacks Represented in Land Models? Land, 5(3), 29-49.

Chen, S., Glass, D. H., \& McCartney, M. (2016b). Characteristics of successful opinion leaders in a bounded confidence model. Physica A: Statistical Mechanics and its Applications, 449, 426-436.

Chiang, A.C. (1984). Fundamental methods of mathematical economics. Singapore: McGraw-Hill.

Cialdini, R.B., \& Goldstein, N.J. (2004). Social influence: Compliance and conformity. Annual Review of Psychology, 55, 591-621.

Clare, A., Barnes, A., McDonagh, J., \& Shackley, S. (2014). From rhetoric to reality: farmer perspectives on the economic potential of biochar in China. International Journal of Agricultural Sustainability, 12(4), 440-458.

Cohen, P. J., Lawless, S., Dyer, M., Morgan, M., Saeni, E., Teioli, H., \& Kantor, P. (2016). Understanding adaptive capacity and capacity to innovate in social-ecological systems: Applying a gender lens. Ambio, 45(3), 309-321.

Colapinto, C., Jayaraman, R., \& Marsiglio, S. (2017). Multi-criteria decision analysis with goal programming in engineering, management and social sciences: a state-of-the art review. Annals of Operations Research, 251(1), 7-40. 
Cortignani, R., \& Severini, S. (2012). Modelling farmer participation to a revenue insurance scheme by the means of the Positive Mathematical Programming. Agricultural Economics-Zemedelska Ekonomika, 58(7), 324-331.

Cozzolino, V., Di Meo, V., Monda, H., Spaccini, R., \& Piccolo, A. (2015). The molecular characteristics of compost affect plant growth, arbuscular mycorrhizal fungi, and soil microbial community composition. Biology and Fertility of Soils, 52(1), 15-29.

Crokidakis, N., \& Forgerini, F. L. (2010). Consequence of reputation in the Sznajd consensus model. Physics Letters, Section A: General, Atomic and Solid State Physics, 374(34), 3380-3383.

Crooks, A.T., \& Heppenstall, A.J. (2012). Introduction to agent-based modelling Agent-based models of geographical systems. Dordrecht: Springer.

CRV (2016). Jaarstatistieken [Yearly statistics]. Retrieved May, 1, 2017, from https://www.crv4all.nl/downloads/ prestaties/jaarstatistieken/.

CupCompost (2015). Waarom composteren? [Why compost?]. Retrieved September 2, 2016, from http://www. cupcompost.nl/index.htm.

Dale, V. H., Kline, K.L., Kaffka, S.R., \& Langeveld, J.W.A. (2013). A landscape perspective on sustainability of agricultural systems. Landscape Ecology, 28(6), 1111-1123.

Dannenberg, A., Löschel, A., Paolacci, G., Reif, C., \& Tavoni, A. (2015). On the provision of public goods with probabilistic and ambiguous thresholds. Environmental and Resource Economics, 61(3), 365-383.

Deffuant, G., Amblard, F., Weisbuch, G., \& Faure, T. (2002). How can extremism prevail? A study based on the relative agreement interaction model. Journal of artificial societies and social simulation, 5(4).

D’Hose, T., Cougnon, M., Vliegher, A. de, Vandecasteele, B., Viaene, N., Cornelis, W., Bockstaele, E. van, \& Reheul, D. (2014). The positive relationship between soil quality and crop production: A case study on the effect of farm compost application. Applied Soil Ecology, 75, 189-198.

Dijk, WFA. van, Lokhorst, A.M., Berendse, F., \& Snoo, G.R. de (2015). Collective agri-environment schemes: How can regional environmental cooperatives enhance farmers' intentions for agri-environment schemes? Land Use Policy, 42, 759-766.

Dijk, W.F.A. van, Lokhorst, A.M., Berendse, F., \& Snoo, G.R. de (2016). Factors underlying farmers' intentions to perform unsubsidised agri-environmental measures. Land Use Policy, 59, 207-216.

Dijkstra, K.M. (2017). Dauwnetel [Large-flowered Hemp-nettle]. Retrieved May, 1, 2017, from https://wildeplanten.nl/dauwnetel.htm.

Diver, S. (2004). Controlled microbial composting and humus management: Luebke compost. Retrieved September 2, 2016, from http://www.ibiblio.org/steved/Luebke/Luebke-compost2.html.

Dogliotti, S., García, M.C., Peluffo, S., Dieste, J. P., Pedemonte, A. J., Bacigalupe, G. F., \& Rossing, W. A. H. (2014). Co-innovation of family farm systems: A systems approach to sustainable agriculture. Agricultural Systems, 126, 76-86.

Doole, G.J., \& Pannell, D.J. (2011). Evaluating environmental policies under uncertainty through application of robust nonlinear programming. Australian Journal of Agricultural and Resource Economics, 55(4), 469-486.

Drechsler, M. (2017). The impact of cost feedbacks on the land-use dynamics induced by a tradable permit market. Ecological Complexity, 29, 82-86.

Eerste Kamer der Staten Generaal (2014). Wet verantwoorde groei melkveehouderij (Law responsible growth dairy sector). Retrieved February 20, 2016, from http://www.eerstekamer.nl/wetsvoorstel/33979_wet_ verantwoorde_groei.

Elands, B.H.M., van Marwijk, R., Jochem, R., Pouwels R., \& de Boer, T.A. (2005). Natuur in Nederland: recreatie en biodiversiteit in balans; een modelstudie naar recreatiekwaliteit [Nature in the Netherlands: recreation 
and biodiversity in balance; a model study of recreational quality]. Wageningen University \& Research, Wageningen Alterra, Alterra-rapport 1220.

EM vereninging Nederland (2015). Proef door gemeente Hengelo: fermenteren van 400 ton bladresten. [Test by the Hengelo municipality, fermenting 400 tons of leafs]. Retrieved September 2, 2016, from http:// www.emvereniging.nl/proef-door-gemeente-hengelo-fermenteren-van-400-ton-bladresten/.

Estrada, E., \& Vargas-Estrada, E. (2013). How peer pressure shapes consensus, leadership, and innovations in social groups. Scientific Reports, 3, 2905.

European Commission (2015). The end of milk quotas. Retrieved February 20, 2016, from http://ec.europa.eu/ agriculture/milk-quota-end/index_en.htm.

European Commission (2017). A short history of milk quotas. Retrieved June, 10, 2017, from https://ec.europa. eu/agriculture/milk-quota-end/history_en.

Eurostat (2015). Glossary: Standard output (SO). Retrieved February 20, 2015 from: http://ec.europa.eu/ eurostat/statistics-explained/index.php/Glossary:Standard_output_(SO).

Fangueiro, D., Pereira, J., Coutinho, J., Moreira, N., \& Trindade, H. (2008). NPK farm-gate nutrient balances in dairy farms from Northwest Portugal. European Journal of Agronomy, 28(4), 625-634.

Fleury, P., Seres, C., Dobremez, L., Nettier, B., \& Pauthenet, Y. (2015). Flowering meadows, a result-oriented agri-environmental measure: technical and value changes in favour of biodiversity. Land Use Policy, 46, 103-114.

Floron (2017). Floron verspreidingsatlas vaatplanten [Floron dispersion atlas vascular plants]. Retrieved May, 1, 2017, from https://www.verspreidingsatlas.nl.

Foley, J.A., DeFries, R., Asner, G.P., Barford, C., Bonan, G., Carpenter, S.R., Chapin, F.S., Coe, M.T., Daily, G.C., Gibbs, H.K., Helkowski, J.H., Holloway, T., Howard, E.A., Kucharik, C.J., Monfredal, C., Patz, J.A., Prentice, I.C., Ramankutty, R., Snyder, P.K. (2005). Global consequences of land use. Science, 309(5734), 570-574.

Foley, J.A., Coe, M.T., Scheffer, M., \& Wang, G. (2003). Regime shifts in the Sahara and Sahel: interactions between ecological and climatic systems in Northern Africa. Ecosystems, 6(6), 524-532.

Folke, C. (2006). Resilience: The emergence of a perspective for social-ecological systems analyses. Global environmental change, 16(3), 253-267.

Folke, C., Carpenter, S., Walker, B., Scheffer, M., Elmqvist, T., Gunderson, L., \& Holling, C.S. (2004). Regime Shifts, Resilience, and Biodiversity in Ecosystem Management. Annual Review of Ecology, Evolution, and Systematics. 35, 557-581.

Freemark, K. (2005). Farmlands for farming and nature: Issues and perspectives in landscape ecology. United Kingdom: Cambridge University Press.

Frisvold, G.B., Bagavathiannan, M.V., \& Norsworthy, J.K. (2017). Positive and normative modeling for Palmer amaranth control and herbicide resistance management. Pest Management Science, 73(6), 1110-1120.

Galam, S. (2002). Minority opinion spreading in random geometry. The European Physical Journal B - Condensed Matter and Complex Systems, 25(4), 403-406.

Galam, S. (2003). Modelling rumors: the no plane Pentagon French hoax case. Physica A: Statistical Mechanics and its Applications, 320, 571-580.

Gass, S.I. (2003). Linear Programming: Methods and Applications. New York: Dover Publications.

Gebrezgabher, S. A., Meuwissen, M. P. M., Kruseman, G., Lakner, D., \& Oude Lansink, A. G. J. M. (2015). Factors influencing adoption of manure separation technology in the Netherlands. Journal of Environmental Management, 150, 1-8.

Gelderlander (2015). Miljonair bouwt kleinere stal in Wichmond na 'negatieve reacties' [Milionaire builts smaller stable in Wichmond after negative comments]. De Gelderlander. Retrieved February 20, 2016, 
from http://www.gelderlander.nl/regio/achterhoek/bronckhorst/miljonair-bouwt-kleinere-stal-inwichmond-na-negatieve-reacties-1.5250453.

Grashof-Bokdam, C.J., Akkermans, L.M.W., Meeuwsen, H.A.M., van der Veen M., \& Vos, C.C. (2009). Synergie: de meerwaarde van het combineren van bos en dooradering voor biodiversiteit [Synergy: the surplus value of combining woodlands and waterstreams for biodiversity]. Wageningen University \& Research, Wageningen Alterra, Alterra-rapport 1854.

Grimm, V., Revilla, E., Berger, U., Jeltsch, F., Mooij, W.M., Railsback, S. F., Thulke, H., Weiner, J., Wiegand, T., DeAngelis, D. L. (2005). Pattern-oriented modeling of agent-based complex systems: Lessons from ecology. Science, 310(5750), 987-991.

Groeneveld, A.N., Peerlings, J., Bakker, M.M., Polman, N.B.P., \& Heijman, W.J.M. (2017). Effects on participation and biodiversity of reforming the implementation of agri-environmental schemes in the Netherlands. Unpublished manuscript.

Guillem, E. E., Murray-Rust, D., Robinson, D. T., Barnes, A., \& Rounsevell, M. D. A. (2015). Modelling farmer decision-making to anticipate tradeoffs between provisioning ecosystem services and biodiversity. Agricultural Systems, 137, 12-23.

Hees, E.M., Rougoor, C., \& Schans, F. van der (2012). Van mestbeleid naar bemestingsbeleid: Relaas van een ontdekkingsreis [From manure policy to manuring policy: narrative of a exploratory expedition]. Retrieved February 20, 2016, from http://www.clm.nl/uploads/pdf/795-mestbeleid_naar_bemestingsbeleid-web. pdf.

Hegselmann, R., \& Krause, U. (2002). Opinion dynamics and bounded confidence models, analysis, and simulation. Journal of Artificial Societies and Social Simulation, 5(3), 1-33.

Helming, J.F.M. (2005). A model of Dutch agriculture based on Positive Mathematical Programming with regional and environmental applications.

Hermans, F., Roep, D., \& Klerkx, L. (2016). Scale dynamics of grassroots innovations through parallel pathways of transformative change. Ecological Economics, 130, 285-295.

Hogarth, J. R. (2016). Evolutionary models of sustainable economic change in Brazil: No-till agriculture, reduced deforestation and ethanol biofuels. Environmental Innovation and Societal Transitions, 24, 130-141.

Holster, H. (2015). Pilot Agrarische Groenstations Skarsterlân [Pilot agricultural green stations Skarsterlân]. Landbouwproject FYLG 215964, Provincie Friesland.

Howitt, R.E. (1995). Positive mathematical programming. American journal of agricultural economics, 77(2), 329-342.

Huang, C.Y., Tzou, P.J., \& Sun, C.T. (2011). Collective opinion and attitude dynamics dependency on informational and normative social influences. Simulation, 87(10), 875-892.

Huettel, S., \& Jongeneel R. (2011). How has the EU milk quota affected patterns of herd-size change? European Review of Agricultural Economics, 38, 497-527.

ILVO (2016). Boerderijcompost verhoogt op termijn bodemkwaliteit én gewasopbrengst [Farmers compost increases soilquality and yield in the long term]. Retrieved September 2, 2016, from http://www. ilvo.vlaanderen.be/language/nl-BE/NL/Pers-en-media/Alle-media/articleType/ArticleView/articleId/2178/Boerderijcompost-verhoogt-op-termijn-bodemkwaliteit-en-gewasopbrengst-Effecten-vanvruchtwisseling-minder-eenduidig.

Insam, H., Franke-Whittle, I., \& Goberna, M. (2010). Microbes at work: From wastes to resources. Germany: Springer Berlin Heidelberg.

Janmaat, L. (2015). Verwerken van maaisel voor landbouwkundig gebruik - Waarde van compost, bokashi en bermgraskuil als meststof. [Processing mowings for agricultural use - value of bokashi and roadside grass as fertilizer]. Retrieved September 2, 2016, from http://www.louisbolk.org/downloads/3102.pdf. 
Jaramillo-López, P. F., Ramírez, M. I., \& Pérez-Salicrup, D. R. (2015). Impacts of Bokashi on survival and growth rates of Pinus pseudostrobus in community reforestation projects. Journal of Environmental Management, 150, 48-56.

Javarone, M. A. (2014). Social influences in opinion dynamics: The role of conformity. Physica A: Statistical Mechanics and its Applications, 414, 19-30.

Johnson, M.E., Masters, W.A., \& Preckel, P.V. (2006). Diffusion and spillover of new technology: a heterogeneous-agent model for cassava in West Africa. Agricultural Economics, 35(2), 119-129.

Johnstone, M.L., \& Hooper, S. (2016). Social influence and green consumption behaviour: a need for greater government involvement. Journal of Marketing Management, 32(9-10), 827-855.

Jongeneel, R. A., Polman, N. B. P., \& Slangen, L. H. G. (2008). Why are Dutch farmers going multifunctional? Land Use Policy, 25(1), 81-94.

Josefsson, J., Lokhorst, A. M., Pärt, T., Berg, Å., \& Eggers, S. (2017). Effects of a coordinated farmland bird conservation project on farmers' intentions to implement nature conservation practices - Evidence from the Swedish Volunteer \& Farmer Alliance. Journal of Environmental Management, 187, 8-15.

Kahn, B. A., Payton, M. E., \& Graetz, D.A. (2012). Compost treatments interact with other factors to affect red radish production. Compost Science \& Utilization, 20(2), 79-86.

Kaiser, H.M., \& Messer K.D. (2011). Mathematical programming for agricultural, environmental and resource economics. Hoboken, NJ: John Wiley and Sons Inc.

Kapoor, K. K., Dwivedi, Y. K., \& Williams, M. D. (2014). Innovation adoption attributes: A review and synthesis of research findings. European Journal of Innovation Management, 17(3), 327-348.

Kalnay, E., \& Cai, M. (2003). Impact of urbanization and land-use change on climate. Nature, 423(6939), 528531.

Karali, E., Brunner, B., Doherty, R., Hersperger, A., \& Rounsevell, M. (2014). Identifying the Factors That Influence Farmer Participation in Environmental Management Practices in Switzerland. Human Ecology, 42(6), 951-963.

Karali, E., Rounsevell, M. D., \& Doherty, R. (2011). Integrating the diversity of farmers' decisions into studies of rural land-use change. Procedia Environmental Sciences, 6, 136-145.

Kassam, A., Friedrich, T., Shaxson, F., \& Pretty, J. (2009). The spread of Conservation Agriculture: justification, sustainability and uptake. International Journal of Agricultural Sustainability, 7(4), 292-320.

Keane, C.R. (2016). Resilience, tipping, and hydra effects in public health: emergent collective behavior in two agent-based models. BMC Public Health, 16(1), 265.

Keane, M., \& O'Connor, D. (2011). Policy Schemes and Trade in Dairy Products / Agricultural Policy Schemes: European Union's Common Agricultural Policy. San Diego: Academic Press.

Kirschenmann, F. (2010). Alternative agriculture in an energy-and resource-depleting future. Renewable Agriculture and Food Systems, 25(2), 85-89.

Kleijn, D., \& Sutherland, W.J. (2003). How effective are European agri-environment schemes in conserving and promoting biodiversity? Journal of Applied Ecology, 40(6), 947-969.

Klerkx, L., \& Nettle, R. (2013). Achievements and challenges of innovation co-production support initiatives in the Australian and Dutch dairy sectors: A comparative study. Food Policy, 40, 74-89.

Knight, J., \& Ensminger, J. (1998). Conflict over changing social norms: Bargaining, ideology, and enforcement. The new institutionalism in sociology, 105, 121.

Koeijer, T. de, Blokland P.W., Daatselaar, C., Helming, J., \& Luesink, H. (2014). Scenario's voor grondgebondenheid : een verkenning van de varianten binnen het wetsvoorstel Verantwoorde groei melkveehouderij [Scenarios for land bound growth: an exploration of the options within the law for responsible growth of the dairy sector]. Retrieved February 20, 2016, from LEI Wageningen UR: http://www.wageningenur.nl/nl/Publicatie-details.htm?publicationId=publication-way-343830323234. 
Kuhfuss, L., Préget, R., Thoyer, S., \& Hanley, N. (2016). Nudging farmers to enrol land into agri-environmental schemes: The role of a collective bonus. European Review of Agricultural Economics, 43(4), 609-636.

Kwakernaak, C., de Lange, H.J., \& Hartgers, E.M. (2015). Perspectieven voor natuur in uitvoeringsprojecten; Tools bij de planvorming voor uitvoeringsprojecten in het kader van het MIRT ende Natuurambitie Grote Wateren [Perspectives for nature in implementation projects; tools used for the development of implementation projects of MIRT and Natuurambitie Grote Wateren] (Alterra-rapport 2676). Wageningen University \& Research, Wageningen Alterra.

Lagane J. (2014). When students run AMAPs: towards a French model of CSA. Agriculture and Human Values, 32, 133-141.

Lai, C.D. (2014). Generalized Weibull Distributions. Berlin/Heidelberg: Springer.

Lalani, B., Dorward, P., Holloway, G., \& Wauters, E. (2016). Smallholder farmers' motivations for using Conservation Agriculture and the roles of yield, labour and soil fertility in decision making. Agricultural Systems, 146, 80-90.

Lanting, K. (2008). De agrarische sector kan een fors aandeel leveren in de klimaatdoelstellingen en meer [The agricultural sector can contribute in a major way to climate goals and more].Retrieved September 2, 2016, from http://www.vbbm.nu/vbbm/4809/FreeTemp004/pdf/Compostprojectokt2008.pdf.

Lastra-Bravo, X. B., Hubbard, C., Garrod, G., \& Tolón-Becerra, A. (2015). What drives farmers' participation in EU agri-environmental schemes?: Results from a qualitative meta-analysis. Environmental Science \& Policy, 54, 1-9.

Leach, C. W., Van Zomeren, M., Zebel, S., Vliek, M. L., Pennekamp, S. F., Doosje, B., Ouwerkerk, J. W., \& Spears, R. (2008). Group-level self-definition and self-investment: a hierarchical (multicomponent) model of in-group identification. Journal of personality and social psychology, 95(1), 144-165.

Lee, J. (2012). Evaluation of composted cattle manure rate on bulb onion grown with reduced rates of chemical fertilizer. HortTechnology, 22(6), 798-803.

LEI Wageningen UR (2015). Bedrijfsresultaat, Agrimatie-Informatie over de agrosector [Business results, information on the agricultural sector]. Available from Agrimatie Web site: http://www.agrimatie.nl/ Data.aspx, (accessed 10.05.2015).

LEI Wageningen UR (2016). Bedrijfsresultaat, Agrimatie-Informatie over de agrosector [Business results, information on the agricultural sector]. Retrieved June, 11, from http://www.agrimatie.nl/Data.aspx.

Levin, S., Xepapadeas, T., Crépin, A.S., Norberg, J., De Zeeuw, A., Folke, C., Hughes, T., Arrow, K., Barrett, S., Daily, G., \& Ehrlich, P. (2013). Social-ecological systems as complex adaptive systems: modeling and policy implications. Environment and Development Economics, 18(2), 111-132.

Li, H., Huang, X., Huang, B., \& Ping, L. (2010). Prediction of urban land use evolution using temporal remote sensing data analysis and a spatial logistic model. Paper presented at the International Geoscience and Remote Sensing Symposium (IGARSS).

Ligmann-Zielinska, A., \& Sun, L. (2010). Applying time-dependent variance-based global sensitivity analysis to represent the dynamics of an agent-based model of land use change. International Journal of Geographical Information Science, 24(12), 1829-1850.

Ligtenberg, A., \& Bregt, A. K. (2014). Simulating opinion dynamics in land use planning. In Advances in Social Simulation (pp. 271-282). Heidelberg: Springer Berlin.

Lokhorst, A. M., Staats, H., van Dijk, J., van Dijk, E., \& Snoo, G. de (2011). What's in it for Me? Motivational Differences between Farmers' Subsidised and Non-Subsidised Conservation Practices. Applied Psychology, 60(3), 337-353.

López-Mosquera, N., \& Sánchez, M. (2012). Theory of Planned Behavior and the Value-Belief-Norm Theory explaining willingness to pay for a suburban park. Journal of environmental management, 113, 251-262. 
Louhichi. K., Kanellopoulos, A., Janssen, S., Flichman, G., Blanco, M., Hengsdijk, H., Heckelei, T., Berentsen, P., Oude Lansink, A., \& Ittersum, M.V. (2010). FSSIM, a bio-economic farm model for simulating the response of EU farming systems to agricultural and environmental policies. Agricultural Systems, 103, 585-597.

Luo, Y., \& Miller, S. A. (2017). Using Game Theory to Resolve the “Chicken and Egg” Situation in Promoting Cellulosic Bioenergy Development. Ecological Economics, 135, 29-41.

Mandemaker, M., Bakker, M., Stoorvogel, J., \& Veldkamp, A. (2014). A pattern-oriented individual-based land-use transition model: Utility maximization at varying levels of complexity and rationality (CORA). Journal of Land Use Science, 9(1), 59-81.

Mandryk, M., Reidsma, P., Kanellopoulos, A., Groot, J. C., \& Ittersum, M. K. van (2014). The role of farmers' objectives in current farm practices and adaptation preferences: a case study in Flevoland, the Netherlands. Regional environmental change, 14(4), 1463-1478.

Manos, B., Papathanasiou, J., Bournaris, T., Paparrizou, A., \& Arabatzis, G. (2009). Simulation of impacts of irrigated agriculture on income, employment and environment. Operational Research, 9(3), 251-266.

Manson, S. M. (2001). Simplifying complexity: a review of complexity theory. Geoforum, 32(3), 405-414.

Marra, M., Pannell, D. J., \& Ghadim A.A. (2003). The economics of risk, uncertainty and learning in the adoption of new agricultural technologies: where are we on the learning curve? Agricultural systems, 75(2), 215-234.

Maru, Y.T., McAllister, R.R.J., \& Smith, M.S. (2007). Modelling community interactions and social capital dynamics: The case of regional and rural communities of Australia. Agricultural Systems, 92(1-3), 179-200.

Marston, J.M. (2015). Modelling Resilience and Sustainability in Ancient Agricultural Systems. Journal of Ethnobiology, 35(3), 585-605.

Martínez-García, C. G., Dorward, P., \& Rehman, T. (2013). Factors influencing adoption of improved grassland management by small-scale dairy farmers in central Mexico and the implications for future research on smallholder adoption in developing countries. Livestock Science, 152(2), 228-238.

Matson, P.A., Parton, W.J., Power, A.G., \& Swift, M. J. (1997). Agricultural intensification and ecosystem properties. Science, 277(5325), 504-509.

Mavrotas, G., Florios, K., \& Vlachou, D. (2010). Energy planning of a hospital using Mathematical Programming and Monte Carlo simulation for dealing with uncertainty in the economic parameters. Energy Conversion and Management, 51, 722-731.

Mbau, S., Karanja, N., \& Ayuke, F. (2015). Short-term influence of compost application on maize yield, soil macrofauna diversity and abundance in nutrient deficient soils of Kakamega County, Kenya. Plant and Soil, 387(1-2), 379-394.

McBride, M. (2006). Discrete public goods under threshold uncertainty. Journal of Public Economics, 90(6), 1181-1199.

McKenzie, A. J., Emery, S. B., Franks, J. R., \& Whittingham, M. J. (2013). Landscape-scale conservation: Collaborative agri-environment schemes could benefit both biodiversity and ecosystem services, but will farmers be willing to participate? Journal of Applied Ecology, 50(5), 1274-1280.

Meetjesland (2016). Resultaten Arbeidsefficiëntie op melkveebedrijven [Results labour efficiency on dairy farms]. Retrieved February 20, 2016, from http://www.meetjesland.be/Sterk_met_melk/AE-resultaten.pdf.

Melkvee.nl (2016). Grootste boeren zitten in Lelystad en Menterwolde. [Largest farms are in Lelystad and Menterwolde]. Retrieved September 2, 2016, from http://www.melkvee.nl/melken/nieuws/8739/ grootste-boeren-zitten-in-lelystad-en-menterwolde.

Melman, T.C.P., Schotman, A.G.M., Meeuwsen, H.A.M., Smidt, R.A., Vanmeulebrouk, B., \& Sierdsema, H. (2016). Ex-ante-evaluatie ANLB-2016 voor lerend beheer; Een eerste blik op de omvang en ruimtelijke kwaliteit van het beheer in het nieuwe stelsel [Ex-ante evaluation ANLB-2016 for managemental learn- 
ing; a first glance at the size and spatial quality of managment in the new system] (Wageningen Environmental Research Rapport 2752). Wageningen University \& Research, Wageningen Environmental Research.

Mercure, J.F., Pollitt, H., Bassi, A.M., Viñuales, J.E., \& Edwards, N.R. (2016). Modelling complex systems of heterogeneous agents to better design sustainability transitions policy. Global Environmental Change, 37, 102-115.

Ministry of Economic Affairs (2016). The cooperative approach under the new Dutch agri-environmentclimate scheme. Retrieved June 19, 2017, from http://enrd.ec.europa.eu/sites/enrd/files/w12_collectiveapproach_nl.pdf.

Mitchell, M., Lockwood, M., Moore, S. A., \& Clement, S. (2015). Incorporating governance influences into social-ecological system models: a case study involving biodiversity conservation. Journal of Environmental Planning and Management, 58(5), 1903-1922.

Mitchell, M. (2009). Complexity: a guided tour. Oxford University press.

Miyasaka, T., Le, Q.B., Okuro, T., Zhao, X., \& Takeuchi, K. (2017). Agent-based modelling of complex social-ecological feedback loops to assess multi-dimensional trade-offs in dryland ecosystem services. Landscape Ecology, 32(4), 707-727.

Montemurro, F., Ciaccia, C., Leogrande, R., Ceglie, F., \& Diacono, M. (2015). Suitability of different organic amendments from agro-industrial wastes in organic lettuce crops. Nutrient Cycling in Agroecosystems, 102(2), 243-252.

Morris, L.R., \& Rowe, R.J. (2014). Historical land use and altered habitats in the Great Basin. Journal of Mammalogy, 95(6), 1144-1156.

Müller, D., Sun, Z., Vongvisouk, T., Pflugmacher, D., Xu, J., \& Mertz, O. (2014). Regime shifts limit the predictability of land-system change. Global Environmental Change, 28, 75-83.

Murray-Rust, D., Dendoncker, N., Dawson, T. P., Acosta-Michlik, L., Karali, E., Guillem, E., \& Rounsevell, M. (2011). Conceptualising the analysis of socio-ecological systems through ecosystem services and agent-based modelling. Journal of Land Use Science, 6(2-3), 83-99.

Natuhara, Y. \& Imai, C. (1999). Prediction of species richness of breeding birds by landscape-level factors of urban woods in Osaka Prefecture, Japan. Biodiversity and Conservation, 8(2), 239-253.

Ndona, R. K., Friedel, J. K., Spornberger, A., Rinnofner, T., \& Jezik, K. (2011). Effective Micro-organisms (EM): An Effective Plant Strengthening Agent for Tomatoes in Protected Cultivation. Biological Agriculture \& Horticulture, 27(2), 189-203.

Nieuwenhuizen, W., Westerink, J., Gerritsen, A. L., Schrijver, R. A. M., \& Salverda, I. E. (2014). Wat je aan elkaar hebt-Sociaal kapitaal in het agrarisch natuur-en landschapsbeheer [Social capital in agricultural nature and landscape conservation] (Alterra rapport 2603). Wageningen University \& Research, Wageningen Alterra.

Nogueira Terra, T., \& Ferreira dos Santos, R. (2012). Measuring cumulative effects in a fragmented landscape. Ecological Modelling, 228, 89-95.

Noordelijke Friese Wouden (2017). Noardlike Fryske Wâlden. Retrieved June 19, 2017, from http://www. noardlikefryskewalden.nl/

NRC (2014). Zo gaat de afschaffing van het melkquotum de markt veranderen [This is how the milk quota abolishment will change the market]. NRC. Retrieved February 20, 2016, from http://www.nrc.nl/ nieuws/2014/11/12/zo-gaat-de-afschaffing-van-het-melkquotum-de-markt-veranderen.

NRC (2015). Dag quotum, welkom nieuwe melkplas [Bye quota, hello new milk lake]. NRC. Retrieved February 20, 2016, from http://www.nrc.nl/nieuws/2015/04/01/dag-quotum-welkom-nieuwe-melkplas. 
Olde, E. M. de, Carsjens, G. J., \& Eilers, C. H. (2017). The role of collaborations in the development and implementation of sustainable livestock concepts in The Netherlands. International Journal of Agricultural Sustainability, 15(2), 153-168.

Ommermarke (2015). Pilot Bokashi. Retrieved September 2, 2016, from http://www.ommermarke.nl/ $\mathrm{cms}$ /?page_id=399.

Ondersteijn, C. J. M., Beldman, A. C. G., Daatselaar, C. H. G., Giesen, G. W. J., \& Huirne, R. B. M. (2003). Farm structure or farm management: effective ways to reduce nutrient surpluses on dairy farms and their financial impacts. Livestock Production Science, 84(2), 171-181.

Oosterveld, E. B. (2013). In singel en wal: biodiversiteit van het coulisselandschap van de Noardlike Fryske Wâlden [In alderbelt and wooded bank: biodiversity in the landscape of the Noardlike Fryske Wâlden] (Altenburg \& Wymenga rapport 1724). Retrieved June 19, 2017, from http://www.altwym.nl/uploads/ pdf/In_Singel_en_Wal_hoofdrapport.pdf.

Overheid in Friesland (2016). Gemeente De Fryske Marren. [The Frisian lakes municipality]. Retrieved September 2, 2016, from http://www.overheidinfriesland.nl/de-fryske-marren/s/128.

Paassen, A., Ridder, N., \& Stroosnijder, L. (2011). Role of an explorative model for learning about sustainable agricultural development in Burkina Faso. International Journal of Agricultural Sustainability, 9(2), 310-321.

Pannell, D. J., Marshall, G. R., Barr, N., Curtis, A., Vanclay, F., \& Wilkinson, R. (2006). Understanding and promoting adoption of conservation practices by rural landholders. Australian journal of experimental agriculture, 46(11), 1407-1424.

Pedersen, A.B., Nielsen, H. Ø., Christensen, T., \& Hasler, B. (2012). Optimising the effect of policy instruments: A study of farmers' decision rationales and how they match the incentives in Danish pesticide policy. Journal of Environmental Planning and Management, 55(8), 1094-1110.

Peerlings, J. \& Polman, N. (2009). Farm choice between agri-environmental contracts in the European Union. Journal of Environmental Planning and Management, 52(5), 593-612.

Peerlings, J, Polman, N. \& Dries, L. (2014). Self-reported resilience of European farms with and without the CAP. Journal of Agricultural Economics, 65(3), 722-738.

Pereira, M. A., Fairweather, J. R., Woodford, K. B., \& Nuthall, P.L. (2016). Assessing the diversity of values and goals amongst Brazilian commercial-scale progressive beef farmers using Q-methodology. Agricultural Systems, 144, 1-8.

Pérez Perdomo, S. A., Farrow, A., Trienekens, J. H., \& Omta, S.W. F. (2016). Stakeholder roles for fostering ambidexterity in Sub-Saharan African agricultural netchains for the emergence of multi-stakeholder cooperatives. Journal on Chain and Network Science, 16(1), 59-82.

Perman, R., Ma, Y., Common, M., Maddison, D., \& McGilvray, J. (2011). Natural Resource and Environmental Economics, 4th edition. Harlow: Pearson Education Limited.

Phipps, M., Ozanne, L. K., Luchs, M. G., Subrahmanyan, S., Kapitan, S., Catlin, J. R., Gau, R., Naylor, R. W., Rose, R. L., Simpson, B., \& Weaver, T. (2013). Understanding the inherent complexity of sustainable consumption: A social cognitive framework. Journal of Business Research, 66(8), 1227-1234.

Ploeg, J. van der, Strijker, D., \& Hoofwijk, H. (2010). Noordelijke Friese Wouden: Leerervaringen [Noordelijke Friese Wouden: Learning experiences]. Retrieved June 19, 2017, from http://edepot.wur.nl/158830.

Portaal Natuur en Landschap (2016). Factsheet agrarisch natuurbeheer 2016 [Factsheet agricultural nature conservation 2016]. Retrieved June 19, 2017, from http://www.portaalnatuurenlandschap.nl/assets/061713_IPO_ANB_Sheet_A4_CMYK_LR.pdf.

Portaal Natuur en Landschap (2017). Agrarisch natuur- en landschapsbeheer 2016 [Agricultural nature and landscape conservation 2016]. Retrieved May, 1, 2017, from: http://www.portaalnatuurenlandschap.nl/ themas/vernieuwd-stelsel-agrarisch-natuurbeheer/over-het-agrarisch-natuurbeheer-2016/. 
Prager, K. (2015). Agri-environmental collaboratives for landscape management in Europe. Current Opinion in Environmental Sustainability, 12, 59-66.

Primdahl, J., Peco, B., Schramek, J., Andersen, E., \& Oñate, J.J. (2003). Environmental effects of agri-environmental schemes in Western Europe. Journal of Environmental Management, 67(2), 129-138.

Rabobank (2016). Rabobank Cijfers \& Trends [Rabobank numbers and trends]. Retrieved June, 10, 2017, from https://www.rabobankcijfersentrends.nl/index.cfm?action=branche\&branche=Melkveehouderij.

Reijnen, R., Jochem, R., de Jong, M., de Heer, M., \& Siersema, H. (2001). LARCH vogels nationaal: Een expertsysteem voor het beoordelen van de ruimtelijke samenhang en de duurzaamheid van broedvogelpopulaties in Nederland [LARCH birds national: an expert system for judging spatial coherence and the sustainability of nestingbird populations in the Netherlands] (Alterra-rapport 235). Wageningen University \& Research, Wageningen Alterra.

Reijnen, M.J.S.M., Pouwels, R., \& Kuipers, H.(2007). Optimalisatie samenhang Ecologische Hoofdstructuur: Ruimtecondities voor duurzaam behoud biodiversiteit diersoorten [Optimisation connection ecological main structure: spatial conditions for sustainable maintenance of animal biodiversity] (Alterra-Report 1296). Wageningen University \& Research, Wageningen Alterra.

Remmelink, G., Middelkoop, J. van, Ouweltjes, W., \& Wemmenhove, H. (2014). Handboek melkveehouderij [Handbook of the dairy farm]. Retrieved February 20, 2016, from: http://www.wageningenur.nl/en/ show/Handboek-Melkveehouderij.htm.

Remmelink, G., Dooren, H.J. van, Middelkoop, J. van, Ouweltjes, W., \& Wemmenhove, H. (2016). Handboek melkveehouderij [Handbook of the dairy farm]. Retrieved June, 19, 2017, from http://www.wageningenur.nl/en/show/Handboek-Melkveehouderij.htm.

Renaud, F.G., Birkmann, J., Damm, M., \& Gallopín, G.C. (2010). Understanding multiple thresholds of coupled social-ecological systems exposed to natural hazards as external shocks. Natural Hazards, 55(3), 749763.

Rietkerk, M., Dekker, S.C., De Ruiter, P.C., \& Koppel, J., van de (2004). Self-organized patchiness and catastrophic shifts in ecosystems. Science, 305 (5692), 1926-1929.

Rijksoverheid (2009). Nederlandse melkveehouders mogen meer dierlijke mest uitrijden op grasland. [Dutch dairy farmers are allowed to put more animal manure on grassland]. Retrieved September 2, 2016, from: https://www.rijksoverheid.nl/actueel/nieuws/2009/09/29/nederlandse-melkveehouders-mogenmeer-dierlijke-mest-uitrijden-op-grasland.

Rijksoverheid (2015a). Algemene maatregel van bestuur grondgebonden groei melkveehouderij [Order of Council land bound growth dairy sector]. Retrieved Februari 20, 2016, from http://www.rijksoverheid. $\mathrm{nl} /$ documenten-en-publicaties/kamerstukken/2015/03/30/algemene-maatregel-van-bestuur-grondgebonden-groei-melkveehouderij.html.

Rijksoverheid (2015b). Kamerbrief over gevolgen stijging Nederlandse melkproductie voor dierenwelzijn [governmental letter on the consequences for animal welfare of an increase in the Dutch milk production]. Retrieved February 20, 2016, from: https://www.rijksoverheid.nl/documenten/kamerstukken/2015/07/14/kamerbrief-over-gevolgen-stijging-nederlandse-melkproductie-voor-dierenwelzijn.

Rijksoverheid (2015c). Aanbiedingsbrief $A M v B$ grondgebonden groei melkveehouderij [letter accompanying the Order of Council on a land bound dairy sector]. Retrieved February 20, 2016, from: https://www. rijksoverheid.nl/documenten/kamerstukken/2015/03/30/aanbiedingbrief-amvb-grondgebondengroei-melkveehouderij.

Roest, K. de, Ferrari, P., \& Knickel, K. (2017). Specialisation and economies of scale or diversification and economies of scope? Assessing different agricultural development pathways. Journal of Rural Studies. Advance online publication. 
Rougoor, C., \& Schans, F. van der (2013). Grondgebonden melkveehouderij: beleidsopties en hun gevolgen [Land bound dairy sector: policy options and their consequences]. CLM Onderzoek en Advies. Retrieved May 10, 2015, from: http://www.clm.nl/uploads/nieuws-pdfs/Rapport835-Grondgebonden_ melkveehouderij-red.pdf.

Rougoor, C., \& Schans, F. van der (2014). Opties voor een grondgebonden melkveehouderij [Options for a land bound dairy sector]. CLM onderzoek en advies. Retrieved May 10, 2015, from: http://www.clm.nl/ uploads/pagina-pdfs/CLMrapport-Opties_grondgebonden_melkveehouderij-859-web.pdf.

Rozakis, S., Sintori, A., \& Tsiboukas, K. (2012). Estimating utility functions of Greek dairy sheep farmers: A multicriteria mathematical programming approach. Agricultural Economics Review, 13(1), 111-120.

Runhaar, H.A.C., Melman, T.C.P., Boonstra, F.G., Erisman, J.W., Horlings, L.G., de Snoo, G.R., Termeer, C.J.A.M., Wassen, M.J., Westerink, J., \& Arts, B.J.M. (2017). Promoting nature conservation by Dutch farmers: a governance perspective. International Journal of Agricultural Sustainability, 15(3), 264-281.

RVO. (2010). Handreiking bedrijfsspecifieke excretie melkvee [Guideline company specific excretion dairy cattle]. Available from: http://www.rvo.nl/file/handreiking-bedrijfsspecifieke-excretie-melkvee, (accessed on 02.09.2016).

RVO (2018). Fosfaatrechten [Phosphate rights]. Retrieved January 28, 2018, from https://www.rvo.nl/onderwerpen/agrarisch-ondernemen/mest/mest/fosfaatrechten.

Saxena, J., Choudhary, S., Pareek, S., Choudhary, A. K., \& Iquebal, M. A. (2015). Recycling of organic waste through four different composts for disease suppression and growth enhancement in mung beans. Clean-Soil Air Water, 43(7), 1066-1071.

Scheffer, M. (2009). Critical transitions in nature and society. Princeton: Princeton University Press.

Scheffer, M., Bascompte, J., Brock, W.A., Brovkin, V., Carpenter, S.R., Dakos, V., Held, H., Van Nes, E.H., Rietkerk, M. and Sugihara, G. (2009). Early-warning signals for critical transitions. Nature, 461(7260), 53-59.

Scheffer, M., Carpenter, S., Foley, J. A., Folke, C., \& Walker, B. (2001). Catastrophic shifts in ecosystems. Nature, 413(6856), 591-596.

Scheffer, M., \& Carpenter, S. R. (2003). Catastrophic regime shifts in ecosystems: linking theory to observation. Trends in Ecology \& Evolution, 18(12), 648-656.

Schmit, T. M., Boisvert, R. N., \& Tauer, L. W. (2001). Measuring the Financial Risks of New York Dairy Producers. Journal of Dairy Science, 84(2), 411-420.

Schnabel, P. (2001). Waarom blijven boeren? Over voortgang en beëindiging van het boerenbedrijf /Why do farmers continue farming? About continuation and exit of the farm]. Retrieved February 20, 2016, from: http://www.scp.nl/Publicaties/Alle_publicaties/Publicaties_2001/Waarom_blijven_boeren.

Schneider, U.A., McCarl, B.A., \& Schmid, E. (2007). Agricultural sector analysis on greenhouse gas mitigation in US agriculture and forestry. Agricultural Systems, 94(2), 128-140.

Schouten, M.A.H. (2013). Resilience in rural social-ecological systems: a spatially explicit agent-based modelling approach.

Schouten, M., Opdam, P., Polman, N., \& Westerhof, E. (2013). Resilience-based governance in rural landscapes: Experiments with agri-environment schemes using a spatially explicit agent-based model. Land Use Policy, 30(1), 934-943.

Sengupta, R., Lant, C., Kraft, S., Beaulieu, J., Peterson, W., \& Loftus, T. (2005). Modeling enrollment in the Conservation Reserve Program by using agents within spatial decision support systems: an example from southern Illinois. Environment and Planning B: Planning and Design, 32(6), 821-834.

Shi, M., Yin, R., \& Lv, H. (2017). An empirical analysis of the driving forces of forest cover change in northeast China. Forest Policy and Economics, 78, 78-87.

Shrestha, S., Barnes, A., \& Ahmadi, B.V. (2016). Farm-level Modelling: Techniques, Applications and Policy. Boston: CABI. 
Shum, L.W.C., McConnel, C.S., Gunn A.A., \& House J.K. (2009). Environmental mastitis in intensive highproducing dairy herds in New South Wales. Australian Veterinary Journal, 87(12), 469-475.

Sinha, R.K., \& Noble, C.H. (2008). The adoption of radical manufacturing technologies and firm survival. Strategic Management Journal, 29(9), 943-962.

Small, B., Brown, P., \& Montes de Oca Munguia, O. (2016). Values, trust, and management in New Zealand agriculture. International Journal of Agricultural Sustainability, 14(3), 282-306.

Sood, V. \& Redner, S. (2005). Voter model on heterogeneous graphs. Physical review letters, 94, 178701.

Stafford, K.J., \& Gregory, N. G. (2008). Implications of intensification of pastoral animal production on animal welfare. New Zealand Veterinary Journal, 56, 274-280.

Steel, H., Peña, E. de la, Fonderie, P., Willekens, K., Borgonie G., \& Bert, W. (2010). Nematode succession during composting and the potential of the nematode community as an indicator of compost maturity. Pedobiologia, 53(3), 181-190.

Stichting Collectief Agrarisch Natuurbeheer (2016). Producten SCAN: Flyer deelnemers ANLB. Retrieved from: http://scan-collectieven.nl/system/files/documenten/3._flyer_deelnemers_anlb.pdf.

Stoate, C., Boatman, N.D., Borralho, R.J., Carvalho, C.R., Snoo, G.R. de, \& Eden, P. (2001). Ecological impacts of arable intensification in Europe. Journal of Environmental Management, 63(4), 337-365.

Straeten, B. van der, Buysse, J., Huylenbroeck G. van, \& Lauwers, L (2009). Impact of policy-induced structural change on milk quality: Evidence from the flemish dairy sector. Journal of Dairy Research, 76, 234-240.

Strapasson, A. (2015). The limits of bioenergy: A complex systems approach to land use dynamics and constraints. Proceedings of the 59th Annual Meeting of the ISSS-2015 Berlin, Germany, 1(1).

Strunz, S. (2014). The German energy transition as a regime shift. Ecological Economics, 100, 150-158.

Sumpsi, J., Amador, F., \& Romero, C. (1997). On farmers' objectives: A multi-criteria approach. European Journal of Operational Research, 96(1), 64-71.

Šūmane, S., Kunda, I., Knickel, K., Strauss, A., Tisenkopfs, T., Ios Rios, I. des, Rivera, M., Chebach, T., \& Ashkenazy, A. (2017). Local and farmers' knowledge matters! How integrating informal and formal knowledge enhances sustainable and resilient agriculture. Journal of Rural Studies. Advance online publication.

Sun, Z. \& Müller, D. (2013). A framework for modelling payments for ecosystem services with agent-based models, Bayesian belief networks and opinion dynamics models. Environmental Modelling \& Software, 45, $15-28$.

Sweeney, J.R., Howitt, R.E., Chan, H.L., Pan, M., \& Leung, P. (2017). How do fishery policies affect Hawaii’s longline fishing industry? Calibrating a positive mathematical programming model. Natural Resource Modelling, 30(2).

Temu, A.B., Rudebjer, G.P., \& Chakeredza, S. (2010). Enhancing integrated approaches in agricultural learning systems using experiences from agroforestry. Scientific Research and Essays, 5(16), 2179-2185.

Tilman, D., Fargione, J., Wolff, B., D’Antonio, C., Dobson, A., Howarth, R., Schindler, D., Schlesinger, W.H., Simberloff, D. and Swackhamer, D. (2001). Forecasting agriculturally driven global environmental change. Science, 292(5515), 281-284.

Trouw (2015). Aantal megastallen groeit in rap tempo [Number of mega-barns increases rapidly]. Trouw. Retrieved February 20, 2016, from: http://www.trouw.nl/tr/nl/5948/Dierenwelzijn/article/detail/3900390/2015/03/13/Aantal-megastallen-groeit-in-rap-tempo.dhtml.

Tweede Kamer der Staten Generaal (2015). Regels ten behoeve van een verantwoorde groei van de melkveehouderij, verslag van een schriftelijk overleg (Wet verantwoorde groei melkveehouderij) [Rules for ensuring a responsible growth of the Dairy sector, report on a written discussion]. Retrieved February 20, 2016, from: https://zoek.officielebekendmakingen.nl/kst-33979-100.html. 
Tziolas, E., Manos, B., \& Bournaris, T. (2016). Planning of agro-energy districts for optimum farm income and biomass energy from crops residues. Operational Research, 17(2), 535-546.

Vagneron, I., Faure, G., \& Loeillet, D. (2009). Is there a pilot in the chain? Identifying the key drivers of change in the fresh pineapple sector. Food policy, 34(5), 437-446.

Valbuena, D., Verburg, P.H., Veldkamp, A., Bregt, A. K., \& Ligtenberg, A. (2010). Effects of farmers' decisions on the landscape structure of a Dutch rural region: An agent-based approach. Landscape and Urban Planning, 97(2), 98-110.

Vargas, A., Lo, A.Y., Rohde, N., \& Howes, M. (2016). Social influences on expressed willingness to pay: results of a deliberative monetary valuation study in Colombia. Journal of Environmental Planning and Management, 60(9), 1-18.

Verburg, P.H. (2006). Simulating feedbacks in land use and land cover change models. Landscape Ecology, 21(8), 1171-1183.

Viaggi, D., Raggi, M., \& Gomez y Paloma, S. (2010). An integer programming dynamic farm-household model to evaluate the impact of agricultural policy reforms on farm investment behaviour. European Journal of Operational Research, 207 (2), 1130-1139.

Vlindernet (2017). Eikenpage (Favonius quercus) [Purple hairstreak (Favonius quercus)]. Retrieved June, 19, 2017, from http://www.vlindernet.nl/vlindersoort.php?vlinderid=1044.

Wageningen UR (2015). Kostenwijzer voedermiddelen [Cost indicator feed stuff]. Available from: http:// applicaties.wageningenur.nl/wever.internet/applications/Kostenwijzer_Voedermiddelen/ (accessed 10.05.2015).

Weisbuch, G., Deffuant, G. and Amblard, F. (2005). Persuasion dynamics. Physica A: Statistical Mechanics and its Applications, 353, 555-575.

Westhoek, H., Berg, R. van den, Hoop, W. de, \& Kamp, A. van der (2004). Economic and environmental effects of the manure policy in The Netherlands: Synthesis of integrated ex-post and ex-ante evaluation. Water Science and Technology, 109-116.

Whittingham, M. J. (2007). Will agri-environment schemes deliver substantial biodiversity gain, and if not why not? Journal of applied ecology, 44(1), 1-5.

Willock, J., Deary, I. J., McGregor, M. M., Sutherland, A., Edwards-Jones, G., Morgan, O., Dent, B., Grieve, R., Gibson, G., \& Austin, E. (1999). Farmers' attitudes, objectives, behaviors, and personality traits: The Edinburgh study of decision making on farms. Journal of Vocational Behavior, 54(1), 5-36.

Woldu, T., Markemann, A., Reiber, C., Kassie, G. T., \& Valle Zárate, A. (2016). Combining revealed and stated preferences to define goat breeding objectives in Ethiopia. Livestock Science, 191,179-186

Yarwood, R., \& Evans N. (2003). Livestock, locality and landscape: EU regulations and the new geography of Welsh farm animals. Applied Geography, 23, 137-157.

Zeweld, W., Huylenbroeck, G. van, Tesfay, G., \& Speelman, S. (2017). Smallholder farmers' behavioural intentions towards sustainable agricultural practices. Journal of Environmental Management, 187, 71-81.

Zimmermann, A., \& Heckelei T. (2012). Structural Change of European Dairy Farms-A Cross-Regional Analysis. Journal of Agricultural Economics, 63, 576-603. 

Summary 

Land use systems determine our well-being to a considerable extent, and therefore many policies have been formulated to regulate them. If land use systems are not fully understood, policies may fail due to the nonlinearities in and complex character of the land use system. An improved understanding of the responses of land use systems can help to predict how land use systems will react to policies and global change, thereby offering insights to improve policy design. Therefore, the aim of this thesis is to improve our understanding of sudden transitions in land use systems.

Regime shifts are a well-known concept within the study of ecological systems. In ecology, amongst other disciplines, the term regime shift is used to describe a sudden, rapid transition of a system from one stable state to another once a certain tipping-point is passed (Rietkerk et al., 2004; Scheffer et al., 2001). When studying land use systems this concept can be useful as well, as it can be used to describe a situation where small changes in circumstances might lead to abrupt responses or a situation where a change in circumstances evokes no response from the land use system at all. The existence of regime shifts in land use systems might be explained by the occurrence of thresholds, cumulative effects and feedbacks and interactions. Of course, these mechanisms are not the only possible explanations for regime shifts. However, in this thesis we investigate the hypothesis that these three mechanisms can be held responsible for unexpected system behaviour.

In a system susceptible to regime shifts (at least) two alternative stable states exists (Scheffer \& Carpenter, 2003), a phenomenon referred to as bi-stability (or multi-stability). The states are relatively stable in the sense that a small change in the driver will - most of the times - not lead to a clear change in the system property. A gradual process might take place which decreases the attraction of the current state relative to the attraction of the other state, without any changes occurring. In this case the driver gradually builds up pressure until a certain threshold is reached and the system moves to the new state. Pressure on the system to move towards a different stable state does not necessarily result from a single driver, but can also result from the cumulative effects of several drivers. In this case several drivers work together to set off a shift within the system. Each of the drivers separately might not be strong enough to lead to a change, but a specific combination of these drivers might push the system past a tipping point. Interactions and feedbacks can provide an explanation for abrupt responses as well as for inertia within the system. Agent interaction can take place when agents communicate, but can also take place when they observe each other. Social norms, networks and informal rules are a product of such agent-interaction, as are learning and social influence (Bell \& Hernandez, 2017; Cialdini \& Goldstein, 2004; Maru, McAllister $\&$ Smith, 2007). Feedbacks can refer to positive feedbacks or negative feedbacks. 
A positive feedback is self-reinforcing, and can lead to a point-of no return, after which the system changes (Manson, 2001). A negative feedback reinforces the current state of the system, leading to a more stable system (Keane, 2016).

The aim of this thesis is to determine if thresholds, cumulative effects, and feedbacks and interactions responsible for unexpected system behaviour in land use systems. To do so we take the Dutch dairy sector as an example. Given its importance for land use in the Netherlands and the large degree of policy intervention it is an ideal sector to study land use systems. Taking the main research question as our starting point we define four sub-questions that we address in chapters $2-5$ in this chapter.

The first sub question in chapter 2 concerned thresholds and asked whether the abolishment of the milk quotas would lead to a shift towards larger and more intensive farms in the Netherlands. For this sub question the Dutch dairy farms and their environment were considered as the land use system. We showed that a sudden shift towards intensive dairy farming can occur when milk quotas are abolished, but only if a threshold in farm size is passed. The second sub question in chapter 3 concerned cumulative effects and asked how the uptake of a new farming practice for processing of organic waste into compost in the "Friese Meren" in the Dutch province of Friesland was influenced by economies of scale, learning, and changing social norms. In this case the dairy farms in the "Friese Meren" and their environment was considered as the land use system. Our findings were that a large uptake of organic waste could only be explained by a combination of economies of scale, learning and changing social norms. The third sub question in chapter 4 concerned feedbacks and asked what the effect would be on the resilience of the system of the shift from an individual to collective application for agri-environmental contracts in the Netherlands and how the resilience of the land use system was affected by the value farmers attach to biodiversity. In this case the land use system studied encompasses the dairy farms in the "Noordelijke Friese Wouden" and their environment. We showed that the introduction of the collective AES programme results in a loss of resilience of the hedgerow landscape, in the sense that a shift towards low biodiversity in the Noordelijke Friese Wouden might be intensified due to the biodiversity and payment feedback that are in place in the collective AES programme. The decrease in resilience is stronger when biodiversity is valued less by the farmers. Finally, the fourth sub question in chapter 5 concerned interactions and asked whether social influence due to the introduction of the collective AES system in the Netherlands would result in a shift towards increased farm participation and a higher level of biodiversity. Again, the land use system studied consisted of the dairy farms in the "Noordelijke Friese Wouden" and their environment. We illustrated 
how the participation of farms in the AES programme to maintain hedgerows in the Noordelijke Friese Wouden might be subject to social influence, but that an increase in social influence does not necessarily result in a shift towards higher farmer participation or more biodiversity.

These findings show that thresholds, cumulative effects, and feedbacks and interactions can be responsible for unexpected system behaviour in land use systems. Thresholds might explain both regime shifts and inertia in the land use system. If the system is close to a threshold a small change in the environment can be the onset of a shift, while a system that is far from the threshold will be much more resilient. Unexpected system behaviour might also be due to the existence of cumulative effects of different drivers of the land use system. In order to properly understand land use systems, all drivers of the system and their interaction need to be considered. Looking at each driver separately may result in a skewed perception of the system and lead to wrong predictions on system behaviour. Feedbacks have the potential to explain unexpected system behaviour as well. Feedbacks from higher scale levels influence individual farm decisions, and these individual farm decisions in turn send a signal to the higher scale levels. Positive feedbacks can increase the effect of a driver of land use change, being self-reinforcing. Negative feedbacks can prevent changes from happening, by reinforcing the current state of the system. Finally, we found that interactions between the agent of a land use system have the potential to explain unexpected system behaviour. Social influence created by farmers' interaction can increase the uptake of an innovation or policy measure. On the other hand, social influence also has the potential to decrease the shift, making the land use system more resilient. However, although we showed that each of the mechanisms can be responsible for unexpected system behaviour, we also showed that this is not always the case, and depends on the specific characteristics of the land use system under consideration.

By taking into account the possible effects of thresholds, cumulative effects, and interactions and feedbacks policy makers might prevent being surprised by unexpected system behaviour. The effect of abolishing or introducing a production limitation on farmers behaviour might be much better anticipated if the thresholds in farming choices are known. As long as the farm is far from the threshold, his decisions will not be constrained by the limitations and his decisions with and without the production limitations do not differ. If the farm produces at a level above the threshold, his decisions will differ between the situation with and without limitations. Promoting a new farming practice might be much easier if cumulative effects can be generated, for instance by both reducing the costs of the new practice and by creating opportunities for farmers to learn from each 
other. Anticipating the effect of a new type of agri-environmental schemes is aided by considering feedbacks and interactions, and simulating the right type of social influence might even result in better results of the new scheme. Thus, taking complexity elements into account can help to predict how land use systems will react to policies and global change, thereby offering insights to improve policy design. 


\section{Acknowledgements}



Many people helped me and contributed to my PhD-project, for which I am very grateful. I would like to take this opportunity to thank them all, and to mention some of them in particular.

First of all, the members of my supervising team: Jack, Martha and Wim. Jack, thank you for all your support and your efforts to help me. Your help made it possible to finish my thesis, and I enjoyed working together. Martha, I appreciated your guidance during my $\mathrm{PhD}$ project, and your attention to detail. Wim, thank you for your confidence in me, this always motivated me to keep going. My experience during your supervision of my bachelor thesis was one of the reasons that convinced me to come back to Wageningen for my PhD. I would also like to thank Nico Polman,for his contributions on my papers on agri-environmental schemes.

Of course, I also want to mention all my colleagues from both the Agricultural Economics and Rural Policy group and the Land Use Planning group. Thank you for providing a great working environment, and for the friendly chats and laughter in between. I would also like to thank the members of the Complex Adaptive System working group, thank you for your inputs and discussions.

To my fellow PhD colleagues, it was great to go through this PhD-experience together, and to be able to share the ups and downs together. A few of you I would like to mention especially. Yang, it was very nice to have you as a roommate, and to be able to discuss our work. Min, I am still very glad for the day you became my roommate! You soon became a very good friend and I can always count on you for which I am very grateful. Although you went back to China I am sure we will still see each other and remain friends for a long time. Lara, I am very happy that we started our projects around the same time. Thank you for being my friend and for all the nice walks, evenings and dinners we had (and hopefully will have) together.

A big thank you also goes to all of my family and friends, thank you for all the fun I had with you and for always reminding me there was life outside my $\mathrm{PhD}$. I am extra grateful for the never-ending support and unconditional love of my parents. Mum and dad, thank you! You taught me the self-discipline that I needed to finish my $\mathrm{PhD}$ and so much more. I also like to thank Sander and Ilse; you make me very happy to be a sister. Sander, I admire how you are brave enough to follow your dreams, even if it seems unconventional. Ilse, thank you for being one of my best friends. Another thank you goes to my grandpas, one loved science and the other one loved agriculture. Thanks to my grandmas for always making me feel at home.

Last but not least, I want to thank Hildert. Thank you for all your love and support. It was great you were there to share all the small victories of my $\mathrm{PhD}$ project 
with me, and great to have you around when things did not go as smoothly as planned. Thank you for always being there at the end of the day, for making my home a home. I count myself very lucky to have taken that introduction course, as you are the very best thing that came from doing my PhD in Wageningen. 


\section{Anne Nouschka Groeneveld \\ Wageningen School of Social Sciences (WASS) \\ Completed Training and Supervision Plan}

\begin{tabular}{|c|c|c|c|}
\hline Name of the learning activity & Department/Institute & Year & ECTS* \\
\hline \multicolumn{4}{|l|}{ A) Project related competences } \\
\hline Advanced Microeconomics, ECH 32306 & WUR & 2014 & 6 \\
\hline $\begin{array}{l}\text { Agent-Based Modelling of Complex } \\
\text { Adaptive systems, INF } 50806\end{array}$ & WUR & 2014 & 6 \\
\hline Advanced Econometrics, AEP 60306 & WUR & 2014 & 6 \\
\hline \multicolumn{4}{|l|}{ B) General research related competences } \\
\hline WASS Introduction Course & WASS & 2013 & 1 \\
\hline $\begin{array}{l}\text { Techniques for Writing and Presenting a } \\
\text { Scientific Paper }\end{array}$ & WGS & 2014 & 1.2 \\
\hline $\begin{array}{l}\text { Econometric and Mathematical } \\
\text { Programming Models for Policy Analysis } \\
\text { using FADN Data }\end{array}$ & WASS & 2013 & 1.5 \\
\hline Agricultural Economics \& Policy & WASS & 2016 & 2 \\
\hline \multicolumn{4}{|c|}{ C) Career related competences/personal development } \\
\hline 'Regime shifts in land use systems' & $\begin{array}{l}\text { EAAE congress, } \\
\text { Ljubljana, Slovenia }\end{array}$ & 2014 & 1 \\
\hline $\begin{array}{l}\text { 'Identifying regime shifts in land use } \\
\text { systems' }\end{array}$ & $\begin{array}{l}\text { GLP congress, Berlin, } \\
\text { Germany }\end{array}$ & 2014 & 1 \\
\hline $\begin{array}{l}\text { 'Update of on-farm processing of organic } \\
\text { waste' }\end{array}$ & WUR seminar & 2016 & 1 \\
\hline Teaching and supervising students & WUR & 2015 & 2 \\
\hline LAR/LUP PHD meetings & WUR & $2013-2015$ & 1 \\
\hline CAS PHD meetings & WUR & $2013-2015$ & 1 \\
\hline CAS workgroup tipping points & WUR & $2014-2015$ & 1 \\
\hline 'Defining and describing regime shifts' & WASS PhD day & 2014 & 1 \\
\hline Total & & & 32.7 \\
\hline
\end{tabular}

*One credit according to ECTS is on average equivalent to 28 hours of study load 

The research described in this thesis was financially supported by the Wageningen University IPOP project Complex Adaptive Systems.

Financial support from the Agricultural Economics and Rural Policy Group for printing this thesis is gratefully acknowledged.

Cover design by: ProefschriftMaken // www.proefschriftmaken.nl Lay-out and print by: ProefschriftMaken // www.proefschriftmaken.nl 
1. Peer pressure among farmers shapes biodiversity.

(this thesis)

2. Farmers that are not motivated by economic gain are essential for the uptake of sustainable farming practices in the Dutch dairy sector.

(this thesis)

3. From a welfare theoretical point of view the degree of female labour participation is optimal in the Netherlands.

4. Monetary valuation of environmental goods and services is required.

5. Regardless of the research question the answer is "it depends".

6. The subject you learn most about during your $\mathrm{PhD}$ studies is yourself.

Propositions belonging to the thesis, entitled

Complexity in land use change; the case of the Dutch dairy sector

Anouschka Groeneveld

Wageningen, 20 June 2018 